DOE CONTRACT DE-FC36-04GO14276

INSTITUTE OF

Dr. William A. Goddard III

Principal Investigator

TECHNOLOGY

CALTECH

\title{
Using Ionic Liquids in Selective Hydrocarbon Conversion Processes
}

- Covering the Period July, 2004 - June, 2009

- Date of Report - September $28^{\text {th }}, 2009$

- Award Number - DE-FC36-04GO14276

- Project Title - Using Ionic Liquids in Selective Hydrocarbon Conversion Processes

- Project Period - from 07/01/2004 through 06/30/2009

- Recipient Organization - California Institute of Technology

- Partners

1. Power, Energy, and Environmental Research Center (PEER)

California Institute of Technology

2. Material and Process Simulation Center (MSC)

California Institute of Technology

3. Loker Hydrocarbon Institute, University of Southern California

4. ChevronTexaco Corp (15\% cost-sharing)

5. Sachem Inc (15\% cost sharing)

- Team Members

PI:

Co-PI's:

Staff Members:

Postdoctoral Scholars:

Graduate Students:

Senior Technician:
William A. Goddard III

Yongchun Tang, Roy Periana

Weiqun Chen, Adri van Duin, Robert Nielsen, Patrick Shuler, Qisheng Ma, Mario Blanco, Zaiwei Li, Jonas Oxgaard, Jihong Cheng,

Sam Cheung, Sanja Pudar

Mark Haught 


\section{CONTACT INFORMATION}

- Technical Contact:

Yongchun Tang

Mailing Address: 738 Arrow Grand Circle, Covina, CA 91722

(626) 8585077 (Tel.) (626) 858-9250 (Fax.), tang@,peer.caltech.edu

\section{William A. Goddard III}

Mailing Address: 321 Beckman Institute, Mail Code: Chemistry 139-74, California Institute of Technology, Pasadena, CA 91125

(626) 395-2731 (Tel.) (626) 585-0918 (Fax.), wag@wag.caltech.edu

- Business Contact: Richard P. Seligman

Mailing Address: 1200 E. California Blvd. Mail Code: 201-15, California Institute of Technology, Pasadena, CA 91125

(626) 395-6357 (Tel.) (626) 395-4571 (Fax), Richard.seligman@caltech.edu

- DOE Project Officer: Bill Prymak

Mailing Address: Golden Field Office, 1617 Cole Blvd., Golden, CO 80401

(303) 275-4931 (Tel.) (303) 275-4753 (Fax), bill.prymak@go.doe.gov

- DOE Project Monitor:

- DOE HQ contactor:

- DOE Contract Specialist: Beth H. Dwyer

Mailing Address: Golden Field Office, 1617 Cole Blvd. Golden, CO 80401

(303) 275-4719 (Tel.) (303) 275-4788 (Fax.), beth.dwyer@go.doe.gov 
Disclaimer

This report was prepared as an account of work sponsored by an agency of the United States Government. Neither the United States Government nor any agency thereof, nor any of their employees, makes any warranty, express or implied, or assumes any legal liability or responsibility for the accuracy, completeness, or usefulness of any information, apparatus, product, or process disclosed, or represents that its use would not infringe privately owned rights. Reference herein to any specific commercial product, process, or service by trade name, trademark, manufacturer, or otherwise does not necessarily constitute or imply its endorsement, recommendation, or favoring by the United States Government or any agency thereof. The views and opinions of authors expressed berein do not necessarily state or reflect those of the United States Government or any agency thereof.

\begin{abstract}
This is the Final Report of the five-year project "Using Ionic Liquids in Selective Hydrocarbon Conversion Processes" (DE-FC36-04GO14276, July 1, 2004June 30, 2009), in which we present our major accomplishments with detailed descriptions of our experimental and theoretical efforts.

Upon the successful conduction of this project, we have followed our proposed breakdown work structure completing most of the technical tasks. Finally, we have developed and demonstrated several optimized homogenously catalytic methane conversion systems involving applications of novel ionic liquids, which present much more superior performance than the Catalytica system (the best-todate system) in terms of three times higher reaction rates and longer catalysts lifetime and much stronger resistance to water deactivation. We have developed indepth mechanistic understandings on the complicated chemistry involved in homogenously catalytic methane oxidation as well as developed the unique yet effective experimental protocols (reactors, analytical tools and screening methodologies) for achieving a highly efficient yet economically feasible and environmentally friendly catalytic methane conversion system.
\end{abstract}

The most important findings have been published, patented as well as reported to DOE in this Final Report and our 20 Quarterly Reports. 


\section{TABLE OF CONTENTS}

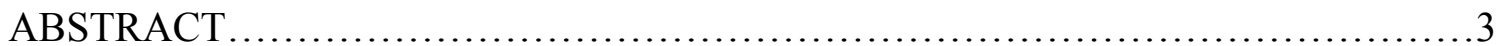

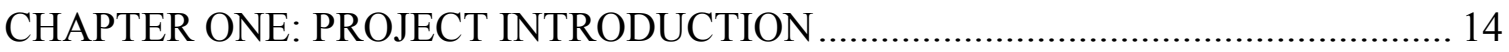

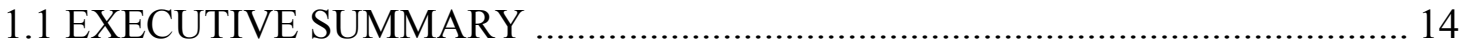

1.2 BACKGROUND INFORMATION ............................................................... 14

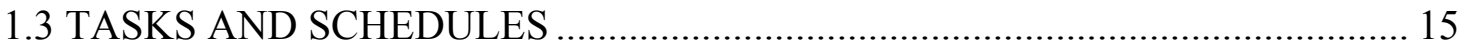

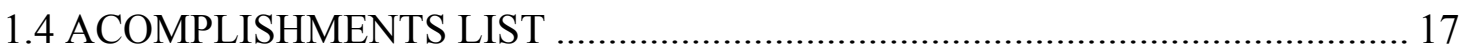

CHAPTER TWO: REACTORS AND ANALYTICAL TOOLS .................................... 19

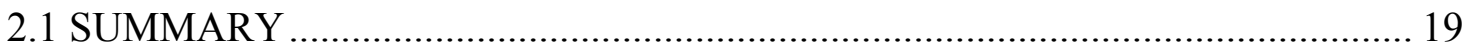

2.2 LOW PRESSURE REACTORS ................................................................ 19

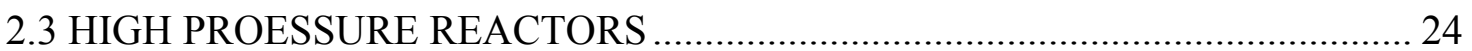

2.4 CHARACTERIZATIONS AND QUANTIFICATIONS ................................... 27

CHAPTER THREE: IONIC LIQUIDS FOR HYDROCARBON CONVERSION......... 32

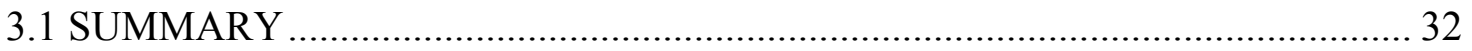

3.2 MOLECULAR MODELING OF IONIC LIQUID DATABASE ........................ 32

3.3 PEER SYNTHESIZED IONIC LIQUIDS..................................................... 34

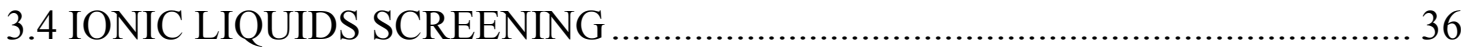

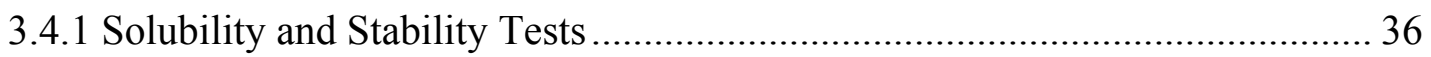

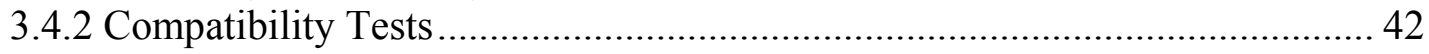

3.5 STABLE IONIC LIQUIDS FOR CATALYTIC METHANE CONVERSION..... 45

CHAPTER FOUR: Pt-CATALYST/IL/H2SO4 SYSTEMS ...................................... 48

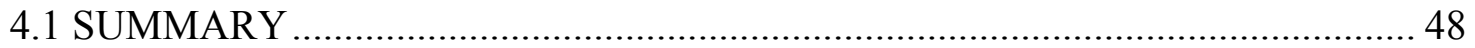

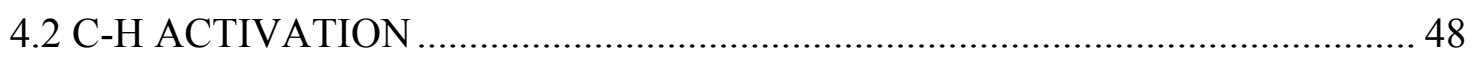

4.3 METHANE OXIDATION TO METHANOL .................................................... 50 
4.4 ROLES OF IONIC LIQUIDS IN METHANE ACTIVATION \& OXIDATION.. 54

CHAPTER FIVE: CATALYTIC SYSTEMS FOR METHANE CONVERSION........... 57

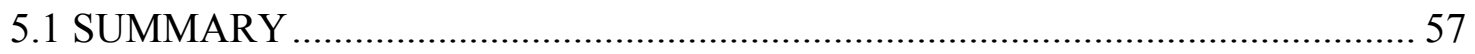

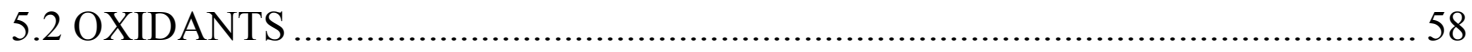

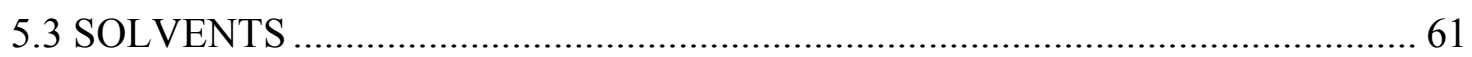

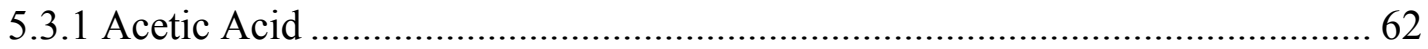

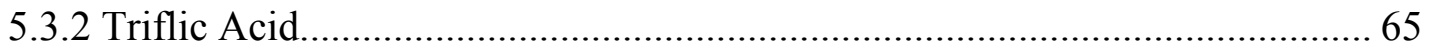

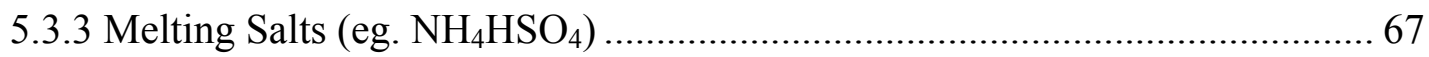

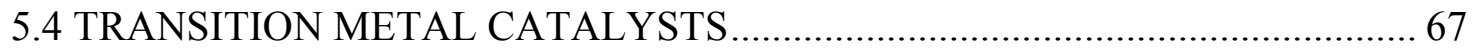

CHAPTER SIX: HIGH-TEMPERATURE SHILOV-LIKE SYSTEM ........................ 74

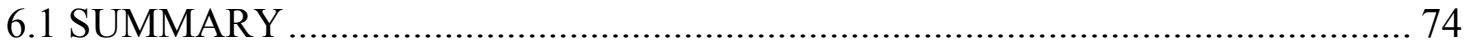

6.2 C-H ACTIVATION IN THE SHILOV SYSTEM.......................................... 75

6.3 KINETICS STUDY ON THE H/D EXCHANGE REACTION IN HIGHTEMPERATURE SHILOV SYSTEM [K ${ }_{2}$ PTCL (5 MM) + CD $_{3}$ COOD (30\%) + DCL

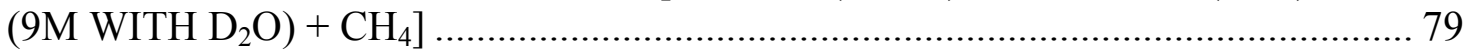

6.4 STABILITIES OF VARIOUS PARTIAL OXIDATION PRODUCTS OF

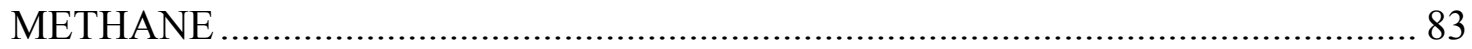

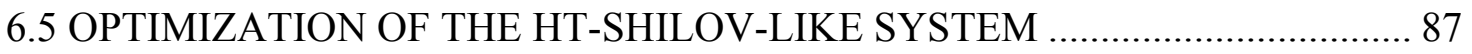

CHAPTER SEVEN: REAXFF METHOD AND VRP METHOD ............................... 92

7.1 A BRIEF SUMMARY ON CALIBRATING THE REAXFF METHOD WITH

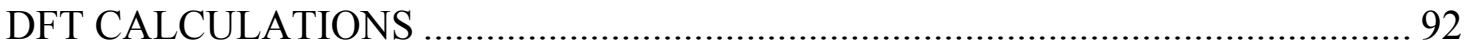

7.2 THE REAXFF POTENTIAL FOR IONIC LIQUIDS AND QM STUDIES OF

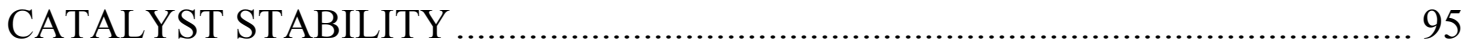

7.2.1 Development of a ReaxFF potential for imidazolium/anion ionic liquids ...... 95

7.2.2 Development of a ReaxFF potential for Pt-complexes................................. 95

7.2.3 Molecular modeling and calibration of the ReaxFF method on methane

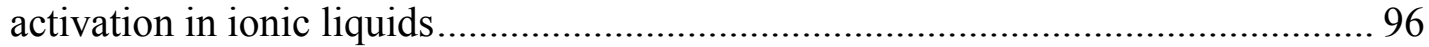

7.2.4 ReaxFF simulation for the Pt complexes in $\mathrm{H}_{2} \mathrm{SO}_{4}$ with ionic liquids .......... 102 
7.3 A VIRTUAL RAPID PROTOTYPING (VRP) METHOD FOR FAST-

SCREENINGS OF APPROPRIATE IONIC LIQUIDS.

CHAPTER EIGHT: MECHANISTIC INVESTIGATION ......................................... 110

8.1 TYPICAL QUANTUM MECHANICAL METHODS UTILIZED ...................... 110

8.2 REACTION MECHANISM OF C-H ACTIVATION CATALYZED BY PTCL ${ }_{4}^{2-}$

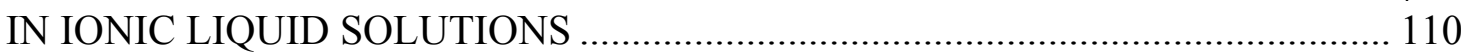

8.3 MECHANISTIC UNDERSTANDING ON SHILOV CHEMISTRY …………... 112

8.4 EFFECTIVE OXIDATION STATE OF PT-CATALYST IN HOT

CONCENTRATED SULFURIC ACID FOR CATALYTIC METHANE

CONVERSION

8.5 THE OXIDATION STEP OF SHILOV CHEMISTRY WITH HIGHLYCONCENTRATED [CL'].

CHAPTER NINE: PROPOSED FUTURE WORK 


\section{LIST OF TABLES}

Table 1.1: Task To be Performed (Original Schedule for the Four-Year Duration) ........ 16

Table 1.2: Task To be Performed (Revised Schedule for the Last Two Quarters of Year

Four and the Extended One-Year) .......................................................................... 16

Table 1.3: Status of updated task performance (with the expanded tasks 6.1 and 6.2 for

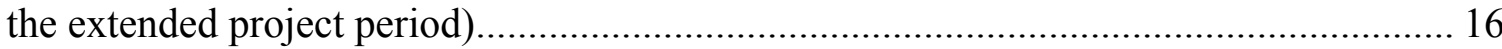

Table 2.1: Compatibility between ionic liquids and concentrated sulfuric acid at room temperature and at elevated temperatures

Table 2.2: Compatibility of Pt-based catalysts in concentrated sulfuric acid at room temperature and at elevated temperatures.

Table 2.3: Compatibility of Pt-based catalysts in ionic liquids, primarily dependent on the type of anion.

Table 2.4: Stability of ternary systems of $\mathrm{H}_{2} \mathrm{SO}_{4} /$ Catalyst/Ionic Liquid at $200{ }^{0} \mathrm{C}$......... 22

Table 2.5: Oxidation rate study of $\mathrm{H}_{2} \mathrm{SO}_{4} /$ Catalyst/[bmim $][\mathrm{Cl}]$ ternary system at $200{ }^{0} \mathrm{C}$. [bmim] was used as a model compound for oxidation. Rates were determined based on $1 \mathrm{H} \mathrm{NMR}$ in $\mathrm{D}_{2} \mathrm{SO}_{4}$ using acetic acid as the internal standard.

Table 2.6: Summary of high-pressure reactor designs and applications.

Table 3.1: Molecular Calculations of Selected Monosubstituted Imidazolium Derivatives

Table 3.2: Index of ionic liquids synthesized at PEER ........................................... 34

Table 3.3: Compatibility between ionic liquids and concentrated sulfuric acid at room temperature and at elevated temperatures.....

Table 3.4: Compatibility of Pt-based catalysts in concentrated sulfuric acid at room temperature and at elevated temperatures.

Table 3.5: Compatibility of Pt-based catalysts in ionic liquids, primarily dependent on the type of anion.

Table 3.6: Stability of ternary systems of $\mathrm{H}_{2} \mathrm{SO}_{4} /$ Catalyst/Ionic Liquid at $200{ }^{\circ} \mathrm{C}$.

Table 3.7: Compatibility studies of ionic liquids in ternary systems. Three steps are developed (1) stability in Periana's system $\left(\mathrm{H}_{2} \mathrm{SO}_{4}+\left[\right.\right.$ bpym] $\left.\mathrm{PtCl}_{2}\right)$ at $200{ }^{\circ} \mathrm{C}$; (2) solubility of $\mathrm{PtCl}_{2}$ in ionic liquids upon heating; (3) compatibility of $\mathrm{PtCl}_{2}+\mathrm{ILs}$ in sulfuric acid upon heating

Table 3.8: Compatibility of Pt-based catalysts (both $\mathrm{Pt}(\mathrm{II})$ and $\mathrm{Pt}(\mathrm{IV})$ species) in ionic liquids.

Table 3.9: Summary of studied ionic liquids (ILs) in the application of catalytic conversion of methane to methanol....

Table 4.1: Methane C-H activation in $\mathrm{Pt} / \mathrm{IL} / \mathrm{D}_{2} \mathrm{SO}_{4}$ ternary systems monitored by $\mathrm{H} / \mathrm{D}$ exchange at $150^{\circ} \mathrm{C}$ for $2 \mathrm{hr}$ in the $10 \mathrm{~mL}$ short reactor (Entries 1-13) and in the mini gold tube reactor (Entries 14-21). 
Table 4.2: Catalytic oxidation of methane to methanol in $96 \% \mathrm{H}_{2} \mathrm{SO}_{4}{ }^{\mathrm{a}}$.......

Table 4.3: Effects of water concentration in difference catalyst systems on methane $\mathrm{C}-\mathrm{H}$ activation and oxidation to methanol

Table 5.1: Summary of candidates for each component of the catalytic system for direct methane conversion tested with the systems with optimized performance shaded in yellow.

Table 5.2: Compatibility tests for new oxidants potentially used for partial oxidation of methane to methanol.

Table 5.3: Compatibility studies of $\mathrm{Pt} / \mathrm{ILs} / \mathrm{AcOH}$ systems. The concentration of $\mathrm{Pt}$ species was $12.5 \mathrm{mM}$. AcOH was added as $1 \mathrm{~mL}$.

Table 5.4: $\mathrm{C}-\mathrm{H}$ bond activation of the butyl group in [bmim] ionic liquid via H/D exchange in $\mathrm{Pt} / \mathrm{IL} / \mathrm{AcOH}-\mathrm{d}_{4}$ systems at $250^{\circ} \mathrm{C}$.

Table 5.5: Solubility tests on several potential transition metal catalysts with $\mathrm{NH}_{4} \mathrm{HSO}_{4}$

as dissolution media or solvent.

Table 5.6: Methane C-H activation catalyzed by selected $\mathrm{Re}$ - and Ru-based catalysts, in comparison with Os-based catalysts monitored by H/D exchange in gold tube reactors at $250{ }^{\circ} \mathrm{C}$ for $4 \mathrm{~h}$.

Table 5.7: Preliminary results of methane $\mathrm{C}-\mathrm{H}$ activation in selected Os-based systems monitored by $\mathrm{H} / \mathrm{D}$ exchange in gold tube reactors.

Table 5.8: Effects of ionic liquids on $\mathrm{C}-\mathrm{H}$ activation of methane catalyzed by Os-04 and Os-05 in sulfuric acid (98 and $85 \%$ ) at $250{ }^{\circ} \mathrm{C}$ for $4 \mathrm{~h}$.

Table 5.9: $\mathrm{H} / \mathrm{D}$ exchange at different $\mathrm{C}-\mathrm{H}$ sites of [bmim]- ionic liquid in $\mathrm{Os} /[\mathrm{bmim}] \mathrm{Cl} / \mathrm{D}_{2} \mathrm{SO}_{4}(98 \%)$ quantified by ${ }^{1} \mathrm{H} \mathrm{NMR}$ with $\mathrm{D}_{2} \mathrm{SO}_{4}(98 \%)$ as solvent and $\mathrm{CH}_{3} \mathrm{COOH}$ as internal standard. 72

Table 6.1: H/D Exchange Experiments at $140^{\circ} \mathrm{C}$ in Shilov's System ........................... 75

Table 6.2; H/D Exchange Experiments at $185^{\circ} \mathrm{C}$ in Shilov's System .......................... 76

Table 6.3: $\mathrm{H} / \mathrm{D}$ Exchange Experiments at $185^{\circ} \mathrm{C}$ with Varied $\mathrm{Cl}^{-}$Concentration $\left(\mathrm{K}_{2} \mathrm{PtCl}_{4}\right.$ $\left.(20 \mathrm{mM})+30 \% \mathrm{CD}_{3} \mathrm{COOD}\right)$

Table 6.4: H/D Exchange in High-Temperature-Shilov system $\left[\mathrm{K}_{2} \mathrm{PtCl}(5 \mathrm{mM})+\right.$ $\mathrm{CD}_{3} \mathrm{COOD}(30 \%)+\mathrm{DCl}\left(9 \mathrm{M}\right.$ with $\left.\left.\mathrm{D}_{2} \mathrm{O}\right)+\mathrm{CH}_{4}\right]$ at $200{ }^{\circ} \mathrm{C}$ for varied reaction time ..... 79

Table 6.5: Definition of reactions occurred in methane H/D exchange experiments for kinetics fitting and the preliminary fitting results.

Table 6.6: Gold-tube experiments on methanol stability tests under various reaction conditions.

Table 6.7: Gold-tube experiments on methlychloride stability tests under various reaction conditions. 86

Table 6.8: Fast heating gold-tube experiments investigating the effect of reaction temperature and time on product selectivity of high-temperature Shilov-like system. 
(Experimental conditions: $\mathrm{K}_{2} \mathrm{PtCl}_{4}(5 \mathrm{mM})+\mathrm{CuCl}_{2}(300 \mathrm{mM})+\mathrm{HCl}(8.4 \mathrm{M})+\mathrm{CH}_{4}(\sim 50$

PSi) + Hydraulic Pressure ( 3400 PSi) $)$.

Table 7.1: Coordination energies for imidazole- $\mathrm{PtCl}_{2}\left(\mathrm{NH}_{3}\right)$ complexes at various position on the imidazole ring. All complexes with $\mathrm{Pt}$ were calculated using

B3LYP/LACV3P**++ otherwise B3LYP/6311G**++. Diffuse functions were excluded

in solvation-phase calculation.

Table 7.2: Relative energies of amidazole (mim), $\mathrm{Cl}^{-}$and $\mathrm{H}_{2} \mathrm{O}$ for $\mathrm{PtCl}_{2}$ in imidazole. All complexes with Pt were calculated using B3LYP/LACV3P**++ otherwise

B3LYP/6311G**++. Diffuse functions were excluded in solvation-phase calculation. 100

Table 7.3: Coordination energies for imidazole- $\mathrm{PtCl}_{2}\left(\mathrm{NH}_{3}\right)$ complexes at various position on the imidazole ring. All complexes with Pt were calculated using B3LYP/LACV3P ${ }^{* *++}$ otherwise B3LYP/6311G ${ }^{* *+}$. Diffuse functions were excluded in solvation-phase calculations.

Table 7.4: Relative energies of L-PtCl(IM) complexes and ligands. All complexes with Pt were calculated using B3LYP/LACV3P ${ }^{* *++}$ otherwise B3LYP/6311G ${ }^{*++}$. Diffuse functions were excluded in solvation-phase calculations.

Table 7.5: Relative stabilities of selected $\mathrm{Pt}(\mathrm{II})$ complexes in $\mathrm{H}_{2} \mathrm{SO}_{4}$ solutions.

Table 7.6: QM results for selected $\mathrm{Pt}(\mathrm{II})$ complexes react with methane.

Table 7.7: QM results for replacing a chloride ligand in complexes 2 and 3 with a water molecule.

Table 7.8: Calculated C-N Bond Rupture Energies of Imidazolium and their Derivatives.

Table 7.9: Calculated C-N Bond Rupture Energies of Diazine and their Derivatives. .. 107

Table 8.1: Free energies, relative to $\mathrm{PtCl}_{4}{ }^{2-}$ in $\mathrm{kcal} \mathrm{mol}^{-1}$, for substituted $\mathrm{Pt}^{\mathrm{II}}$ species... 113

Table 8.2: Free energies, relative to $\mathrm{PtCl}_{4}{ }^{2-}$ in $\mathrm{kcal} \mathrm{mol}^{-1}$, for dissociative methane uptake intermediates.

Table 8.3: Free energies, relative to $\mathrm{PtCl}_{4}{ }^{2-}$ in $\mathrm{kcal} \mathrm{mol}^{-1}$, for the methane uptake products.

Table 8.4: Free energies, relative to $\mathrm{PtCl}_{4}{ }^{2-}$ in $\mathrm{kcal} \mathrm{mol}^{-1}$, for the deprotonated oxidative addition products.

Table 8.5; Free energies, relative to $\mathrm{PtCl}_{4}{ }^{2-}$ in $\mathrm{kcal} \mathrm{mol}^{-1}$, for the deprotonated oxidative addition products.

Table 8.6: Comparison of the performance of the standard Los Alamos pseudopotentials and valence basis functions with a valence basis augmented with additional $\mathrm{p}$ - and $\mathrm{f}$ functions.

Table 8.7: Comparision of two pseudopotentials (by Los Alamos and Ermler, et al.)... 121

Table 8.8: Evaluation chlorine thermodynamics with and without d- and f-angular momentum polarization functions 


\section{LIST OF FIGURES}

Figure 2.1: ${ }^{1} \mathrm{H}$ NMR spectra of the liquid of $\mathrm{H}_{2} \mathrm{SO}_{4} /[\mathrm{bpym}] \mathrm{PtCl}_{2} /[\mathrm{bmim}][\mathrm{Cl}]$ ternary system after rate tests using the low pressure reactor. (a) room temperature, as reference; (b) $200{ }^{\circ} \mathrm{C}, 2 \mathrm{hr}$; and (c) $200^{\circ} \mathrm{C}, 27 \mathrm{hr}$.

Figure 2.2: ${ }^{1} \mathrm{H}$ NMR spectra of the liquid of $\mathrm{H}_{2} \mathrm{SO}_{4} / \mathrm{Pt}(\mathrm{IV})$ Catalyst/ $\mathrm{CH}_{4}$ ternary system after methane oxidation tests using the high-pressure reactor. (a) $\mathrm{PtCl}_{4}+\mathrm{IL}-003$ system; (b) $\mathrm{PtO}_{2}+\mathrm{IL} 006$ system. Acetic acid was used as the internal standard. 28

Figure 2.3: Gas chromatograph of methane after partially exchanged with deuterated solvent of (a) the Periana system, (bpym) $\mathrm{PtCl}_{2}$ in $98 \% \mathrm{D}_{2} \mathrm{SO}_{4}$; and (b) PtCl2 + IL-004-d in $98 \% \mathrm{D}_{2} \mathrm{SO}_{4}$. Fig. 1(c) is an overlaid chromatograph for mass ions of methane isotopes of system (b). 30

Figure 2.4: GC-MS spectra of the liquid of $\mathrm{H}_{2} \mathrm{SO}_{4} /$ Catalyst/CH $\mathrm{CH}_{4}$ ternary system after methane oxidation tests using the high-pressure reactor. (a) system $\# 1$, using [bpym] $\mathrm{PtCl}_{2}$ as the catalyst; and (b) system \#2, using $\mathrm{PtCl}_{2}-\mathrm{IL} 003$ as the catalyst. About $0.2 \mathrm{~mL}$ liquid after each reaction run was hydrolyzed in $5 \mathrm{~mL} \mathrm{H}_{2} \mathrm{O}$ solution and then neutralized with $\mathrm{NaOH}$. They differ in the total peak area integrated. 31

Figure 3.1: 9 Basic classes of cations (a) Monosubstituted imidazolium; (b) Disubstituted Imidazolium; (c) Trisubstituted Imidazolium; (d) Pyridinium; (e) Phosphonium; Ammonium; (f) Pyrrolidinium; (g) Guanidinium; (i) Isouronium 33

Figure 3.2: Typical Anions (a) Monoatom, Cl, Br. I; (b) Borates; (c) Phosphates and Antimonates; (d) Sulfates; (e) Sulfonates; (f) Tosylates; (g) Amides (CN) ${ }_{2} \mathrm{~N}^{-}$; (h) Imides; (i) Methanes $\left[\mathrm{HC}\left(\mathrm{SO}_{2} \mathrm{CF}_{3}\right)_{2}\right]^{-}$; (j) Cobalt-tetracarbonyl Co- $\left(\mathrm{CO}_{4}\right)^{-}$; (k) Trifluoroacetate $\mathrm{CF}_{3} \mathrm{COO}^{-}$.

Figure 3.3: 1H-NMR spectra of [bmim] $\left[\mathrm{BF}_{4}\right]$ in $\mathrm{D}_{2} \mathrm{SO}_{4}$ at $25^{\circ} \mathrm{C}$ for (a) $5 \mathrm{hr}$, (b) $30 \mathrm{hr}$, and (c) $60 \mathrm{hr}$, respectively.....

Figure 3.4: ${ }^{1} \mathrm{H}-\mathrm{NMR}$ spectra for $[\mathrm{bmim}]\left[\mathrm{BF}_{4}\right]$ solution in $\mathrm{D}_{2} \mathrm{SO}_{4}$ (a) at room temperature, (b) at $100{ }^{\circ} \mathrm{C}$, and (c) $150{ }^{\circ} \mathrm{C}$ for $3 \mathrm{hr}$ each.

Figure 3.5: ${ }^{1} \mathrm{H}-\mathrm{NMR}$ spectra for $(\mathrm{a})[\mathrm{bmim}]\left[\mathrm{BF}_{4}\right]$ solution in $\mathrm{D}_{2} \mathrm{O}$ resulting from neutralization of $\mathrm{D}_{2} \mathrm{SO}_{4}$ with $\mathrm{NaOD}$, and (b) [bmim] $\left[\mathrm{BF}_{4}\right]$ dissolved in $\mathrm{D}_{2} \mathrm{O}$ directly.... 40

Figure 4.1: ${ }^{1} \mathrm{H}$ NMR spectra from the liquid of Carbon-13 methane oxidation test using $\mathrm{PtCl}_{2}$ and IL-004.

Figure 4.2: Methanol yield as a function of the concentration of $\mathrm{H}_{2} \mathrm{SO}_{4}$ (reaction conditions: $200{ }^{\circ} \mathrm{C}, 2.5 \mathrm{hr}$ ). The methanol concentration from the Catalytica reaction in $2 \%$ oleum was $600 \mathrm{mM}$ and was not indicated in the plot.

Figure 5.1: Temperature dependence of the calculated amounts (in mole) of $\mathrm{SO}_{3}$ in 100 $\mathrm{mg}$ of sulfuric acid solutions with different concentrations............................................5

Figure 5.2: ${ }^{1} \mathrm{H}$ NMR spectra of the liquids from methane oxidation tests using $10 \mathrm{wt} \%$ PEER-6 type ionic liquids at $200{ }^{\circ} \mathrm{C}$ for $2.5 \mathrm{hrs}$. (a) $\mathrm{PtCl}_{2}+\mathrm{IL}-050$ only as a blank; (b) $\mathrm{PtCl}_{2}+\mathrm{IL}-050+\mathrm{K}_{2} \mathrm{SeO}_{4}$; and (3) $\mathrm{PtCl}_{2}+\mathrm{IL}-050+\mathrm{V}_{2} \mathrm{O}_{5}$. Acetic acid was used as the internal standard. 
Figure 5.3: Possible sites in an ionic liquid containing [bmim] as the cation for $\mathrm{C}-\mathrm{H}$ activation that are similar to methane C-H bonds. (a) Schematic structure; and (b) ${ }^{1} \mathrm{H}$ NMR spectrum.

Figure 5.4: ${ }^{1} \mathrm{H}$ NMR spectra of the liquids from mini gold tube reactors at $200{ }^{\circ} \mathrm{C}$ for 4

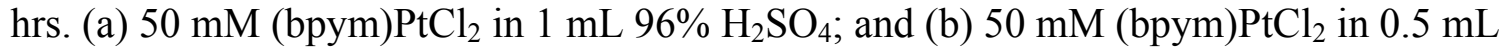
$96 \% \mathrm{H}_{2} \mathrm{SO}_{4}+0.5 \mathrm{~mL} \mathrm{CF}_{3} \mathrm{SO}_{3} \mathrm{H}$. Acetic acid was used as the internal standard. 66

Figure 5.5: Ratios of different methane isotopomers to the original methane after $\mathrm{H} / \mathrm{D}$ exchange experiments in Os- $03 / \mathrm{D}_{2} \mathrm{SO}_{4}(98 \%)$ at 220 and $250{ }^{\circ} \mathrm{C}$, respectively. 70

Figure 6.1: Comparison of the $\mathrm{C}-\mathrm{H}$ activation products of the PEER, Shilov and PerianaCatalytica system.

Figure 6.2: $\mathrm{CD}_{\mathrm{x}} \mathrm{H}_{4-\mathrm{x}}$ isotopomer distribution of methane $\mathrm{H} / \mathrm{D}$ exchange experiments in $\left[\mathrm{K}_{2} \mathrm{PtCl}(5 \mathrm{mM})+\mathrm{CD}_{3} \mathrm{COOD}(30 \%)+\mathrm{DCl}\left(9 \mathrm{M}\right.\right.$ with $\left.\left.\mathrm{D}_{2} \mathrm{O}\right)+\mathrm{CH}_{4}\right]$ at $200{ }^{\circ} \mathrm{C}$ (a) exchange ratio v.s. time and (b) relative isotopomer distribution.

Figure 6.3: Comparison of the experimental data and the calculated data from empirical fitting for H/D exchange experiments in the HT-Shilov-like system.

Figure 6.4: GC-MS chromatogram and spectrum for liquid products of reaction $[0.3 \mathrm{~mL}$ $\mathrm{D}_{2} \mathrm{O}$ (with $8.4 \mathrm{M} \mathrm{DCl}, 5 \mathrm{mM} \mathrm{K}_{2} \mathrm{PtCl}_{4}$ and $300 \mathrm{mM} \mathrm{FeCl}_{3}$ ) $+100 \mu$ mole $\mathrm{CH}_{4}$ ] in gold tube reactor with $\sim 3700 \mathrm{PSi}$ hydraulic external pressure at $\sim 320^{\circ} \mathrm{C}$ for $4 \mathrm{~h}$. (a) Chromatogram, (b) Spectrum of the HCOOD peak, and (c) standard spectrum of $\mathrm{HCOOH}$

Figure 7.1: ReaxFF and QM (Mulliken) charge distributions for an imidazole cation/HTFS anion dimer.

Figure 7.2: ReaxFF and QM-energies for an imidazole dimer as a function of intermolecular $\mathrm{N}-\mathrm{H}$ distance.

Figure 7.3: Snapshot from a ReaxFF MD/NVT simulation on a trifluorimidazole cation/HTFS anion/trifluorimidazole mixture, showing a concerted hydrogen transfer event. Hydrogens involved in the transfer event are bright green (for clarity), other hydrogens are white. Note that in the simulations ReaxFF uses the same atom type for all hydrogens.

Figure 7.4Total and vehicular diffusion obtained from ReaxFF MD/NVT (400K) simulations on $8 \%$ and $30 \%$ trifluorimidazole cation/trifuorimidazole/HTFS anion mixtures.

Figure 7.5: DFT singlet (black) /triplet (red) and ReaxFF (green) energies for Pt-X bond dissociation in $\mathrm{PtClX}\left(\mathrm{NH}_{3}\right)_{2}$-clusters.

Figure 7.6: Imidazole/pyrazine cations, anions, and Pt-complexes obtained from DFT simulations and included in the ReaxFF training set. (White, gray, blue, green and purple balls represent $\mathrm{H}, \mathrm{C}, \mathrm{N}, \mathrm{Cl}$, and $\mathrm{Pt}$ atoms respectively.).

Figure 7.7: Various bonding configurations of a $\mathrm{PtCl}_{2}\left(\mathrm{NH}_{3}\right)$ complex to a) 1methylimidazole cation [mim] $]^{+}$through the b) N1 atom, c) C2 atom, d) N3 atom, e) C4 atom, and the f) $\mathrm{C} 5$ atom. Blue, gray and white balls represent $\mathrm{N}, \mathrm{C}$ and $\mathrm{H}$ atoms, respectively. 
Figure 7.8: Optimized molecular geometry of the stable and ring-opened imidazole and their derivatives for different $\mathrm{C}-\mathrm{N}$ bond ruptures.

Figure 7.9: Optimized molecular geometry of the stable and ring-opened diazine and their derivatives for different $\mathrm{C}-\mathrm{N}$ bond ruptures.

Figure 7.10: Development and applications of the Virtual Rapid Prototyping (VRP) to identify stable ionic liquids in the presence of the Pt catalyst. that the reaction $\left[\mathrm{PtCl}_{4}\right][\mathrm{HIm}]_{2} \rightarrow\left[\mathrm{PtCl}_{3}-\mathrm{Im}\right][\mathrm{HIm}]+\mathrm{HCl}$ is exothermic by $-0.1 \mathrm{kcal} / \mathrm{mol}$, while calculations on the ionic liquid [H-Pyrazolium] $[\mathrm{Cl}]([\mathrm{HPz}][\mathrm{Cl}])$ show that the reaction $\left[\mathrm{PtCl}_{4}\right][\mathrm{HPz}]_{2} \rightarrow \quad\left[\mathrm{PtCl}_{3}-\mathrm{Pz}\right][\mathrm{HPz}]+\mathrm{HCl}$ is endothermic by 8.9 or $12.1 \mathrm{kcal} / \mathrm{mol} \ldots \ldots .108$

Figure 8.1: Reaction energy profile of C-H activation catalyzed by $\mathrm{PtCl}_{4}{ }^{2-}$ in acidic condition (relative energies are in $\mathrm{kcal} / \mathrm{mol}$ )

Figure 8.2: Reaction energy profile of C-H activation catalyzed by $\mathrm{PtCl}_{4}{ }_{4}^{2-}$ in pyrazolium based ionic liquid solution (relative energies are in $\mathrm{kcal} / \mathrm{mol}$ )

Figure 8.3: Key structures and relative stabilities $(\mathrm{kcal} / \mathrm{mol})$ along a possible hydrogen exchange pathway

Figure 8.4: Schematics and free energies, relative to $\mathrm{PtCl}_{4}{ }^{2-}$ in $\mathrm{kcal} \mathrm{mol}^{-1}$, for four methane uptake transition states.

Figure 8.5: Reaction schematic for oxidative addition transition state and pyramidal product for the 5 possible cases. Free energies are in $\mathrm{kcal} \mathrm{mol}^{-1}$, bond distances in Angstroms and angles in degrees.

Figure 8.6: Free energy schematic for lowest energy mechanism to form activated $\mathrm{Pt}^{\mathrm{II}}$ $\mathrm{CH}_{3}$. All free energies are in $\mathrm{kcal} \mathrm{mol}^{-1}$.

Figure 8.7: Free energy diagram, relative to $\mathrm{PtCl}_{4}{ }^{2-}$ in $\mathrm{kcal} \mathrm{mol}^{-1}$, for methane activation using the lowest energy single acetate species, $\mathrm{PtCl}_{3} \mathrm{OAc}^{2-}$.

Figure 8.8: Free energy diagram, relative to $\mathrm{PtCl}_{4}{ }^{2-}$ in $\mathrm{kcal} \mathrm{mol}^{-1}$, for methane activation using the cis and trans bis-acetate species, $\mathrm{PtCl}_{2} \mathrm{OAc}_{2}{ }^{2-}$.

Figure 8.9:.Oxidation of the $\mathrm{Pt}^{\mathrm{II}}$ complex 1 to the $\mathrm{Pt}^{\mathrm{IV}}$ complex

Figure 8.10:. Methane activation by $\mathrm{Pt}^{\mathrm{IV}}$ and $\mathrm{Pt}^{\mathrm{II}}$. $\mathrm{Pt}^{\mathrm{IV}}$ is found to have an inaccessible reaction barrier in agreement with experimental results, hence oxidation of the catalyst inactivates it towards reaction with methane. Relative $\mathrm{G}(500)$ in italics.

Figure 8.11: Inner-sphere electron transfer between non-methylated $\mathrm{Pt}^{\mathrm{IV}}$ and methylated $\mathrm{Pt}^{\mathrm{II}}$. Relative $\mathrm{G}(500)$ in italics. 128

Figure 8.12: Nucleophilic functionalization of the methylated $\mathrm{Pt}^{\mathrm{IV}}$ generates the methyl bisulphate product and regenerates the active $\mathrm{Pt}^{\mathrm{II}}$ catalyst. Relative $\mathrm{G}(500)$ in italics... 128

Figure 8.13: Free Energies of variously substituted reactant complexes in Shilov system

Figure 8.14: Energy barrier for formation of encounter complex $\mathrm{Pt}^{\mathrm{II}}\left(\mathrm{CH}_{3}\right)(\mathrm{Cl})_{2}\left(\mathrm{H}_{2} \mathrm{O}\right)$. $\mathrm{Pt}^{\mathrm{N}}(\mathrm{Cl})_{4}\left(\mathrm{H}_{2} \mathrm{O}\right)_{2}{ }^{1-}$ 
Figure 8.15: Energy barrier for formation of encounter complex $\mathrm{Pt}^{\mathrm{II}}\left(\mathrm{CH}_{3}\right)(\mathrm{Cl})_{2}\left(\mathrm{H}_{2} \mathrm{O}\right)$. $\mathrm{Pt}^{\mathrm{N}}(\mathrm{Cl})_{5}\left(\mathrm{H}_{2} \mathrm{O}\right)^{2}$

Figure 8.16: Energy barrier for formation of encounter complex $\mathrm{Pt}^{\mathrm{II}}\left(\mathrm{CH}_{3}\right)(\mathrm{Cl})_{2}\left(\mathrm{H}_{2} \mathrm{O}\right)$. $\mathrm{Pt}^{\mathrm{NN}}(\mathrm{Cl})_{6}$

Figure 9.1: Schematic Diagram of in situ UV-vis spectroscopy to monitor the oxidation state change of $\mathrm{Pt}^{\mathrm{II}}$ and $\mathrm{Pt}^{\mathrm{IV}}$ 136 


\section{CHAPTER ONE: PROJECT INTRODUCTION}

\subsection{EXECUTIVE SUMMARY}

The final objective of this project is to improve catalytic systems for methane oxidation by using ionic liquids as the reaction media. In particular, the plan is to develop a low-temperature, cost-effective, environmental-friendly catalytic oxidation process for methane conversion to methanol with Pt-based catalysts using selected ionic liquids as reaction media in place of sulfuric acid. Our approach is based on a strongly integrated theoretical/experimental/industrial investigation to develop and optimize a catalyst/ oxidant/ solvent system that would be ready to work towards commercialization. In Phase I our experimental programs were focused on determining compatibility and performance of various combined systems of catalysts, oxidants, and ionic liquids; and to obtain information to calibrate our computational methods and validate theoretical findings. At the theoretical aspect, we have successfully use molecular modeling techniques to establish a database of various ionic liquids prototypes and to calibrate the developing ReaxFF method. In Phase II, we combined the experimental and theoretical knowledge from phase I to more deeply understand the roles of ILs in $\mathrm{C}-\mathrm{H}$ activation reaction and to evaluate using ILs as solvent for methane conversion. We successfully developed several $\mathrm{Pt} / \mathrm{IL} / \mathrm{H}_{2} \mathrm{SO}_{4}$ systems (PEER system) for methane to methanol conversion, some of which present higher water tolerance, higher reaction rates and longer lifetime compared to the Periana-Catalytica system. Mechanistic studies were conducted as well to provide fundamental understanding on the methane to methanol conversion process in the PEER system. In addition, a Virtual Rapid Prototyping (VRP) method was established for fastscreenings of appropriate ionic liquids. In Phase III, we continued to optimize the selected solvent/catalyst/oxidant catalytic system based on the experimental and theoretical achievements during Phase I and II. We have demonstrated the optimized catalytic system, which potentially can be commercialized for low temperature methane functionalization. Efforts have also been taken into scaling-up reactor design and modification so that we will be able to further advance our work toward larger scale investigations providing necessary data and information for the potential industrial applications. The ultimate goal of this project is to develop an efficient yet economically feasible as well as environmentally friendly technology to utilize the abundant yet mostly untapped natural gas resources of the U.S. and the whole world.

\subsection{BACKGROUND INFORMATION}

The direct oxidative conversion of methane to an easily transportable liquid such as methanol has been extensively investigated for decades. However, the most current available technologies rely on the initial conversion of methane to syn-gas $\left(\mathrm{CO} / \mathrm{H}_{2}\right)$ which is carried out at high temperature $\left(>500{ }^{\circ} \mathrm{C}\right)$ using gas-phase tubes and shell reactors that require expensive and energy-consuming processors. An improvement on this process is our recently developed homogeneously catalytic systems, which can directly convert methane to methanol in an unprecedented, high one-pass yield (40 70\% based on the added methane) with a high selectivity ( $>90 \%)$ at temperature below 220 ${ }^{0} \mathrm{C}$. However, this promising direct methane to methanol conversion process involves 
using highly concentrated sulfuric acid as the reaction media. This substantially increases the capital costs due to the requirement to separate the produced methanol from the sulfuric acid.

Searching for the ideal reaction media to replace or limit the use of the sulfuric acid has been an on-going effort, with ionic liquids emerging as most promising. Recognized as "green" and "designer" reaction solvents, ionic liquids have demonstrated advantages as replacements over conventional solvents in selective hydrocarbon conversion processes. In order to rationalize the potential usage of ionic liquids in direct methane oxidation reactions and in other selective hydrocarbon conversion processes, we proposed a strong integration of theoretical and experimental program to develop a fastscreening method to identify the best ionic liquids for an optimized catalyst/ oxidant/ solvent system, that can be operated at low-temperature, that is highly product selective, that is product friendly for easier separation, and that is cost-effective.

The success of utilizing ionic liquids as reaction media to improve current methane conversion processes as well as developing new chemical processes relies on our fundamental understanding of the functionality of ionic liquids. Since the physical and chemical properties of ionic liquids are very sensitive to molecular structures of composing ionic species, understanding their influences in chemical reactions should be done at the atomic level. Advances of molecular modeling in the last decade provide an important computational tool for this task. Throughout this project, we will combine the modern quantum mechanics (QM) calculations with our newly developed Reactive Force Field (ReaxFF) method, in conjunction with our extensive experimental efforts to develop an optimized homogeneously catalyzed partial methane oxidation process mediated by proper ionic liquids as a replacement for at least part of the sulfuric acid.

\subsection{TASKS AND SCHEDULES}

Tests of compatibility

Task 1.1 - Stability of ionic liquids to sulfuric acid

Task 1.2 - Stability of methanol in ionic liquid containing sulfuric Novel reactor designs

Task 2.1 - Low-pressure reactor for testing methane conversion

Task 2.2 - High-pressure reactor for methane conversion to methanol

Quantitative Analyses

Task 3.1 - Quantitative gas analysis of methane isotopomers and other gases

Task 3.2 - Quantitative analysis of methanol formation rates Theoretical Programs

Task 4.1 - Establishing a database of the molecular structural information ionic liquid prototypes

Task 4.2 - Calibrating the ReaxFF method with DFT calculations

\section{PHASE II}


Task 5.1 - Development of the fundamental understanding on roles of ionic liquids to the chemical reactions, in particular the $\mathrm{C}-\mathrm{H}$ activation reaction

Task 5.2 - Evaluation of the utility of ionic liquids as solvent for methane conversion

Task 5.3 - Development of a Virtual Rapid Prototyping (VRP) method fastscreenings of appropriate ionic liquids

\section{PHASE III}

Task 6.1 - Optimizing the selected solvent/acid/oxidant catalytic system

Task 6.2 - Demonstrating the optimized solvent/acid/oxidant catalytic system

Table 1.1: Task To be Performed (Original Schedule for the Four-Year Duration)

\begin{tabular}{|c|c|c|c|c|c|c|c|c|c|c|c|c|c|c|c|c|}
\hline \multirow{2}{*}{ Task } & \multicolumn{10}{|c|}{ Duration (Quarter) } \\
\hline & 1 & 2 & 3 & 4 & 5 & 6 & 7 & 8 & 9 & 10 & 11 & 12 & 13 & 14 & 15 & 16 \\
\hline Task 1.1 & & & & & & & & & & & & & & & & \\
\hline Task 1.2 & & & & & & & & & & & & & & & & \\
\hline Task 2.1 & & & & & & & & & & & & & & & \\
\hline Task 2.2 & & & & & & & & & & & & & & & \\
\hline Task 3.1 & & & & & & & & & & & & & & & \\
\hline Task 3.2 & & & & & & & & & & & & & & & \\
\hline Task 4.1 & & & & & & & & & & & & & & & \\
\hline Task 4.2 & & & & & & & & & & & & & & \\
\hline Task 5.1 & & & & & & & & & & & & & & & \\
\hline Task 5.2 & & & & & & & & & & & & & & & \\
\hline Task 5.3 & & & & & & & & & & & & & & & \\
\hline Task 6.1 & & & & & & & & & & & & & & \\
\hline Task 6.2 & & & & & & & & & & & & & & & \\
\hline
\end{tabular}

Table 1.2: Task To be Performed (Revised Schedule for the Last Two Quarters of Year Four and the Extended One-Year)

\begin{tabular}{|c|c|c|c|c|c|c|c|}
\hline \multirow{2}{*}{ Task } & \multirow{2}{*}{ DESCRIPTION } & \multicolumn{7}{|c|}{ Duration (Quarter) } \\
\cline { 3 - 8 } & & 15 & 16 & 17 & 18 & 19 & 20 \\
\hline Task & Reaction media selection & & & & & & \\
6.1 .1 & Salvent/Acid/Oxidant catalytic & & & & & & \\
\hline 6.1 .2 & system optimization & & & & & & \\
\hline Task & Bench-scale reactor design & & & & & & \\
6.2 .1 & System demonstration with & & & & & & \\
\hline Task & Syatem & & & & & & \\
6.2 .2 & catalyst deactivation evaluation & & & & & & \\
\hline
\end{tabular}

Table 1.3: Status of updated task performance (with the expanded tasks 6.1 and 6.2 for the extended project period)

\begin{tabular}{|c|c|c|c|c|c|c|}
\hline \multirow[b]{2}{*}{$\begin{array}{c}\text { Task } \\
\text { Number }\end{array}$} & \multirow[b]{2}{*}{$\begin{array}{l}\text { Title or Brief Task } \\
\text { Description }\end{array}$} & \multicolumn{4}{|c|}{ Task Completion Date } & \multirow[b]{2}{*}{$\begin{array}{c}\text { Progress } \\
\text { Notes }\end{array}$} \\
\hline & & $\begin{array}{l}\text { Original } \\
\text { Planned }\end{array}$ & $\begin{array}{l}\text { Revised } \\
\text { Planned }\end{array}$ & Actual & $\begin{array}{l}\text { Percent } \\
\text { Complete }\end{array}$ & \\
\hline 1.1 & Stability of IL in $\mathrm{H} 2 \mathrm{SO} 4$ & $\begin{array}{c}07 / 01 / 04- \\
06 / 30 / 05\end{array}$ & NA & NA & 100 & \\
\hline
\end{tabular}




\begin{tabular}{|c|c|c|c|c|c|}
\hline 1.2 & Stability of $\mathrm{CH} 3 \mathrm{OH}$ in IL & $\begin{array}{c}07 / 01 / 20- \\
06 / 30 / 05\end{array}$ & NA & NA & 100 \\
\hline 2.1 & Low-pressure Reactor & $\begin{array}{c}07 / 01 / 04- \\
12 / 31 / 05\end{array}$ & NA & NA & 100 \\
\hline 2.2 & High-pressure Reactor & $\begin{array}{c}01 / 01 / 04- \\
06 / 30 / 06\end{array}$ & NA & NA & 100 \\
\hline 3.1 & Gas Analysis & $\begin{array}{c}01 / 01 / 04- \\
06 / 30 / 06 \\
\end{array}$ & NA & NA & 100 \\
\hline 3.2 & $\mathrm{CH} 3 \mathrm{OH}$ Formation Rate & $\begin{array}{c}07 / 01 / 05- \\
06 / 30 / 06\end{array}$ & NA & NA & 100 \\
\hline 4.1 & Database of IL & $\begin{array}{c}07 / 01 / 04- \\
12 / 31 / 05\end{array}$ & NA & NA & 100 \\
\hline 4.2 & Calibration of ReaxFF & $\begin{array}{c}01 / 01 / 05- \\
12 / 31 / 06 \\
\end{array}$ & NA & NA & 100 \\
\hline 5.1 & Roles of IL & $\begin{array}{c}07 / 01 / 05- \\
06 / 30 / 07\end{array}$ & NA & NA & 100 \\
\hline 5.2 & Evaluation of IL as Solvent & $\begin{array}{c}07 / 01 / 06- \\
06 / 30 / 07\end{array}$ & NA & NA & 100 \\
\hline 5.3 & VRP Method & $\begin{array}{c}07 / 01 / 06- \\
06 / 30 / 07\end{array}$ & NA & NA & 100 \\
\hline 6.1 & Optimization & $\begin{array}{c}07 / 01 / 06- \\
12 / 31 / 07\end{array}$ & NA & NA & 100 \\
\hline 6.2 & Demonstration & $\begin{array}{c}07 / 01 / 07- \\
06 / 30 / 08\end{array}$ & NA & NA & 100 \\
\hline 6.1 .1 & Reaction Media Selection & $\begin{array}{c}01 / 01 / 08- \\
09 / 30 / 08\end{array}$ & NA & NA & 100 \\
\hline 6.1 .2 & System Optimization & $\begin{array}{l}01 / 01 / 08- \\
12 / 31 / 08\end{array}$ & NA & NA & 100 \\
\hline 6.2 .1 & Bench Scale Reactor & $\begin{array}{l}07 / 01 / 08- \\
06 / 30 / 09\end{array}$ & NA & NA & 100 \\
\hline 6.2 .2 & Demonstration & $\begin{array}{c}01 / 01 / 09- \\
06 / 30 / 09\end{array}$ & NA & NA & 100 \\
\hline
\end{tabular}

\subsection{ACOMPLISHMENTS LIST}

During this 5-year project, we have achieved enormous accomplishments on developing the efficient low temperature catalytic methane conversion technology. In addition, our critical findings on $\mathrm{C}-\mathrm{H}$ activation/oxidation processes and the innovated roles of ionic liquids in hydrocarbon chemical reactions can also be applied to other valuable chemical processes and thus bring enormous impacts to the nation's chemical industrial and energy strategy. Below listed are the major accomplishments during this project, and in the following chapters we will present our work in details.

(1) We have identified and patented 6 types of stable ionic liquids under harsh conditions involving strong acid, strong oxidant, powerful catalyst and relatively high temperature $\left(<250{ }^{\circ} \mathrm{C}\right)$. ("Stable Ionic Liquids as Media Using at High Temperature, Highly Oxidative and Strong Acidic Conditions”, Z. Li, Y. Tang and J. Cheng, U.S. Provisional Patent Application 60/673509, 2006) 
(2) We have developed several PEER catalytic systems (Pt-Catalyst/Concentrated Sulfuric Acid/ILs) with significant improvements compared to the Catalytica system in terms of 3 times of reaction rate, longer catalyst lifetime and enhanced water resistance. The PEER systems have been reported in Chemical Communication of Royal Chemical Society and won the honor of the most downloaded paper.

(3) We have developed the Reactive Force Field (ReaxFF) method and the Virtual Rapid Prototyping (VRP) method as our theoretical tools for mechanism understanding and catalytic system fast screening. Effectively integrating the experimental and theoretical efforts has provided us indepth mechanistic understandings on the ionic liquids affiliated catalytic methane conversion process. ("The mechanism by which ionic liquids enable Shilov-type $\mathrm{CH}$ activation in an oxidizing medium", Xu Z., Oxgaard J. and Goddard III, W.A Organometallics, 2008, 27 (15), 3770)

(4) We have achieved many fundamental understandings on the various functions of ionic liquids in chemical reactions, especially in catalytic methane converting reactions. Such knowledge can be applied to further work on discovering efficient direct methane oxidation chemistry as well as many other important chemical industrial applications where the innovated coordination chemistry introduced by ionic liquid participation might lead to breakthrough improvements.

(5) We have successfully designed and established experimental protocols, reactors, characterization tools for developing and optimizing efficient catalytic methane conversion systems.

(6) Preliminary efforts have been taken to extend the possible catalytic systems in terms of the reaction medias $\left(\mathrm{H}_{2} \mathrm{SO}_{4}, \mathrm{CF}_{3} \mathrm{COOH}, \mathrm{CH}_{3} \mathrm{COOH}, \mathrm{H}_{2} \mathrm{O}\right.$ etc), catalysts (various of $\mathrm{Pt}, \mathrm{Os}, \mathrm{Ru}$ based compounds), oxidants $\left(\mathrm{H}_{2} \mathrm{SO}_{4}, \mathrm{Pt}(\mathrm{IV}), \mathrm{Fe}(\mathrm{III})\right.$, $\mathrm{Cu}(\mathrm{II})$ ), with the application of suitable ( stability, reactivity, solubility of catalyst/oxidant) ionic liquids. ("Use of Ionic Liquids as Coordination Ligands for Organometallic Catalysis", Z. Li, Y. Tang and J. Cheng, U.S. Patent Application 20060069169, 2006)

(7) We have also developed a High-Temperature- Shilov-like system for low temperature homogenous methane oxidation. With application of appropriate stabilizer (mineral acids, ionic liquids, benzene, etc) we have been able to stabilize the Pt-catalyst to up to $300{ }^{\circ} \mathrm{C}$ resulting in significantly increased methane conversion. In addition, cheaper oxidants such as $\mathrm{FeCl}_{3}, \mathrm{CuCl}_{2}$ were found to present similar efficiency to the expensive Pt(IV) oxidant making this system further attractive in terms of production costs. ("Novel Concept of Methane Oxidation" Y. Tang, Z. Li, and Chen, W. Provisional Patent application, CIT-4892-P, 2007) 


\section{CHAPTER TWO: REACTORS AND ANALYTICAL TOOLS}

\subsection{SUMMARY}

This highly challenging project is successfully completed through a strongly integrated theoretical-experimental approach. Our experimental experts have taken intensive efforts on experimental protocol design, novel reactor build-up and modification, and suitable analytical tools selection to carry out various tasks in effective yet cost/time efficient ways. This part of work has been conducted throughout the whole project and served as the fundamental of this study. On the other hand, our achievements on reactors and analytical methodologies themselves are of great significance to the researches of low temperature homogeneously catalytic methane conversion and can be potentially applied (with necessary modifications) to other laboratory chemistry studies.

Specifically designed for various experiments (ionic liquid stability and solubility tests, ionic liquids, catalysts, oxidants and reaction media binary or ternary compatibility tests, C-H bond activation probed by model compounds (suitable ionic liquids, such as [bmim]-ionic liquids), kinetics study of H/D exchange in methane activation and direct oxidation of methane), we have developed low pressure reactors, which are low cost and easy to operate and four types of high pressure reactors. We would like to proudly emphasize that our custom-made mini gold reactors combined with the high pressure autoclave can provide experimental conditions assuring 100\% mass balance, 3700 PSi external hydraulic pressure and highly reproducible heating profiles. The experimental results can be analyzed and quantified by GC with FID, TCD, FPD and MSD detectors, ${ }^{1} \mathrm{H}$ NMR spectroscopy as well as HPLC-UV method.

Detailed information of these experimental protocols, reactors and analytical tools are introduced in the following sections.

\subsection{LOW PRESSURE REACTORS}

The low pressure reactors utilized in this project are easy to build, operate control with low cost. They are mainly used in ionic liquid solubility and stability tests and catalytic system compatibility tests which are designed to efficiently screen the huge variety of ionic liquids for developing effective IL/Catalyst/Oxidant/Media catalytic systems for methane conversion.

During an experiment with a low pressure reactor, solid/liquid components are added into liquid phase media where a magnetic stir bar is applied to assist the dissolution and mixing. The test is open to atmosphere and does not involve gas phase reactants. Heating is realized by oil bath or heating tape. The liquid products are easy to collect and ready for characterization. Table 2.1, 
Table 2.2, Table 2.3, and Table 2.4 presents some compatibility testing results for binary systems (ionic liquid/concentrated sulfuric acid, Pt-catalyst/concentrated sulfuric acid, Ptcatalyst/ionic liquid) and ternary systems (Pt-catalyst/ionic liquid/concentrated sulfuric acid) at room temperature and elevated temperature (above $200{ }^{\circ} \mathrm{C}$, which is the target reaction temperature range of the proposed methane catalytic systems), respectively. In fact a huge amount of such tests have been conducted on over 285 types of commercial ionic liquids and 55 types of custom-synthesized ionic liquids at our lab. We have been able to efficiently screen out several types of extremely stable ionic liquids which can survive under the harsh conditions (high temperature, strong acid and oxidant, powerful catalyst) of catalytic methane conversion.

Table 2.5 lists the results of another type of test with our low pressure reactor. $[\mathrm{bmim}][\mathrm{Cl}]$ was used as the model compound to probe the oxidation rate of $\mathrm{H}_{2} \mathrm{SO}_{4} /$ Catalyst/[bmim] [Cl] ternary system at $200{ }^{0} \mathrm{C}$. Typical experimental conditions were $0.05 \mathrm{mmol}$ Pt-based catalyst and $0.73 \mathrm{mmol}$ ionic liquid in $1 \mathrm{~mL} 96 \% \mathrm{H}_{2} \mathrm{SO}_{4}$ at atmospheric pressure using oil bath $\left(200{ }^{\circ} \mathrm{C}\right)$ and magnetic stirring. The rates were all normalized to reference ternary systems that were prepared at room temperature. The conversion rate is arbitrarily defined from NMR as the intensity decrease of the $-\mathrm{CH}_{3}$ on the butyl group, but in fact the intensities of $\mathrm{CH}_{2}$ groups also decreased. When the butyl group changes, the electronic environment of the methyl group also changes, which leads to a new $-\mathrm{CH}_{3}$ peak right next to the old one. As expected, the total intensity remains almost the same. The oxidation rate is thus defined as the newly formed $-\mathrm{CH}_{3}$ peak intensity relative to the total. As seen from Table 2.5, oxidation rate is fastest in the [bpym] $\mathrm{PtCl}_{2}$ system and decreases in the order of [bpym] $\mathrm{PtCl}_{2}, \mathrm{~K}_{2} \mathrm{PtCl}_{4}$, and $\mathrm{PtCl}_{2}$. The ${ }^{1} \mathrm{H}$ NMR spectra for the [bpym] $\mathrm{PtCl}_{2}$ system for different reaction times are plotted in Figure 2.1.

Table 2.1: Compatibility between ionic liquids and concentrated sulfuric acid at room temperature and at elevated temperatures

\begin{tabular}{|c|c|c|c|}
\hline \multirow{2}{*}{ Ionic Liquid } & \multirow{2}{*}{$\begin{array}{l}\text { Solubility in } \\
\mathrm{H}_{2} \mathrm{SO}_{4} \text { at R. T. }\end{array}$} & \multicolumn{2}{|c|}{ Stability in $\mathrm{H}_{2} \mathrm{SO}_{4}$ up to $200^{\circ} \mathrm{C}$} \\
\hline & & Cation & Anion \\
\hline $\begin{array}{l}\text { Ammonium-based } \\
\left(\mathrm{CH}_{3}\right)_{3} \mathrm{~N}\left(\mathrm{C}_{14} \mathrm{H}_{29}\right) \mathrm{Br}\end{array}$ & Soluble & Stable & $\mathrm{HBr}$ released \\
\hline$\left(\mathrm{CH}_{3}\right)_{4} \mathrm{NCl}$ & Soluble & Stable & $\mathrm{HCl}$ released \\
\hline $\begin{array}{l}\text { Phosphonium-based } \\
\qquad\left(\mathrm{CH}_{3}\right)_{3} \mathrm{P}\left(\mathrm{C}_{16} \mathrm{H}_{33}\right) \mathrm{Br}\end{array}$ & Soluble & Stable & $\mathrm{HBr}$ released \\
\hline $\begin{array}{c}\text { Pyridinium-based } \\
{[\mathrm{bpy}][\mathrm{Cl}]}\end{array}$ & Soluble & Stable & $\mathrm{HCl}$ released \\
\hline $\begin{array}{c}\text { Imidazolium-based } \\
{[\text { bmim }]\left[\mathrm{PF}_{6}\right]} \\
{[\mathrm{mmim}]\left[\mathrm{CH}_{3} \mathrm{SO}_{4}\right]}\end{array}$ & $\begin{array}{c}\text { Slow and small } \\
\text { Soluble }\end{array}$ & Stable & Decomposes \\
\hline
\end{tabular}




\begin{tabular}{cllc}
\hline$[\mathrm{bmim}][\mathrm{Cl}]$ & Soluble & Stable & $\mathrm{HCl}$ released \\
{$[\mathrm{bmim}]\left[\mathrm{BF}_{4}\right]$} & Soluble & Stable & $\mathrm{HF} / \mathrm{BF}_{3}$ released \\
{$[\mathrm{emim}]\left[\mathrm{CF}_{3} \mathrm{SO}_{3}\right]$} & Soluble & Stable & Stable \\
\hline
\end{tabular}

Table 2.2: Compatibility of Pt-based catalysts in concentrated sulfuric acid at room temperature and at elevated temperatures.

\begin{tabular}{lll}
\hline \multirow{2}{*}{ Pt-based Catalyst } & \multicolumn{2}{c}{ Solubility and Stability in $\mathrm{H}_{2} \mathrm{SO}_{4}$} \\
\cline { 2 - 3 } & Room Temp. & High Temp., up to $220^{\circ} \mathrm{C}$ \\
\hline$[$ bpym $] \mathrm{PtCl}_{2}$ & Yes & $\begin{array}{l}\text { Free ligand bpym is observed } \\
\text { by NMR at }>110{ }^{\circ} \mathrm{C} .\end{array}$ \\
& & $\begin{array}{l}\text { Decomposes at }>180{ }^{\circ} \mathrm{C} \text { and } \\
\text { PtCl }\end{array}$ \\
{$\left[\mathrm{NH}_{3}\right]_{2} \mathrm{PtCl}_{2}$} & Yes & No \\
$\mathrm{K}_{2} \mathrm{PtCl}_{4}$ & No, decomposes to $\mathrm{PtCl}_{2}$ & No \\
$\mathrm{PtCl}_{2}$ & No & No \\
\hline
\end{tabular}

Table 2.3: Compatibility of Pt-based catalysts in ionic liquids, primarily dependent on the type of anion.

\begin{tabular}{lclll}
\hline \multirow{2}{*}{ Ionic Liquid } & \multicolumn{4}{c}{ Pt-based Catalyst Solubility in IL, up to $220{ }^{\circ} \mathrm{C}$} \\
\cline { 2 - 5 } & {$[$ bpym $] \mathrm{PtCl}_{2}$} & {$\left[\mathrm{NH}_{3}\right]_{2} \mathrm{PtCl}_{2}$} & $\mathrm{~K}_{2} \mathrm{PtCl}_{4}$ & $\mathrm{PtCl}_{2}$ \\
\hline$[\mathrm{bmim}]\left[\mathrm{BF}_{4}\right]$ & No & No & No & No \\
{$[\mathrm{emim}]\left[\mathrm{CF}_{3} \mathrm{SO}_{3}\right]$} & No & No & No & No \\
{$[\mathrm{bmim}][\mathrm{Cl}]$} & $\begin{array}{l}\text { Yes at } 200{ }^{\circ} \mathrm{C} ; \\
\text { free bpym is seen }\end{array}$ & $\begin{array}{l}\text { Yes upon } \\
\text { melting }\end{array}$ & Yes at $200{ }^{\circ} \mathrm{C}$ & $\begin{array}{l}\text { Yes upon } \\
\text { melting }\end{array}$ \\
\hline
\end{tabular}




\begin{tabular}{lllll}
\hline$[$ bmim $]\left[\mathrm{HSO}_{4}\right]$ & $\begin{array}{l}\text { Yes at } 200{ }^{\circ} \mathrm{C} ; \\
\text { free bpym is seen }\end{array}$ & Yes at $200{ }^{\circ} \mathrm{C}$ & Yes at $200^{\circ} \mathrm{C}$ & Yes at $200^{\circ} \mathrm{C}$ \\
\hline
\end{tabular}

Table 2.4: Stability of ternary systems of $\mathrm{H}_{2} \mathrm{SO}_{4} /$ Catalyst/Ionic Liquid at $200{ }^{\circ} \mathrm{C}$.

\begin{tabular}{llll}
\hline \multirow{2}{*}{ Ionic Liquid } & \multicolumn{3}{c}{ Pt-based Catalyst $^{\mathrm{a}}$} \\
\cline { 2 - 4 } & [bpym] $\mathrm{PtCl}_{2}$ system & $\mathrm{K}_{2} \mathrm{PtCl}_{4}$ system & $\mathrm{PtCl}_{2}$ system \\
\hline$[\mathrm{mmim}]\left[\mathrm{HSO}_{4}\right]$ & $\begin{array}{l}\text { Cation stable; } \\
\text { Anion decomposed }\end{array}$ & (Insoluble) & (Insoluble) \\
{$[\mathrm{emim}]\left[\mathrm{CF}_{3} \mathrm{SO}_{3}\right]$} & $\begin{array}{l}\text { Ethyl oxidized; } \\
\text { Anion stable }\end{array}$ & (Insoluble) & (Insoluble) \\
{$[\mathrm{bmim}]\left[\mathrm{BF}_{4}\right]$} & $\begin{array}{l}\text { Butyl oxidized; } \\
\mathrm{BF}_{4} \text { decomposed }\end{array}$ & (Insoluble) & (Insoluble) \\
{$[\mathrm{bmim}][\mathrm{Cl}] /\left[\mathrm{HSO}_{4}\right]$} & $\begin{array}{l}\text { Butyl oxidized } \\
\text { IL-003 to IL-009 }\end{array}$ & Butyl oxidized & Butyl oxidized \\
\end{tabular}

\footnotetext{
${ }^{a}$ Pt-based catalysts were either dissolved in $\mathrm{H}_{2} \mathrm{SO}_{4}$ first or in ionic liquid first at elevated temperature.

${ }^{\mathrm{b}}$ Ionic liquids (IL-003 to IL-009) are home designed and synthesized and meet the compatibility requirement in the ternary system up to $220^{\circ} \mathrm{C}$.
}

Table 2.5: Oxidation rate study of $\mathrm{H}_{2} \mathrm{SO}_{4} /$ Catalyst/[bmim] [Cl] ternary system at $200{ }^{\circ} \mathrm{C}$. [bmim] was used as a model compound for oxidation. Rates were determined based on $1 \mathrm{H} \mathrm{NMR} \mathrm{in} \mathrm{D}_{2} \mathrm{SO}_{4}$ using acetic acid as the internal standard.

\begin{tabular}{ccccccc}
\hline \multirow{2}{*}{$\begin{array}{c}\text { Time at } \\
200\end{array}{ }^{\circ} \mathrm{C}$} & \multicolumn{2}{c}{$[\mathrm{bpym}] \mathrm{PtCl}_{2}$ system } & \multicolumn{2}{c}{$\mathrm{K}_{2} \mathrm{PtCl}_{4}$ system } & \multicolumn{2}{c}{$\mathrm{PtCl}_{2}$ system } \\
\cline { 2 - 7 } & Conversion $^{\text {a }}$ & Yield $^{\mathrm{a}}$ & Conversion & Yield & Conversion & Yield \\
\hline R.T. (ref.) & 0 & 0 & 0 & 0 & 0 & 0 \\
$70 \mathrm{~min}$ & $37 \%$ & $37 \%$ & $47 \%$ & $20 \%$ & $24 \%$ & $12 \%$ \\
$2 \mathrm{hr}$ & $65 \%$ & $55 \%$ & $\sim 60 \%$ & $24 \%$ & $\sim 40 \%$ & $21 \%$ \\
\hline
\end{tabular}




\begin{tabular}{lllllll}
\hline $27 \mathrm{hr}$ & $100 \%$ & $100 \%$ & $80 \%$ & $72 \%$ & $50 \%$ & $50 \%$ \\
\hline
\end{tabular}

${ }^{a}$ See the definitions of conversion and yield in the text.

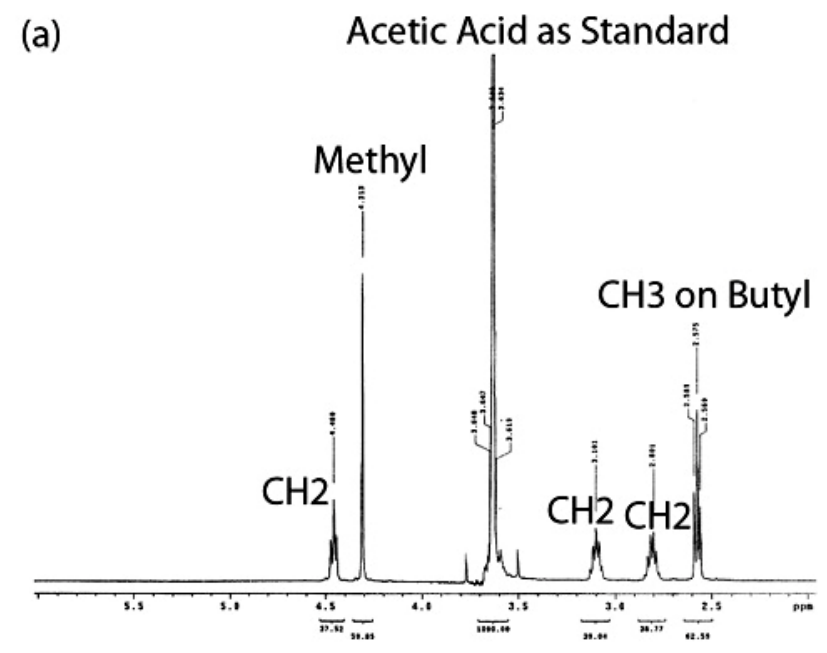

(b)
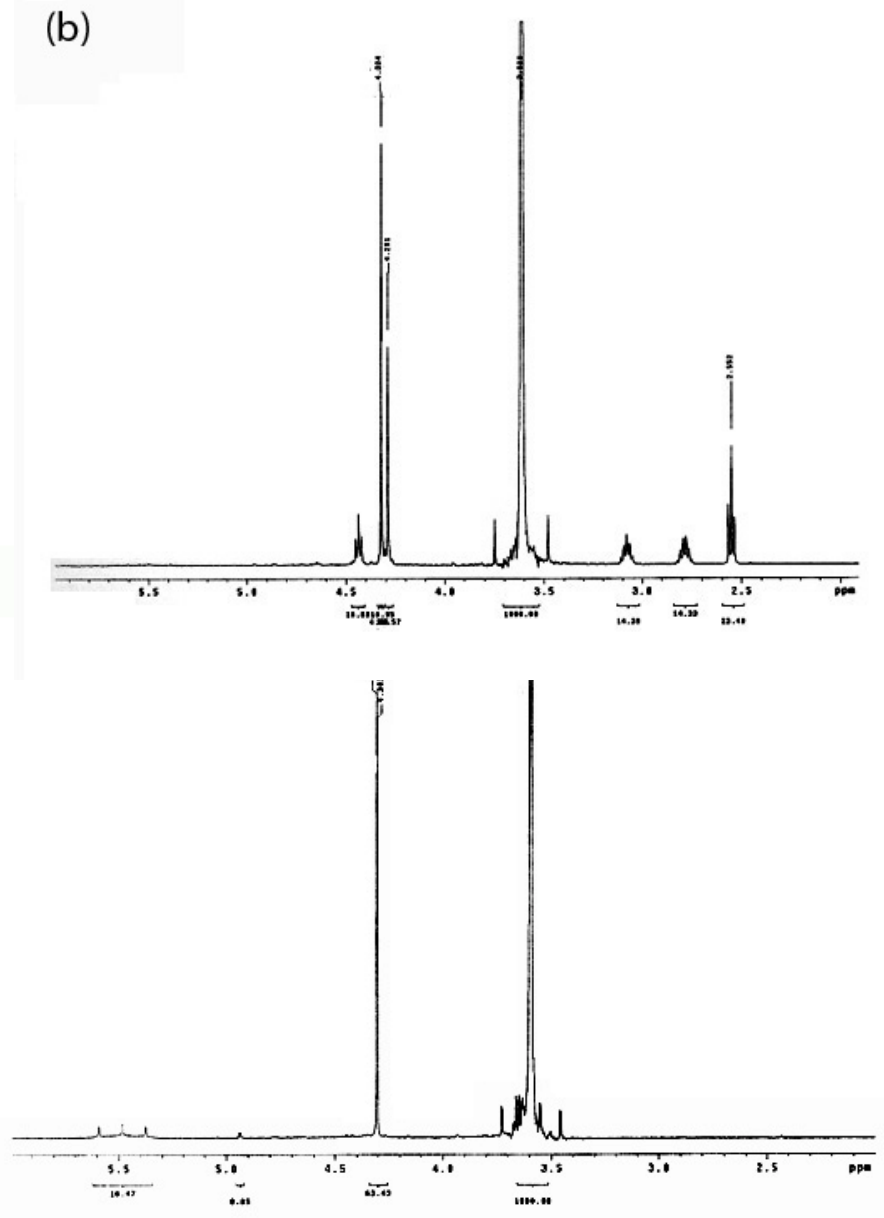
Figure 2.1: ${ }^{1} \mathrm{H}$ NMR spectra of the liquid of $\mathrm{H}_{2} \mathrm{SO}_{4} /[\mathrm{bpym}] \mathrm{PtCl}_{2} /[\mathrm{bmim}][\mathrm{Cl}]$ ternary system after rate tests using the low pressure reactor. (a) room temperature, as reference; (b) $200{ }^{\circ} \mathrm{C}, 2 \mathrm{hr}$; and (c) 200 ${ }^{\circ} \mathrm{C}, 27 \mathrm{hr}$.

\subsection{HIGH PROESSURE REACTORS}

Due to the poor solubility of methane gas in the reaction liquid, effective contact between the methane and other reactants in the liquid phase requires high pressure and efficient mixing/stirring. In addition, the reaction media is very corrosive, so that the high pressure reactor design is much more challenging. Table 2.6 summarizes the four types of major high pressure reactors designed/built/modified and utilized during this project, which are resulted from our unique and world leading expertise on experimental investigations on homogenous catalysis especially on selective hydrocarbon conversion. The progresses we have made on these high pressure reactors are valuable for not only future work on the development of efficient homogenously catalytic methane conversion systems but also can be applied for other innovated studies in catalytic inorganic/organic chemistry.

Table 2.6: Summary of high-pressure reactor designs and applications.

\begin{tabular}{|c|c|c|c|c|c|}
\hline $\begin{array}{l}\text { Reactor } \\
\text { Name }\end{array}$ & $\begin{array}{l}\text { Volume } \\
\text { (mL) }\end{array}$ & $\begin{array}{l}\text { Physical } \\
\text { Description }\end{array}$ & $\begin{array}{l}\text { Gas/Liquid } \\
\text { Mixing }\end{array}$ & $\begin{array}{l}\text { Application \& } \\
\text { Conditions }\end{array}$ & Pros and Cons \\
\hline $\begin{array}{l}\text { Big } \\
\text { Reactor }\end{array}$ & $\sim 69$ & $\begin{array}{l}\text { Lab-built, from } \\
\text { stainless steel } \\
\text { tube, } 5 \text { in. long }\end{array}$ & $\begin{array}{l}\text { Magnetic stir } \\
\text { bar spinning }\end{array}$ & $\begin{array}{l}\text { Oxidation, } 1 \\
\text { mL liquid }+ \\
500{\text { psi } \mathrm{CH}_{4}}^{2}\end{array}$ & $\begin{array}{l}\text { Easy to operate } \\
\text { Low conversion } \\
\text { Poor T/P control }\end{array}$ \\
\hline $\begin{array}{l}\text { Short } \\
\text { Reactor }\end{array}$ & $\sim 6$ & $\begin{array}{l}\text { Lab-built, from } \\
\text { stainless steel } \\
\text { tube, } 2 \text { in. long }\end{array}$ & $\begin{array}{l}\text { Magnetic stir } \\
\text { bar spinning }\end{array}$ & $\begin{array}{l}\text { Activation, } 1 \\
\text { mL liquid }+ \\
500 \text { psi } \mathrm{CH}_{4}\end{array}$ & $\begin{array}{l}\text { Easy to operate } \\
\text { Low mixing speed } \\
\text { Poor T/P control }\end{array}$ \\
\hline $\begin{array}{l}\text { Mini } \\
\text { Reactor }\end{array}$ & $\sim 1$ & $\begin{array}{l}\text { Gold tube, } 4 \text { in. } \\
\text { long, sealing by } \\
\text { arc welding }\end{array}$ & $\begin{array}{l}\text { External } \\
\text { hydraulic } \\
\text { pressure up to } \\
3700 \text { psi }\end{array}$ & $\begin{array}{l}\text { Activation \& } \\
\text { Oxidation, } 0.3 \\
\text { mL liquid }+ \\
50 \mathrm{psi}^{-} \mathrm{CH}_{4}\end{array}$ & $\begin{array}{l}\text { High conversion } \\
\text { High yield } \\
\text { Difficult to operate }\end{array}$ \\
\hline $\begin{array}{l}\text { Parr } \\
\text { Reactor }\end{array}$ & 25 & $\begin{array}{l}\text { Purchased but } \\
\text { gold coated } \\
\text { inside and with } \\
\text { modified baffle }\end{array}$ & $\begin{array}{l}\text { Rotation of } \\
\text { axle and } \\
\text { baffle up to } \\
1500 \mathrm{rpm}\end{array}$ & $\begin{array}{l}\text { Activation \& } \\
\text { Oxidation, } 10 \\
\text { mL liquid }+ \\
500{\text { psi } \mathrm{CH}_{4}}\end{array}$ & $\begin{array}{l}\text { High conversion } \\
\text { High yield } \\
\text { High cost for a run } \\
\text { Difficult to operate }\end{array}$ \\
\hline
\end{tabular}

A home-built stainless steel high-pressure reactor was initially used for the methane oxidation tests. There are some drawbacks associated with this reactor design. (1) 
Large dead volume. The total capacity of the reactor is about $69 \mathrm{~mL}$ but we usually only load $1 \mathrm{~mL}$ reaction liquid. It is not surprising to see a low conversion rate and a low yield thereafter. Thus this reactor is not in an optimized condition for methane oxidation. (2) Poor temperature control for the reaction zone. The lower part of the cylindrical reactor was submerged into an oil bath whose temperature can be well controlled. However, the liquid inside is hard to reach a stable desired temperature. (3) Low mixing speed for gasliquid phases. A magnetic stir bar driven by the stirring plate can only provide a gas/liquid surface reaction, thus a low yield is expected. Overall, these several factors result in a relatively large uncertainty for the yield determination. Later, this big stainless steel reactor was mainly used for semi-quantitative tests on new catalytic systems and for some tests requiring high pressure gas mixture $\left(\mathrm{CH}_{4}+\mathrm{O}_{2}\right)$ in the reaction system. This reactor has excellent gas evacuation/refill system and convenient gas sampling part for $\mathrm{GC}$ analysis.

A modified stainless steel high-pressure reactor with much shrunk size $(10 \mathrm{~mL}$, later to $6 \mathrm{~mL}$ ), the Short Reactor was designed and built for methane activation study at $150{ }^{\circ} \mathrm{C}$ or below. The smaller size reduces the total amount of methane loaded and ensures an observable H/D exchange. One milliliter of reaction liquid is added into the reactor and the gas/liquid is mixed by a magnetic stir bar spinning. Similarly, this Short Reactor bears the advantages and disadvantages of the Big Reactor.

We would like to emphasize our innovated reactor design - the mini gold tube reactor which assures $100 \%$ mass balance, uniform temperature control and 3700 Psi external hydraulic pressure and thus efficient contact between the gas phase methane and the liquid phase reaction media with catalysts, ionic liquids and oxidants. The mini gold tube has a total volume of about $1 \mathrm{~mL}, 30 \%$ of which is loaded with reaction liquid and the remaining space can be filled by methane gas (usually $50-100 \mathrm{psi}$ ). Arc welding is used for sealing at both ends. Sealed tubes are placed in a stainless autoclave to which an external hydraulic pressure of up to $3700 \mathrm{psi}$ will be applied. Then the autoclave is heated in a box furnace at desired temperature. The weight of each gold tube is recorded before and after reaction and usually the mass difference is no more than $0.1 \mathrm{mg}$. Gas phases are analyzed using GC and liquid phase is by ${ }^{1} \mathrm{H}$ NMR. In addition, multiple mini gold tube reactors can be placed into one autoclave for heating and our box oven has multiple heating slots with very close temperature to each other upon heating. Therefore, parallel experiments with different variables (catalytic system compositions, heating temperature, heating time etc) can be conducted with good reproducibility and good T/P control. With the mini gold tube reactors, high conversion and high yield can be achieved at the price of difficult operation and relatively high costs, for example, the cost for manufacturing/recycling the gold tubes.

Most of the gold tube experiments were conducted in the big box oven where heating was achieved through hot air circulation oven. The temperature is controlled by a thermocouple sitting inside of the oven. Such a heating system is not able to provide precise temperature control. More important, the time required for reaching system equilibrium, i.e. heating the reactor to desired temperatures $\left(200^{\circ} \mathrm{C} \sim 350^{\circ} \mathrm{C}\right)$ and reach equilibrium can take as long as couple hours. Even if we place the autoclave into the 
oven after it reaches the desired temperature, it still takes 30 minutes or one hour for the thermocouple sitting directly on the autoclave to stabilize. During this slow heating process, we are afraid that some reactions, i.e. slow oxidation of methanol, could also finish after methanol conversion. We built a heating system with an autoclave that could still hold gold tube reactor yet could reach equilibrium temperature $\left(200^{\circ} \mathrm{C} \sim 350^{\circ} \mathrm{C}\right)$ within a couple of minutes. This short heating process allowed us to stop the reaction and analyze the final products in a very short time.

The old autoclave is made of steel, and has a dimension of 1.5" hexagonal crosssection and 14" long. Although sturdy, it is slow in conducting heat and reaching temperature equilibrium. The circulating air in the oven is quite slow in passing the heat to the autoclave. In addition, the inside space is much larger than necessary for holding one mini-gold-tube reactor so that relatively large amount of water will fill out that space to provide the over 3000 PSi hydraulic external pressure for the reaction. Therefore the heating response is very slow in this system. We first redesigned the autoclave that holds the gold tube reactor. The material is changed from Steel to Aluminum (Al6061T), and the designs still allow the autoclave and connectors to hold water at high pressure (over $3,000 \mathrm{PSi}$ ) and high temperature (up to $350^{\circ} \mathrm{C}$ ). In this way the reaction conditions, i.e. temperature ranging from $200^{\circ} \mathrm{C} \sim 350^{\circ} \mathrm{C}$ and pressure up to $3,000 \mathrm{PSi}$, are still available to the gold tube reactor, much the same as the large steel autoclave. The size of the aluminum autoclave is reduced to 1 " hexagonal cross-section and only 5" long when assembled. The reduced size and mass of the aluminum autoclave directly translate into reduced heat capacity; while the aluminum material could allow heat to transfer from the outside to the inside of the autoclave at a much faster rate, i.e. Aluminum has heat conductivity almost 5 times as that of steel. These changes allowed temperature to go up at much faster rate compared to the old steel system if the heating system could provide strong enough heat flow for transfer.

The heating system was also changed from the large hot air circulating oven, much like a roast turkey in an oven, to a flux solder tin pot where the Aluminum autoclave is dipped into the pot, much like a chicken drum dipped into a hot frying pot. The latter heating system obviously could provide much stronger heat flow for transferring into the autoclave. The newly purchased solder tin pot (Model C161, Made in China) uses $3 \mathrm{~kg}$ of Tin (70\%)-Cu (30\%) alloy and could provide a pot of melt solder tin at controlled temperature from $180^{\circ} \mathrm{C}$ to $450^{\circ} \mathrm{C}$. The dimension of the Titanum pot is $140 \mathrm{~mm} \times 70 \mathrm{~mm} \times 43 \mathrm{~mm}$, which is suitable for the newly designed small Al autoclave. Preliminary results show that we could reach a temperature stability of $\pm 4^{\circ} \mathrm{C}$ at $300^{\circ} \mathrm{C}$ within 3 minutes.

Upon developing some promising catalytic systems for efficient methane conversion with the stainless steel reactors and the mini gold tube reactors, we advanced our efforts on developing a bench scale reactor ---modification of the commercially purchased Parr Reactor. This commercial product is superior at providing high pressure (up to $1000 \mathrm{Psi}$ ), high gas-liquid mixing (rotating baffles at $3000 \mathrm{rpm}$ ) and in-situ temperature and pressure control. However, this reactor is not applicable for our catalytic methane conversion system mainly due to its poor corrosion resistance. On the other 
hand, the heating rate for this reactor is too slow, which is not desired for the repeatability and quantification of our experiments. Creative yet minor modifications have been applied. For example, we increased the reaction vessel size from $25 \mathrm{~mL}$ to $50 \mathrm{~mL}$ for larger reaction volume and larger space for the rotating baffle. Besides gold-coating all exposed surfaces, we also inserted a liner inside of the reaction vessel to avoid damage/precipitates on the wall of the reaction vessel. While, our preliminary tests showed that such minor modifications still could not meet the requirements for our harsh experimental conditions. Because of the inevitable vibration caused by the high-speed baffle-rotation, frictions between the rotation baffle, the reaction vessel and the thermocouple will wear off the protecting gold coating and then corrode the parts leading to serious damage to the reactor. In addition, gold coating can not reach some tunnels in the reactor where the corrosive acid vapor can reach. It is also possible to damage other electronic components of the reactor. In short, cost for test with the modified Parr Reactor can be very high with potential damage to the gold coating, quartz liner or other components. Therefore, to completely solve the corrosion problem requires major modification of the reactor such as replacing some of the exposed components by Tantalum material. However, such major modification will be very costive and require a long proceeding time which can not be realized within the time-frame and the budget of the current project.

Based on our experience with the Parr Reactor Modification and development of various custom-made small scale reactors (stainless steel reactor, gold tube reactor, fast heating system), we have propose to build up a new bench scale reactor which is capable to operate under highly corrosive condition, to provide in-situ temperature/pressure control (including heating rate), and to enable in-line result analysis (GC, GC/MS measurements on the reaction gases).

\subsection{CHARACTERIZATIONS AND QUANTIFICATIONS}

The major analytic tools utilized in this project are ${ }^{1} \mathrm{H}$ NMR (Proton Nuclear Magnetic Resonance) and GC (Gas Chromatography) coupled with FID (Flame Ionization Detector), TCD (Thermal Conductivity Detector) or MSD (Mass Selective Detector). Also utilized are HPLC (High Performance Liquid Chromatography) with a UV (Ultraviolet) and Elemental Analysis.

${ }^{1} \mathrm{H}$ NMR is heavily employed in various compatibility tests and methanol/methyl bisulfate production quantification. It is worth to be pointed out that we have developed a suitable protocol for analyzing our concentrated sulfuric acid containing reaction liquids. Instead of those normally utilized deuterated solvents, we are using $98 \% \mathrm{D}_{2} \mathrm{SO}_{4}$ as the solvent and $\mathrm{CH}_{3} \mathrm{COOH}$ as the internal standard for most NMR measurements. A Varian Mercury $300 \mathrm{MHz}$ NMR spectrometer was utilized to conduct all NMR measurements. Table 2.5 and Figure 2.1 show one example of the NMR analysis, i.e. using NMR to quantify the oxidation rate of $\mathrm{H}_{2} \mathrm{SO}_{4} /$ Catalyst/[bmim $][\mathrm{Cl}]$ ternary system at $200{ }^{0} \mathrm{C}$. While, Figure 2.2 show typical NMR spectra for the liquid of $\mathrm{H}_{2} \mathrm{SO}_{4} / \mathrm{Pt}(\mathrm{IV})$ Catalyst $/ \mathrm{CH}_{4}$ ternary system after methane oxidation tests using the high-pressure reactor. 

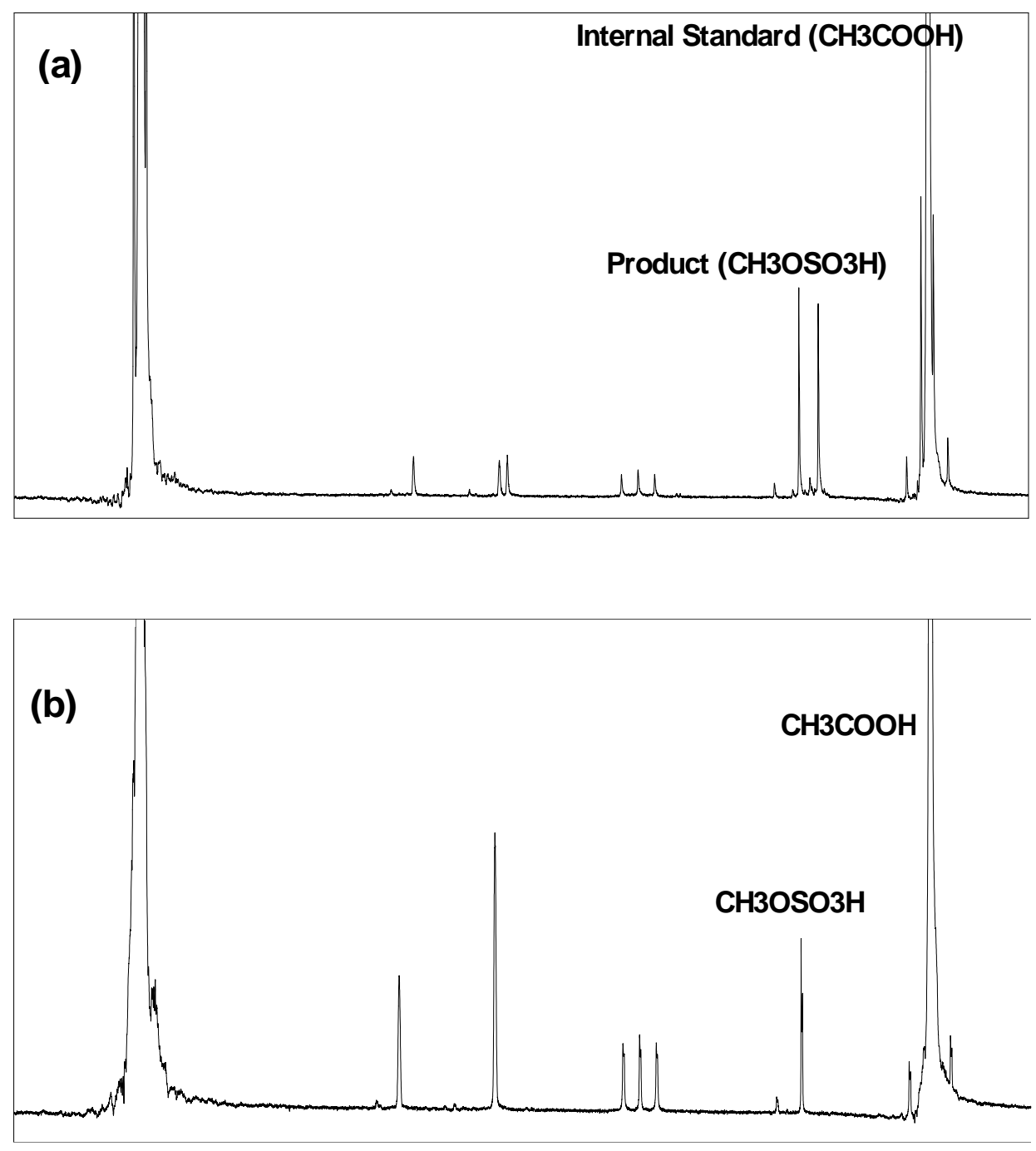

Figure 2.2: ${ }^{1} \mathrm{H}$ NMR spectra of the liquid of $\mathrm{H}_{2} \mathrm{SO}_{4} / \mathrm{Pt}(\mathrm{IV})$ Catalyst/ $\mathrm{CH}_{4}$ ternary system after methane oxidation tests using the high-pressure reactor. (a) $\mathrm{PtCl}_{4}+$ IL-003 system; (b) PtO $\mathrm{P}_{2}+$ IL006 system. Acetic acid was used as the internal standard.

An HP 6890 GC with MSD detector and specially designed sample holder was used for the quantification of the deuterated methane isotopomers produced from the H/D exchange experiments designed for investigating the $\mathrm{C}-\mathrm{H}$ activation of methane. Figure 2.3 shows the gas chromatographs of methane after partially exchanged with deuterated solvent of (a) the Periana system, (bpym) $\mathrm{PtCl}_{2}$ in $98 \% \mathrm{D}_{2} \mathrm{SO}_{4}$; and (b) PtCl2 + IL-004- $\mathrm{d}_{5}$ in $98 \% \mathrm{D}_{2} \mathrm{SO}_{4}$; (c) is an overlaid chromatograph for mass ions of methane isotopes of system (b).

Two types of reactors, the mini gold tube and the short stainless steel reactor, were used for the H/D exchange experiments. The results from each reactor provide an internal check about the validity of the data. The Pt catalyst concentration was kept at 50 $\mathrm{mM}$. The dilution of sulfuric acid is achieved by adding $\mathrm{D}_{2} \mathrm{O}$ or deuterated ionic liquids. Two deuterated imidazolium-based ionic liquids, IL-004- $\mathrm{d}_{5}$ (alkylated) and IL-007- $\mathrm{d}_{5}$, were synthesized through $\mathrm{H} / \mathrm{D}$ exchange between the regular ones and $\mathrm{D}_{2} \mathrm{SO}_{4}$. The gold 


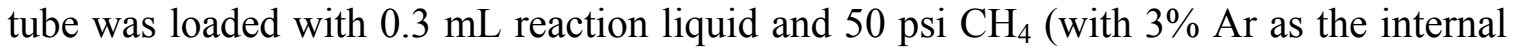
standard). The short reactor was loaded with $1 \mathrm{~mL}$ reaction liquid and $500 \mathrm{psi} \mathrm{CH}_{4}$. Both were heated at $150{ }^{\circ} \mathrm{C}$ for 2 hours. The gold tube was in an oven and the short reactor was in an oil bath. The gas phases after reaction were introduced into the HP 6890 GC-MS system. The total amount of methane was deduced from the internal standard Ar integration. The methane isotopes were identified from their characteristic ion masses such as 20 for $\mathrm{CD}_{4}, 19$ for $\mathrm{CHD}_{3}, 18$ for $\mathrm{CH}_{2} \mathrm{D}_{2}$, and 17 for $\mathrm{CH}_{3} \mathrm{D}$.
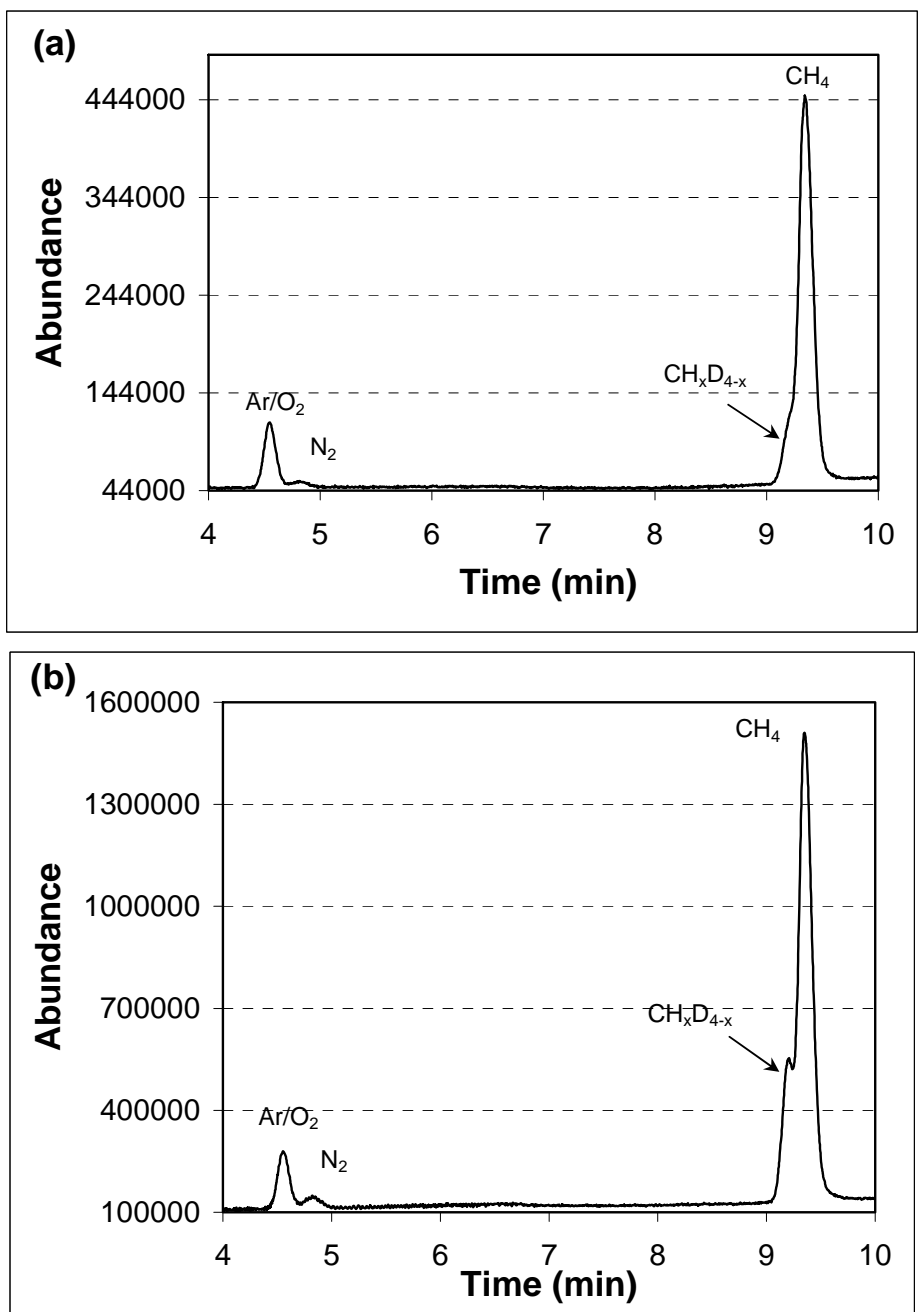


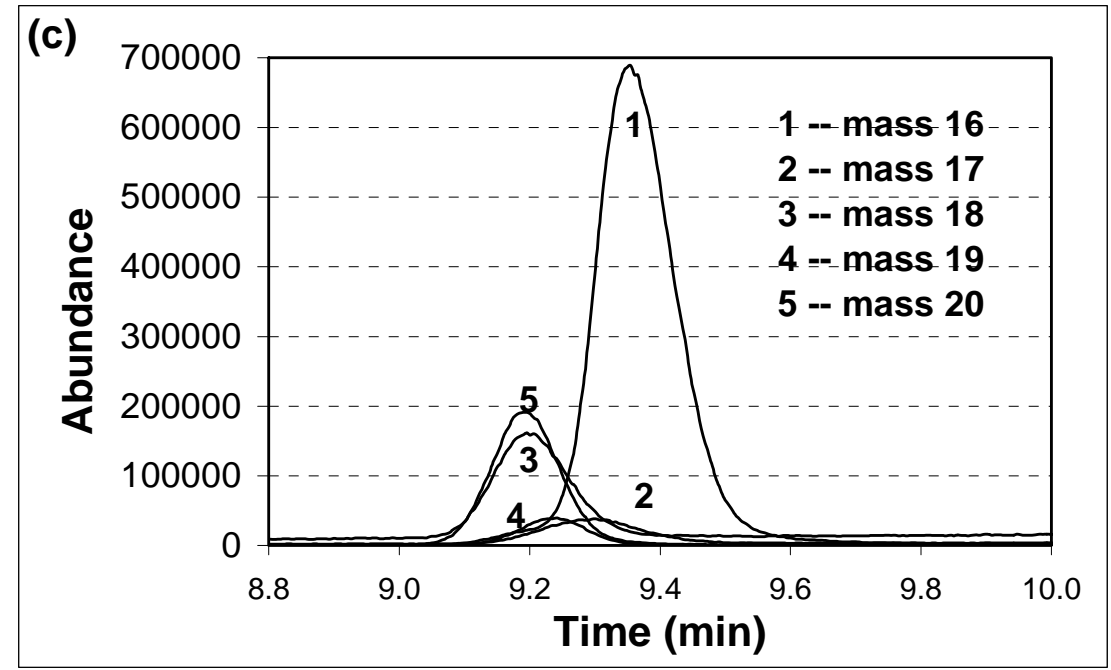

Figure 2.3: Gas chromatograph of methane after partially exchanged with deuterated solvent of (a) the Periana system, (bpym) $\mathrm{PtCl}_{2}$ in $98 \% \mathrm{D}_{2} \mathrm{SO}_{4}$; and (b) $\mathrm{PtCl} 2+\mathrm{IL}-004-d_{5}$ in $98 \% \mathrm{D}_{2} \mathrm{SO}_{4}$. Fig. 1(c) is an overlaid chromatograph for mass ions of methane isotopes of system (b).

An HP 5890 GC with MSD detector can also be used to quantify the methanol (and methyl bisulfate) production. The liquid after reaction was hydrolyzed and neutralized with $\mathrm{NaOH}$ to a $\mathrm{PH} \sim 7$ for the GC-MS measurements. are shown in Figure 2.4 shows the GC-MS spectra of the liquid of $\mathrm{H}_{2} \mathrm{SO}_{4} / \mathrm{Catalyst} / \mathrm{CH}_{4}$ ternary system after methane oxidation tests highlighting both the free $\mathrm{CH}_{3} \mathrm{OH}$ peak and the $\mathrm{CH}_{3} \mathrm{HSO}_{4}$ peak.

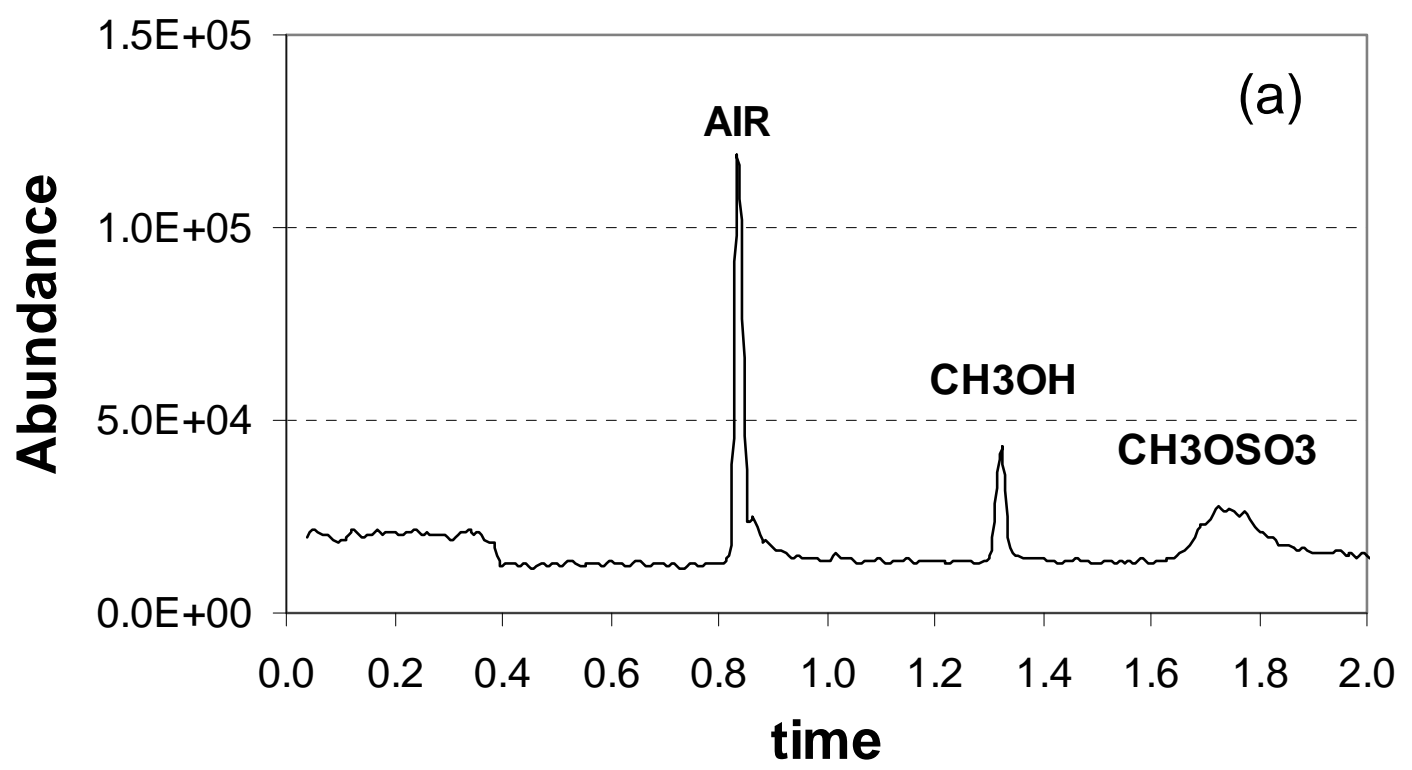




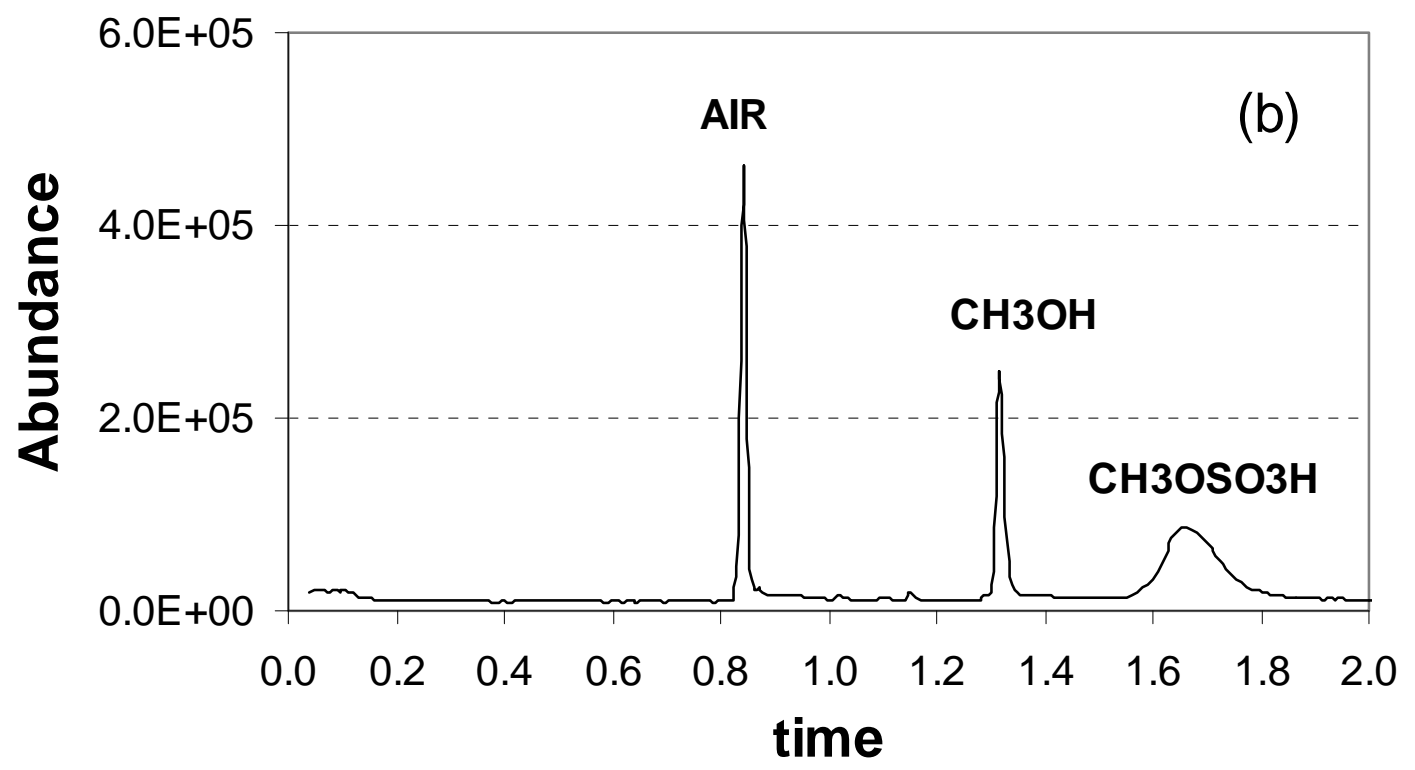

Figure 2.4: GC-MS spectra of the liquid of $\mathrm{H}_{2} \mathrm{SO}_{4} / \mathrm{Catalyst} / \mathrm{CH}_{4}$ ternary system after methane oxidation tests using the high-pressure reactor. (a) system \#1, using [bpym]PtCl $\mathrm{Pa}_{2}$ the catalyst; and (b) system \#2, using $\mathrm{PtCl}_{2}-\mathrm{IL003}$ as the catalyst. About $0.2 \mathrm{~mL}$ liquid after each reaction run was hydrolyzed in $5 \mathrm{~mL} \mathrm{H}_{2} \mathrm{O}$ solution and then neutralized with $\mathrm{NaOH}$. They differ in the total peak area integrated

The gas phase products from the methane oxidation experiments were transferred, quantified and analyzed with an HP 6890 GC with FID, TCD and FPD (Flame Photometric Detector) detectors. The methane gas reactant contains 3\% or $15 \% \mathrm{He}$ as internal standard. Through this analytical protocol, we were able to characterize/quantify the total amounts of methane loaded and remained, $\mathrm{CH}_{3} \mathrm{Cl}, \mathrm{CO}_{2}$ and $\mathrm{SO}_{2}$ generation, which gave us the conversion and selectivity data. 


\section{CHAPTER THREE: IONIC LIQUIDS FOR HYDROCARBON CONVERSION}

\subsection{SUMMARY}

During this five-year project, totally 285 commercial ionic liquids and 55 PEERsynthesized ionic liquids have been tested and screened for application in homogeneously catalytic conversion of methane. One of our powerful tools for describing/predicting the major physical and chemical properties of the huge amount of varieties of ionic liquids is the molecular modeling based on the DFT calculations. Combined the molecular modeling results and the experimental observations on eight major types of ionic liquids, we have been able to not only identify/synthesize several classes of super stable ionic liquids under the harsh conditions (high temperature $\sim 250^{\circ} \mathrm{C}$, highly acidic and oxidative of concentrated sulfuric acid, and powerful catalysts $\mathrm{Pt}$ or other transition metal compounds) for catalytic methane oxidation reaction, but also achieve mechanistic understandings of the functions of ionic liquids in catalytic methane conversion systems or other catalytic chemical reactions.

Our findings on innovated applications of ionic liquids in chemical reactions are of critical significance to open some new chemistry in some chemical industries. Enormous beneficial impacts can be expected from such innovated applications of ionic liquids given their "green" and "designer" nature.

\subsection{MOLECULAR MODELING OF IONIC LIQUID DATABASE}

The potential combinations of different ionic liquids are enormous. A simple statistical estimation of currently-known cation/anion combinations results in a $10^{14}$ different ionic liquid prototypes. A comprehensive list of various ionic liquid candidates is essential for the screening purpose. Currently, we have identified nearly 300 different types of ionic liquids that are commercially available. These ionic liquid compounds serve as basic components of our ionic liquid database. Upon collections of their physical and chemical properties from vast literature search and from direct input from Sachem, molecular modeling based on the Density Functional Theory (DFT) calculations was initiated.

To examine the molecular properties of ionic liquid compounds, and to obtain their geometry, chemical bonding and energetic relations as important inputs for the calibrations of the ReaxFF method, an ion-pair formation of the ionic liquid is computed. Geometry of the ion-pair in fully optimized in gas-phase, and in various organic solvents using the continuous solvation model. Structural information, such as H-bonding, can then be obtained. Other structural related properties such as dipole moment, highest occupied molecular orbital (HOMO), lowest unoccupied molecular orbital (LOMO), as well as molecular weight, surface, and volume, can also be determined.

Basically, there are 9 major cation classes that are most commonly used to form ionic liquids; and the variation of their molecular structure such as different alkyl chain length and attached positions, have great impact to the ionic liquid physical properties 
such as melting point and stability. Figure 3.1 illustrates these cation classes. On the other hand, the molecular compositions of the anion are more various. In general, the influence of the anion species is more relevant to the ionic liquid chemical properties, such as acidity and chemical reactivity. Figure 3.2 are some common anion species of ionic liquids. In Table 3.1, we list a few calculated molecular properties of the monosubstituted Imidazolium Derivatives.

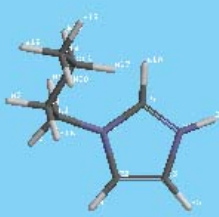

(a)
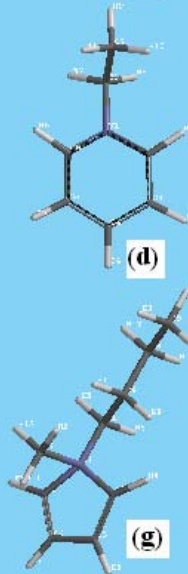

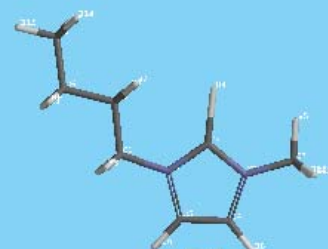

(b)
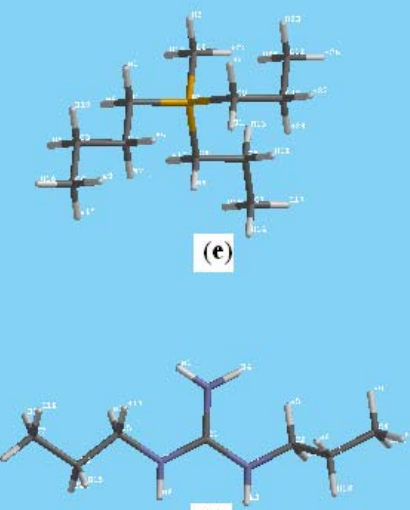

(h)

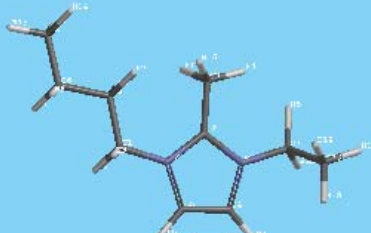

(c)

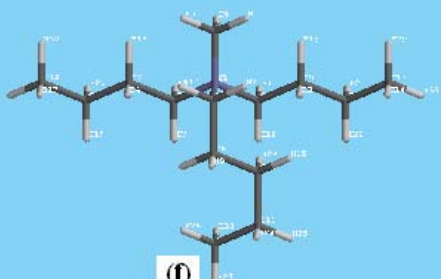

(f)

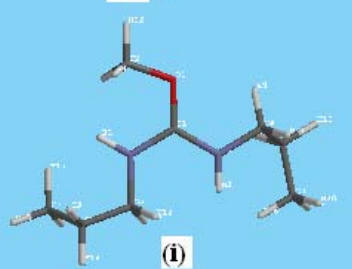

Figure 3.1: 9 Basic classes of cations (a) Monosubstituted imidazolium; (b) Disubstituted Imidazolium; (c) Trisubstituted Imidazolium; (d) Pyridinium; (e) Phosphonium; Ammonium; (f) Pyrrolidinium; (g) Guanidinium; (i) Isouronium

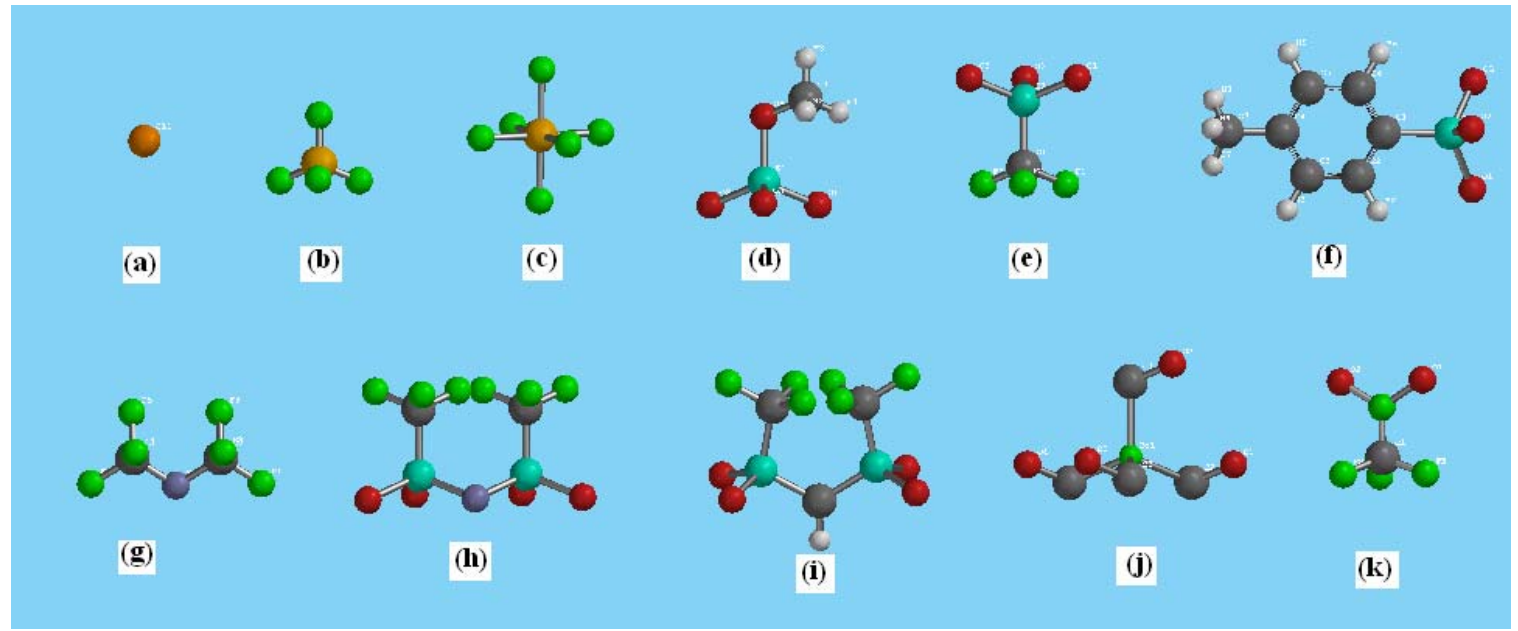

Figure 3.2: Typical Anions (a) Monoatom, Cl, Br. I; (b) Borates; (c) Phosphates and Antimonates; (d) Sulfates; (e) Sulfonates; (f) Tosylates; (g) Amides (CN) $)_{2} \mathrm{~N}^{-}$; (h) Imides; (i) Methanes

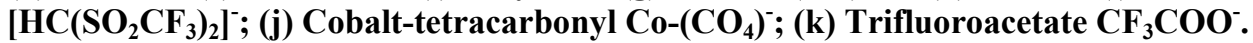


Table 3.1: Molecular Calculations of Selected Monosubstituted Imidazolium Derivatives

\begin{tabular}{|l|l|l|l|l|l|l|l|}
\hline Name & E $(\mathrm{kcal} / \mathrm{mol})$ & $\begin{array}{l}\mathrm{E} \text { LUMO } \\
(\mathrm{kcal} / \mathrm{mol})\end{array}$ & $\begin{array}{l}\mathrm{E} \text { HOMO } \\
(\mathrm{kcal} / \mathrm{mol})\end{array}$ & $\begin{array}{l}\text { Dipole } \\
(\mathrm{debye})\end{array}$ & $\begin{array}{l}\text { CPK } \\
\left(\AA^{2}\right)\end{array}$ & $\begin{array}{l}\text { CPK } \\
\text { Volume } \\
\left(\AA^{3}\right)\end{array}$ & $\begin{array}{l}\text { Molecular } \\
\mathrm{Wt} .(\mathrm{amu})\end{array}$ \\
\hline BuIM-PF6 & -407.365502 & -27.9160612 & -262.510724 & 17.5133907 & 259.800966 & 222.379222 & 270.157 \\
\hline MIM-PF6 & -386.986348 & -30.3499635 & -265.059038 & 17.3223922 & 201.724106 & 167.361035 & 228.076 \\
\hline BuIM-BF4 & -303.604583 & -24.0957444 & -252.201981 & 15.1715128 & 234.085348 & 203.385083 & 211.998 \\
\hline MIM-BF4 & -287.737826 & -25.0096852 & -256.243402 & 15.1686695 & 175.292662 & 147.621564 & 169.917 \\
\hline BuIM-CF3SO3 & -235.447322 & -24.9744165 & -226.134191 & 15.0997478 & 270.381686 & 235.584331 & 274.263 \\
\hline MIM-CF3SO4 & -214.714862 & -27.6667009 & -225.935397 & 15.6620077 & 217.530773 & 181.046419 & 232.182 \\
\hline BuIM-Tosylate & -52.8853165 & -12.8444881 & -209.308256 & 8.37428936 & 333.214469 & 302.236697 & 296.391 \\
\hline MIM-Tosylate & -32.8452996 & -14.3166646 & -209.670742 & 8.50752999 & 272.966536 & 246.868164 & 254.31 \\
\hline
\end{tabular}

\subsection{PEER SYNTHESIZED IONIC LIQUIDS}

Guided by our molecular modeling calculations and experimental observations, we have synthesized about 54 types of new ionic liquids as listed in Table 3.2. Therefore, our ionic liquid pool includes not only those commercially available products but also some types that can be synthesized at our facilities. Expertise on design, synthesis and characterization of ionic liquids has brought us great advantages on achieving the desired ionic liquids with tailored structure (and thus properties) for applications in catalytic methane conversion.

Table 3.2: Index of ionic liquids synthesized at PEER

\begin{tabular}{|c|c|}
\hline IL No. & Name \\
\hline IL-001 & 1-neopentyl-3-methylimidazolium chloride [npmim][Cl] \\
\hline IL-002 & 1-isopropyl-3-methylimidazolium bromide [ipmim][Br] \\
\hline IL-003 & 1-methylimidazolium chloride, [1-mim][Cl] \\
\hline IL-004 & 1-methylimidazolium bisulfate, $[1-\mathrm{mim}]\left[\mathrm{HSO}_{4}\right]$ \\
\hline IL-005 & 1-methylimidazolium triflate, $[1-\mathrm{mim}]\left[\mathrm{CF}_{3} \mathrm{SO}_{3}\right]$ \\
\hline IL-006 & Imidazolium chloride, $[\mathrm{im}][\mathrm{Cl}]$ \\
\hline IL-007 & Imidazolium bisulfate, $[\mathrm{im}]\left[\mathrm{HSO}_{4}\right]$ \\
\hline IL-008 & 1,3-dimethylimidazolium iodide, $[\mathrm{mmim}][\mathrm{I}]$ \\
\hline IL-009 & 1,3-dimethylimidazolium bisulfate, $[\mathrm{mmim}]\left[\mathrm{HSO}_{4}\right]$ \\
\hline IL-010 & Tetramethylammonium trifluoroacetate \\
\hline
\end{tabular}




\begin{tabular}{|c|c|}
\hline IL-011 & 2-methylimidazolium bisulfate, [2-mim] $\left[\mathrm{HSO}_{4}\right]$ \\
\hline IL-012 & 4-methylimidazolium bisulfate, [4-mim] $\left[\mathrm{HSO}_{4}\right]$ \\
\hline IL-013 & 1,2-dimethylimidazolium bisulfate, $[1,2$-dimim $]\left[\mathrm{HSO}_{4}\right]$ \\
\hline IL-014 & 1,4-dimethylimidazolium bisulfate, $[1,4$-dimim $]\left[\mathrm{HSO}_{4}\right]$ \\
\hline IL-015 & $\begin{array}{l}\text { 1,2,3-trimethylimidazolium methanesulfate, }[1,2,3- \\
\text { trimim] }\left[\mathrm{CH}_{3} \mathrm{SO}_{4}\right]\end{array}$ \\
\hline IL-016 & 2,4,5- trimethyloxazolium bisulfate, $[2,4,5$-trimox $]\left[\mathrm{HSO}_{4}\right]$ \\
\hline IL-017 & 1-trifluoroacetylimidazolium bisulfate \\
\hline IL-018 & 1-methylbenzimidazolium bisulfate \\
\hline IL-019 & 1,3-dimethylbenzimidazolium bisulfate \\
\hline IL-020 & Pyridinium bisulfate, $[\mathrm{pyr}]\left[\mathrm{HSO}_{4}\right]$ \\
\hline IL-021 & 1,4-dimethylpyridinium bisulfate \\
\hline IL-022 & 2,6-lutidinium bisulfate \\
\hline IL-023 & 3,5-lutidinium bisulfate \\
\hline IL-024 & Pyrazinium bisulfate, $[\mathrm{pyz}]\left[\mathrm{HSO}_{4}\right]$ \\
\hline IL-025 & 1-methylpyrazinium bisulfate \\
\hline IL-026 & 2-methylpyrazinium bisulfate \\
\hline IL-027 & 2,3-dimethylpyrazinium bisulfate \\
\hline IL-028 & 2,3,5-trimethylpyrazinium bisulfate \\
\hline IL-029 & 2,3,5,6-tetramethylpyrazinium bisulfate \\
\hline IL-030 & 1,2,3,5,6-pentamethylpyrazinium bisulfate \\
\hline IL-031 & Quinoxalinium bisulfate \\
\hline IL-032 & Quinoxalinium chloride \\
\hline IL-033 & Pyrimidinium bisulfate \\
\hline IL-034 & 1-methylpyrimidinium bisulfate \\
\hline IL-035 & 4,6-dimethylpyrimidinium bisulfate \\
\hline IL-036 & Triazinium bisulfate \\
\hline IL-037 & Bipyrimidinium bisulfate \\
\hline
\end{tabular}




$\begin{array}{ll}\text { IL-038 } & \text { 1-methylbipyrimidinium bisulfate } \\ \text { IL-039 } & \text { Aminopyrazinium bisulfate } \\ \text { IL-040 } & \text { Pyrazinecarbonitrile bisulfate } \\ \text { IL-041 } & \text { 2,3-pyrazinedicarbonitrile bisulfate } \\ \text { IL-042 } & \text { 2-Methoxypyrazinium Bisulfate } \\ \text { IL-043 } & \text { Chloropyrazinium Bisulfate } \\ \text { IL-044 } & \text { 1,2,4-triazolium bisulfate } \\ \text { IL-045 } & \text { 1H-1,2,3-triazolium bisulfate } \\ \text { IL-046 } & \text { 1,2,4-triazolo(1,5-a)pyrimidine in } \mathrm{H}_{2} \mathrm{SO}_{4} \\ \text { IL-047 } & \text { 2-aminoimidazolium bisulfate } \\ \text { IL-048 } & \text { Pyrazolium Bisulfate } \\ \text { IL-049 } & \text { Pyrazolium Chloride } \\ \text { IL-050 } & \begin{array}{l}\text { 1-MethylPyrazolium Bisulfate } \\ \text { IL-051 }\end{array} \\ \text { IL-052 } & \begin{array}{l}\text { 1-MethylPyrazolium Chloride } \\ \text { IL-053 }\end{array} \\ \text { IL-054 } & \text { 4-MethethylPyrazolium Bisulfate } \\ \end{array}$

\subsection{IONIC LIQUIDS SCREENING}

\subsubsection{Solubility and Stability Tests}

Our experimental screening started from the solubility and stability tests on commercial ionic liquids. Table 3.3 presents the testing results of the four main categories of ionic liquids distinguished by their cations, namely ammonium-based, phosphonium-based, pyridinium-based, and imidazolium-based. Solubility and stability of ionic liquids in concentrated sulfuric acid were tested at room temperature and elevated temperature (up to $200{ }^{\circ} \mathrm{C}$ ) for varied periods of time. The stabilities of the cations and anions were evaluated respectively. 
Table 3.3: Compatibility between ionic liquids and concentrated sulfuric acid at room temperature and at elevated temperatures.

\begin{tabular}{|c|c|c|c|}
\hline \multirow{2}{*}{ Ionic Liquid } & \multirow{2}{*}{$\begin{array}{l}\text { Solubility in } \\
\mathrm{H}_{2} \mathrm{SO}_{4} \text { at R. T. }\end{array}$} & \multicolumn{2}{|c|}{ Stability in $\mathrm{H}_{2} \mathrm{SO}_{4}$ up to $200{ }^{\circ} \mathrm{C}$} \\
\hline & & Cation & Anion \\
\hline $\begin{array}{l}\text { Ammonium-based } \\
\left(\mathrm{CH}_{3}\right)_{3} \mathrm{~N}\left(\mathrm{C}_{14} \mathrm{H}_{29}\right) \mathrm{Br}\end{array}$ & Soluble & Stable & $\mathrm{HBr}$ released \\
\hline$\left(\mathrm{CH}_{3}\right)_{4} \mathrm{NCl}$ & Soluble & Stable & $\mathrm{HCl}$ released \\
\hline $\begin{array}{l}\text { Phosphonium-based } \\
\qquad\left(\mathrm{CH}_{3}\right)_{3} \mathrm{P}\left(\mathrm{C}_{16} \mathrm{H}_{33}\right) \mathrm{Br}\end{array}$ & Soluble & Stable & $\mathrm{HBr}$ released \\
\hline $\begin{array}{c}\text { Pyridinium-based } \\
{[\mathrm{bpy}][\mathrm{Cl}]}\end{array}$ & Soluble & Stable & $\mathrm{HCl}$ released \\
\hline $\begin{array}{c}\text { Imidazolium-based } \\
{[\text { bmim }]\left[\mathrm{PF}_{6}\right]}\end{array}$ & Slow and small & & \\
\hline$[\mathrm{mmim}]\left[\mathrm{CH}_{3} \mathrm{SO}_{4}\right]$ & Soluble & Stable & Decomposes \\
\hline$[\mathrm{bmim}][\mathrm{Cl}]$ & Soluble & Stable & $\mathrm{HCl}$ released \\
\hline$[\mathrm{bmim}]\left[\mathrm{BF}_{4}\right]$ & Soluble & Stable & $\mathrm{HF} / \mathrm{BF}_{3}$ released \\
\hline$[\mathrm{emim}]\left[\mathrm{CF}_{3} \mathrm{SO}_{3}\right]$ & Soluble & Stable & Stable \\
\hline
\end{tabular}

${ }^{1} \mathrm{H}$ NMR was the main analytic tool for these stability tests. Prepared solutions were analyzed at different time intervals at room temperature (Figure 3.3). No obvious changes (chemical shifts or peak integral) were observed for this IL. Then the solutions were heated at different temperatures for a certain time followed by NMR analysis (Figure 3.4). It is clear to see the intensity of the peaks next to the $\mathrm{D}_{2} \mathrm{SO}_{4}$ peak (left side) decreased with increasing temperature while others stayed almost unchanged. Does decomposition occur during heating? Comparison among the NMR spectra for the starting materials 1-methylimidazole, chlorobutane, their mixture at the ratio of 1:1, and the product $[\mathrm{bmim}][\mathrm{Cl}]$ that is the precursor of $[\mathrm{bmim}]\left[\mathrm{BF}_{4}\right]$ allows an easy assignment of those peaks to the protons on the imidazolium ring. It is unreasonable to justify that protons on the ring lose while protons in alkyl groups are still stable. Instead, it is more likely that those protons on the ring have exchanged with deuterium in $\mathrm{D}_{2} \mathrm{SO}_{4}$. Heating accelerated this process, resulting in a dramatic drop in proton concentration. So, it is possible that the drop in proton concentration is associated with an exchange process instead of thermal decomposition.

To make sure that $[\mathrm{bmim}]\left[\mathrm{BF}_{4}\right]$ did not decompose right after it was added to $\mathrm{D}_{2} \mathrm{SO}_{4}$ and before subjected to NMR, the acid solution was neutralized with NaODsaturated solution in $\mathrm{D}_{2} \mathrm{O}$. The NMR spectrum after neutralization is shown in Figure 3.5 (a), together with Figure 3.5 (b) for comparison, the one for $[\mathrm{bmim}]\left[\mathrm{BF}_{4}\right]$ dissolved in $\mathrm{D}_{2} \mathrm{O}$ directly. All characteristic peaks were reproducible. This strongly suggests that [bmim] $\left[\mathrm{BF}_{4}\right]$ not only dissolves well in sulfuric acid, but also is stable for a prolonged time. 

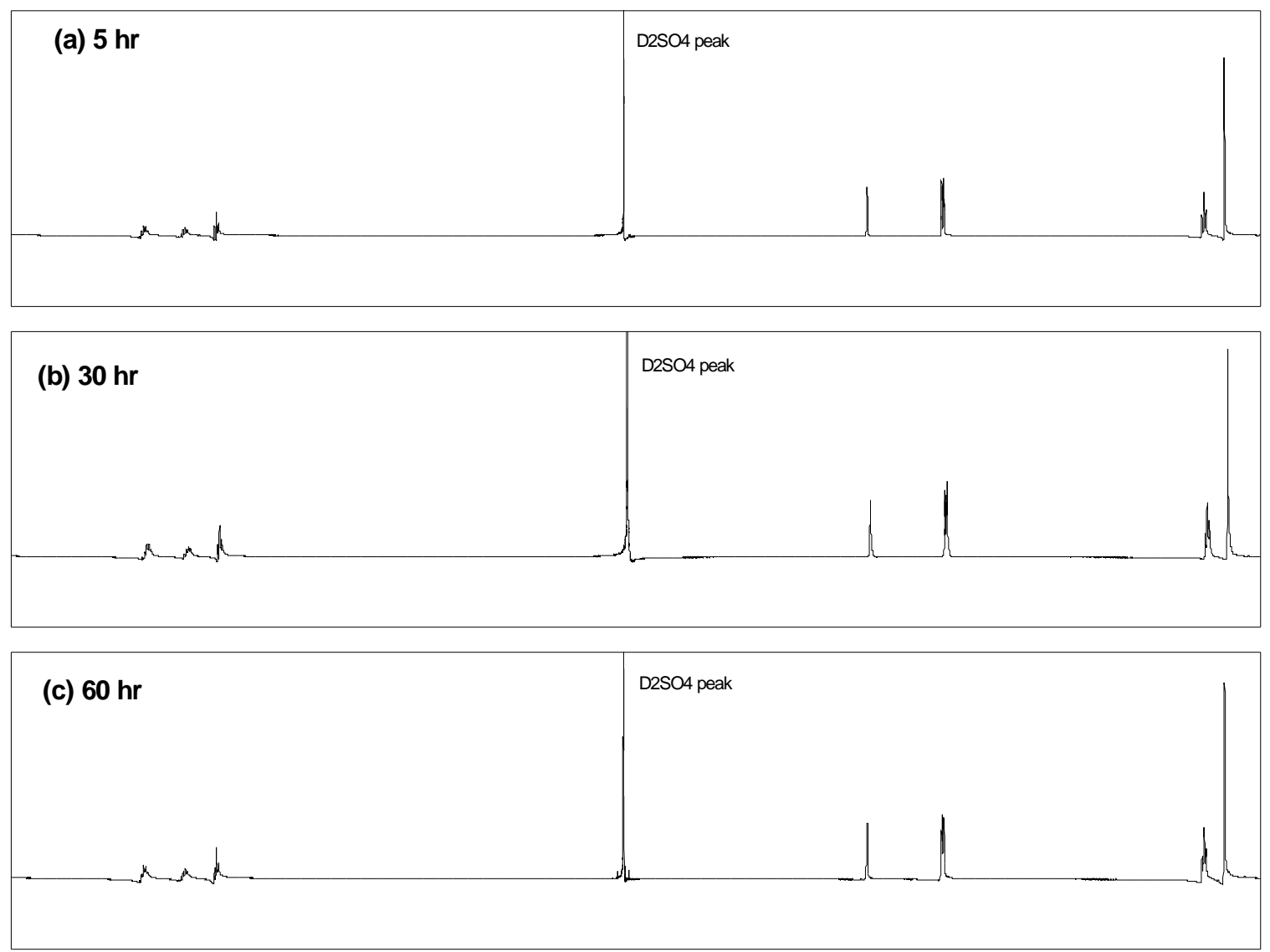

Figure 3.3: 1H-NMR spectra of [bmim] $\left[\mathrm{BF}_{4}\right]$ in $\mathrm{D}_{2} \mathrm{SO}_{4}$ at $25^{\circ} \mathrm{C}$ for (a) $5 \mathrm{hr}$, (b) $30 \mathrm{hr}$, and (c) $60 \mathrm{hr}$, respectively. 

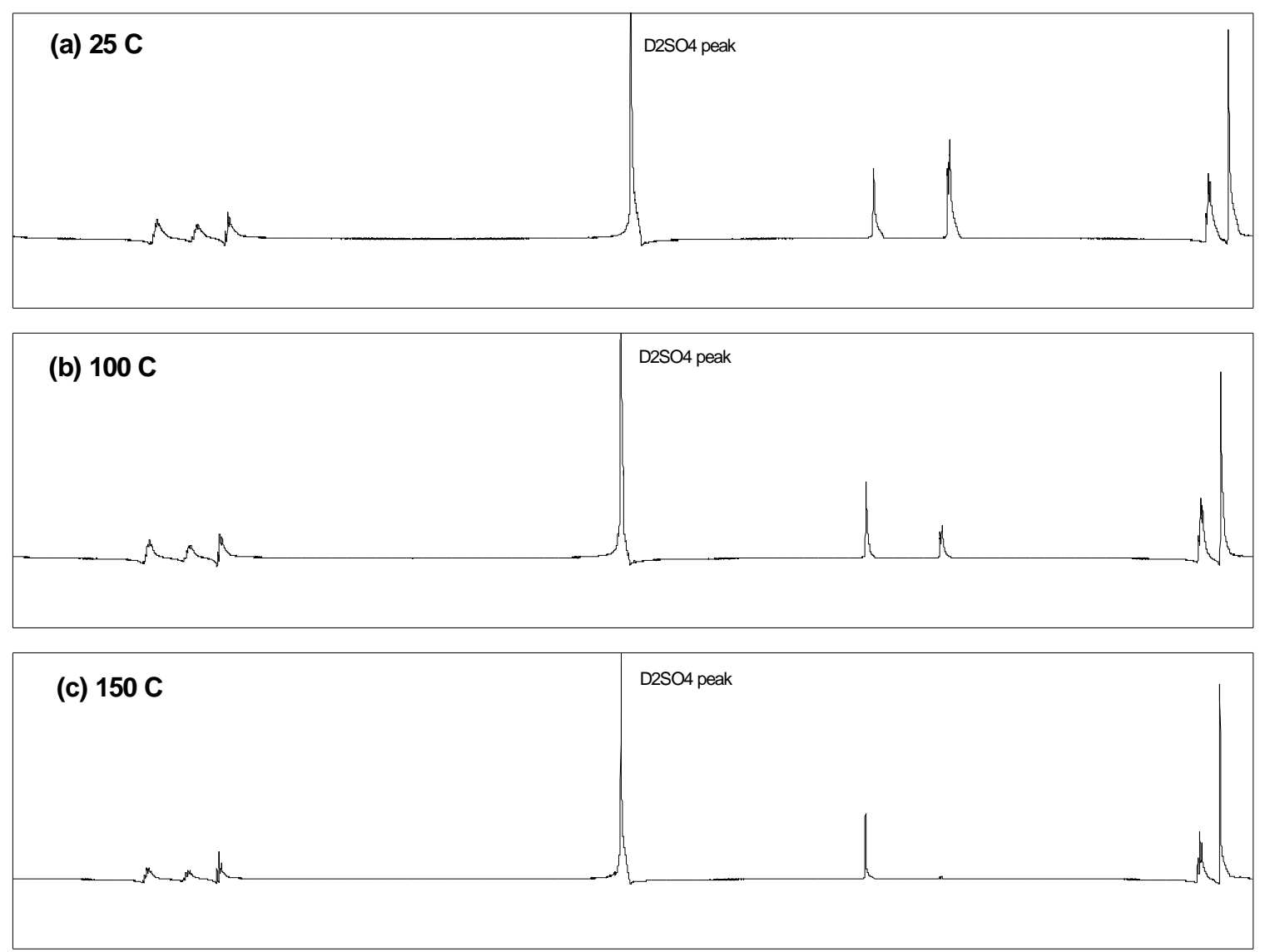

Figure 3.4: ${ }^{1} \mathrm{H}-\mathrm{NMR}$ spectra for $[\mathrm{bmim}]\left[\mathrm{BF}_{4}\right]$ solution in $\mathrm{D}_{2} \mathrm{SO}_{4}$ (a) at room temperature, (b) at 100 ${ }^{0} \mathrm{C}$, and (c) $150{ }^{\circ} \mathrm{C}$ for $3 \mathrm{hr}$ each. 


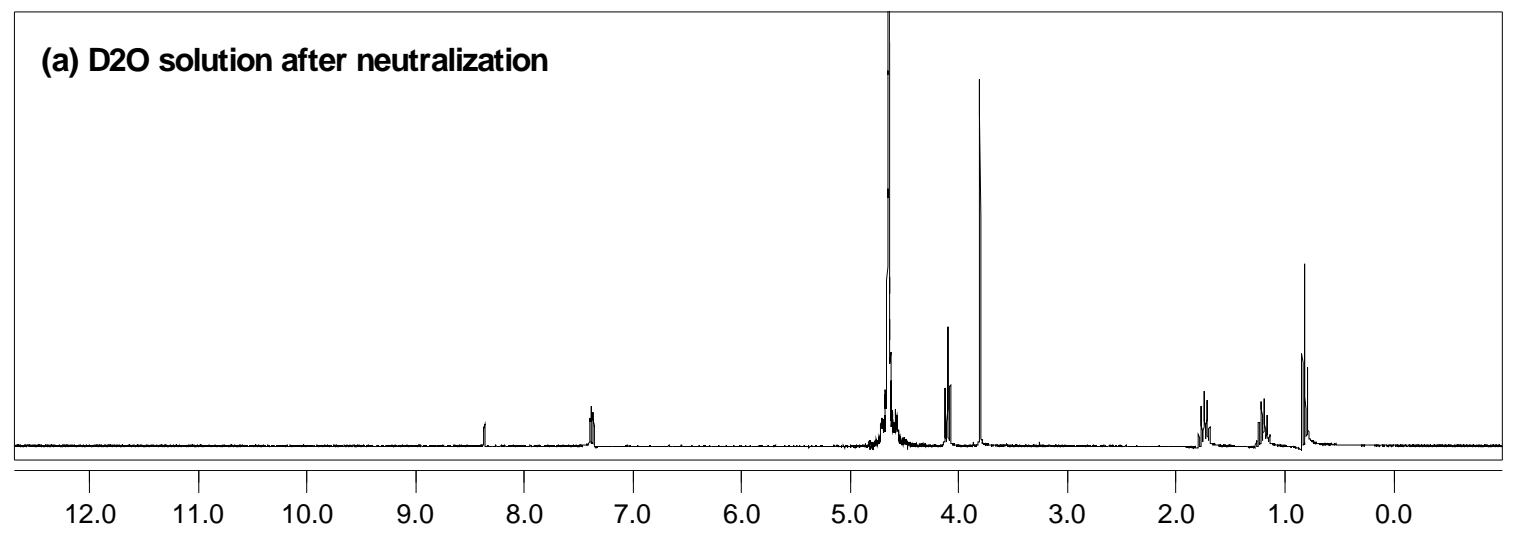

(b) direct D2O solution

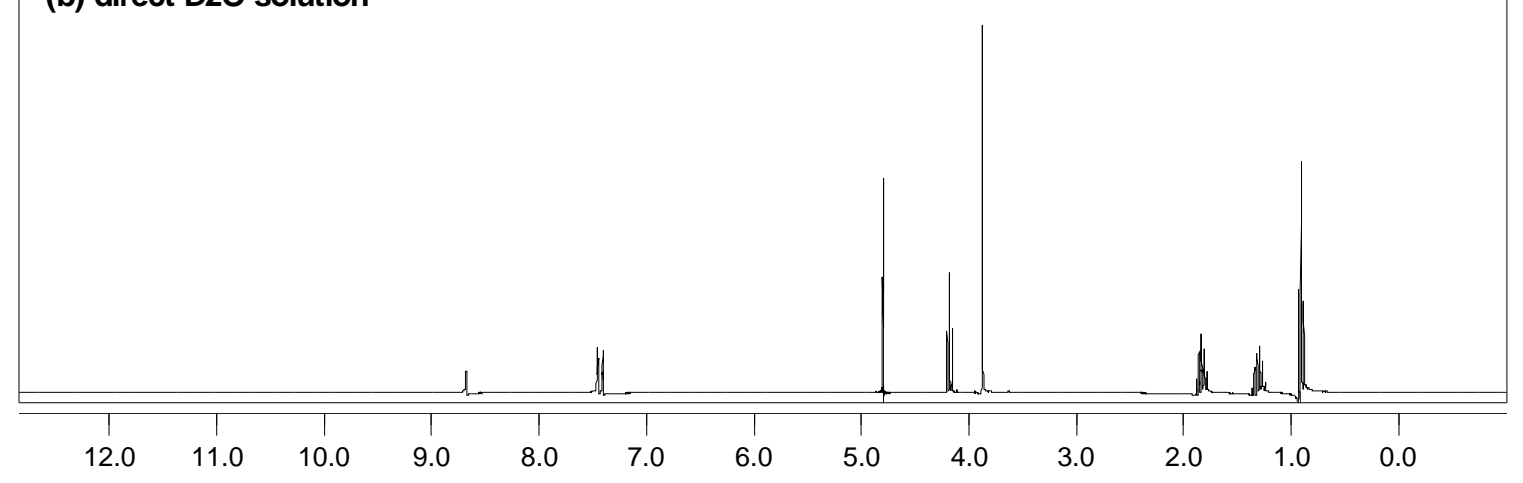

Figure 3.5: ${ }^{1} \mathrm{H}-\mathrm{NMR}$ spectra for (a) $[\mathrm{bmim}]\left[\mathrm{BF}_{4}\right]$ solution in $\mathrm{D}_{2} \mathrm{O}$ resulting from neutralization of $\mathrm{D}_{2} \mathrm{SO}_{4}$ with $\mathrm{NaOD}$, and (b) [bmim] $\left[\mathrm{BF}_{4}\right]$ dissolved in $\mathrm{D}_{2} \mathrm{O}$ directly.

The solubility and stability tests of ionic liquids in concentrated sulfuric acid have covered all four major types (ammonium-based, phosphonium-based, pyridinium-based, and imidazolium-based). All the cations are found to be stable but for anions only triflate $\left(\mathrm{CF}_{3} \mathrm{SO}_{3}{ }^{-}\right)$and bisulfate $\left(\mathrm{HSO}_{4}^{-}\right)$are stable. The anion decomposition was indicated by gas release in the form of $\mathrm{HX}$ gas $\left(\mathrm{X}=\mathrm{Cl}^{-}\right.$or $\left.\mathrm{Br}^{-}\right)$. For $[\mathrm{bmim}]\left[\mathrm{BF}_{4}\right]$, the anion $\left(\mathrm{BF}_{4}^{-}\right)$ decomposed to $\mathrm{HF}$ and $\mathrm{BF}_{3}$ in $\mathrm{H}_{2} \mathrm{SO}_{4}$ at elevated temperatures. Because ionic liquids with trilfate as the anion do not dissolve platinum-based catalysts very well, we use most ionic liquids with a bisulfate anion. From the cation side, we decide to continue focusing on the imidazolium-based and start to develop new heterocyclic cation-based ionic liquids. The reasons are (1) ammonium and phosphonium-based ionic liquids are poor solvents for Ptbased catalysts (such as $\mathrm{PtCl}_{2}$ ) probably due to their poor coordination capability; (2) pyridinium-based ionic liquids can dissolve Pt-based catalysts but the ternary system almost did not show any catalytic activity for methane oxidation; and (3) imidazoliumbased ionic liquids have demonstrated excellent performance in methane to methanol conversion tests.

Table 3.4 shows the solubility and stability of several Pt-catalysts ([bpym] $\mathrm{PtCl}_{2}$, $\left[\mathrm{NH}_{3}\right]_{2} \mathrm{PtCl}_{2}, \mathrm{~K}_{2} \mathrm{PtCl}_{4}$ and $\mathrm{PtCl}_{2}$ ). It is already known that [bpym] $\mathrm{PtCl}_{2}$, the so-called Catalytica catalyst dissolves well and is stable in concentrated sulfuric acid at room temperature. $\left[\mathrm{NH}_{3}\right]_{2} \mathrm{PtCl}_{2}$ shows better catalytic activity at $180{ }^{\circ} \mathrm{C}$ than $[\mathrm{bpym}] \mathrm{PtCl}_{2}$, 
however, it decomposes within a short time and produces $\mathrm{PtCl}_{2}$ which is insoluble in $\mathrm{H}_{2} \mathrm{SO}_{4} \cdot \mathrm{K}_{2} \mathrm{PtCl}_{4}$ is the starting material for the synthesis of $[\mathrm{bpym}] \mathrm{PtCl}_{2}{ }^{1}{ }^{1}$ It is worth noting that ${ }^{1} \mathrm{H}$ NMR observations revealed the free ligand, bipyrimidine (bpym), from [bpym $] \mathrm{PtCl}_{2}$ after being heated at elevated temperatures, but no $\mathrm{PtCl}_{2}$ precipitated.

Table 3.4: Compatibility of Pt-based catalysts in concentrated sulfuric acid at room temperature and at elevated temperatures.

\begin{tabular}{lll}
\hline \multirow{2}{*}{ Pt-based Catalyst } & \multicolumn{2}{c}{ Solubility and Stability in $\mathrm{H}_{2} \mathrm{SO}_{4}$} \\
\cline { 2 - 3 } & Room Temp. & High Temp., up to $220^{\circ} \mathrm{C}$ \\
\hline$\left[\right.$ bpym] $\mathrm{PtCl}_{2}$ & Yes & $\begin{array}{l}\text { Free ligand bpym is observed } \\
\text { by NMR at }>110{ }^{\circ} \mathrm{C} .\end{array}$ \\
{$\left[\mathrm{NH}_{3}\right]_{2} \mathrm{PtCl}_{2}$} & Yes & $\begin{array}{l}\text { Decomposes at }>180{ }^{\circ} \mathrm{C} \text { and } \\
\text { PtCl }\end{array}$ \\
$\mathrm{K}_{2} \mathrm{PtCl}_{4}$ & No, decipitates. \\
$\mathrm{PtCl}_{2}$ & No & No \\
\hline
\end{tabular}

Here comes the first major function of ionic liquid applied in catalytic methane conversion systems: to assist the dissolution of potential transition metal based catalysts which are otherwise insoluble in most reaction media. Table 3.5 shows the solubility tests of Pt-based catalysts in a variety of imidazolium-based ionic liquids. The molar ratio of ionic liquid to Pt-compound was at least 4:1 to ensure a complete dissolution. As seen in the table, the catalyst dissolution is greatly facilitated with heating, and it is strongly influenced by select anions. Chloride and bisulfate ionic liquids readily dissolve all Ptbased catalysts after heating at $200{ }^{\circ} \mathrm{C}$ for several minutes, while tetrafluoroborate and triflate are not effective at all. On the other hand, the cations, e.g., [bmim] vs. [emim], seem not to significantly affect the solubility. Since dialkylimidazolium choloroplatinates (both II and IV) have been synthesized at similar conditions, we propose the dissolution during heating is actually a chelating process in which the anions of the ionic liquid coordinate to the Pt center to form a new anion. Remarkably, the new compound (with excess ionic liquid) dissolves well in concentrated $\mathrm{H}_{2} \mathrm{SO}_{4}$, presumably due to the replacement of $\mathrm{Cl}^{-}$by $\mathrm{HSO}_{4}^{-}$.

Table 3.5: Compatibility of Pt-based catalysts in ionic liquids, primarily dependent on the type of anion.

\begin{tabular}{lcccc}
\hline \multirow{2}{*}{ Ionic Liquid } & \multicolumn{4}{c}{ Pt-based Catalyst Solubility in IL, up to $220{ }^{\circ} \mathrm{C}$} \\
\cline { 2 - 5 } & {$[\mathrm{bpym}] \mathrm{PtCl}_{2}$} & {$\left[\mathrm{NH}_{3}\right]_{2} \mathrm{PtCl}_{2}$} & $\mathrm{~K}_{2} \mathrm{PtCl}_{4}$ & $\mathrm{PtCl}_{2}$ \\
\hline$[\mathrm{bmim}]\left[\mathrm{BF}_{4}\right]$ & $\mathrm{No}$ & $\mathrm{No}$ & $\mathrm{No}$ & No \\
{$[\mathrm{emim}]\left[\mathrm{CF}_{3} \mathrm{SO}_{3}\right]$} & $\mathrm{No}$ & No & No & No \\
\hline
\end{tabular}




\begin{tabular}{lllll}
\hline$[\mathrm{bmim}][\mathrm{Cl}]$ & $\begin{array}{l}\text { Yes at } 200{ }^{\circ} \mathrm{C} ; \\
\text { free bpym is seen }\end{array}$ & $\begin{array}{l}\text { Yes upon } \\
\text { melting }\end{array}$ & Yes at $200{ }^{\circ} \mathrm{C}$ & $\begin{array}{l}\text { Yes upon } \\
\text { melting }\end{array}$ \\
{$[$ bmim $]\left[\mathrm{HSO}_{4}\right]$} & $\begin{array}{l}\text { Yes at } 200{ }^{\circ} \mathrm{C} ; \\
\text { free bpym is seen }\end{array}$ & Yes at $200{ }^{\circ} \mathrm{C}$ & Yes at $200{ }^{\circ} \mathrm{C}$ & Yes at $200{ }^{\circ} \mathrm{C}$ \\
\hline
\end{tabular}

After the binary systems, we advanced to the stability test of ternary systems at elevated temperatures. [bpym] $\mathrm{PtCl}_{2}$ was used as the primary catalyst but $\mathrm{PtCl}_{2}$ and $\mathrm{K}_{2} \mathrm{PtCl}_{4}$ were also studied for comparison. The results are summarized in

Table 3.6. Commercially available ionic liquids are usually with dialkyl groups on the imidazolium ring.

Table 3.6 shows that the alkyl groups longer than methyl are not stable in the presence of Pt-based catalysts in hot sulfuric acid. It is not surprising to see that the butyl group was oxidized, considering the power of [bpym] $\mathrm{PtCl}_{2}$ for methane oxidation in such conditions. One important point is that $\mathrm{K}_{2} \mathrm{PtCl}_{4}$ and $\mathrm{PtCl}_{2}$ have similar catalytic capability when dissolved in ionic liquids. Furthermore, development of stable ternary systems for methane oxidation, with consideration to avoid potentially oxidizable ionic liquids, has led to the development of new ionic liquids designed and synthesized in our laboratory.

Table 3.6: Stability of ternary systems of $\mathrm{H}_{2} \mathrm{SO}_{4} /$ Catalyst/Ionic Liquid at $200{ }^{0} \mathrm{C}$.

\begin{tabular}{llll}
\hline \multirow{2}{*}{ Ionic Liquid } & \multicolumn{3}{c}{ Pt-based Catalyst $^{\mathrm{a}}$} \\
\cline { 2 - 4 } & {$[\mathrm{bpym}] \mathrm{PtCl}_{2}$ system } & $\mathrm{K}_{2} \mathrm{PtCl}_{4}$ system & $\mathrm{PtCl}_{2}$ system \\
\hline$[\mathrm{mmim}]\left[\mathrm{HSO}_{4}\right]$ & $\begin{array}{l}\text { Cation stable; } \\
\text { Anion decomposed }\end{array}$ & (Insoluble) & (Insoluble) \\
{$[\mathrm{emim}]\left[\mathrm{CF}_{3} \mathrm{SO}_{3}\right]$} & $\begin{array}{l}\text { Ethyl oxidized; } \\
\text { Anion stable }\end{array}$ & (Insoluble) & (Insoluble) \\
{$[\mathrm{bmim}]\left[\mathrm{BF}_{4}\right]$} & $\mathrm{Butyl}$ oxidized; & (Insoluble) & (Insoluble) \\
& $\mathrm{BF}_{4}$ decomposed & & \\
{$[\mathrm{bmim}][\mathrm{Cl}] /\left[\mathrm{HSO}_{4}\right]$} & Butyl oxidized & Butyl oxidized & Butyl oxidized
\end{tabular}

\footnotetext{
${ }^{\text {a }}$ Pt-based catalysts were either dissolved in $\mathrm{H}_{2} \mathrm{SO}_{4}$ first or in ionic liquid first at elevated temperature.

${ }^{\mathrm{b}}$ Ionic liquids (IL-003 to IL-009) are home designed and synthesized and meet the compatibility requirement in the ternary system up to $220^{\circ} \mathrm{C}$.
}

\subsubsection{Compatibility Tests}

Compatibility here means the combination of solubility, stability as well as catalytic reactivity for $\mathrm{C}-\mathrm{H}$ activation/oxidation. After the initial screening upon solubility and stability tests, the potential ionic liquids for methane conversion 
applications have be greatly narrowed down. Therefore, our efforts on synthesizing new ionic liquids have been focused on imidazolium-based and related ionic liquids. Table 3.7 shows the compatibility test results for part of ionic liquids synthesized at our laboratory.

Table 3.7: Compatibility studies of ionic liquids in ternary systems. Three steps are developed (1) stability in Periana's system $\left(\mathrm{H}_{2} \mathrm{SO}_{4}+\left[\right.\right.$ bpym] $\left.\mathrm{PtCl}_{2}\right)$ at $200{ }^{\circ} \mathrm{C}$; (2) solubility of $\mathrm{PtCl}_{2}$ in ionic liquids upon heating; (3) compatibility of $\mathrm{PtCl}_{2}+\mathrm{ILs}$ in sulfuric acid upon heating

\begin{tabular}{llll}
\hline \multirow{2}{*}{$\begin{array}{l}\text { Ionic Liquid } \\
\left(\text { default anion }=\mathrm{HSO}_{4}{ }^{-}\right)\end{array}$} & STEP 1 & \multicolumn{1}{c}{ STEP 2 } & \multicolumn{1}{c}{ STEP 3 } \\
\cline { 2 - 4 } & $\begin{array}{l}\text { IL's Stability in } \\
\text { Periana System }\end{array}$ & $\begin{array}{l}\text { Solubility of } \\
\mathrm{PtCl}_{2} \text { in IL }\end{array}$ & $\begin{array}{l}\text { Compatibility of } \\
\mathrm{PtCl}_{2}+\mathrm{IL} \text { in } \mathrm{H}_{2} \mathrm{SO}_{4}\end{array}$ \\
\hline
\end{tabular}

Five-member Ring

IL-011 to IL-015 a

(alkylated imidazolium)

Unstable

Soluble

Soluble but unstable

IL-016

Unstable

(alkylated oxazolium)

IL-017

Unstable

(1- $\mathrm{CF}_{3} \mathrm{CO}$-imidazolium)

IL-018 and IL-019

(fused benzimidazolium)

Imidazole ring Soluble

is stable

Soluble \& imidazole

Six-member Ring

\begin{tabular}{|c|c|c|c|}
\hline $\begin{array}{l}\text { IL-020 } \\
\text { (pyridinium) }\end{array}$ & Unstable & Soluble & Soluble but unstable \\
\hline $\begin{array}{l}\text { IL-021 to IL-023 } \\
\text { (alkylated pyridinium) }\end{array}$ & Unstable & $\begin{array}{l}\text { Tested IL-023 } \\
\text { Soluble }\end{array}$ & Soluble but unstable \\
\hline $\begin{array}{l}\text { IL-024 } \\
\text { (heterocyclic cation) }\end{array}$ & Stable & Soluble & Soluble and stable \\
\hline $\begin{array}{l}\text { IL-025 to IL-030 } \\
\text { (alkylated IL-024) }\end{array}$ & Unstable & & \\
\hline $\begin{array}{l}\text { IL-031 and IL-032 }{ }^{\mathrm{b}} \\
\text { (fused aromatic IL-024) }\end{array}$ & Stable & Soluble & Soluble but unstable \\
\hline $\begin{array}{l}\text { IL-033 } \\
\text { (heterocyclic cation) }\end{array}$ & Unstable & Soluble & Soluble but unstable \\
\hline $\begin{array}{l}\text { IL-034 and IL-035 } \\
\text { (alkylated IL-033) }\end{array}$ & Unstable & Soluble & Soluble but unstable \\
\hline $\begin{array}{l}\text { IL-036 } \\
\text { (heterocyclic cation) }\end{array}$ & Unstable & & \\
\hline i Six-member Ring & & & \\
\hline $\begin{array}{l}\text { IL-037 } \\
\text { (bipyrimidinium) }\end{array}$ & Stable & Soluble & Soluble and stable \\
\hline IL-038 & Stable & Low solubility & \\
\hline
\end{tabular}


(alkylated bpym)

${ }^{a}$ The anion of IL-015 is methanesulfate. ${ }^{b}$ The anion of IL-032 is chloride

A set of procedures for fast screening of stable ionic liquids have been established. The stability of ionic liquids in sulfuric acid is not a major concern here as most ionic liquids contain the stable anion, bisulfate. Our emphasis is on the solubility of platinum salts in ionic liquids and then the solubility and stability of the ionic liquids in a ternary system containing sulfuric acid. To oxidize methane, the ionic liquids themselves should be stable in a catalytic system. The procedures of fast screening of ionic liquids can be described as follows. First, some amount of ionic liquids (bisulfate) is added into the Periana system at room temperature which is homogenous and catalytic. The solution was heated at $200-220{ }^{\circ} \mathrm{C}$ for 2.5 hours and then checked by ${ }^{1} \mathrm{H}$ NMR. Any chemical shift change or peak intensity change give information for the ionic liquid's structure change. Particularly, the triple peak $\left(\mathrm{NH}_{4}{ }^{+}\right)$is a characteristic indication for ring opening. If we observe that the ionic liquid is stable, we proceed to the next step. Table 3.7 shows that alkylated imidazolium-based, alkylated pyridinium-based, and alkylated other heterocyclic (containing carbon and nitrogen) six member ring cation-based ionic liquids are all unstable in the Periana system. However, we are still able to identify a few truly stable ionic liquids, for examples, fused heterocyclic imidazolium-based IL-018 and IL019, heterocyclic IL-024 and IL-037. The second step is to test the solubility of $\mathrm{PtCl}_{2}$ (and other Pt species if applicable) in those ionic liquids that have passed the first step screening. Not surprising, most ionic liquids are powerful solvents for platinum salts such as $\mathrm{PtCl}_{2}$ after heating at $200{ }^{\circ} \mathrm{C}$ for a certain period. The third and key step is to test the solubility and stability of $\mathrm{PtCl}_{2}$-ionic liquid solution in concentrated sulfuric acid at elevated temperatures. IL-024 and IL-037 have showed good solubility and stability. The common features of these two ionic liquids include highly symmetric structure and possessing lone electron pair of nitrogen on the heterocyclic rings.

With certain selected ionic liquids, compatibility tests can be advanced to searching for new platinum catalysts. Table 3.8 lists some Pt species' solubility in a number of representative ionic liquids. These findings are important because they make many homogeneous catalysis processes in ionic liquids possible, including our current methane to methanol oxidation project. Selected Pt(IV) salts dissolved in imidazoliumbased ionic liquids and then in sulfuric acid have also shown high catalytic reactivity for methane oxidation.

Table 3.8: Compatibility of Pt-based catalysts (both Pt(II) and Pt(IV) species) in ionic liquids.

\begin{tabular}{ccccc}
\hline \multirow{2}{*}{ Ionic Liquid } & \multicolumn{4}{c}{ Pt-based Catalyst Solubility in IL, up to $220{ }^{\circ} \mathrm{C}$} \\
\cline { 2 - 5 } & $\mathrm{PtCl}_{2}$ & $\mathrm{PtCl}_{4}$ & $\mathrm{H}_{2} \mathrm{PtCl}_{6}$ & $\mathrm{PtO}_{2}$ \\
\hline IL-003 & Yes at & Yes at & Yes at & Yes at \\
(imidazolium-based chloride) & $200^{\circ} \mathrm{C}$ & $200{ }^{\circ} \mathrm{C}$ & $200{ }^{\circ} \mathrm{C}$ & $200{ }^{\circ} \mathrm{C}$ \\
IL-004 & Yes at & Yes at & Yes at & Yes at \\
(imidazolium-based bisulfate) & $200^{\circ} \mathrm{C}$ & $200{ }^{\circ} \mathrm{C}$ & $200{ }^{\circ} \mathrm{C}$ & $200{ }^{\circ} \mathrm{C}$ \\
\hline
\end{tabular}




\begin{tabular}{ccccc}
\hline IL-006 & Yes at & Yes at & Yes at & Yes at \\
(imidazolium-based chloride) & $200^{\circ} \mathrm{C}$ & $200{ }^{\circ} \mathrm{C}$ & $200{ }^{\circ} \mathrm{C}$ & $200^{\circ} \mathrm{C}$ \\
IL-020 & Yes at & Yes at & & No \\
(pyridinium-based bisulfate) & $200^{\circ} \mathrm{C}$ & $200^{\circ} \mathrm{C}$ & & \\
IL-024 & Yes at & Yes at & No \\
(heterocyclic cation-based bisulfate) & $200^{\circ} \mathrm{C}$ & $200{ }^{\circ} \mathrm{C}$ & & \\
IL-037 & Yes at & & \\
(bipyrimidinium-based bisulfate) & $230^{\circ} \mathrm{C}$ & & & \\
\hline
\end{tabular}

\subsection{STABLE IONIC LIQUIDS FOR CATALYTIC METHANE CONVERSION}

As one of the major accomplishments achieved during this project, we have synthesized/identified several classes of ionic liquids which are super stable under the typical harsh conditions for catalytic methane conversion. Table 3.9 summaries the compatibility tests of the eight major classes of ionic liquids (including six PEER types). More valuable is that we have achieved some fundamental understandings on tailoring the compatibility of methane catalytic systems with ionic liquids, which has critical significance to developing the target low temperature efficient catalytic methane conversion systems.

Table 3.9: Summary of studied ionic liquids (ILs) in the application of catalytic conversion of methane to methanol

\begin{tabular}{|c|c|c|c|c|c|}
\hline Type of IL & Source & $\begin{array}{l}\text { Typical } \\
\text { Example }\end{array}$ & $\begin{array}{l}\text { Pt-catalyst } \\
\text { Solubility }\end{array}$ & $\begin{array}{l}\text { IL Stability in } \\
\mathrm{Pt} / \mathrm{IL} / \mathrm{H}_{2} \mathrm{SO}_{4} \\
\text { system }\end{array}$ & $\begin{array}{l}\text { Applicable } \\
\text { in } \mathrm{CH}_{4} \\
\text { conversion }\end{array}$ \\
\hline \multicolumn{6}{|c|}{ Ammonium-based } \\
\hline & Purchased & $\begin{array}{l}\left(\mathrm{CH}_{3}\right)_{3} \mathrm{~N}\left(\mathrm{C}_{14}\right. \\
\left.\mathrm{H}_{29}\right) \mathrm{Br}\end{array}$ & Insoluble & & No \\
\hline \multicolumn{6}{|c|}{ Phosphonium-based } \\
\hline & Purchased & $\begin{array}{l}\left(\mathrm{CH}_{3}\right)_{3} \mathrm{P}\left(\mathrm{C}_{16}\right. \\
\left.\mathrm{H}_{33}\right) \mathrm{Br}\end{array}$ & Insoluble & & No \\
\hline \multicolumn{6}{|c|}{$\begin{array}{l}\text { Imidazolium-based } \\
\text { (PEER-1) }\end{array}$} \\
\hline & $\begin{array}{l}\text { Purchased \& } \\
\text { Synthesized }\end{array}$ & $\begin{array}{l}\text { IL-003 } \\
\text { IL-004 }\end{array}$ & Soluble & $\begin{array}{l}\text { Good for a } \\
\text { short time }\end{array}$ & Yes \\
\hline \multicolumn{6}{|c|}{$\begin{array}{l}\text { Pyridinium-based } \\
\text { (PEER-2) }\end{array}$} \\
\hline & $\begin{array}{l}\text { Purchased \& } \\
\text { Synthesized }\end{array}$ & IL-020 & Soluble & $\begin{array}{l}\text { Good for a } \\
\text { short time }\end{array}$ & $\begin{array}{l}\text { Not } \\
\text { effective }\end{array}$ \\
\hline \multicolumn{6}{|c|}{$\begin{array}{l}\text { Bipyrimidinium-based } \\
\text { (PEER-3) }\end{array}$} \\
\hline & Synthesized & IL-037 & Soluble & $\begin{array}{l}\text { Good for a } \\
\text { short time }\end{array}$ & Yes \\
\hline
\end{tabular}




\begin{tabular}{|c|c|c|c|c|c|}
\hline \multicolumn{6}{|c|}{$\begin{array}{l}\text { Pyrazinium-based } \\
\text { (PEER-4): }\end{array}$} \\
\hline & Synthesized & IL-024 & Soluble & $\begin{array}{l}\text { Stable below } \\
200^{\circ} \mathrm{C}\end{array}$ & $\begin{array}{l}\text { Not } \\
\text { effective }\end{array}$ \\
\hline \multicolumn{6}{|c|}{$\begin{array}{l}\text { Triazolium-based } \\
\text { (PEER-5) }\end{array}$} \\
\hline & Synthesized & IL-044 & Soluble & $\begin{array}{l}\text { Stable up to } \\
220^{\circ} \mathrm{C}\end{array}$ & $\begin{array}{l}\text { No } \\
\text { reactivity }\end{array}$ \\
\hline \multicolumn{6}{|c|}{$\begin{array}{l}\text { Pyrazolium-based } \\
\text { (PEER-6) }\end{array}$} \\
\hline & Synthesized & $\begin{array}{l}\text { IL-048 to } \\
\text { IL-053 }\end{array}$ & Soluble & $\begin{array}{l}\text { Stable up to } \\
220^{\circ} \mathrm{C}\end{array}$ & Yes \\
\hline
\end{tabular}

The major results from the compatibility tests can be summarized as below:

1) The compatibility (solubility and stability) of eight types of ionic liquids (ammonium-based, phosphonium-based, pyridinium-based, imidazolium-based, bypyridinium-based, pyrizinium-based, trizzolium-based and pyrazolium-based ) with concentrated sulfuric acid has been tested. All the cations are found to be stable but for anions (such as $\mathrm{BF}_{4}^{-}, \mathrm{PF}_{6}^{-}, \mathrm{CF}_{3} \mathrm{SO}_{3}^{-}, \mathrm{HSO}_{4}^{-}, \mathrm{CH}_{3} \mathrm{SO}_{4}^{-}$and halide) only triflate $\left(\mathrm{CF}_{3} \mathrm{SO}_{3}^{-}\right.$), bisulfate $\left(\mathrm{HSO}_{4}^{-}\right)$and chloride $\left(\mathrm{Cl}^{-}\right)$are stable.

2) Most inorganic $\mathrm{Pt}$ compounds (such as $\mathrm{PtCl}_{2}, \mathrm{PtCl}_{4}, \mathrm{~K}_{2} \mathrm{PtCl}_{4}, \mathrm{H}_{2} \mathrm{PtCl}_{6}$ and $\mathrm{PtO}_{2}$ ) can be dissolved in PEER1 through PEER6 ionic liquids with $\mathrm{HSO}_{4}{ }^{-}$or $\mathrm{Cl}^{-}$as their anion. Heating facilitates the dissolution process. Ammonium and phosphonium-based ionic liquids are poor solvents for Pt catalysts probably due to their poor coordination capability. These inorganic $\mathrm{Pt}$ compounds usually are insoluble or decompose in concentrated $\mathrm{H}_{2} \mathrm{SO}_{4}$.

3) Pre-treated Pt species in ionic liquids can be dissolved in concentrated $\mathrm{H}_{2} \mathrm{SO}_{4}$ at room temperature to give a homogeneous ternary solution. Stability of ionic liquids themselves was tested in a low-pressure reactor. In the case of imidazolium-based ionic liquids, side chains (on 1 and 3 position) longer than methyl will be catalytically oxidized in the ternary systems. On the other side, this also indicated that these ternary systems are catalytically active in alkane oxidation.

4) Compatible ternary systems were applied to direct methane oxidation tests using high-pressure reactors. Though, pyridinium-based, pyrizinium-based and trizzolium-based ionic liquids can dissolve Pt-based catalysts, the ternary systems in $\mathrm{H}_{2} \mathrm{SO}_{4}$ only showed negligible activity for methane conversion to methanol. Imidazolium-based ionic liquids have demonstrated excellent performance. However, imidazolium ring is not stable enough in the harsh environment for a long time. Ring opening (deep oxidation) was observed at the same time of methane oxidation to methanol. Pyrazolium-based ionic liquids turn out to be the most promising candidates for catalytic methane conversion since they possess not only excellent stability but also form catalytically active systems for methane conversion. . 
6) Most ionic liquids, including those commercially available and home made, are miscible with methanol $\left(\mathrm{CH}_{3} \mathrm{OH}\right)$ and are stable. Methanol in concentrated sulfuric acid exists as a mixture of free methanol (small part) and methyl bisulfate $\left(\mathrm{CH}_{3} \mathrm{OHSO}_{3}\right)$ (large part), as determined from ${ }^{1} \mathrm{H}$ NMR in $\mathrm{D}_{2} \mathrm{SO}_{4}$. 


\section{CHAPTER FOUR: Pt-CATALYST/IL/H2SO4 SYSTEMS}

\subsection{SUMMARY}

So far, the most successful system for direct methane conversion is the Catalytic system discovered by Dr. Roy Periana et al. in late 90s, in which a platinum-based catalyst $\left((\mathrm{bpym}) \mathrm{PtCl}_{2}\right)$ enabled a high one-pass yield $(>70 \%)$ and high selectivity ( $>$ $80 \%)$ of methane conversion at low temperatures $\left(<250{ }^{\circ} \mathrm{C}\right)$ in concentrated sulfuric acid. However, this technology suffers from several severe obstacles, including insufficient reaction rate, catalyst poisoning by water, high cost for product separation, high cost for the regeneration of concentrated sulfuric acid, and the environmental concerns for using concentrated sulfuric acid.

Our initial efforts on developing an efficient catalytic methane conversion system started from the Catalytica system. Upon addition of certain ionic liquids, we were not only able to dissolve most of Pt-catalysts to form homogenously catalytic system but also potentially modified/optimized the catalytic methane conversion chemistry through certain coordination introduced by ionic liquids. Several PEER systems (Ptcatalysts/ILs/Sulfuric Acid ternary systems) we have developed during this project presented much more superior performance compared to the Catalytica system in terms of higher reaction rate, longer catalysts lifetime and stronger resistance to water.

While developing the PEER systems, we have also investigated the possible functions of ionic liquids in these systems which will serve as the basis for our further discovering effective homogenously catalytic system for methane conversion with other transition metal catalysts, oxidants and reaction media.

\subsection{C-H ACTIVATION}

It has been generally accepted that the first step of the direct partial oxidation of methane to methanol is $\mathrm{C}-\mathrm{H}$ bond activation. Periana et al. has showed that in deuterated sulfuric acid solution at $150{ }^{\circ} \mathrm{C}$, the regular methane, $\mathrm{CH}_{4}$, will exchange the protons with deuterium in the solvent to generate methane isotopes, $\mathrm{CH}_{\mathrm{x}} \mathrm{D}_{4-\mathrm{x}}(\mathrm{x}=0-3)$. Those systems presenting excellent performance in solubility and stability tests were further subjected to H/D exchange experiments, which served as a very important step for developing and optimizing the catalytic systems for methane conversion.

Table 4.1: Methane $\mathrm{C}-\mathrm{H}$ activation in $\mathrm{Pt} / \mathrm{IL} / \mathrm{D}_{2} \mathrm{SO}_{4}$ ternary systems monitored by $\mathrm{H} / \mathrm{D}$ exchange at $150{ }^{\circ} \mathrm{C}$ for $2 \mathrm{hr}$ in the $10 \mathrm{~mL}$ short reactor (Entries 1-13) and in the mini gold tube reactor (Entries 14-21)

\begin{tabular}{llllclc}
\hline Entry & Pt Catalyst & $\begin{array}{l}\text { Ionic } \\
\text { Liquid }\end{array}$ & Acid & $\begin{array}{c}{[\text { acid] }} \\
(\mathrm{wt} \%)\end{array}$ & $\begin{array}{l}\text { Diluent } \\
(\mathrm{wt} \%)\end{array}$ & $\begin{array}{l}\text { Exchange Rate } \\
\left(\left[\mathrm{CH}_{\mathrm{x}} \mathrm{D}_{4-\mathrm{x}}\right] /\left[\mathrm{CH}_{4}\right]\right)\end{array}$ \\
\hline 1 & $\left(\right.$ bpym) $\mathrm{PtCl}_{2}$ & -- & $\mathrm{D}_{2} \mathrm{SO}_{4}$ & $98 \%$ & $2 \% \mathrm{D}_{2} \mathrm{O}$ & $3.6 \%$ \\
2 & $\mathrm{PtCl}_{2}$ & $007-\mathrm{d}_{5}$ & $\mathrm{D}_{2} \mathrm{SO}_{4}$ & $98 \%$ & $2 \% \mathrm{D}_{2} \mathrm{O}$ & $2.6 \%$ \\
\hline
\end{tabular}




\begin{tabular}{|c|c|c|c|c|c|c|}
\hline 3 & $\mathrm{PtCl}_{2}$ & $004-d_{5}$ & $\mathrm{D}_{2} \mathrm{SO}_{4}$ & $98 \%$ & $2 \% \mathrm{D}_{2} \mathrm{O}$ & $4.0 \%$ \\
\hline 4 & $\mathrm{PtCl}_{2}$ & $009-\mathrm{d}_{4}$ & $\mathrm{D}_{2} \mathrm{SO}_{4}$ & $98 \%$ & $2 \% \mathrm{D}_{2} \mathrm{O}$ & $3.5 \%$ \\
\hline 5 & $\mathrm{PtCl}_{4}$ & $004-d_{5}$ & $\mathrm{D}_{2} \mathrm{SO}_{4}$ & $98 \%$ & $2 \% \mathrm{D}_{2} \mathrm{O}$ & $3.9 \%$ \\
\hline 6 & (bpym) $\mathrm{PtCl}_{2}$ & -- & $\mathrm{D}_{2} \mathrm{SO}_{4}$ & $94 \%$ & $6 \% \mathrm{D}_{2} \mathrm{O}$ & $3.1 \%$ \\
\hline 7 & $\mathrm{PtCl}_{2}$ & $007-d_{5}$ & $\mathrm{D}_{2} \mathrm{SO}_{4}$ & $94 \%$ & $6 \% \mathrm{D}_{2} \mathrm{O}$ & $2.3 \%$ \\
\hline 8 & $\mathrm{PtCl}_{2}$ & $004-d_{5}$ & $\mathrm{D}_{2} \mathrm{SO}_{4}$ & $94 \%$ & $6 \% \mathrm{D}_{2} \mathrm{O}$ & $3.7 \%$ \\
\hline 9 & $\mathrm{PtCl}_{2}$ & $024-d_{6}$ & $\mathrm{D}_{2} \mathrm{SO}_{4}$ & $70 \%$ & $\begin{array}{l}2 \% \mathrm{D}_{2} \mathrm{O} \\
28 \% \mathrm{IL}\end{array}$ & Non-detectable \\
\hline 10 & $\mathrm{PtCl}_{2}$ & $043-d_{5}$ & $\mathrm{D}_{2} \mathrm{SO}_{4}$ & $70 \%$ & $\begin{array}{l}2 \% \mathrm{D}_{2} \mathrm{O} \\
28 \% \mathrm{IL}\end{array}$ & Non-detectable \\
\hline 11 & $\mathrm{PtCl}_{2}$ & $004-d_{5}$ & $\mathrm{D}_{2} \mathrm{SO}_{4}$ & $50 \%$ & $\begin{array}{l}2 \% \mathrm{D}_{2} \mathrm{O} \\
48 \% \mathrm{IL}\end{array}$ & $\begin{array}{l}\text { Detectable but } \\
\text { small }\end{array}$ \\
\hline 12 & $\left(\mathrm{NH}_{3}\right)_{2} \mathrm{PtCl}_{2}$ & $004-d_{5}$ & $\mathrm{D}_{2} \mathrm{SO}_{4}$ & $50 \%$ & $\begin{array}{l}2 \% \mathrm{D}_{2} \mathrm{O} \\
48 \% \mathrm{IL}\end{array}$ & $\begin{array}{l}\text { Detectable but } \\
\text { small }\end{array}$ \\
\hline 13 & (bpym) $\mathrm{PtCl}_{2}$ & $004-d_{5}$ & $\mathrm{D}_{2} \mathrm{SO}_{4}$ & $50 \%$ & $\begin{array}{l}2 \% \mathrm{D}_{2} \mathrm{O} \\
48 \% \mathrm{IL}\end{array}$ & $\begin{array}{l}\text { Detectable but } \\
\text { small }\end{array}$ \\
\hline 14 & (bpym) $\mathrm{PtCl}_{2}$ & -- & $\mathrm{D}_{2} \mathrm{SO}_{4}$ & $98 \%$ & $2 \% \mathrm{D}_{2} \mathrm{O}$ & $19.9 \%$ \\
\hline 15 & $\mathrm{PtCl}_{2}$ & $007-d_{5}$ & $\mathrm{D}_{2} \mathrm{SO}_{4}$ & $98 \%$ & $2 \% \mathrm{D}_{2} \mathrm{O}$ & $17.1 \%$ \\
\hline 16 & $\mathrm{PtCl}_{2}$ & $004-d_{5}$ & $\mathrm{D}_{2} \mathrm{SO}_{4}$ & $98 \%$ & $2 \% \mathrm{D}_{2} \mathrm{O}$ & $26.0 \%$ \\
\hline 17 & (bpym) $\mathrm{PtCl}_{2}$ & -- & $\mathrm{D}_{2} \mathrm{SO}_{4}$ & $94 \%$ & $6 \% \mathrm{D}_{2} \mathrm{O}$ & $23.6 \%$ \\
\hline 18 & $\mathrm{PtCl}_{2}$ & $007-d_{5}$ & $\mathrm{D}_{2} \mathrm{SO}_{4}$ & $94 \%$ & $6 \% \mathrm{D}_{2} \mathrm{O}$ & $8.8 \%$ \\
\hline 19 & $\mathrm{PtCl}_{2}$ & $007-d_{5}$ & $\mathrm{D}_{2} \mathrm{SO}_{4}$ & $90 \%$ & $\begin{array}{l}2 \% \mathrm{D}_{2} \mathrm{O}+ \\
8 \% \mathrm{IL}\end{array}$ & $9.3 \%$ \\
\hline 20 & $\left(\mathrm{NH}_{3}\right)_{2} \mathrm{PtCl}_{2}$ & $007-d_{5}$ & $\mathrm{D}_{2} \mathrm{SO}_{4}$ & $90 \%$ & $\begin{array}{l}2 \% \mathrm{D}_{2} \mathrm{O}+ \\
8 \% \mathrm{IL}\end{array}$ & $16.4 \%$ \\
\hline 21 & $\mathrm{PtCl}_{2}$ & $007-d_{5}$ & $\mathrm{D}_{2} \mathrm{SO}_{4}$ & $70 \%$ & $\begin{array}{l}2 \% \mathrm{D}_{2} \mathrm{O}+ \\
28 \% \mathrm{IL}\end{array}$ & $8.3 \%$ \\
\hline
\end{tabular}

Table 4.1 presents some methane $\mathrm{C}-\mathrm{H}$ activation experiments on different $\mathrm{Pt}$ species, e.g., $\mathrm{PtCl}_{2}, \mathrm{PtCl}_{4},\left(\mathrm{NH}_{3}\right)_{2} \mathrm{PtCl}_{2}$ and (bpym) $\mathrm{PtCl}_{2}$ and varied $\mathrm{D}_{2} \mathrm{SO}_{4}$ concentration ( $98 \%$ and $94 \%$ ) as well as on diluting $\mathrm{D}_{2} \mathrm{SO}_{4}$ with large amount of ionic liquids, say, 50 wt $\%$. Pt catalyst concentration was about $50 \mathrm{mM}$. The dilution of acid is achieved by adding $\mathrm{D}_{2} \mathrm{O}$ or deuterated ionic liquids. Deuterated ionic liquids were synthesized through $\mathrm{H} / \mathrm{D}$ exchange between the regular ones and $\mathrm{D}_{2} \mathrm{SO}_{4}$. The short reactor was loaded 
with $1 \mathrm{~mL}$ reaction liquid and 500 psi $\mathrm{CH}_{4}$, followed by heating at $150{ }^{\circ} \mathrm{C}$ for 2 hours. The gold tube was loaded with $0.3 \mathrm{~mL}$ reaction liquid and $50 \mathrm{psi} \mathrm{CH}_{4}$ (with $3 \% \mathrm{Ar}$ as the internal standard). The gas phases after reaction were introduced into a HP 6890+ GC system with a mass selective detector (MSD). The total amount of methane was deduced from the internal standard Ar integration. The methane isotopomers were identified from their characteristic ion masses such as 20 for $\mathrm{CD}_{4}, 19$ for $\mathrm{CHD}_{3}, 18$ for $\mathrm{CH}_{2} \mathrm{D}_{2}$, and 17 for $\mathrm{CH}_{3} \mathrm{D}$.

The different exchange rates achieved from the similar experiments conducted with the Short reactor and the mini gold tube reactor were mainly caused by the different amounts of total methane gas loaded. However, the trends on $\mathrm{C}-\mathrm{H}$ activation variations corresponding to different system compositions are the same indicated by experiments with the two types of reactors. Basically all systems exhibited a similar or higher H/D exchange rate and water content increasing from $2 \%$ to $6 \%$ seemed not to severely affect the rate. When using ionic liquids to dilute the sulfuric acid, we gradually increased the amount of ionic liquids in sulfuric acid from $6 \%$ to $28 \%$ to $50 \%$. The overall trend for Pt reactivity in methane activation is quite clear: decrease with adding more ionic liquids.

A few other phenomena are also worth discussing. First is the C-H activation through a $\mathrm{Pt}(\mathrm{IV})$ metal center. Though the Periana paper indicated that $\mathrm{Pt}(\mathrm{II})$ was the species to activate methane and $\mathrm{Pt}(\mathrm{IV})$ to oxidize, we demonstrated that $\mathrm{Pt}(\mathrm{IV}) / \mathrm{IL} / \mathrm{D}_{2} \mathrm{SO}_{4}$ system was highly active at $150{ }^{\circ} \mathrm{C}$. Second, PEER-4 type ionic liquid systems resulted in non-detectable $\mathrm{H} / \mathrm{D}$ exchange. Instead, appreciable amount of $\mathrm{CO}_{2}$ and $\mathrm{SO}_{2}$ was observed which was a strong sign of deep methane oxidation.

\subsection{METHANE OXIDATION TO METHANOL}

Methane oxidation to methanol is our target reaction for this project. The oxidation experiments were conducted with systems having good compatibility. We have successfully developed several Pt-catalyst $/ \mathrm{IL} / \mathrm{H}_{2} \mathrm{SO}_{4}$ ternary catalytic systems, the socalled PEER systems which present superior performance to the Catalytica system in terms of reaction rates, catalysts lifetime and water tolerance.

Upon observations of methanol/ methyl bisulfate from GC and NMR analysis, we first confirmed that the products were indeed generated from methane, not the ionic liquids added in the system. In cases of using methylated imidazolium-based ionic liquids as the solvent for platinum catalysts, one may argue that the product methylbisulfate is possibly from the dissociation of the methyl group from the imidazole ring. So we conducted the methane oxidation test using a pure ${ }^{13} \mathrm{CH}_{4}$ instead of the normal ${ }^{12} \mathrm{CH}_{4}$ with $\mathrm{PtCl}_{2}$ and IL-004. Figure 4.1 clearly showed that the majority of methylbisulfate was

${ }^{13} \mathrm{CH}_{3} \mathrm{HSO}_{4}(>95 \%)$. This proves that the product is almost exclusively from the oxidation of the methane gas. 


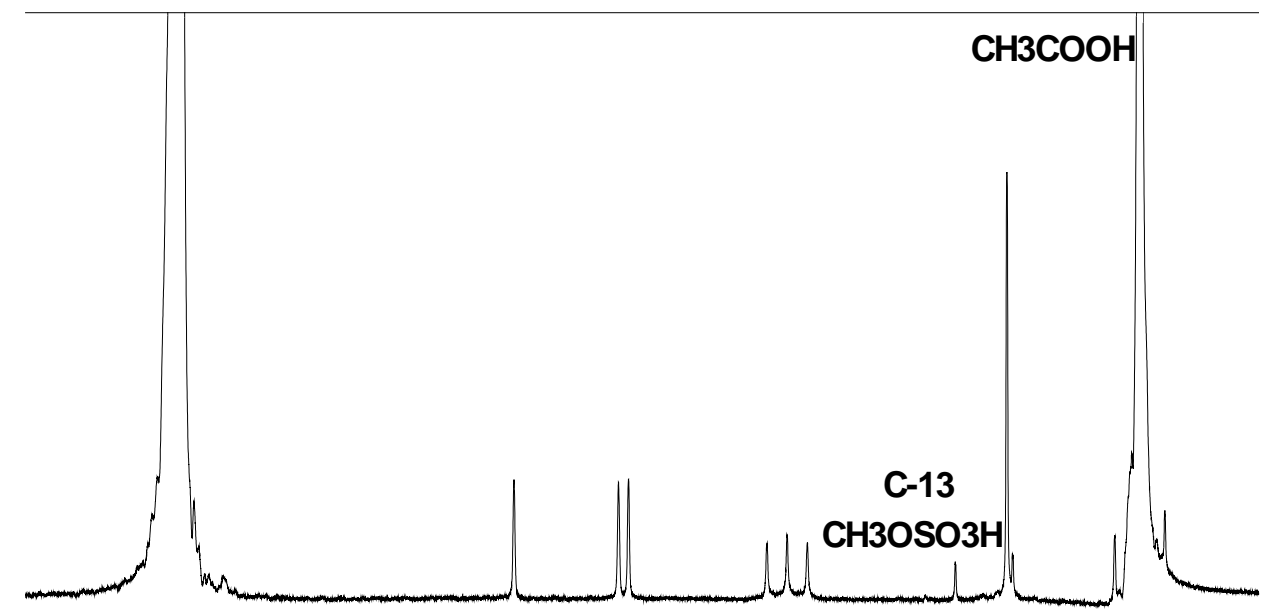

Figure 4.1: ${ }^{1} \mathrm{H}$ NMR spectra from the liquid of Carbon-13 methane oxidation test using $\mathrm{PtCl}_{2}$ and IL004.

\section{results listed in}

Extensive methane oxidation experiments have been conducted with some highlighted

\section{Table 4.2,}

Table 4.3 and Figure 4.2. These results can be briefly summarized as below:

1) Almost all Pt-compounds tested ((bpym) $\mathrm{PtCl}_{2}, \mathrm{PtCl}_{2}, \mathrm{~K}_{2} \mathrm{PtCl}_{4}, \mathrm{PtCl}_{4}, \mathrm{PtO}_{2}$, and $\mathrm{H}_{2} \mathrm{PtCl}_{6}$ ) can be dissolved in concentrated $\mathrm{H}_{2} \mathrm{SO}_{4}$ and present some activity on methane oxidation given the appropriate ionic liquid addition.

2) Among those stable ionic liquids synthesized at PEER, the pyridinium-based, pyrizinium-based and triazolium-based ionic liquids did not make active systems for direct methane oxidation to methanol, but the imidazolium-based ionic liquids have demonstrated excellent performance.

3) Systems containing no $\mathrm{Cl}^{-}$were found not active, which might be attributed to the coordination chemistry between $\mathrm{Pt}$ and $\mathrm{Cl}^{-}$during the methane conversion process.

4) In $96 \% \mathrm{H}_{2} \mathrm{SO}_{4}$, several PEER ( $\left.\mathrm{Pt} / \mathrm{IL} / \mathrm{H}_{2} \mathrm{SO}_{4}\right)$ systems showed comparable or much better reactivity than the Catalytica system. 
5) Although, dilution of $\mathrm{H}_{2} \mathrm{SO}_{4}$ lowered the reactivity on $\mathrm{C}-\mathrm{H}$ activation and methane to methanol conversion of both the PEER systems and the Catalytica system, the application of ionic liquids significantly improved the water tolerance of the PEER systems.

Table 4.2: Catalytic oxidation of methane to methanol in $96 \% \mathrm{H}_{2} \mathrm{SO}_{4}{ }^{\mathrm{a}}$.

\begin{tabular}{|c|c|c|c|c|c|}
\hline Entry & Catalyst & Ionic Liquid $^{b}$ & $\begin{array}{l}\text { Temp. } \\
\left({ }^{\circ} \mathrm{C}\right)\end{array}$ & $\begin{array}{l}\mathrm{CH}_{3} \mathrm{OH} \\
(\mathrm{mM})^{\mathrm{c}}\end{array}$ & TON \\
\hline 1 & (bpym) $\mathrm{PtCl}_{2}$ & & 220 & 31 & 0.6 \\
\hline 2 & (bpym) $\mathrm{PtCl}_{2}$ & {$[\mathrm{im}][\mathrm{Cl}]$} & 220 & 26 & 0.5 \\
\hline 3 & $\mathrm{PtCl}_{2}$ & {$[1-\mathrm{mim}][\mathrm{Cl}]$} & 220 & 173 & 3.5 \\
\hline 4 & $\mathrm{PtCl}_{2}$ & {$[\mathrm{im}][\mathrm{Cl}]$} & 220 & 100 & 2.0 \\
\hline 5 & $\mathrm{PtCl}_{2}$ & {$[\mathrm{mmim}]\left[\mathrm{HSO}_{4}\right]$} & 220 & 73 & 1.5 \\
\hline 6 & $\mathrm{~K}_{2} \mathrm{PtCl}_{4}$ & {$[1-\mathrm{mim}][\mathrm{Cl}]$} & 220 & 105 & 2.1 \\
\hline 7 & $\mathrm{PtCl}_{4}$ & {$[1-\mathrm{mim}][\mathrm{Cl}]$} & 220 & 89 & 1.8 \\
\hline 8 & $\mathrm{PtO}_{2}$ & {$[\mathrm{im}][\mathrm{Cl}]$} & 220 & 52 & 1.0 \\
\hline 9 & $\mathrm{PtO}_{2}$ & {$[1-\mathrm{mim}]\left[\mathrm{HSO}_{4}\right]$} & 220 & 0 & 0 \\
\hline 10 & $\mathrm{H}_{2} \mathrm{PtCl}_{6}$ & {$[1-\mathrm{mim}][\mathrm{Cl}]$} & 220 & 157 & 3.1 \\
\hline 11 & $\mathrm{PtCl}_{2}$ & {$\left[\right.$ pyrid] $\left[\mathrm{HSO}_{4}\right]$} & 220 & 1 & $\sim 0$ \\
\hline 12 & $\mathrm{PtCl}_{2}$ & {$\left[\right.$ pyraz] $\left[\mathrm{HSO}_{4}\right]$} & 200 & 42 & 0.8 \\
\hline 13 & $\mathrm{PtCl}_{2}$ & {$[1-\mathrm{mpyraz}]\left[\mathrm{HSO}_{4}\right]$} & 200 & 79 & 1.6 \\
\hline 14 & $\mathrm{PtCl}_{2}$ & {$[\mathrm{mmpyraz}]\left[\mathrm{HSO}_{4}\right]$} & 200 & 94 & 1.9 \\
\hline 15 & $\mathrm{PtCl}_{2}$ & {$[$ triaz $]\left[\mathrm{HSO}_{4}\right]$} & 200 & 0 & 0 \\
\hline \multicolumn{6}{|c|}{$\begin{array}{l}{ }^{\mathrm{a}} \text { Reaction conditions: } 0.05 \mathrm{mmol} \mathrm{Pt} \text { species }+0.3 \mathrm{mmol} \mathrm{IL}+1 \mathrm{~mL} 96 \% \mathrm{H}_{2} \mathrm{SO}_{4}+ \\
3.4 \mathrm{MPa} \mathrm{CH}_{4} \text { in a } 69 \mathrm{~mL} \text { reactor at a temperature for } 2.5 \mathrm{hr} .{ }^{\mathrm{b}} \mathrm{IL}: \mathrm{im}=\text { imidazolium; } \\
\text { 1-mim }=1 \text {-methylimidazolium; mmim }=1,3 \text {-dimethylimidazolium; pyrid }= \\
\text { pyridinium; pyraz }=\text { pyrazolium; } 1 \text {-mpyraz }=1 \text {-methylpyrazolium; mmpyraz }=1,2- \\
\text { dimethylpyrazolium; triaz }=1,2,4 \text {-triazolium. }{ }^{\mathrm{c}} \text { The methanol concentration was } \\
\text { determined from }{ }^{1} \mathrm{H} \mathrm{NMR} \text {, which was the sum of free or protonated methanol, and }\end{array}$} \\
\hline
\end{tabular}


the ester $\left(\mathrm{CH}_{3} \mathrm{OSO}_{3} \mathrm{H}\right)$.

Table 4.3: Effects of water concentration in difference catalyst systems on methane C-H activation and oxidation to methanol

\begin{tabular}{llllll}
\hline \multirow{2}{*}{ Entry } & System & \multicolumn{3}{l}{ Activation at $150{ }^{\circ} \mathrm{C}^{\mathrm{a}}$} & \multicolumn{2}{l}{ Oxidation at $200{ }^{\circ} \mathrm{C}^{\mathrm{b}}$} \\
\cline { 3 - 6 } & $\begin{array}{l}{\left[\mathrm{CH}_{\mathrm{x}} \mathrm{D}_{4-\mathrm{x}}\right]} \\
(\mathrm{mmol})\end{array}$ & $\mathrm{TON}$ & $\begin{array}{l}{\left[\mathrm{CH}_{3} \mathrm{OH}\right]} \\
(\mathrm{mmol})\end{array}$ & $\mathrm{TON}$ \\
\hline 1 & $\begin{array}{l}\text { (bpym) } \mathrm{PtCl}_{2}+2 \% \text { water } \\
2\end{array}$ & 0.367 & 7.35 & 0.047 & 0.94 \\
& $\begin{array}{l}\text { (bpym) } \mathrm{PtCl}_{2}+6 \% \text { water } \\
3\end{array}$ & 0.276 & 5.51 & 0.016 & 0.31 \\
$\mathrm{PtCl}_{2}+[1-\mathrm{mim}]\left[\mathrm{HSO}_{4}\right]+$ & 0.480 & 9.60 & 0.065 & 1.31 \\
& $\begin{array}{l}2 \% \text { water } \\
\mathrm{PtCl}_{2}+[1-\mathrm{mim}]\left[\mathrm{HSO}_{4}\right]+\end{array}$ & 0.420 & 8.39 & 0.037 & 0.73 \\
\hline
\end{tabular}

\footnotetext{
${ }^{a} \mathrm{H} / \mathrm{D}$ exchange occurred between $\mathrm{CH}_{4}$ and deuterated liquid media $\mathrm{D}_{2} \mathrm{SO}_{4}, \mathrm{D}_{2} \mathrm{O}$ and [1-mim- $\left.\mathrm{d}_{4}\right]\left[\mathrm{DSO}_{4}\right]$. TON was determined from the gas analysis for methane isotopomers by GC-MS. Reaction conditions: $0.05 \mathrm{mmol} \mathrm{Pt}(\mathrm{II})+0.3 \mathrm{mmol} \mathrm{IL}+1 \mathrm{~mL}$ $\mathrm{D}_{2} \mathrm{SO}_{4}+3.4 \mathrm{MPa} \mathrm{CH}{ }_{4}$ in a $15 \mathrm{~mL}$ reactor; $150{ }^{\circ} \mathrm{C}, 2.0 \mathrm{hr}$. ${ }^{\mathrm{b}}$ Tests were performed using non-deuterated liquid media. Reaction conditions were the same as those in Table 1.
} 


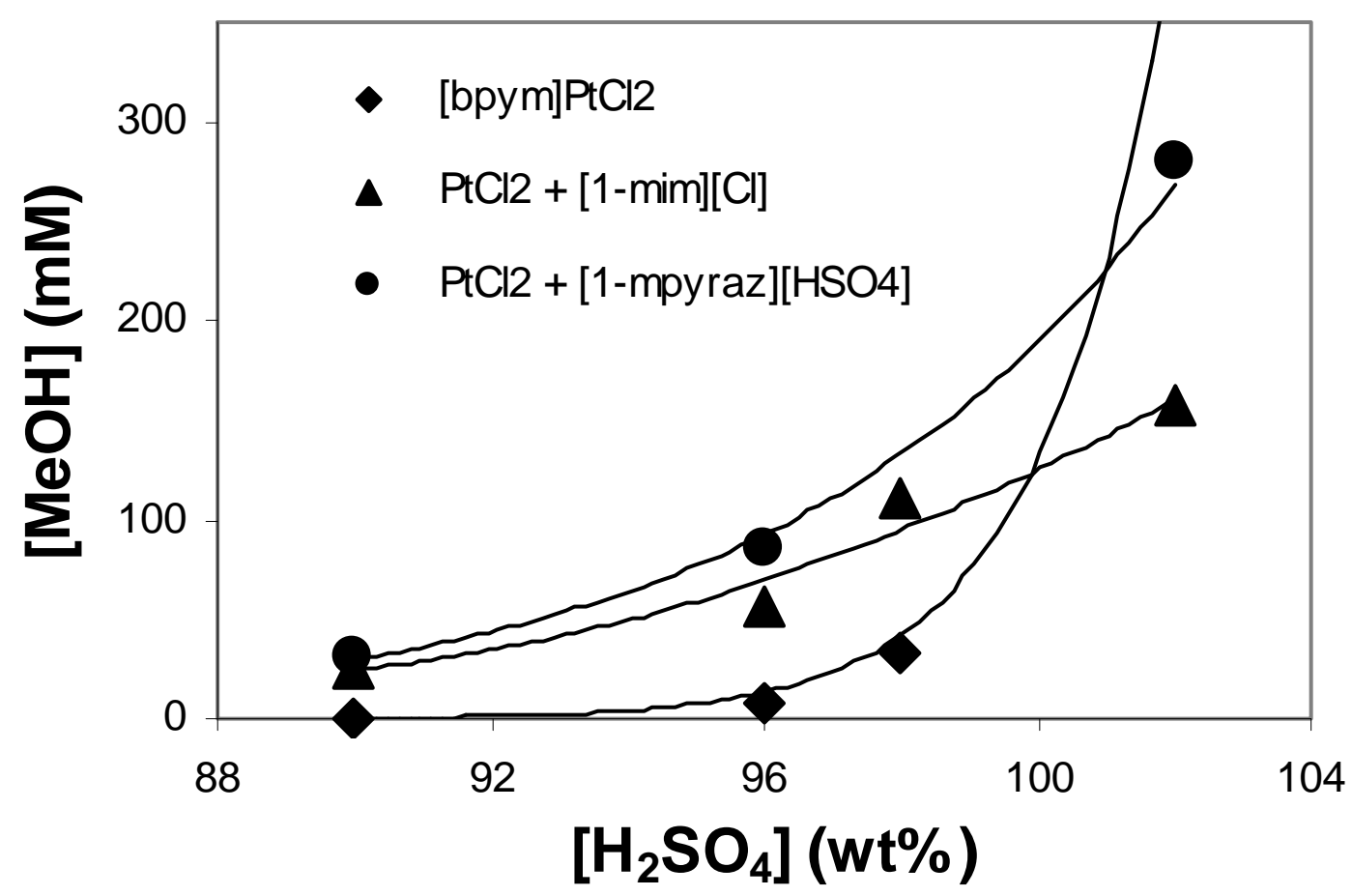

Figure 4.2: Methanol yield as a function of the concentration of $\mathrm{H}_{2} \mathrm{SO}_{4}$ (reaction conditions: $200{ }^{\circ} \mathrm{C}$, $2.5 \mathrm{hr}$ ). The methanol concentration from the Catalytica reaction in $2 \%$ oleum was $600 \mathrm{mM}$ and was not indicated in the plot.

\subsection{ROLES OF IONIC LIQUIDS IN METHANE ACTIVATION \& OXIDATION}

During the process of developing PEER systems for efficient methane to methanol conversion, we have also built-up of our preliminary knowledge on the major roles of ionic liquids corresponding to the nature of the cations:

(1) Dissolution media: Six types of ionic liquids all can performance this function. Virtually any Pt compounds, as well as many other transition metal (e.g., Ru, $\mathrm{Rh}, \mathrm{Os}$, Ir, $\mathrm{Au}$, etc.) compounds, can be dissolved in ionic liquids upon heating. The initial dissolution is believed to be via anion coordination.

(2) Promotion of Pt reactivity in catalysis: The Pt reactivity has been found to be very much related to the ionic liquids used. First, cation ring structure difference matters most. For example, imidazolium and pyrazolium-based ionic liquids can catalyze methane to methanol conversion at a higher rate than the Catalytica reaction in $96 \%$ $\mathrm{H}_{2} \mathrm{SO}_{4}$, while triazolium-based ionic liquids gave zero methanol production. Second, the variations on a same ring structure also modifies the Pt reactivity, which was verified by the no methyl, 1-methyl and 1,3-dimethyl imidazolium-based ionic liquid cases.

(3) Co-solvent and interaction with other solvents: Using ionic liquids dilutes sulfuric acid or any other solvent. This modifies the whole system's acidity and oxidizing 
power. Furthermore, ionic liquids sometimes react with $\mathrm{H}_{2} \mathrm{SO}_{4}$. For example, in the case of imidazolium-based ionic liquids, the ring structure can not sustain for a long time in the presence of Pt. Deep decomposition to $\mathrm{CO}_{2}$ has been observed. In the case of pyrazolium-based ionic liquid, though there is no ring decomposition, structure modifications such as sulfonation or dimerization are proposed. We have found that ring structure changes had an adverse affect on the Pt reactivity. On the other hand, this gives us clues to design new stable ionic liquids, such as nitrated, sulfonated, or dimerized PEER-6 type ionic liquids.

(4) Catalysis of other chemical reactions: One good example is about the pyrazinium-based ionic liquids. Upon the formation of methyl bisulfate, it will be quickly converted to $\mathrm{CO}_{2}$ due to the catalysis of this ionic liquid itself. A complete catalytic route can be described as: Step 1: C-H bond activation through the Pt(II) metal center; Step 2: oxidation through the Pt(IV) metal center; Step 3: functionalization of the methyl to methylbisulfate; Step 4: methylbisulfate was quickly converted to IL-025; Step 5: methyl group on IL-025 was quickly oxidized to $\mathrm{CO}_{2}$ and IL-025 goes back to IL-024.

(5) Probe for monitoring catalyst reactivity: We have found for a long time that [bmim] cation are good substrate for studying the $\mathrm{C}-\mathrm{H}$ bond activation by monitoring the $\mathrm{H} / \mathrm{D}$ exchange between a regular butyl group $\left(-\mathrm{CH}_{2} \mathrm{CH}_{2} \mathrm{CH}_{2} \mathrm{CH}_{3}\right)$ and deuterated solvent such as $\mathrm{D}_{2} \mathrm{SO}_{4}$. It serves as dissolution media for Pt catalysts and is compatible with other solvents so there is no worry about solubility issue.

(6) Reduction of product separation cost: Methanol is miscible with most ionic liquids, so it is possible to use ionic liquids to extract methanol out from a specific system. But this procedure awaits a more powerful catalytic system.

Here we report a group of experiments using $\left(\mathrm{NH}_{3}\right)_{2} \mathrm{PtCl}_{2}$, imidazolium-based ionic liquids and concentrated acetic acid (with $10 \mathrm{wt} \%$ water), through which we can understand the multiple roles of ionic liquids in $\mathrm{C}-\mathrm{H}$ activation.

Acetic acid vaporizes at temperatures above $120{ }^{\circ} \mathrm{C}$ and severely corrodes steel parts. Stainless steel reactors even with gold plating were not convenient as gas/liquid mixing would be big challenge. We thus decided to use the mini gold tube reactor. The mini gold tube has a total volume of about $1 \mathrm{~mL}, 50 \%$ of which is loaded with reaction liquids and the remaining space can be filled with methane $\left(\mathrm{CH}_{4}\right.$ with $\left.3 \% \mathrm{Ar}\right)$ or flushed with Ar. Arc welding is used for sealing at both ends. Sealed tubes are placed in a stainless steel vessel to which an external hydraulic pressure of up to 3700 psi will be applied. Then the vessel is heated in a box furnace at $200-250{ }^{\circ} \mathrm{C}$ for four hours. The weight of each gold tube is recorded before and after reaction and usually the mass difference is no more than $0.1 \mathrm{mg}$. Gas phases are analyzed using GC-MS and liquid phase is by ${ }^{1} \mathrm{H}$ NMR. Usually the Pt catalysts were used as $20 \mathrm{mM}$ and first dissolved in $200 \mathrm{mM}$ ionic liquid. Then the prepared Pt/IL mixture was dissolved in 1 $\mathrm{mL}$ deuterated acetic acid and $\mathrm{D}_{2} \mathrm{O}$ solution at room temperature. As usual, H/D exchange rates were determined from ${ }^{1} \mathrm{H}$ NMR peak integration for [bmim] and from GC-MS for methane isotopomers. 
Experiment 1: [bmim] $\left[\mathrm{CH}_{3} \mathrm{COO}\right]$ was used as the model compound. $\left(\mathrm{NH}_{3}\right)_{2} \mathrm{PtCl}_{2}$ was heated in this ionic liquid at $150{ }^{\circ} \mathrm{C}$ for 30 minutes and then was soluble in $\mathrm{CD}_{3}$ COOD- $\mathrm{D}_{2} \mathrm{O}$ solution. $\mathrm{H} / \mathrm{D}$ exchange occurred readily at $250^{\circ} \mathrm{C}$ as evidenced by the butyl group peak intensity drop in ${ }^{1} \mathrm{H}$ NMR.

Experiment 2: [1-mim] [Cl] was used as the dissolution media for $\left(\mathrm{NH}_{3}\right)_{2} \mathrm{PtCl}_{2}$ at 200 ${ }^{\circ} \mathrm{C}$ for 30 minutes. We tried to monitor the $\mathrm{H} / \mathrm{D}$ exchange at $250{ }^{\circ} \mathrm{C}$ between $\mathrm{CH}_{4}$ and deuterated solvents by GC-MS. Unfortunately, no measurable exchange was observed.

Experiment 3: [1-mim] $\left[\mathrm{HSO}_{4}\right]$ was used as the dissolution media for $\left(\mathrm{NH}_{3}\right)_{2} \mathrm{PtCl}_{2}$ at $200{ }^{\circ} \mathrm{C}$ for 30 minutes. Once again, we did not see measurable amount of methane isotopomers.

A few conclusions can be drawn through this set of parallel experiments. (1) Ionic liquids serve as dissolution media for Pt catalysts, but the processing temperature largely depends on the length of the side chains, e.g., 1-butyl-3-methyl $\left(150^{\circ} \mathrm{C}\right)$ vs. 1methyl $\left(200^{\circ} \mathrm{C}\right)$. (2) The coordination chemistry of ionic liquids plays a decisive role in catalysis. Here the acetate-ligated $\mathrm{Pt}$ seems to be active, while $\mathrm{Cl}$ or HSO4-ligated Pt was inactive. (3) The inertness of butyl group might be quite different from that of methane.

One straightforward experiment for next step would be to test $[1-\mathrm{mim}]\left[\mathrm{CH}_{3} \mathrm{COO}\right]$ ionic liquid. 


\section{CHAPTER FIVE: CATALYTIC SYSTEMS FOR METHANE CONVERSION}

\subsection{SUMMARY}

One of the major functions of applying ionic liquids in homogenously catalytic methane conversion systems is to employ their super dissolving power to greatly enlarge the candidate pool for each component: catalysts, oxidants and reaction media, because most of the transition-metal based compounds which are promising effective catalysts for methane conversion are insoluble to normal acid or base media. During this project, we have successfully developed several Pt-catalyst/ Concentrated sulfuric acid/ Ionic liquid catalytic systems for efficient and selective low temperature methane conversion, which present greatly improved performance compared to the Periana-Catalytica system in terms of reaction rate, catalyst lifetime and water tolerance. These optimized catalytic systems elaborate the success of this multi-year project and will serve as a promising start point for our future efforts on achieving a commercially viable methane utilization technique to solve the nation's energy crisis and to provide alternative hydrocarbon chemical feedstocks for the nation's chemical industry.

Table 5.1 summarizes the various candidates of the system component we have investigated. The combinations of the yellow-shaded ones are the currently optimal systems. In the following sections, we will explain in details of the optimization of each category.

Table 5.1: Summary of candidates for each component of the catalytic system for direct methane conversion tested with the systems with optimized performance shaded in yellow.

\begin{tabular}{|c|c|c|c|}
\hline Catalyst & Ionic Liquid & Solvent & Oxidant \\
\hline $\begin{array}{l}\text { Pt-based } \\
\text { Os-based } \\
\text { Ru-based } \\
\text { Re-based } \\
\text { Ir-based }\end{array}$ & $\begin{array}{c}\text { Imidazolium-based } \\
\text { Pyrazolium-based } \\
\text { (Bi)Pyridinium-based } \\
\text { Pyrazinium-based } \\
\text { Bi-diazine-based } \\
\text { 1,2,4-triazolium-based } \\
\text { Ammonium-based } \\
\text { Phosphonium-based } \\
\text { with anion of } \\
\mathrm{HSO}_{4}^{-}, \mathrm{Cl}^{-} \text {or } \mathrm{Br}^{-} \\
\text {and } \mathrm{NH}_{4} \mathrm{HSO}_{4}\end{array}$ & $\begin{array}{c}\text { sulfuric acid } \\
\text { (concentrated and } \\
\text { diluted); } \\
\text { hydrochloric acid, } \\
\text { acetic acid } \\
\text { (pure and concentrated) } \\
\text { triflic acid } \\
\text { trifluoroacetic acid } \\
\text { basic solution } \\
\text { pure water }\end{array}$ & $\begin{array}{c}\text { sulfuric acid } \\
\text { (concentrated) } \\
\mathrm{K}_{2} \mathrm{PtCl}_{6} \\
\mathrm{FeCl}_{3} \\
\mathrm{CuCl}_{2} \\
\mathrm{~V}_{2} \mathrm{O}_{5} \\
\mathrm{CeO}_{2} \\
\left(\mathrm{NH}_{4}\right)_{2} \mathrm{Ce}_{\left(\mathrm{NO}_{3}\right)_{6}} \\
\mathrm{H}_{2} \mathrm{SeO}_{4}\end{array}$ \\
\hline
\end{tabular}




\subsection{OXIDANTS}

Our experimental and theoretical work proposes that the effective oxidizing species in the Periana system and the PEER system is actually $\mathrm{SO}_{3}$ instead of $\mathrm{SO}_{4}{ }^{2-}$ which might be a possible reason for the sulfuric acid concentration dependence of the system performance. Figure 5.1 shows the calculated temperature dependence of the amounts (in mole) of $\mathrm{SO}_{3}$ in $100 \mathrm{mg}$ of sulfuric acid solutions with different concentrations. Clearly, at above $200{ }^{\circ} \mathrm{C}$, the amount of $\mathrm{SO}_{3}$ decreases dramatically upon the sulfuric acid concentration.

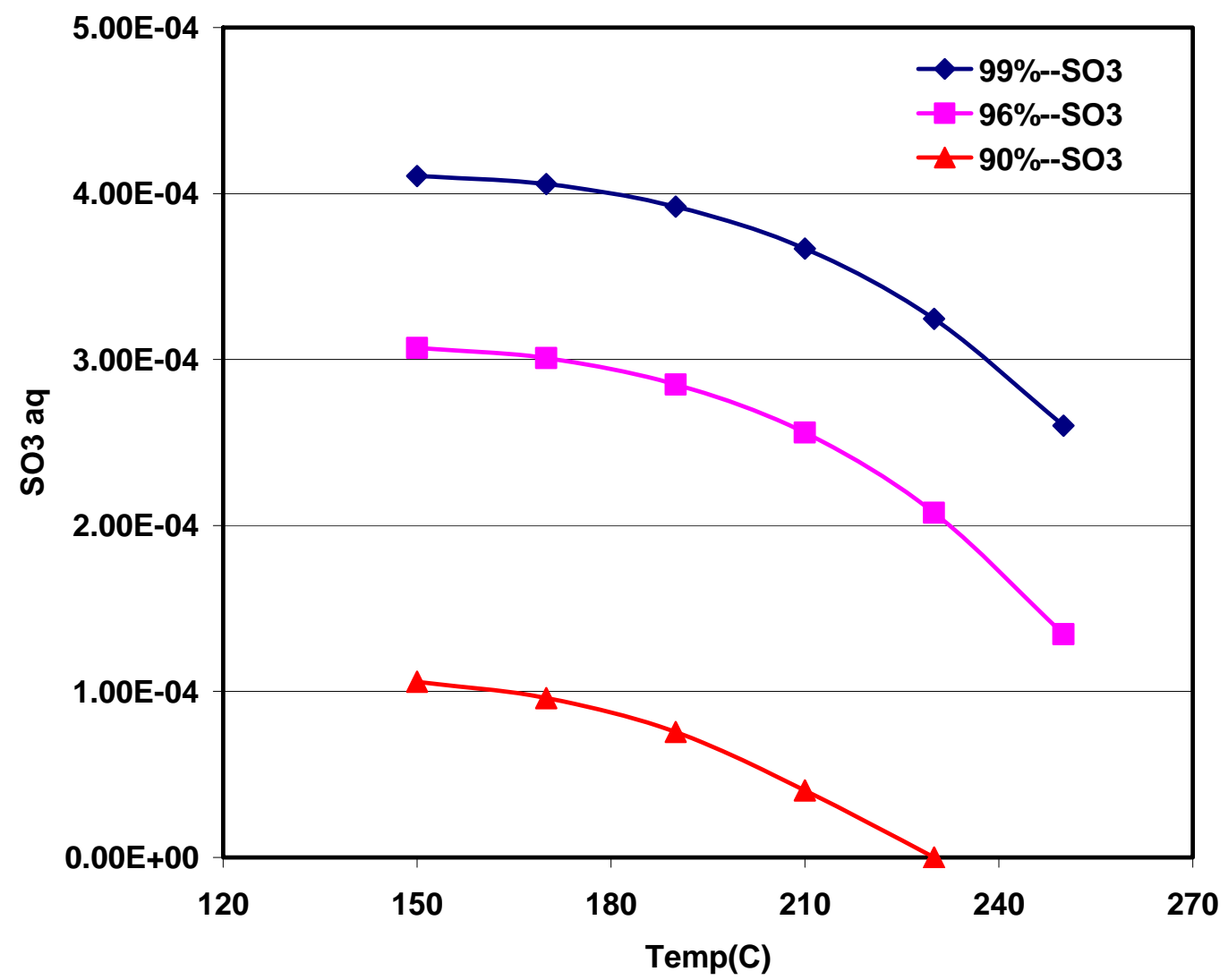

Figure 5.1: Temperature dependence of the calculated amounts (in mole) of $\mathrm{SO}_{3}$ in $100 \mathrm{mg}$ of sulfuric acid solutions with different concentrations.

Using concentrated sulfuric acid as the oxidant automatically assures the high selectivity of the methane oxidation, because the oxidized product methly bisulfate is more stable than methane in this system. However, utilization of concentrated sulfuric acid also brings concerns on reactor cost and operation cost as well as environment damage. Search for alternative oxidants which are effective yet cheap has not been conducted intensively. Three criteria have been established for the screening: (1) the redox potential of the new oxidant is higher than sulfuric acid; (2) redox cycle of the new oxidant is relatively easy and inexpensive; and (3) new oxidants need to be compatible with ionic liquids, Pt-based catalysts and diluted sulfuric acid. 
Table 5.2 summarized the compatibility tests we have conducted. $\mathrm{Ce}(\mathrm{IV}), \mathrm{Cu}(\mathrm{II})$ and $\mathrm{V}(\mathrm{V})$ seem to meet those criteria and the solubility of their compounds such as $\mathrm{CeO}_{2}$, $\left(\mathrm{NH}_{4}\right)_{2} \mathrm{Ce}\left(\mathrm{NO}_{3}\right)_{6}, \mathrm{CuCl}_{2}$, and $\mathrm{V}_{2} \mathrm{O}_{5}$ was studied in both sulfuric acid and ionic liquids. Hydrogen peroxide is a strong oxidizer, but it is not compatible with Pt catalysts. In fact, we also tested selenic acid $\left(\mathrm{H}_{2} \mathrm{SeO}_{4}\right)$, which turned out too strong so that over-oxidation occurred with a large amount of $\mathrm{CO}_{2}$ generation.

Table 5.2: Compatibility tests for new oxidants potentially used for partial oxidation of methane to methanol.

\begin{tabular}{|c|c|c|c|c|}
\hline Oxidant & Solvent & $\begin{array}{l}\text { Treatment } \\
\text { Conditions }\end{array}$ & Solubility & $\begin{array}{l}\text { Compatibility in a } \\
\text { Catalytic system }\end{array}$ \\
\hline $\mathrm{CeO}_{2}$ & $96 \% \mathrm{H}_{2} \mathrm{SO}_{4}$ & $90^{\circ} \mathrm{C} 1 \mathrm{hr}$ & $\begin{array}{l}\text { Low, a lot of } \\
\text { precipitates }\end{array}$ & Not compatible \\
\hline $\mathrm{CeO}_{2}$ & IL-024 & $95{ }^{\circ} \mathrm{C} 1 \mathrm{hr}$ & Insoluble & Not compatible \\
\hline$\left(\mathrm{NH}_{4}\right)_{2} \mathrm{Ce}\left(\mathrm{NO}_{3}\right)_{6}$ & $96 \% \mathrm{H}_{2} \mathrm{SO}_{4}$ & $90^{\circ} \mathrm{C} 1 \mathrm{hr}$ & $\begin{array}{l}\text { Low, a lot of } \\
\text { precipitates }\end{array}$ & Not compatible \\
\hline$\left(\mathrm{NH}_{4}\right)_{2} \mathrm{Ce}\left(\mathrm{NO}_{3}\right)_{6}$ & IL-024 & $100{ }^{\circ} \mathrm{C} 15 \mathrm{~min}$ & Soluble & $\begin{array}{l}\text { Not compatible with } \\
\mathrm{H}_{2} \mathrm{SO}_{4}\end{array}$ \\
\hline $\mathrm{CuCl}_{2} \cdot 2 \mathrm{H}_{2} \mathrm{O}$ & $96 \% \mathrm{H}_{2} \mathrm{SO}_{4}$ & $90^{\circ} \mathrm{C} 1 \mathrm{hr}$ & $\begin{array}{l}\text { Low, a lot of } \\
\text { precipitates }\end{array}$ & Possibly compatible \\
\hline $\mathrm{CuCl}_{2} \cdot 2 \mathrm{H}_{2} \mathrm{O}$ & IL-024 & $95^{\circ} \mathrm{C} 1 \mathrm{hr}$ & Soluble & Possibly compatible \\
\hline $\mathrm{CuO}$ & {$[\mathrm{bmim}][\mathrm{Cl}]$} & $\begin{array}{l}\text { Heating upon } \\
\text { the IL melts }\end{array}$ & Soluble & $\begin{array}{l}\text { Not compatible as } \\
\text { [bmim] is not stable }\end{array}$ \\
\hline $\mathrm{CuO}$ & IL-024 & $95^{\circ} \mathrm{C} 1 \mathrm{hr}$ & Insoluble & Not compatible \\
\hline $\mathrm{H}_{2} \mathrm{O}_{2}$ & -- & $\begin{array}{l}\text { Pt black and } \\
\mathrm{PtCl}_{2} \text { and } \mathrm{PtO}_{2}\end{array}$ & Insoluble & $\begin{array}{l}\text { Not compatible as } \\
\mathrm{H}_{2} \mathrm{O}_{2} \text { is not stable }\end{array}$ \\
\hline $\mathrm{V}_{2} \mathrm{O}_{5}$ & {$[\mathrm{bmim}][\mathrm{Cl}]$} & $150{ }^{\circ} \mathrm{C} 30 \mathrm{~min}$ & Soluble & $\begin{array}{l}\text { Not compatible as } \\
\text { [bmim] is not stable }\end{array}$ \\
\hline $\mathrm{V}_{2} \mathrm{O}_{5}$ & IL-004 & $150{ }^{\circ} \mathrm{C} 30 \mathrm{~min}$ & $\begin{array}{l}\text { Soluble, dark } \\
\text { red solution }\end{array}$ & $\begin{array}{l}\text { Compatible with } \\
\mathrm{H}_{2} \mathrm{SO}_{4}\end{array}$ \\
\hline $\mathrm{V}_{2} \mathrm{O}_{5}$ & $96 \% \mathrm{H}_{2} \mathrm{SO}_{4}$ & $150{ }^{\circ} \mathrm{C} 15 \mathrm{~min}$ & $\begin{array}{l}\text { Soluble, read } \\
\text { solution }\end{array}$ & $\begin{array}{l}\text { Compatible with IL } \\
\text { and Pt catalysts }\end{array}$ \\
\hline
\end{tabular}

Vanadium oxide was both soluble in the acid and ionic liquids and thus was subjected to further study such as methane activation and oxidation. We started with $\mathrm{PtCl}_{2}, 10 \mathrm{wt} \%$ ionic liquid and $90 \mathrm{wt} \% \mathrm{H}_{2} \mathrm{SO}_{4}$ (initial concentration $102 \%$ ), which were processed to give a homogeneous solution. $\mathrm{K}_{2} \mathrm{SeO}_{4}$ and $\mathrm{V}_{2} \mathrm{O}_{5}$ were used as new oxidants to enhance the oxidizing power. The product yields, in the form of methylbisulfate, from these runs were determined from ${ }^{1} \mathrm{H}$ NMR (Figure 5.2). 
The blank run (without new oxidant), Figure 5.2 (a), only resulted in less than 1 turnover number amount of methanol. $\mathrm{K}_{2} \mathrm{SeO}_{4}$ is a strong oxidant when it is dissolved in concentrated $\mathrm{H}_{2} \mathrm{SO}_{4}$ as selenic acid $\left(\mathrm{H}_{2} \mathrm{SeO}_{4}\right)$ will be formed. Unfortunately, this oxidant seemed too strong. Figure 5.2 (b) showed that there was nearly zero methanol formed. On the other hand, gas analysis for this run indicated a large amount of $\mathrm{CO}_{2}$, implying methane was over-oxidized. $\mathrm{V}_{2} \mathrm{O}_{5}$ is also a strong oxidant and is soluble in concentrated sulfuric acid. This system was eventually successful in catalyzing methane up to 4 turnover numbers with negligible $\mathrm{CO}_{2}$ emission (Figure 5.2 (c)).

Therefore, we have performed the proof-of-concept work. At least $10 \mathrm{wt} \%$ of PEER-6 type ionic liquids can be incorporated into concentrated sulfuric acid. With the aid of more powerful oxidants, the catalytic systems are able to efficiently convert methane to methanol (in the form of methylbisulfate) at a high selectivity. Nevertheless, there are still quite a few issues that need to be solved, such as how to recycle the oxidant, how to separate the methanol from the reaction media, and how to improve the efficiency.

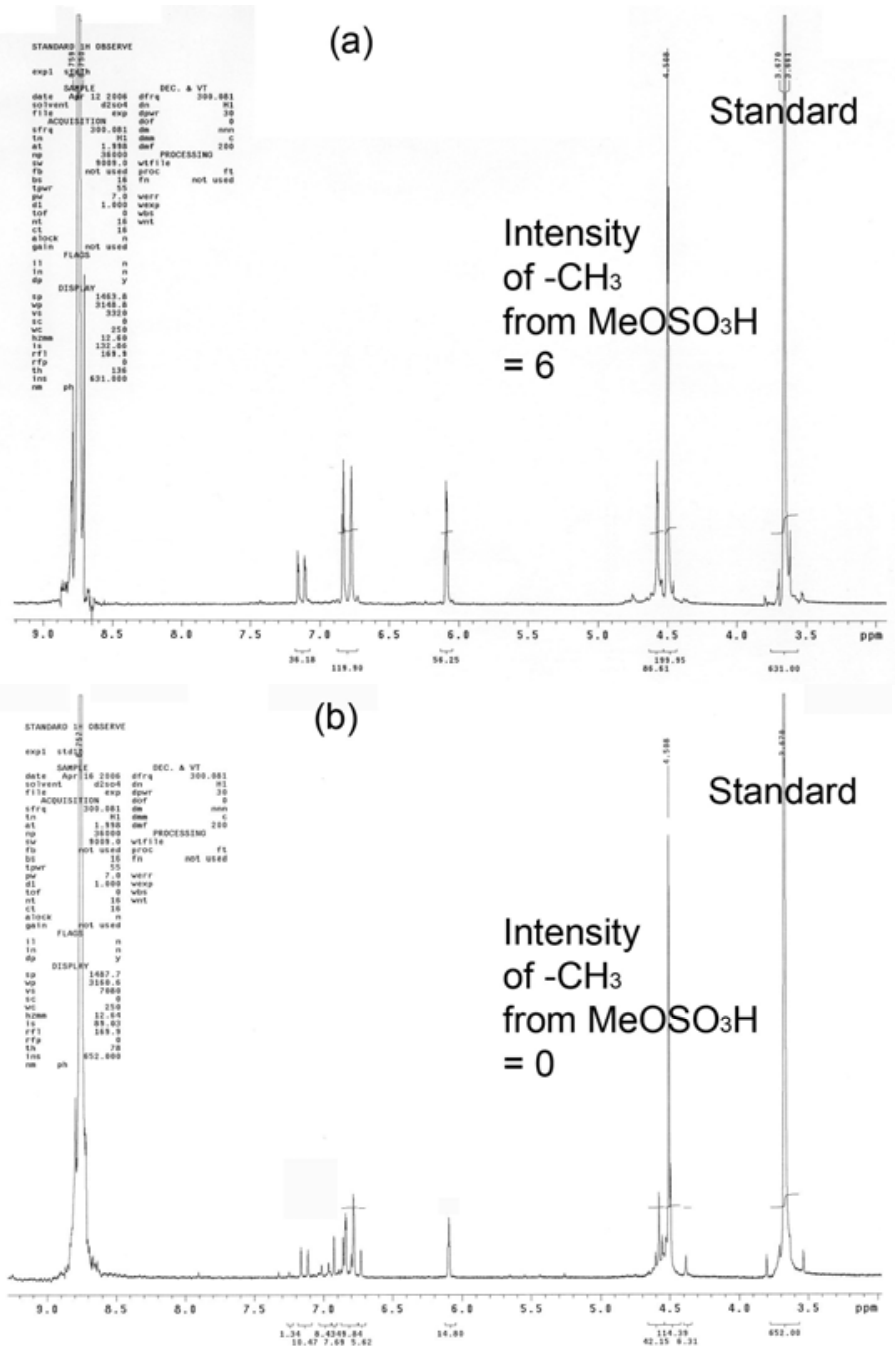




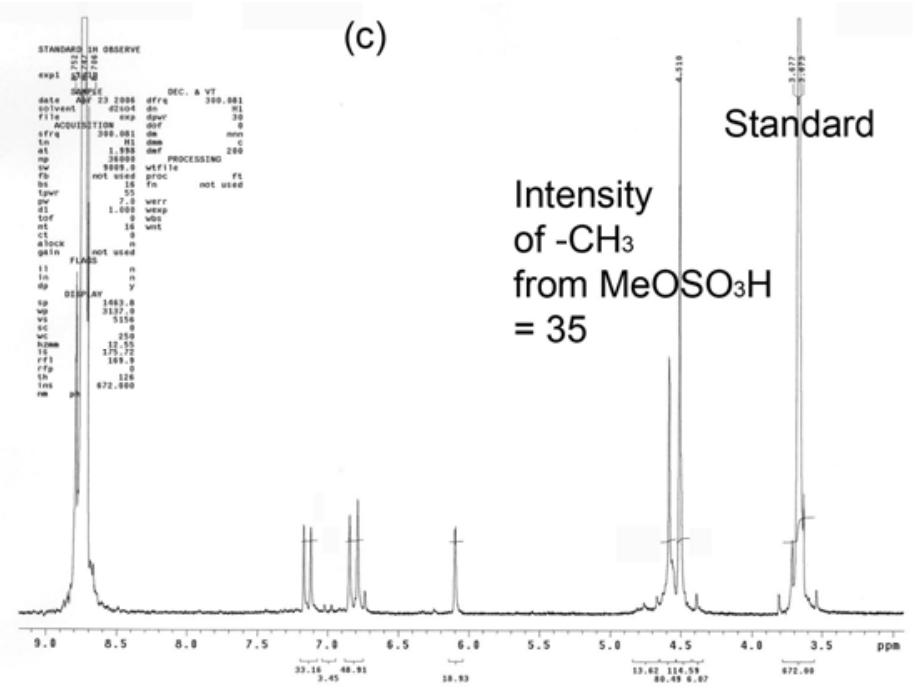

Figure 5.2: ${ }^{1} \mathrm{H}$ NMR spectra of the liquids from methane oxidation tests using $10 \mathrm{wt} \%$ PEER-6 type ionic liquids at $200{ }^{\circ} \mathrm{C}$ for $2.5 \mathrm{hrs}$. (a) $\mathrm{PtCl}_{2}+\mathrm{IL}-050$ only as a blank; (b) $\mathrm{PtCl}_{2}+\mathrm{IL}-050+\mathrm{K}_{2} \mathrm{SeO}_{4}$; and (3) $\mathrm{PtCl}_{2}+\mathrm{IL}-050+\mathrm{V}_{2} \mathrm{O}_{5}$. Acetic acid was used as the internal standard.

\subsection{SOLVENTS}

The Periana reaction using (bpym) $\mathrm{PtCl}_{2}$ in $102 \%$ oleum can catalyze methane oxidation to methanol with $\sim 70 \%$ conversion and a final methanol concentration of $\sim 1 \mathrm{M}$ within 2.5 hours at $220^{\circ} \mathrm{C}$. However, this process is still not commercially viable largely because of the quick Pt catalyst deactivation by the product (methanol) or the by product (water). The current TOF is only about $10^{-3} \mathrm{~s}^{-1}$, which is not efficient enough to meet the industrial requirement, $1 \mathrm{~s}^{-1}$. Theoretical and experimental studies have shown that the ground state stabilization of the platinum complex by reversible binding to water or methanol is about $10 \mathrm{kcal} / \mathrm{mol}$ lower than the $\mathrm{HSO}_{4}{ }^{-}$complex. At the same time, using concentrated $\mathrm{H}_{2} \mathrm{SO}_{4}$ places a big challenge for the reactor design as corrosion would be severe for most materials. Thus, replacing sulfuric acid with a less corrosive solvent would be highly desirable while the catalyst rates can still be achieved or improved.

We have tried various ionic liquids as the solvent, because the non-measurable vapor pressure makes them "green". In addition, replacing concentrated sulfuric acid with ionic liquids can also avoid the high product separation cost considering the cost for reconcentration of sulfuric acid. However, at the current stage we can only partially replace the sulfuric acid with suitable ionic liquid and have achieved significantly improved catalytic performance for the system. As the main body of the catalytic system, solvent, i.e. the reaction media is actually affecting the chemistry of all other components which can be viewed as additions to the solvent.

With/without ionic liquids as dissolution media, we have tested many potential methane partial oxidation systems with different solvents including sulfuric acid (concentrated and diluted), hydrochloric acid, acetic acid (pure and concentrated), triflic acid, trifluoroacetic acid, basic solution and pure water. Except for the basic solution, we 
have observed catalytic capability on $\mathrm{C}-\mathrm{H}$ activation in all other solvents primarily catalyzed by certain Pt-based catalysts. However, other than using concentrated sulfuric acid as the oxidant, alternative oxidants are required for systems with other solvents. A partially oxidized product which can survive in the catalytic system without being further oxidized to $\mathrm{CO}_{2}$ becomes the major concern if possessing enough oxidation power. Besides the systems relying on the utilization of concentrated sulfuric acid, another very promising methane conversion system developed is the High-Temperature Shilov system. In this system, the reaction media is milder (hydrochloric acid) and the oxidants can be cheap compounds of $\mathrm{Cu}$ and $\mathrm{Fe}$. Thus, this system has great potential of becoming the improved to a cost-effective as well as environment-friendly methane conversion technique. We will present our findings on this system in details in the following chapter.

\subsubsection{Acetic Acid}

Acetic acid $(\mathrm{AcOH})$ is an excellent polar protic solvent and has been extensively used for chemical reactions, such as in the production of terephthalic acid (TPA) (a raw material for polyethylene terephthalate (PET)), and in Friedel-Crafts alkylation, to name a few. In the application of homogeneous catalysis for $\mathrm{C}-\mathrm{H}$ bond activation, acetic acid and/or its aqueous solutions have also widely used as reaction media ${ }^{2}$ With all the knowledge combined, we evaluated the possibility of applying ternary systems of $\mathrm{Pt} / \mathrm{ILs} / \mathrm{AcOH}$ to $\mathrm{C}-\mathrm{H}$ activation and methane oxidation.

Similar to the sulfuric acid system, the compatibility between ionic liquids, Ptbased catalysts, and acetic acid was the first thing we need to study (Table 5.3).

Table 5.3: Compatibility studies of Pt/ILs/AcOH systems. The concentration of Pt species was 12.5 mM. AcOH was added as $1 \mathrm{~mL}$.

\begin{tabular}{lllll}
\hline Ionic Liquid & Pt Species & Molar Ratio & $\begin{array}{l}\text { Treatment } \\
\text { Temp. }\left({ }^{\circ} \mathrm{C}\right)\end{array}$ & $\begin{array}{l}\text { Soluble in } \mathrm{AcOH} \\
\text { at R. T.? }\end{array}$ \\
\hline [bmim][Cl] (PEER-1) & $\mathrm{PtCl}_{2}$ & $\geq 6: 1$ & $180-200$ & Yes \\
& $\mathrm{K}_{2} \mathrm{PtCl}_{4}$ & $\geq 6: 1$ & 200 & Yes \\
& $\mathrm{PtCl}_{4}$ & $\geq 6: 1$ & 200 & Yes \\
& $\mathrm{H}_{2} \mathrm{PtCl}_{6}$ & $\geq 6: 1$ & 200 & Yes \\
[bmim][CH$\left.{ }_{3} \mathrm{COO}\right]$ & $\mathrm{PtCl}_{2}$ & $10: 1$ & 200 & Yes; also soluble \\
$(\mathrm{PEER}-1)$ & $\left(\mathrm{bpym}^{2} \mathrm{PtCl}_{2}\right.$ & $10: 1$ & 200 & in 10 wt $\mathrm{H}_{2} \mathrm{O}$ \\
& $\mathrm{PtCl}_{4}$ & $\geq 6: 1$ & 200 & Yes \\
& $\mathrm{PtCl}_{2}$ & $6: 1$ & $\leq 200$ & No \\
\hline IL-003 (PEER-1) & & & & \\
\hline
\end{tabular}




\begin{tabular}{lllll} 
& $\mathrm{K}_{2} \mathrm{PtCl}_{4}$ & $6: 1$ & 200 & Very little \\
& $\mathrm{PtCl}_{4}$ & $6: 1$ & 200 & Very little \\
& $\mathrm{PtCl}_{2}$ & $20: 1$ & 200 & Yes \\
& $\mathrm{K}_{2} \mathrm{PtCl}_{4}$ & $20: 1$ & 200 & Yes \\
IL-004 (PEER-1) & $\mathrm{PtCl}_{2}$ & $6: 1$ & $\leq 200$ & No \\
& $\mathrm{K}_{2} \mathrm{PtCl}_{4}$ & $6: 1$ & 200 & Very little \\
& $\mathrm{PtCl}_{4}$ & $6: 1$ & 200 & Very little \\
& $\mathrm{PtCl}_{2}$ & $20: 1$ & 200 & Yes \\
& $\mathrm{PtCl}_{4}$ & $20: 1$ & 200 & Most \\
& $\mathrm{Any} \mathrm{Pt}_{\text {IL-050 (PEER-6) }}$ & $6: 1$ & 200 & No \\
& $\mathrm{PtCl}_{2}$ & $20: 1$ & 200 & Very little \\
\hline
\end{tabular}

As shown in Table 5.3, the compatibility of pre-treated Pt/ILs in AcOH depends on a number of factors: (1) the treatment temperature. It seems that most Pt/ILs systems need to be heated above $180{ }^{\circ} \mathrm{C}$ to enable a complete dissolution in $\mathrm{AcOH}$ at room temperature. (2) the cation nature of ionic liquids. PEER-6 type ionic liquid systems seem more difficult in terms of solubility in AcOH than the PEER-1 type ionic liquid systems. (3) alkyl groups attached to an ionic liquid ring also make a remarkable difference on solubility. 1-butyl-3-methylimidazolium chloride readily dissolves most Pt species at the ratio of $6: 1$ at $200{ }^{\circ} \mathrm{C}$, but ionic liquids with shorter chains such as IL-003/004 need a ratio of 20:1. On the contrary, the nature of $\mathrm{Pt}$ species, such as $\mathrm{PtCl}_{2}$ vs. $\mathrm{PtCl}_{4}$, has less impact on the solubility. Mechanistic understanding for these observations is currently under investigation.

(a)

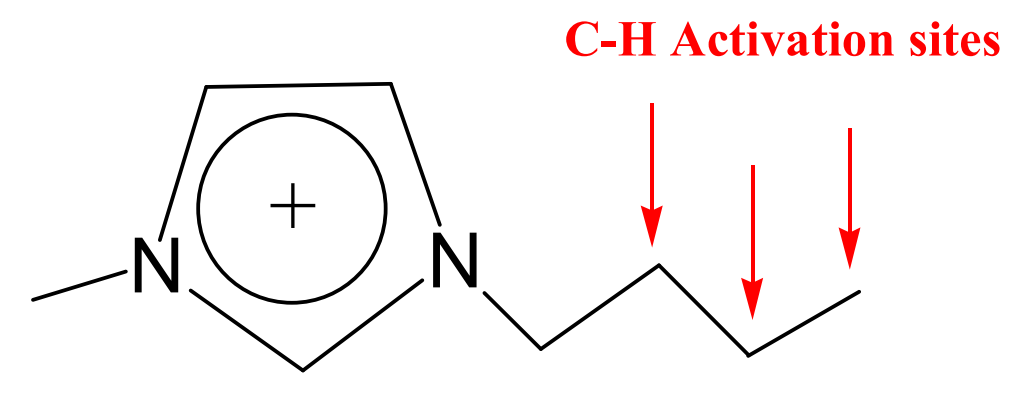




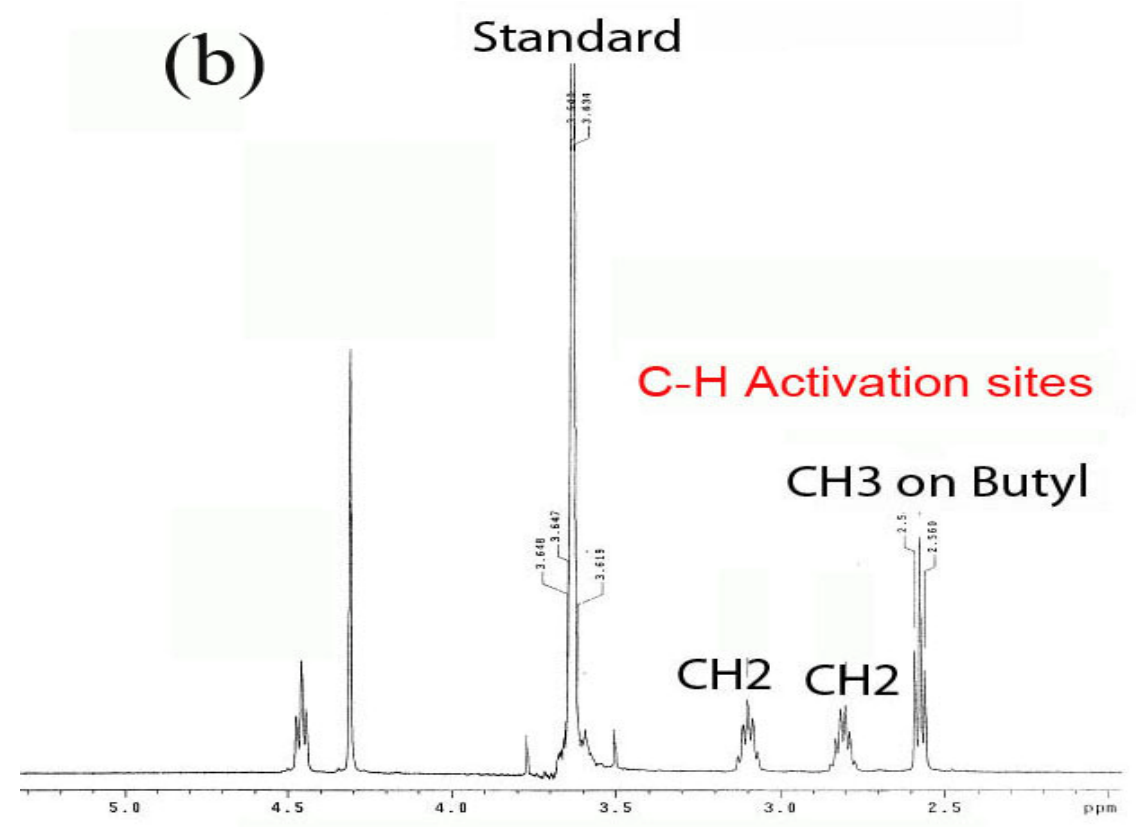

Figure 5.3: Possible sites in an ionic liquid containing [bmim] as the cation for $\mathrm{C}$-H activation that are similar to methane $\mathrm{C}-\mathrm{H}$ bonds. (a) Schematic structure; and (b) ${ }^{1} \mathrm{H}$ NMR spectrum.

Also demonstrated in Table 5.3 is that we have successfully identified a few compatible ternary systems of $\mathrm{Pt} / \mathrm{ILs} / \mathrm{AcOH}$, such as $\mathrm{PtCl}_{2} /[\mathrm{bmim}]\left[\mathrm{CH}_{3} \mathrm{COO}\right] / \mathrm{AcOH}$. Next steps include the stability tests for these systems and eventually the catalytic reactivity tests for methane oxidation. Stability of ionic liquids themselves in a catalytic system is a major challenge considering that methane is one of the most inert hydrocarbons. In $\mathrm{Pt} / \mathrm{ILs} / \mathrm{H}_{2} \mathrm{SO}_{4}$ systems, Sulfuric acid plays roles of reaction media and oxidant simultaneously, but in $\mathrm{AcOH}$ systems we expect no oxidation would occur due to the lack of oxidant. One convenient way to evaluate the stability is then to measure the $\mathrm{H} / \mathrm{D}$ exchange between a regular ionic liquid and deuterated acetic acid. This strategy has actually been applied to the Pt reactivity studies in $\mathrm{Pt} / \mathrm{ILs} / \mathrm{H}_{2} \mathrm{SO}_{4}$ systems where [bmim] ionic liquid was used as a model compound for oxidation. Here in $\mathrm{AcOH}$ systems, we use [bmim] ionic liquid as the model compound for $\mathrm{C}-\mathrm{H}$ activation. Possible activation sites that are similar to methane $\mathrm{C}-\mathrm{H}$ bonds are illustrated in Figure 5.3(a) and (b).

$\mathrm{C}-\mathrm{H}$ bond activation of alkanes by $\mathrm{Pt}$ species in acetic acid might start from a temperature as low as $100^{\circ} \mathrm{C}$, but our experiments showed that significant $\mathrm{H} / \mathrm{D}$ exchange only started at temperatures above $180{ }^{\circ} \mathrm{C}$. Considering the boiling point of acetic acid is below $120{ }^{\circ} \mathrm{C}$, an appropriate reactor is desired that can sustain high pressure vapor and keep part of acetic acid as liquid at higher temperatures. Characterization after H/D exchange was performed with ${ }^{1} \mathrm{H}$ NMR in $\mathrm{D}_{2} \mathrm{SO}_{4}$. Decrease in peak integration indicates deuterium replacement for hydrogen (Figure 5.3 (b)).

Similarly, with [bmim] ionic liquid as the model compound, C-H activation in different Pt/ILs/AcOH systems was investigated as summarized in Table 5.4. Usually the Pt catalysts were used as $20 \mathrm{mM}$ and first dissolved in $200 \mathrm{mM}$ ionic liquid 
([bmim] $\left.\left[\mathrm{CH}_{3} \mathrm{COO}\right]\right)$. Then the prepared $\mathrm{Pt} / \mathrm{IL}$ mixture was dissolved in $1 \mathrm{~mL}$ deuterated acetic acid (or its aqueous solution) at room temperature. H/D exchange rates can be determined from ${ }^{1} \mathrm{H}$ NMR peak integration.

Table 5.4: C-H bond activation of the butyl group in [bmim] ionic liquid via $H / D$ exchange in

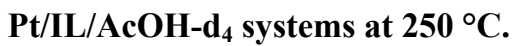

\begin{tabular}{|c|c|c|c|c|c|c|}
\hline \multirow{2}{*}{$\begin{array}{l}\text { Pt species } \\
+ \text { IL }\end{array}$} & \multirow{2}{*}{$\begin{array}{l}\text { Reaction } \\
\text { Media }\end{array}$} & \multirow{2}{*}{$\begin{array}{l}\mathrm{C}-\mathrm{H} \\
\text { Activation Site }\end{array}$} & \multicolumn{4}{|c|}{ H/D Exchange Rate (\%) } \\
\hline & & & 0 & $4 \mathrm{hr}$ & $12 \mathrm{hr}$ & $20 \mathrm{hr}$ \\
\hline \multirow{3}{*}{$\begin{array}{l}\mathrm{PtCl}_{2}+ \\
{[\mathrm{bmim}][\mathrm{AcO}]}\end{array}$} & $\mathrm{CD}_{3} \mathrm{CO}_{2} \mathrm{D}$ & $-\mathbf{C H}_{2}-\mathrm{CH}_{2}-\mathrm{CH}_{3}$ & 100 & 25 & 33 & 39 \\
\hline & & $-\mathrm{CH}_{2}-\mathbf{C H}_{2}-\mathrm{CH}_{3}$ & 100 & 19 & 29 & 34 \\
\hline & & $-\mathrm{CH}_{2}-\mathrm{CH}_{2}-\mathbf{C H}_{3}$ & 100 & 12 & 22 & 25 \\
\hline \multirow[t]{3}{*}{$\begin{array}{l}\mathrm{PtCl}_{2}+ \\
{[\mathrm{bmim}][\mathrm{AcO}]}\end{array}$} & $\begin{array}{l}\mathrm{CD}_{3} \mathrm{CO}_{2} \mathrm{D}+ \\
\mathrm{D}_{2} \mathrm{O}(10 \mathrm{wt} \%)\end{array}$ & $-\mathbf{C H}_{2}-\mathrm{CH}_{2}-\mathrm{CH}_{3}$ & 100 & 40 & & \\
\hline & & $-\mathrm{CH}_{2}-\mathbf{C H}_{2}-\mathrm{CH}_{3}$ & 100 & 31 & & \\
\hline & & $-\mathrm{CH}_{2}-\mathrm{CH}_{2}-\mathbf{C H}_{3}$ & 100 & 25 & & \\
\hline \multirow{3}{*}{$\begin{array}{l}\mathrm{PtCl}_{4}+ \\
{[\mathrm{bmim}][\mathrm{AcO}]}\end{array}$} & $\mathrm{CD}_{3} \mathrm{CO}_{2} \mathrm{D}$ & $-\mathbf{C H}_{2}-\mathrm{CH}_{2}-\mathrm{CH}_{3}$ & 100 & 21 & & \\
\hline & & $-\mathrm{CH}_{2}-\mathbf{C H}_{2}-\mathrm{CH}_{3}$ & 100 & 18 & & \\
\hline & & $-\mathrm{CH}_{2}-\mathrm{CH}_{2}-\mathbf{C H}_{3}$ & 100 & 13 & & \\
\hline
\end{tabular}

The most remarkable observation from Table 5.4 is the ternary system of $\mathrm{PtCl}_{2} / \mathrm{IL} / \mathrm{AcOH}-\mathrm{d}_{4}$ catalyzed much more $\mathrm{H} / \mathrm{D}$ exchange in aqueous solution of $\mathrm{CD}_{3} \mathrm{CO}_{2} \mathrm{D}$ $+\mathrm{D}_{2} \mathrm{O}$ than in pure $\mathrm{CD}_{3} \mathrm{CO}_{2} \mathrm{D}$. In other words, Pt reactivity is actually promoted by the presence of water. This is in sharp contrast to the $\mathrm{Pt} / \mathrm{IL} / \mathrm{H}_{2} \mathrm{SO}_{4}$ systems where Pt catalysts would be poisoned by trace amount of water due to the ground state effect. Also worth noting is the comparison between $\mathrm{PtCl}_{2}$ and $\mathrm{PtCl}_{4}$. The preliminary data suggest that both $\mathrm{Pt}(\mathrm{II})$ and $\mathrm{Pt}(\mathrm{IV})$ can activate $\mathrm{C}-\mathrm{H}$ bond activation at a similar rate. Therefore, we expect different $\mathrm{C}-\mathrm{H}$ activation mechanisms for $\mathrm{Pt} / \mathrm{IL} / \mathrm{AcOH}$ aqueous systems.

\subsubsection{Triflic Acid}

Triflic acid $\left(\mathrm{CF}_{3} \mathrm{SO}_{3} \mathrm{H}\right)$ is known as a superacid and its acidity is about a thousand times stronger than $100 \%$ sulfuric acid, but it is of little oxidizing power comparing with a concentrated $\mathrm{H}_{2} \mathrm{SO}_{4}$. We dissolved the Periana catalyst, (bpym) $\mathrm{PtCl}_{2}$, into a mixed acid solution $\left(0.5 \mathrm{~mL} 96 \% \mathrm{H}_{2} \mathrm{SO}_{4}\right.$ and $\left.0.5 \mathrm{~mL} \mathrm{CF}_{3} \mathrm{SO}_{3} \mathrm{H}\right)$ which has higher acidity and half water concentration comparing with $1 \mathrm{~mL} 96 \% \mathrm{H}_{2} \mathrm{SO}_{4}$. Methane oxidation experiments were conducted using the mini gold tube and the results of ${ }^{1} \mathrm{H}$ NMR for each liquid phase were presented in Figure 5.4. 
The methanol yield of the mixed acid case (Figure 5.4 (b)) was about twice higher than the $\mathrm{H}_{2} \mathrm{SO}_{4}$ case (Figure 5.4 (a)). Considering the water concentration drops half and the acidity increases many times, we tend to confirm that water (either bonding with Pt or reducing the oxidizing power of $\mathrm{SO}_{3}$ ) is the major cause for the catalyst deactivation.

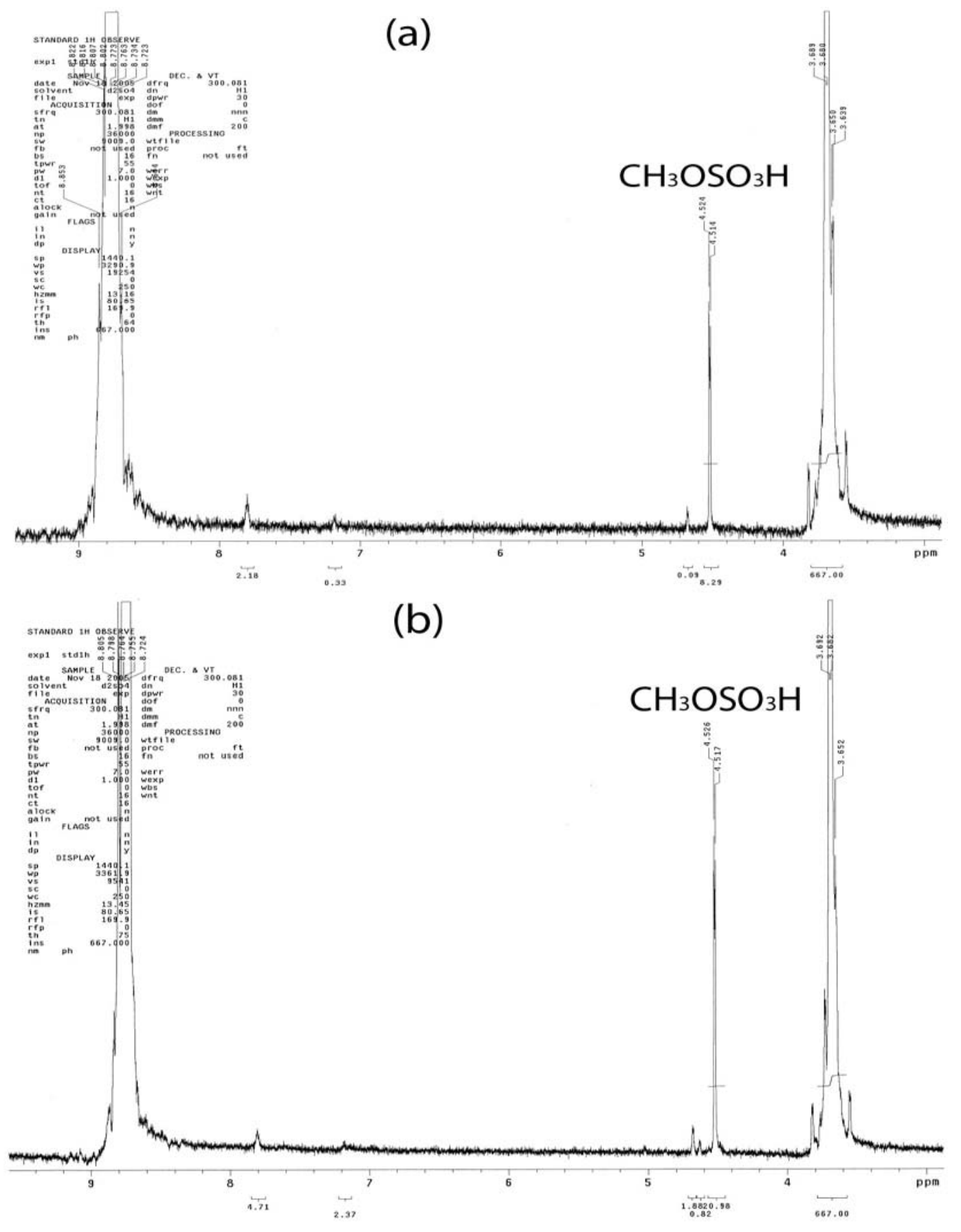

Figure 5.4: ${ }^{1} \mathrm{H}$ NMR spectra of the liquids from mini gold tube reactors at $200{ }^{\circ} \mathrm{C}$ for 4 hrs. (a) 50 $\mathrm{mM}$ (bpym) $\mathrm{PtCl}_{2}$ in $1 \mathrm{~mL} \mathrm{96 \%} \mathrm{H}_{2} \mathrm{SO}_{4}$; and (b) $50 \mathrm{mM}$ (bpym) $\mathrm{PtCl}_{2}$ in $0.5 \mathrm{~mL} 96 \% \mathrm{H}_{2} \mathrm{SO}_{4}+0.5 \mathrm{~mL}$ $\mathrm{CF}_{3} \mathrm{SO}_{3} \mathrm{H}$. Acetic acid was used as the internal standard. 


\subsubsection{Melting Salts (eg. $\left.\mathrm{NH}_{4} \mathrm{HSO}_{4}\right)$}

For the stable ionic liquids we have identified so far (PEER-4: pyrazinium-based, PEER-5: triazolium-based, and PEER-6 pyrazolium-based), the instability mainly comes from the N-heterocyclic ring decomposition, which limits the operating temperature of the catalytic system. In this sense, another type of ionic liquid, melting salts can also have the super dissolution capability serving as dissolution media or solvent in the catalyst/oxidant/solvent ternary catalytic system for direct methane to methanol conversion. The major advantage of melting salts is that they can be stable at relatively high temperatures.

Table 5.5: Solubility tests on several potential transition metal catalysts with $\mathrm{NH}_{4} \mathrm{HSO}_{4}$ as dissolution media or solvent.

\begin{tabular}{|c|c|c|c|}
\hline Catalysts & $\mathbf{N H}_{\mathbf{4}} \mathbf{H S O}_{\mathbf{4}}$ & $\mathbf{H}_{\mathbf{2}} \mathbf{S O}_{\mathbf{4}} \mathbf{( 9 6 \% )}$ & Solubility \\
\hline $\mathbf{V}_{\mathbf{2}} \mathbf{O}_{\mathbf{5}}$ & as solvent & No & Completely dissolved \\
\hline \multirow{2}{*}{ Re-01 } & No & Yes & Completely dissolved \\
\hline \multirow{2}{*}{ Ru-01 } & $10: 1$ & Yes & Partially dissolved \\
\cline { 2 - 4 } & No & Yes & Not dissolved \\
\hline \multirow{2}{*}{ Ru-02 } & $10: 1$ & Yes & Partially dissolved \\
\hline \multirow{2}{*}{ Ir-01 } & $10: 1$ & Yes & Not dissolved \\
\cline { 2 - 4 } & $50: 1$ & Yes & Not dissolved \\
\hline
\end{tabular}

Note: to assist dissolution, $30 \mathrm{~min}$ of oil bath at $200{ }^{\circ} \mathrm{C}$ was applied to each test.

Table 5.5 lists the solubility tests on several potential catalysts with $\mathrm{NH}_{4} \mathrm{SO}_{4}$ as dissolution media or solvent. Based on the solubility test results, several experiments were conducted with the mini gold tube reactor to look for new potential methane to methanol conversion catalytic systems. As well known, $\mathrm{V}_{2} \mathrm{O}_{5}$ is a very cheap compound which can be used as both catalyst and/or oxidant in chemical reactions. A gold tube experiment was conducted with $\mathrm{V}_{2} \mathrm{O}_{5}+\mathrm{NH}_{4} \mathrm{HSO}_{4}+\mathrm{CH}_{4}$ system at $200{ }^{\circ} \mathrm{C}$ for $4 \mathrm{~h}$. Although, no methanol was detected, a small amount of $\mathrm{CO}_{2}$ was generated indicating the occurrence of methane activation and oxidation. Therefore, suitable catalysts and oxidants need to be identified.

\subsection{TRANSITION METAL CATALYSTS}

In the Periana-Catalytica system, the specially designed (bpym) $\mathrm{PtCl}_{2}$ catalyst can be easily dissolved in concentrated sulfuric acid while presenting excellent catalytic ability on selective methane oxidation by sulfuric acid. However, this catalyst is deactivated upon water or methanol formation and precipitation forms when the concentration of sulfuric acid is lower than certain value. We have found that most of Pt- 
compounds can be dissolved in concentrated sulfuric acid if pre-treated with suitable ionic liquids. Instead of the complicate (bpym) $\mathrm{PtCl}_{2}$ catalyst, we have utilized several commercially available Pt-compounds including $\mathrm{PtCl}_{2}, \mathrm{PtCl}_{4}, \mathrm{PtO}_{2}, \mathrm{H}_{2} \mathrm{PtCl}_{6}, \mathrm{~K}_{2} \mathrm{PtCl}_{4}$. All these Pt-compounds showed comparable reactivity in the catalytic systems with application of appropriate ionic liquids. This finding can significantly reduce the cost for catalyst production and thus greatly advances the realization of a cost-effective methane conversion process. As pointed previously, if $\mathrm{PtO}_{2}$ is used as the catalyst, $\mathrm{Cl}^{-}$needs to be provided from other sources.

With the assistance of the super solubility of ionic liquids, we have been able to achieve many other homogenous catalytic systems with other transtion metal based catalysts. For example, we have tested the $\mathrm{Pd}\left(\mathrm{CH}_{3} \mathrm{COO}\right)_{2},\left(\mathrm{NH}_{3} \mathrm{CH}_{2} \mathrm{CH}_{2} \mathrm{NH}_{3}\right) \mathrm{PdCl}_{2}$, $\mathrm{AuCl}_{3}, \mathrm{RuCl}_{3}, \mathrm{ReCl}$, $\mathrm{ReCl}$, IrCl5 and some $\mathrm{Os}(\mathrm{III})$ and $\mathrm{Os}(\mathrm{IV})$-compounds catalysts on the solubility, stability and reactivity on $\mathrm{C}-\mathrm{H}$ bond activation. For the first time, it is found that high valent Osmium compound (III or IV) can also catalyze the C-H activation of methane in concentrated sulfuric acid. However, we have not yet found any effective systems for methane oxidation with catalysts other than Pt-compounds.

Table 5.6: Methane $\mathrm{C}-\mathrm{H}$ activation catalyzed by selected $\mathrm{Re}-$ and $\mathrm{Ru}$-based catalysts, in comparison with Os-based catalysts monitored by $\mathrm{H} / \mathrm{D}$ exchange in gold tube reactors at $250{ }^{\circ} \mathrm{C}$ for $4 \mathrm{~h}$.

\begin{tabular}{|c|c|c|c|c|}
\hline \multirow{2}{*}{ Entry } & \multirow{2}{*}{ Catalyst } & \multirow{2}{*}{ Reaction Media } & \multicolumn{2}{|c|}{ Exchange Ratio (\%) } \\
\cline { 3 - 5 } & & $\frac{\underline{\mathrm{CD}}_{\mathrm{x}} \underline{\mathrm{H}}_{4-\mathrm{x}}}{\mathrm{C}}$ & $\underline{\mathrm{D}}$ \\
\hline 1 & $\mathrm{Re}-01$ & $\mathrm{D}_{2} \mathrm{SO}_{4}(98 \%)$ & 85 & 48 \\
\hline 2 & $\mathrm{Ru}-01$ & $\mathrm{D}_{2} \mathrm{SO}_{4}(98 \%)+\mathrm{NH}_{4} \mathrm{HSO}_{4}(10: 1)$ & 44 & 26 \\
\hline 3 & $\mathrm{Ru}-02$ & $\mathrm{D}_{2} \mathrm{SO}_{4}(98 \%)+\mathrm{NH}_{4} \mathrm{HSO}_{4}(10: 1)$ & 80 & 44 \\
\hline 4 & Os-01 & $\mathrm{D}_{2} \mathrm{SO}_{4}(98 \%)$ & 72 & 43 \\
\hline 5 & Os-02 & $\mathrm{D}_{2} \mathrm{SO}_{4}(98 \%)$ & 83 & 45 \\
\hline
\end{tabular}

Note: All catalysts were added at $20 \mathrm{mM}$ and totally $0.3 \mathrm{~mL}$ reaction liquid and $100 \mathrm{umol} \mathrm{of} \mathrm{CH}_{4}$ were loaded into the gold tube reactors.

Table 5.6 shows the $\mathrm{H} / \mathrm{D}$ exchange between $\mathrm{CH}_{4}$ and $\mathrm{D}_{2} \mathrm{SO}_{4}$ catalyzed by selected transition metal catalysts. Quantification was realized by GC-MS analysis. The selected Re-based and Ru-based catalysts were found to have comparable reactivity to Os-based catalysts on $\mathrm{C}-\mathrm{H}$ bond activation of $\mathrm{CH}_{4}$. For the Ru-catalysts, which are insoluble in concentrated sulfuric acid, $\mathrm{NH}_{4} \mathrm{HSO}_{4}$ served as good dissolution media. The distribution of different $\mathrm{CD}_{\mathrm{x}} \mathrm{H}_{4-\mathrm{x}}$ isotopomers of the $\mathrm{H} / \mathrm{D}$ exchange experiments with Re-, $\mathrm{Ru}$ - and Os-based catalysts shares the same trend: single exchange is easier than multiple exchanges. Such a trend is different from that of the H/D exchange experiments involving Pt-catalysts investigated previously, in which the amount $\mathrm{CD}_{4}$ is much larger than $\mathrm{CDH}_{3}$. Thus, we can probably expect some different mechanisms for $\mathrm{C}-\mathrm{H}$ activation of methane catalyzed by these different transition metal-based compounds. 
Using various precious metal-complexs to catalyze methane activation has been investigated intensively. However, only one experimental study on methane activation catalyzed by Os(0) was reported by Flood et al. ${ }^{3}$ more than twenty years ago. For the first time, we reported in our project that $\mathrm{C}-\mathrm{H}$ activation of methane can be catalyzed by relatively high valence Os-based compounds in concentrated sulfuric acid.

Table 5.7: Preliminary results of methane C-H activation in selected Os-based systems monitored by $\mathrm{H} / \mathrm{D}$ exchange in gold tube reactors.

\begin{tabular}{|c|c|c|c|c|c|}
\hline \multirow{2}{*}{ Entry } & \multirow{2}{*}{ Catalyst } & Reaction Media & \multirow{2}{*}{$\mathbf{T}$} & \multicolumn{2}{|c|}{ Exchange Rate (\%) } \\
\cline { 5 - 6 } & & & $\left.\mathbf{(}^{\mathbf{}} \mathbf{C}\right)$ & ${\underline{\underline{\mathrm{CD}_{2}}}}_{\mathbf{2}} \underline{\mathrm{H}}_{4-\mathrm{x}}$ & $\underline{\mathrm{D}}$ \\
\hline 1 & Os-01 & $\mathrm{KOH}(10 \mathrm{wt} \%)+\mathrm{D}_{2} \mathrm{O}$ & 220 & 0 & 0 \\
\hline 2 & Os-02 & $\mathrm{D}_{2} \mathrm{O}$ & 220 & 0 & 0 \\
\hline 3 & Os-03 & $\mathrm{KOH}(2.5 \mathrm{wt} \%)+\mathrm{D}_{2} \mathrm{O}$ & 250 & 0 & 0 \\
\hline 4 & Os-03 & $\mathrm{D}_{2} \mathrm{SO}_{4}(98 \%)$ & 220 & 75 & 31 \\
\hline 5 & Os-03 & $\mathrm{D}_{2} \mathrm{SO}_{4}(98 \%)$ & 250 & 61 & 37 \\
\hline 6 & Os-03 & $\mathrm{D}_{2} \mathrm{SO}_{4}(98 \%)$ & 250 & 72 & 43 \\
\hline 7 & Os-03 & $\mathrm{D}_{2} \mathrm{SO}_{4}(85 \%)$ & 250 & 13 & 4 \\
\hline 8 & Os-04 & $\mathrm{D}_{2} \mathrm{SO}_{4}(98 \%)+\mathrm{IL}-007(6: 1)$ & 250 & 53 & 28 \\
\hline 9 & Os-04 & $\mathrm{D}_{2} \mathrm{SO}_{4}(85 \%)+\mathrm{IL}-007(6: 1)$ & 250 & 34 & 12 \\
\hline 10 & Os-05 & $\mathrm{D}_{2} \mathrm{SO}_{4}(98 \%)$ & 250 & 83 & 45 \\
\hline 11 & Os-05 & $\mathrm{D}_{2} \mathrm{SO}_{4}(85 \%)$ & 250 & 29 & 10 \\
\hline 12 & Os-05 & $\mathrm{CF}_{3} \mathrm{SO}_{3} \mathrm{D}$ & 150 & 2.4 & 0.6 \\
\hline 13 & Os-05 & $\mathrm{CF}_{3} \mathrm{SO}_{3} \mathrm{D}$ & 200 & 20 & 5 \\
\hline 14 & Os-05 & $\mathrm{CF}_{3} \mathrm{SO}_{3} \mathrm{D}$ & 250 & ------ & ----- \\
\hline
\end{tabular}

${ }^{a}$ Reaction conditions: Os-based catalyst, $0.02 \mathrm{mmol}$; ionic liquid, $0.3 \mathrm{mmol}$; total liquid volume, $0.3 \mathrm{~mL}$; $\mathrm{CH}_{4}, 64.7$ psi, $100 \mu \mathrm{mol}$; external hydraulic pressure 3700 psi.; heating time $4 \mathrm{~h} .{ }^{\mathrm{b}}$ IL-007 is PEER-1 type, imidazolium-based.

As listed in Table 5.7, we tested five types of Os-based catalysts with different ligands. Osmium in Os-01, 02 and 03 is at a higher valence state, while in Os-04 and 05 is at a lower valence state. The preliminary results show that Os-complexes don't have any reactivity in basic or neutral pure aqueous solution (entries 1-3). While, Oscomplexes with either higher valence or lower valence show significant reactivity on methane $\mathrm{C}-\mathrm{H}$ bond activation in sulfuric acid, even as diluted as 85\% (entries 4-11). However, when sulfuric acid was further diluted, the H/D exchange rate (C-H activation) was decreased, the same trend as observed in those $\mathrm{Pt} / \mathrm{D}_{2} \mathrm{SO}_{4}$ systems investigated before. More work needs be done on the fundamental understanding of the reaction mechanisms. We expect different mechanisms in $\mathrm{Os} / \mathrm{H}_{2} \mathrm{SO}_{4}$ systems and $\mathrm{Pt} / \mathrm{H}_{2} \mathrm{SO}_{4}$ systems due to their very different electronic structures and other intrinsic properties. Efforts have also been 
put on characterizing the actual state of the Os-complexes in the reaction liquid under the experimental conditions.

Comparison between entry 4 and 5 shows the effect of the reaction temperature. The exchange rate based on methane molecule decreased from 75 to $61 \%$ when the temperature increased from 220 to $250{ }^{\circ} \mathrm{C}$. However, the $\mathrm{H} / \mathrm{D}$ exchange rate of $\mathrm{H}$ atom at $220{ }^{\circ} \mathrm{C}$ was lower than that at $250^{\circ} \mathrm{C}$.

Figure 5.5 depicts the difference between entry 4 and 5 in more details by showing the percentages of different isotopomers. As the reaction temperature increases, i.e. as H/D exchange is promoted, more exchange will occur on the same molecule.

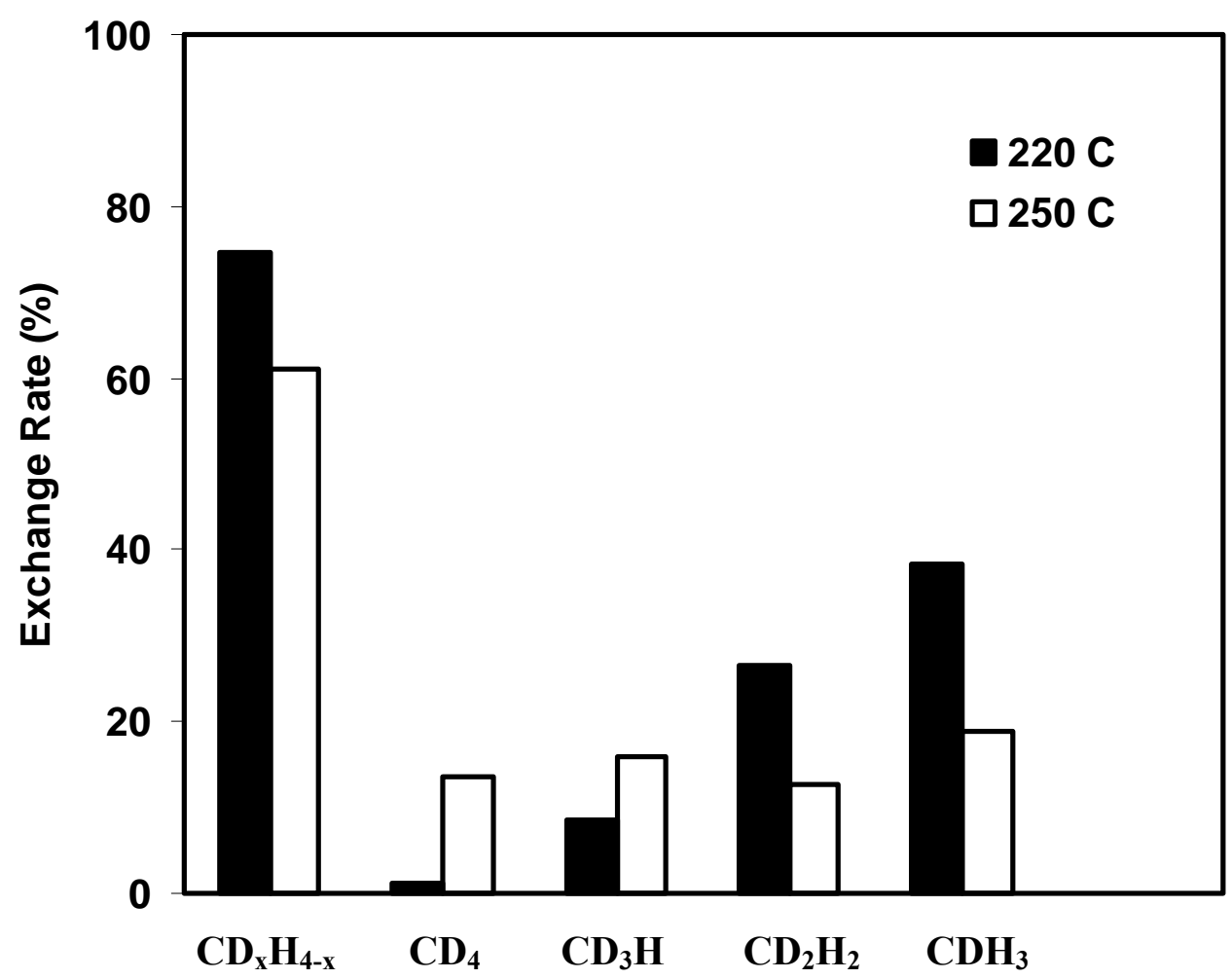

Figure 5.5: Ratios of different methane isotopomers to the original methane after $\mathrm{H} / \mathrm{D}$ exchange experiments in $\mathrm{Os}-03 / \mathrm{D}_{2} \mathrm{SO}_{4}(98 \%)$ at 220 and $250{ }^{\circ} \mathrm{C}$, respectively.

In order to replace $\mathrm{H}_{2} \mathrm{SO}_{4}$, we also tried $\mathrm{CF}_{3} \mathrm{SO}_{3} \mathrm{H}$, a super acid with acidity as 1000 times as that of $\mathrm{H}_{2} \mathrm{SO}_{4}$. We first conducted the experiment with Os-05/ $\mathrm{CF}_{3} \mathrm{SO}_{3} \mathrm{D} / \mathrm{CH}_{4}$ at $250{ }^{\circ} \mathrm{C}$ for 4 hour (entry 14) producing a large amount of $\mathrm{CO}_{2}$ and $\mathrm{SO}_{2}$ gases with very little $\mathrm{CH}_{4}$ left. Therefore, at this temperature, not only $\mathrm{C}-\mathrm{H}$ bond activation but also over-oxidization of $\mathrm{CH}_{4}$ occurred in this system. In addition, $\mathrm{CF}_{3} \mathrm{SO}_{3} \mathrm{D}$ was proved to have not only acidity but also significant oxidizing ability at $250{ }^{\circ} \mathrm{C}$. For the next step, we tried lower reaction temperatures to avoid over-oxidization while to keep reasonable reactivity on $\mathrm{C}-\mathrm{H}$ activation. We found that, almost no $\mathrm{H} / \mathrm{D}$ exchange 
occurred at $150{ }^{\circ} \mathrm{C}$ (entry 12), while some $\mathrm{H} / \mathrm{D}$ exchange occurred at $200{ }^{\circ} \mathrm{C}$. Experiments using $\mathrm{CF}_{3} \mathrm{SO}_{3} \mathrm{H}$ instead of $\mathrm{CF}_{3} \mathrm{SO}_{3} \mathrm{D}$ need to be run for further identify the oxidized product. At the same, some oxidants can be introduced to this system wishing to get stable intermediate oxidized product of methane, for example $\mathrm{CH} 3 \mathrm{CF}_{3} \mathrm{SO}_{3}$, which can be further converted to $\mathrm{CH}_{3} \mathrm{OH}$.

In a short summary, Os-complexes have shown very good reactivity in $\mathrm{C}-\mathrm{H}$ activation of methane, which makes them promising candidates for the catalysts of an efficient system in methane to methanol conversion. Both the components of the reaction system and the experimental conditions need to be further tuned for better results. Therefore, we further advanced our efforts to the effects of ionic liquids on $\mathrm{Os} / \mathrm{H}_{2} \mathrm{SO}_{4}$ systems (Table 5.8).

Table 5.8: Effects of ionic liquids on $\mathrm{C}-\mathrm{H}$ activation of methane catalyzed by $\mathrm{Os}-04$ and $\mathrm{Os}-05$ in sulfuric acid $(98$ and $85 \%)$ at $250{ }^{\circ} \mathrm{C}$ for $4 \mathrm{~h}$.

\begin{tabular}{|c|c|c|c|c|c|}
\hline \multirow{2}{*}{ Entry } & \multirow{2}{*}{ Catalyst } & \multirow{2}{*}{$\mathbf{D}_{\mathbf{2}} \mathbf{S O 4}$} & \multirow{2}{*}{ Ionic Liquid } & \multicolumn{2}{|c|}{ H/D Exchange Ratio (\%) } \\
\cline { 5 - 6 } & & & & CH4-based & H-based \\
\hline 1 & Os-04 & $98 \%$ & IL-007 (6:1) & 53 & 28 \\
\hline 2 & Os-04 & $98 \%$ & IL-048 (6:1) & 88 & 50 \\
\hline 3 & Os-04 & $85 \%$ & IL-007 (6:1) & 34 & 12 \\
\hline 4 & Os-04 & $85 \%$ & IL-048 (10:1) & 12 & 4 \\
\hline 5 & Os-05 & $98 \%$ & ----- & 83 & 45 \\
\hline 6 & Os-05 & $98 \%$ & IL-048 (6:1) & 101 & 79 \\
\hline 7 & Os-05 & $85 \%$ & ----- & 29 & 10 \\
\hline 8 & Os-05 & $85 \%$ & IL-007 (6:1) & 15 & 5 \\
\hline
\end{tabular}

We have tested two Os-complexes, one insoluble (Os-04) and one soluble in sulfuric acid (Os-05). For Os-04, ionic liquid is necessary for dissolving the catalyst (190 ${ }^{\circ} \mathrm{C}, 30 \mathrm{~min}$ ). In $98 \% \mathrm{D}_{2} \mathrm{SO}_{4}$, the $\mathrm{H} / \mathrm{D}$ exchange ratio in the system with IL-048 (PEER 6 type) is around $40-50 \%$ higher than that in the system with IL-007 (PEER 1 type) (both at mole ratio of 6:1); While, in $85 \% \mathrm{D}_{2} \mathrm{SO}_{4}$, IL-048 (10:1) was found to result in a lower $\mathrm{H} / \mathrm{D}$ exchange ratio than IL-007 (6:1). In case of Os-05, IL-048 was found to increase the $\mathrm{H} / \mathrm{D}$ exchange ratio compared to the system without IL in $98 \% \mathrm{D}_{2} \mathrm{SO}_{4}$, but to decrease the $\mathrm{H} / \mathrm{D}$ exchange ratio in $85 \% \mathrm{D}_{2} \mathrm{SO}_{4}$. Therefore, more work need to be done to identify the most efficient compositions of the reaction media as well as to understand the mechanisms of the interactions between ionic liquid, sulfuric acid and Os-based catalysts.

As the initial effort to study the mechanisms in $\mathrm{C}-\mathrm{H}$ activation of methane catalyzed by the $\mathrm{Os} / \mathrm{H}_{2} \mathrm{SO}_{4}$ system we tested the selectivity of Os-based catalysts on C-H activation with [bmim]-ionic liquid as the model compound. 
Table 5.9: $\mathrm{H} / \mathrm{D}$ exchange at different $\mathrm{C}-\mathrm{H}$ sites of $[\mathrm{bmim}]$ - ionic liquid in $\mathrm{Os} /[\mathrm{bmim}] \mathrm{Cl}_{2} / \mathrm{D}_{2} \mathrm{SO}_{4}(98 \%)$ quantified by ${ }^{1} \mathrm{H}$ NMR with $\mathrm{D}_{2} \mathrm{SO}_{4}(\mathbf{9 8 \%})$ as solvent and $\mathrm{CH}_{3} \mathrm{COOH}$ as internal standard.

\begin{tabular}{|c|c|c|c|c|c|}
\hline \multirow{2}{*}{ Catalyst } & \multirow{2}{*}{ Temperature } & \multirow{2}{*}{ Activation Site } & \multicolumn{3}{|c|}{ Exchange \% } \\
\hline & & & $4 \mathrm{~h}$ & $8 \mathrm{~h}$ & $12 \mathrm{~h}$ \\
\hline \multirow{10}{*}{ Os-01 } & \multirow{5}{*}{$200{ }^{\circ} \mathrm{C}$} & $\mathrm{N}-\mathbf{C H}_{3}$ & 2 & -3 & ---- \\
\hline & & $\mathrm{N}-\mathrm{CH}_{2}-\mathrm{CH}_{2}-\mathrm{CH}_{2}-\mathrm{CH}_{3}$ & -2 & -6 & ---- \\
\hline & & $\mathrm{N}-\mathrm{CH}_{2}-\mathrm{CH}_{2}-\mathrm{CH}_{2}-\mathrm{CH}_{3}$ & -1 & -2 & ---- \\
\hline & & $\mathrm{N}-\mathrm{CH}_{2}-\mathrm{CH}_{2}-\mathbf{C H}_{2}-\mathrm{CH}_{3}$ & -1 & -3 & ---- \\
\hline & & $\mathrm{N}-\mathrm{CH}_{2}-\mathrm{CH}_{2}-\mathrm{CH}_{2}-\mathbf{C H}_{3}$ & 6 & 8 & ---- \\
\hline & \multirow{5}{*}{$220^{\circ} \mathrm{C}$} & $\mathrm{N}-\mathbf{C H}_{3}$ & 11 & 15 & ---- \\
\hline & & $\mathrm{N}-\mathrm{CH}_{2}-\mathrm{CH}_{2}-\mathrm{CH}_{2}-\mathrm{CH}_{3}$ & 10 & 16 & ---- \\
\hline & & $\mathrm{N}-\mathrm{CH}_{2}-\mathbf{C H}_{2}-\mathrm{CH}_{2}-\mathrm{CH}_{3}$ & 12 & 11 & ---- \\
\hline & & $\mathrm{N}-\mathrm{CH}_{2}-\mathrm{CH}_{2}-\mathbf{C H}_{2}-\mathrm{CH}_{3}$ & 11 & 11 & ---- \\
\hline & & $\mathrm{N}-\mathrm{CH}_{2}-\mathrm{CH}_{2}-\mathrm{CH}_{2}-\mathbf{C H}_{3}$ & 27 & 39 & ---- \\
\hline \multirow{5}{*}{ Os-02 } & \multirow{5}{*}{$220^{\circ} \mathrm{C}$} & $\mathrm{N}-\mathbf{C H}_{3}$ & 7 & 15 & 26 \\
\hline & & $\mathrm{N}-\mathrm{CH}_{2}-\mathrm{CH}_{2}-\mathrm{CH}_{2}-\mathrm{CH}_{3}$ & 6 & 18 & 29 \\
\hline & & $\mathrm{N}-\mathrm{CH}_{2}-\mathbf{C H}_{2}-\mathrm{CH}_{2}-\mathrm{CH}_{3}$ & 10 & 19 & 29 \\
\hline & & $\mathrm{N}-\mathrm{CH}_{2}-\mathrm{CH}_{2}-\mathbf{C H}_{2}-\mathrm{CH}_{3}$ & 9 & 18 & 30 \\
\hline & & $\mathrm{N}-\mathrm{CH}_{2}-\mathrm{CH}_{2}-\mathrm{CH}_{2}-\mathbf{C H}_{3}$ & 24 & 44 & 59 \\
\hline
\end{tabular}

Note:

(1) Reaction conditions: Catalyst: $20 \mathrm{mM}$; [bmim] Cl: $100 \mathrm{mM}$; $\mathrm{D}_{2} \mathrm{SO}_{4}: 98 \%$

Oil bath with magnetic stirring in glass vials

(2) ${ }^{1} \mathrm{H}-\mathrm{NMR}$ : Solvent: $\mathrm{D}_{2} \mathrm{SO}_{4}(98 \%)$; Internal Standard: $\mathrm{CH}_{3} \mathrm{COOH}$

(3) Negative values for Os- 01 at $200{ }^{\circ} \mathrm{C}$ reflect the scattering of the measurements.

Such results can be read as no significant exchange occurred at these sites.

As described in Table 5.9, experiments to identify H/D exchange between [bmim] and $\mathrm{D}_{2} \mathrm{SO}_{4}(98 \%)$ catalyzed by two different Os-compounds were conducted at 200 and $220^{\circ} \mathrm{C}$ for 4,8 and $12 \mathrm{~h}$, respectively. Quantification was conducted by ${ }^{1} \mathrm{H}-\mathrm{NMR}$ with $\mathrm{D}_{2} \mathrm{SO}_{4}$ as solvent and $\mathrm{CH}_{3} \mathrm{COOH}$ as internal standard. The integrated peak area is proportional to the amount of $-\mathrm{H}$ with certain chemical shift. Most of the $-\mathrm{H}$ on the ring were exchanged in each experiment. At $200^{\circ} \mathrm{C}$, no significant exchange was observed; while, at $220^{\circ} \mathrm{C}, \mathrm{H} / \mathrm{D}$ exchange occurred at all $\mathrm{C}-\mathrm{H}$ sites on the [bmim] side chains with the terminal $-\mathrm{CH}_{3}$ site as the preferred attacking site. $\mathrm{H} / \mathrm{D}$ exchange at the other alkyl sites was similar and much smaller than that at the terminal site. Though, the H/D exchange at $220{ }^{\circ} \mathrm{C}$ increased with longer reaction time, the exchange rate obviously decreased for Os-01. In $\mathrm{H} / \mathrm{D}$ exchange experiments between $\mathrm{CH}_{4}$ and $\mathrm{D}_{2} \mathrm{SO}_{4}$ catalyzed by 
Os-01 and Os-02, dark coating was observed on the walls of the gold tube reactors for Os-01, but not for Os-02. Such catalyst deactivation is consistent with the decreased H/D exchange rate in the selectivity experiments. On the other hand, no $\mathrm{NH}^{4+}$ peaks were observed on the NMR spectra of the Os-01 system (Because Os-02 is an aminecontaining compound, small $\mathrm{NH}^{4+}$ peaks were detected in this system.) indicating that the [bmim] Cl ionic liquid is very stable in $\mathrm{D}_{2} \mathrm{SO}_{4}(98 \%)$ at $220{ }^{\circ} \mathrm{C}$ with the presence of Oscatalyst. 


\section{CHAPTER SIX: HIGH-TEMPERATURE SHILOV-LIKE SYSTEM}

\subsection{SUMMARY}

Both experimental and theoretical work has shown that the PEER system, the $\mathrm{Pt} / \mathrm{IL} / \mathrm{H}_{2} \mathrm{SO}_{4}$ ternary system, is a combination of the Shilov system and the Catalytica system, while it is much closer to the Shilov one. As depicted in Figure 6.1, both the relative stability and the charge distribution of the $\mathrm{C}-\mathrm{H}$ activation product of the PEER system are between those of the Shilov and Catalytica systems, but closer to the former one.

\section{Mulliken atomic charges}

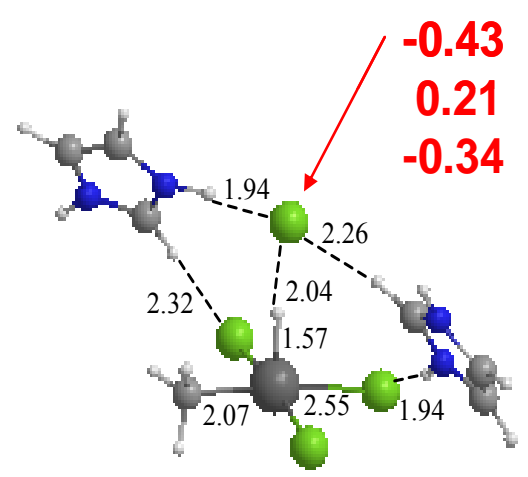

10.8

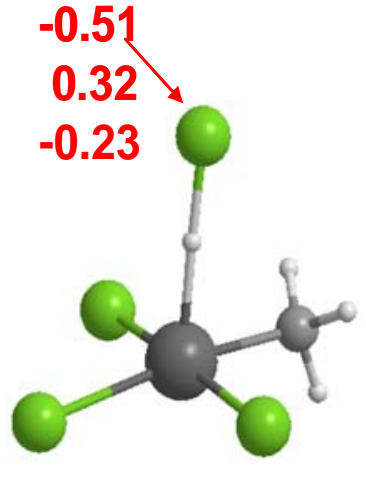

12.7

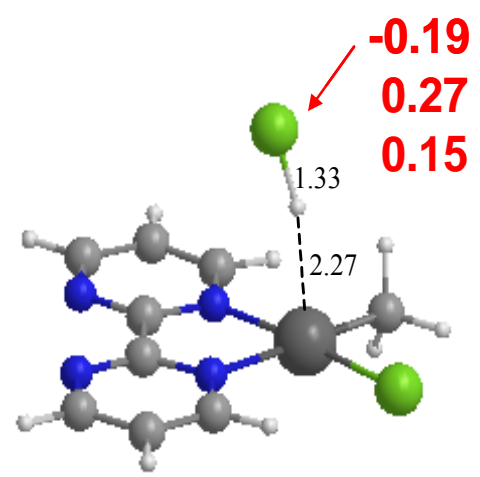

19.6
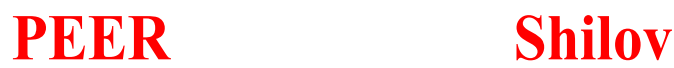

\section{Periana}

Figure 6.1: Comparison of the $\mathrm{C}-\mathrm{H}$ activation products of the PEER, Shilov and Periana-Catalytica system.

As the first breakthrough in direct methane to methanol conversion, the Shilov system has three major drawbacks: catalyst deactivation through $\mathrm{Pt}(0)$ precipitation, expensive Pt(IV) oxidant and low conversion rate. However, compared to the Catalytica system, the Shilov system is operated under a mild condition (water or acetic acid solution v.s. concentrated sulfuric acid or even oleum) and the product separation is easier. As described above, our PEER system might be a Shilov-like system. Therefore, significant efforts were taken to investigate a high temperature Shilov-like system targeting at stabilizing the Pt-catalyst, replacing the Pt(IV) oxidant by some other cheap ones and increasing the reaction rate with the application of ionic liquids at relatively high temperatures. With our unique experimental apparatus, we have been able to carry out experiments with the Shilov-like system at $250 \sim 300{ }^{\circ} \mathrm{C}$ and successfully stabilize the Pt-catalysts. In addition, $\mathrm{FeCl}_{3}$ and $\mathrm{CuCl}_{2}$ have been found to present comparable, if not superior, oxidization performance for direct methane oxidation. 


\subsection{C-H ACTIVATION IN THE SHILOV SYSTEM}

One of the most promising advantages of the Shilov's system compared to the Catalytica system is that the $\mathrm{C}-\mathrm{H}$ activation is much faster at the same temperature. Therefore, the first priority in the study of the Shilov system is to increase the reaction temperature to achieve desirable $\mathrm{C}-\mathrm{H}$ activation rate while preventing catalyst precipitation. Table 6.1 through Table 6.3 present several series of $\mathrm{H} / \mathrm{D}$ exchange experiments to explore the effects of acids, ionic liquids, and catalyst valance on $\mathrm{C}-\mathrm{H}$ activation in the Shilov's system with some preliminary conclusions followed.

Table 6.1: H/D Exchange Experiments at $140{ }^{\circ} \mathrm{C}$ in Shilov's System

\begin{tabular}{|c|c|c|c|c|c|c|c|}
\hline \multirow[t]{2}{*}{ Entry } & \multirow[t]{2}{*}{ Catalyst } & \multirow{2}{*}{$\begin{array}{l}\text { Reaction } \\
\text { Media }\end{array}$} & \multirow{2}{*}{$\begin{array}{l}\text { Ionic Liquid } \\
(6: 1)\end{array}$} & \multirow{2}{*}{$\begin{array}{l}\text { Time } \\
\text { (h) }\end{array}$} & \multicolumn{2}{|c|}{ H/D Exchange Ratio (\%) } & \multirow{2}{*}{$\begin{array}{l}\text { TON } \\
\text { C-H }\end{array}$} \\
\hline & & & & & $\mathrm{CD}_{\mathrm{x}} \mathrm{H}_{4-\mathrm{x}}$ & $\mathrm{CDH}_{3}$ & \\
\hline 1 & \multirow{10}{*}{$\mathrm{K}_{2} \mathrm{PtCl}_{4}$} & \multirow{3}{*}{$\mathrm{D}_{2} \mathrm{O}$} & ------- & 4 & 7.2 & 3.3 & 0.5 \\
\hline 2 & & & {$\left[\right.$ pyrz] $[\mathrm{HSO} 4]^{\mathrm{H}}$} & 4 & 1.9 & 1.8 & 0.1 \\
\hline 3 & & & {$\left[\right.$ pyrz] $[\mathrm{HSO} 4]^{\mathrm{R}}$} & 4 & 2.0 & 1.7 & 0.1 \\
\hline 4 & & \multirow{5}{*}{$\begin{array}{c}\mathrm{D}_{2} \mathrm{O}+ \\
\mathrm{CD}_{3} \mathrm{COOD} \\
(30 \%)\end{array}$} & ------ & 4 & 13.0 & 5.1 & 2.1 \\
\hline 5 & & & ------- & 12 & 13.1 & 5.0 & 2.1 \\
\hline 6 & & & {$[1 \mathrm{mim}] \mathrm{Cl}^{\mathrm{H}}$} & 4 & 2.2 & 1.7 & 0.4 \\
\hline 7 & & & {$[1 \mathrm{mim}][\mathrm{HSO} 4]^{\mathrm{H}}$} & 4 & 2.2 & 1.8 & 0.4 \\
\hline 8 & & & {$[1 \mathrm{mim}] \mathrm{Cl}^{\mathrm{R}}$} & 4 & 3.1 & 2.2 & 0.5 \\
\hline 10 & & $\begin{array}{c}\mathrm{CD}_{3} \mathrm{COOD} \\
(30 \%)+\mathrm{DCl} \\
(8.4 \mathrm{M})\end{array}$ & & 4 & 2.8 & 2.0 & 0.47 \\
\hline 11 & & $\begin{array}{c}\mathrm{CD}_{3} \mathrm{COOD} \\
(30 \%)^{+} \\
\mathrm{D}_{2} \mathrm{SO}_{4}(1 \mathrm{M})\end{array}$ & & 4 & 2.9 & 1.0 & 0.48 \\
\hline 12 & & $\mathrm{D}_{2} \mathrm{O}+$ & -------- & 12 & 19.4 & 7.3 & 3.2 \\
\hline 13 & $\mathrm{H}_{2} \mathrm{PtCl}_{6}$ & $\begin{array}{c}\mathrm{CD}_{3} \mathrm{COOD} \\
(30 \%)\end{array}$ & {$[1 \mathrm{mim}] \mathrm{Cl}^{\mathrm{R}}$} & 12 & 6.2 & 3.5 & 1.0 \\
\hline 14 & $\begin{array}{c}\mathrm{K}_{2} \mathrm{PtCl}_{4} \\
+ \\
\mathrm{H}_{2} \mathrm{PtCl}_{6}\end{array}$ & $\begin{array}{c}\mathrm{D}_{2} \mathrm{O}+ \\
\mathrm{CD}_{3} \mathrm{COOD} \\
(30 \%)\end{array}$ & --------- & 12 & 31.4 & 8.3 & 0.8 \\
\hline 15 & $\mathrm{~K}_{2} \mathrm{PtCl}_{4}$ & $\begin{array}{c}\mathrm{D}_{2} \mathrm{O}+ \\
\mathrm{F}_{3} \mathrm{COOD} \\
(20 \%)\end{array}$ & --------- & 5 & 18.0 & 9.9 & 2.6 \\
\hline
\end{tabular}

Note:

(1) Systematic Error: $+2 \%$

(2) Shaded: Coating

(3) Experimental conditions: Gold tube experiments were conducted at $140{ }^{\circ} \mathrm{C}$ with 3700 Psi external hydraulic pressure. 
(4) For Entries 1-3 and 15: $\mathrm{K}_{2} \mathrm{PtCl}_{4}(50 \mathrm{mM})$; for Entry 14: $\mathrm{K}_{2} \mathrm{PtCl}_{4}(20 \mathrm{mM})+\mathrm{H}_{2} \mathrm{PtCl}_{6}(100 \mathrm{mM})$; for other entries: $\mathrm{K}_{2} \mathrm{PtCl}_{4}$ was at $20 \mathrm{mM}$.

(5) $\mathrm{CH}_{4}$ loaded at $50 \mathrm{Psi}$ (about $100 \mu \mathrm{mol}$ )

(6) $[\mathrm{pyrz}]\left[\mathrm{HSO}_{4}\right]^{\mathrm{H}}$ : the ionic liquid and the catalyst were heated at $150{ }^{\circ} \mathrm{C}$ for $30 \mathrm{~min}$, and added into the $\mathrm{CD}_{3} \mathrm{COOD}$ solution after cooling down.

[pyrz] $\left[\mathrm{HSO}_{4}\right]^{\mathrm{R}}$ : the ionic liquid, the catalyst and the $\mathrm{CD}_{3} \mathrm{COOD}$ solution were mixed together at room temperature.

Table 6.2; H/D Exchange Experiments at $185^{\circ} \mathrm{C}$ in Shilov's System

\begin{tabular}{|c|c|c|c|c|c|c|c|}
\hline \multirow[t]{2}{*}{ Entry } & \multirow[t]{2}{*}{ Catalyst } & \multirow{2}{*}{$\begin{array}{l}\text { Reaction } \\
\text { Media }\end{array}$} & \multirow{2}{*}{$\begin{array}{c}\text { Ionic Liquid } \\
(6: 1)\end{array}$} & \multirow{2}{*}{$\begin{array}{l}\text { Time } \\
\text { (h) }\end{array}$} & \multicolumn{2}{|c|}{ H/D Exchange Ratio (\%) } & \multirow{2}{*}{$\begin{array}{l}\text { TON } \\
\text { C-H } \\
\end{array}$} \\
\hline & & & & & $\mathrm{CD}_{\mathrm{x}} \mathrm{H}_{4-\mathrm{x}}$ & $\mathrm{CDH}_{3}$ & \\
\hline 16 & \multirow{5}{*}{$\mathrm{K}_{2} \mathrm{PtCl}_{4}$} & $\begin{array}{c}\mathrm{D}_{2} \mathrm{O}(30 \%)+ \\
\mathrm{DCl}(8.4 \mathrm{M})\end{array}$ & & 24 & 54.1 & 11.8 & 30.6 \\
\hline 17 & & \multirow{2}{*}{$\begin{array}{c}\mathrm{CD}_{3} \mathrm{COOD} \\
(30 \%)+\mathrm{DCl} \\
(8.4 \mathrm{M}) \\
\end{array}$} & & 4 & 22.6 & 11.2 & 3.8 \\
\hline 18 & & & & 24 & 66.5 & 22.5 & 37.7 \\
\hline 19 & & $\begin{array}{c}\mathrm{D}_{2} \mathrm{O}+ \\
\mathrm{CD}_{3} \mathrm{COOD} \\
(30 \%)\end{array}$ & {$[1 \mathrm{mim}] \mathrm{Cl}$} & 4 & 9.5 & 5.0 & 1.6 \\
\hline 21 & & $\begin{array}{c}\mathrm{CD}_{3} \mathrm{COOD} \\
(30 \%)+\mathrm{D}_{2} \mathrm{~S} \\
\mathrm{O}_{4}(4.2 \mathrm{M})\end{array}$ & & 4 & 35.5 & 18.0 & 5.9 \\
\hline 22 & \multirow{2}{*}{$\mathrm{H}_{2} \mathrm{PtCl}_{6}$} & $\begin{array}{c}\mathrm{D}_{2} \mathrm{O}+ \\
\mathrm{CD}_{3} \mathrm{COOD} \\
(30 \%)\end{array}$ & {$[1 \mathrm{mim}] \mathrm{Cl}$} & 4 & 15.9 & 8.8 & 2.7 \\
\hline 23 & & $\begin{array}{c}\mathrm{CD}_{3} \mathrm{COOD}( \\
30 \%)+\mathrm{DCl}( \\
8.4 \mathrm{M})\end{array}$ & & 4 & 7.8 & 4.7 & 1.3 \\
\hline 24 & $\begin{array}{c}\operatorname{Pt}(0) \\
(30 \mathrm{mM})\end{array}$ & $\begin{array}{c}\mathrm{D}_{2} \mathrm{O}+ \\
\mathrm{CD}_{3} \mathrm{COOD} \\
(30 \%) \\
\end{array}$ & & 4 & 2.0 & 1.7 & 0.2 \\
\hline 25 & $\begin{array}{c}\operatorname{Pt}(0) \\
(24 \mathrm{mM})\end{array}$ & $\begin{array}{c}\mathrm{CD}_{3} \mathrm{COOD}( \\
30 \%)+\mathrm{DCl}( \\
8.4 \mathrm{M})\end{array}$ & & 4 & 17.5 & 9.0 & 2.4 \\
\hline 26 & $\begin{array}{c}\operatorname{Pt}(0) \\
(20 \mathrm{mM})\end{array}$ & $\begin{array}{l}\mathrm{D}_{2} \mathrm{SO}_{4} \\
(98 \%)\end{array}$ & & 4 & 2.8 & 2.6 & $\begin{array}{l}\mathrm{SO} 2 \\
\text { and } \\
\mathrm{CO} 2\end{array}$ \\
\hline
\end{tabular}

Note:

(1) Experimental conditions: Gold tube experiments were conducted at $185^{\circ} \mathrm{C}$ with 3700 Psi external hydraulic pressure.

(2) For Entries 16 and 18: $\mathrm{K}_{2} \mathrm{PtCl}_{4}(5 \mathrm{mM})$; for other Entries 17, 19-23: $\mathrm{K}_{2} \mathrm{PtCl}_{4}(20 \mathrm{mM})$.

(3) $\mathrm{CH}_{4}$ loaded at 50 Psi Entries 1, 3:about $85 \mu \mathrm{mol}$; the other entries: about 100umol 
Table 6.3: H/D Exchange Experiments at $185{ }^{\circ} \mathrm{C}$ with Varied $\mathrm{Cl}^{-}$Concentration $\left(\mathrm{K}_{2} \mathrm{PtCl}_{4}(20 \mathrm{mM})+\right.$ $\left.30 \% \mathrm{CD}_{3} \mathrm{COOD}\right)$

\begin{tabular}{|c|c|c|c|c|c|}
\hline \multirow{2}{*}{ Entry } & \multirow[t]{2}{*}{ Stabilizer } & \multirow{2}{*}{$\begin{array}{l}{\left[\mathrm{Cl}^{-}\right]} \\
(\mathrm{M})\end{array}$} & \multicolumn{2}{|c|}{ H/D Exchange Ratio (\%) } & \multirow{2}{*}{ Coating } \\
\hline & & & $\mathrm{CD}_{\mathrm{x}} \mathrm{H}_{4-\mathrm{x}}$ & $\mathrm{CDH}_{3}$ & \\
\hline 27 & \multirow{7}{*}{$\mathrm{DCl}$} & 0.7 & 61.0 & 29.0 & Siliver \\
\hline 28 & & 2.8 & 60.7 & 33.7 & Silver \\
\hline 29 & & 4.2 & 61.1 & 22.5 & Silver \\
\hline 30 & & 4.9 & 65.5 & 22.6 & Very Slight Silver \\
\hline 31 & & 5.6 & 58.8 & 22.0 & No \\
\hline 32 & & 6.3 & 43.3 & 18.8 & No \\
\hline 33 & & 8.4 & 22.6 & 11.2 & No \\
\hline 34 & $\mathrm{KCl}$ & $4 *$ & 8.6 & 5.2 & Silver \\
\hline 35 & $\begin{array}{c}\mathrm{KCl} \text { with } 10 \% \\
\mathrm{CF}_{3} \mathrm{SO}_{3} \mathrm{D}\end{array}$ & $4^{*}$ & 20.7 & 10.6 & Silver \\
\hline
\end{tabular}

Note:

(4) Experiments were conducted in gold reactors with 3700 Psi external hydraulic pressure.

(1) $\sim 100$ umol of $\mathrm{CH}_{4}$ and $0.3 \mathrm{~mL}$ of reaction liquid with $20 \mathrm{mM} \mathrm{K} 2 \mathrm{PtCl} 4$ were loaded.

(2) Except an 8 hour reaction for Entry 28, the reaction time of the other reactions was 4 hour.

(3) For Entries 34 and 35, 4M KCl solutions were prepared, however only part of $\mathrm{KCl}$ was dissolved.

\section{Preliminary Conclusions:}

\section{1) Effects of $\mathrm{CH} 3 \mathrm{COOH}$}

As claimed by Shilov, ${ }^{2(a)}$ at least 30 times acceleration should be caused by the addition of $\mathrm{CH}_{3} \mathrm{COOH}$ as the combined results of enhanced solubility of $\mathrm{CH}_{4}$ and chelate formation. However, Shilov only published data from experiments with the addition of $50 \%$ or $30 \%$ acetic acid, and the choice of concentration was claimed as for convenience. 2(a), 4, 5 We took these claims as assumptions and conducted experiments mainly with $30 \% \mathrm{CH}_{3} \mathrm{COOH}$ working on the stabilization of the catalyst and the improvement of the $\mathrm{H} / \mathrm{D}$ exchange rate.

We do observe enhanced H/D exchange conversion from entries 1 v.s. 4. However, since $\operatorname{Pt}(0)$ coating was also observed, precise quantification of the enhancement is not achievable. One possibility is that the addition of acetic acid could slow down the Pt precipitation resulting in higher exchange ratio. For Entries 2, 3 and 6, 7 , 8, the addition of ionic liquids stabilized the $\mathrm{Pt}(\mathrm{II})$, while slowing down the H/D exchange. Considering our experimental scatter, the differences caused by $\mathrm{CH}_{3} \mathrm{COOH}$ addition still can not be quantified. The experiments at higher temperature with higher conversion (Entries 16 v.s 18) indicate that the effect of acetic acid probably is not as significant as claimed by Shilov.

2) Deactivation of catalysts 
For those entries with shades on the TONs (Turn Over Number), coatings were observed on the inside wall of the gold tube reactors. Upon the formation of coating, the catalyst is deactivated as indicated by entries 4 v.s.5, further heating did not produce more exchange.

3) The effects of ionic liquids

Entries 1-8, 12-13 showed that the addition of ionic liquids can prevent $\mathrm{Pt}(\mathrm{II})$ from precipitation at the price of slowing down the H/D exchange rate. However, one concern is that, when ionic liquid was present, H/D exchange also occurred on them, which could also inhibit the H/D exchange on methane.

When the experimental temperature was increased to around $185{ }^{\circ} \mathrm{C}$, coatings were also formed even with addition of ionic liquids. Limited by the stability of ILs, the experimental temperature can not exceed $220^{\circ} \mathrm{C}$.

\section{4) Effects of $\mathrm{HCl}$}

The addition of $8.4 \mathrm{M} \mathrm{HCl}$ effectively prevents the coating formation while slowing down the exchange rate. However, at relatively high temperatures the exchange is fast enough compared to the following oxidation and/or functionalization steps. Therefore, application of $\mathrm{HCl}$ is an effective way for getting significant exchange rate at high temperatures without coating formation.

The stabilization effect of $\mathrm{HCl}$ can mainly be attributed to the addition of large amount of $\mathrm{Cl}^{-}$ions, which can inhibit the $\mathrm{Pt}(0)$ formation reaction $\left(2 \mathrm{PtCl}_{4}{ }^{2-}\right.$ $\left.\rightarrow \mathrm{Pt}(0)+\mathrm{PtCl}_{6}{ }^{2-}+2 \mathrm{Cl}^{-}\right)$as well as the $\mathrm{H} / \mathrm{D}$ exchange reaction. Therefore, the higher the reaction temperature is, the higher the $\mathrm{Cl}^{-}$concentration is required for acceptable catalyst lifetime. As presented in Table 4.3, about $5.6 \mathrm{M} \mathrm{Cl}^{-}$is necessary for prevent observable $\operatorname{Pt}(0)$ formation for a 4 hour experiment at $185^{\circ} \mathrm{C}$, which gives higher $\mathrm{H} / \mathrm{D}$ exchange rate than the other entries with higher $\mathrm{HCl}$ concentrations. Limited by the solubility, chloride salts are not as effective as $\mathrm{HCl}$ (Entries 34 and 35). In addition, the acidity of the solution also has some influences on the H/D exchange process.

5) Other acids

Entry 11 showed that $\mathrm{D}_{2} \mathrm{SO}_{4}$ could neither stabilize the catalyst nor accelerate the $\mathrm{H} / \mathrm{D}$ exchange (compared to Entry 4).

Entry 15 showed that H/D exchange also occurred in $20 \% \mathrm{~F}_{3} \mathrm{COOD}$ with $\mathrm{Pt}(0)$ coating observed on the gold tube reactor. In addition, the resulting TON is comparable to Entry 4 with $30 \% \mathrm{CD}_{3} \mathrm{COOD}$. Is it an indication of similar function due to $\mathrm{COO}^{-}$.

6) $\operatorname{Pt}(0), \operatorname{Pt}(\mathrm{II})$ and $\mathrm{Pt}(\mathrm{IV})$

Entries 13 v.s. 8 and 12 v.s. 4 suggested that at $140{ }^{\circ} \mathrm{C}$ more $\mathrm{H} / \mathrm{D}$ exchange occurred when Pt(IV) was added as catalyst instead of Pt(II). However, entries 17 and 23 showed an opposite trend. Anyway, all results are comparable at the same magnitude. Thus, we can conclude that $\mathrm{Pt}(\mathrm{IV})$ can also catalyze H/D exchange in methane or it is first reduced to $\mathrm{Pt}(\mathrm{II})$ to be effective. Coatings were observed without addition of stabilizer. However, it might be a slower precipitating process with $\mathrm{Pt}(\mathrm{IV})$. 
$\mathrm{Pt}(0)$ was observed active at high temperatures. And the addition of $\mathrm{HCl}$ actually enhanced the reaction according to Entries 24 and 25.

\subsection{KINETICS STUDY ON THE H/D EXCHANGE REACTION IN HIGH- TEMPERATURE SHILOV SYSTEM [K ${ }_{2}$ PTCL (5 MM) + CD $\mathrm{COOD}_{3}(30 \%)+$ DCL (9M WITH $\left.\left.\mathrm{D}_{2} \mathrm{O}\right)+\mathrm{CH}_{4}\right]$}

The previous investigations reported on H/D exchange in Shilov system were mostly limited at reaction temperature not higher than $120^{\circ} \mathrm{C}$ due to the poor stability of the Pt-catalyst. The low reaction rate and the reactor design lead to very low conversion ratio in those low temperature H/D exchange experiments. In our mini gold tube reactor, the application of 3700 psi hydraulic external pressure provides excellent contact between the $\mathrm{CH}_{4}$ molecules and the reaction liquid and assures $100 \%$ mass balance. In our study, the conversion ratio can reach $100 \%$ so that data of the whole range of exchange ratio can be achieved for kinetics study. A set of experiments with the same reaction conditions but varied reaction time were conducted to discover the kinetics of $\mathrm{H} / \mathrm{D}$ exchange in the High-Temperature-Shilov system (

Table 6.4 and Figure 6.2).

Multiple H-D exchange on methane has been observed and reported in low temperature Shilov system. A proposed mechanism for the occurrence of multiple H-D exchange involves the formation of methylene-platinum complex. While, another possibility is that the activation energy for the $\mathrm{CH}_{4}$ uptake step is comparable to that for the $\mathrm{C}-\mathrm{H}$ bond cleavage step. In this case, each $\mathrm{CH}_{4}$ uptake may result in more than one $\mathrm{C}$ $\mathrm{H}$ bond cleavage and thus $\mathrm{H}-\mathrm{D}$ exchange. Kinetics fitting may provide information on the activation energy for the generation of each isotopomers and thus provide clues on the activation mechanism. In order to get rid of the scatter caused by the actual amount of $\mathrm{CH}_{4}$ sealed in each gold tube reactor, the distribution of different exchange products, $\mathrm{CD}_{\mathrm{x}} \mathrm{H}_{4-\mathrm{x}}$ isotopomers relative to the total amount of exchange methane molecules is plotted in Figure 6.2(b), which can more accurately reflect the ratio of multiple exchange. Work on kinetics fitting has already kicked out and will be one of the tasks for next quarter.

Table 6.4: $\mathrm{H} / \mathrm{D}$ Exchange in High-Temperature-Shilov system $\left[\mathrm{K}_{2} \mathrm{PtCl}(5 \mathrm{mM})+\mathrm{CD}_{3} \mathrm{COOD}(30 \%)+\right.$ $\mathrm{DCl}\left(9 \mathrm{M}\right.$ with $\left.\left.\mathrm{D}_{2} \mathrm{O}\right)+\mathrm{CH}_{4}\right]$ at $200{ }^{\circ} \mathrm{C}$ for varied reaction time

\begin{tabular}{|c|c|c|c|c|c|c|c|}
\hline & \multirow{2}{*}{ Entry } & \multirow{2}{*}{ Time(h) } & \multicolumn{6}{|c|}{ H/D Exchange Ratio (\%) } \\
\cline { 3 - 8 } & & $\underline{\mathbf{C D}}_{\mathbf{x}} \underline{\mathbf{H}}_{\mathbf{4 - x}}$ & $\frac{\mathbf{D}}{\mathbf{H}}$ & $\mathbf{C D}_{\mathbf{4}}$ & $\mathbf{C D}_{\mathbf{3}} \mathbf{H}$ & $\mathbf{C D}_{\mathbf{2}} \mathbf{H}_{\mathbf{2}}$ & $\mathbf{C D H}_{\mathbf{3}}$ \\
\hline 1 & 4 & 4.90 & 1.58 & 0.00 & 0.00 & 1.43 & 3.47 \\
\hline 2 & 8 & 13.09 & 5.50 & 0.00 & 1.96 & 4.99 & 6.14 \\
\hline 3 & 8 & 22.72 & 9.81 & 0.00 & 3.86 & 8.78 & 10.07 \\
\hline 4 & 20 & 59.32 & 32.67 & 8.69 & 14.41 & 16.45 & 19.77 \\
\hline 5 & 24 & 90.99 & 62.56 & 26.48 & 30.23 & 19.34 & 14.93 \\
\hline 6 & 32 & 87.51 & 58.23 & 24.81 & 26.31 & 18.38 & 18.01 \\
\hline 7 & 120 & 100 & 100 & 86.93 & 13.07 & 0 & 0 \\
\hline
\end{tabular}



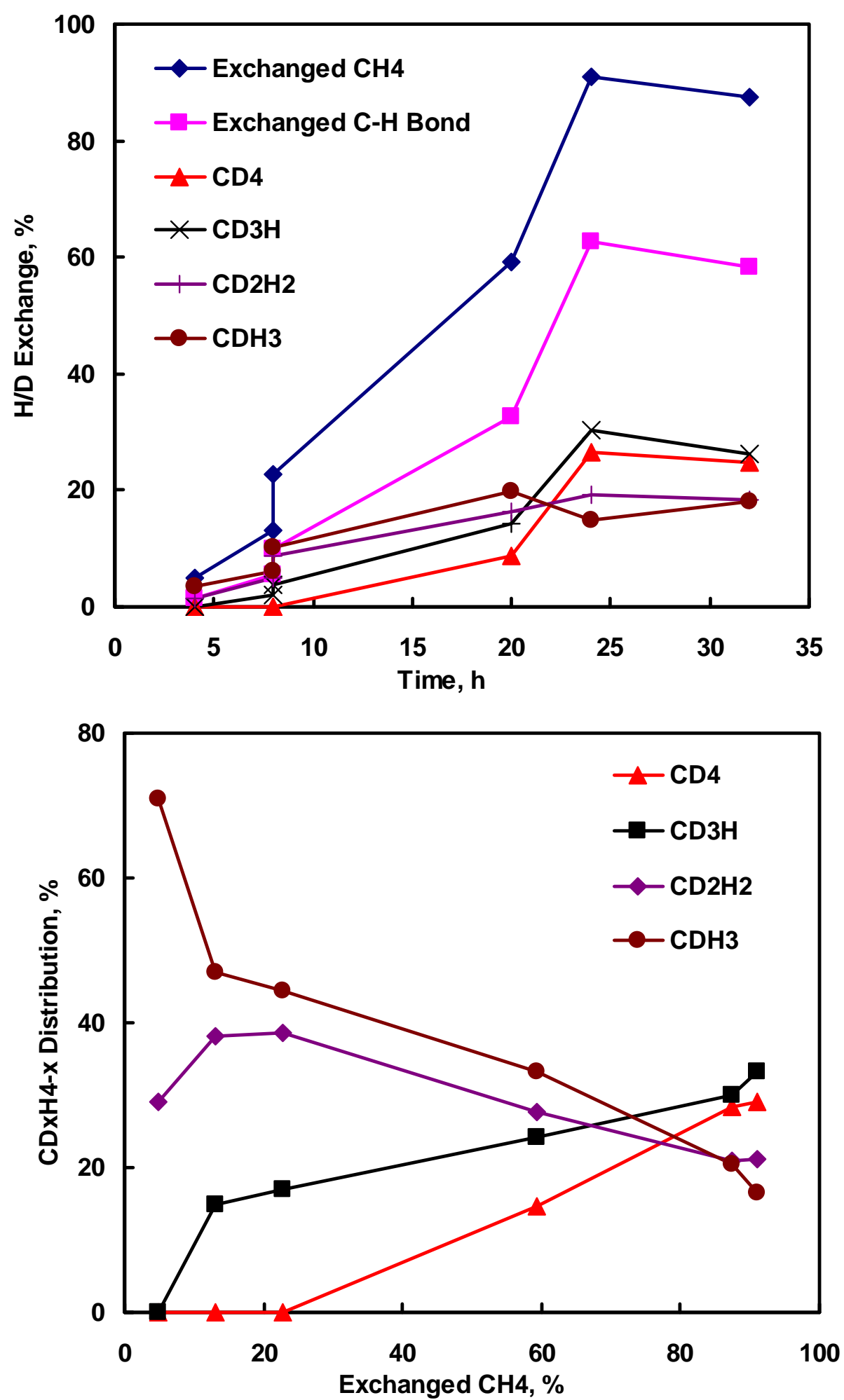

Figure 6.2: $\mathrm{CD}_{\mathrm{x}} \mathrm{H}_{4-\mathrm{x}}$ isotopomer distribution of methane $\mathrm{H} / \mathrm{D}$ exchange experiments in [ $\mathrm{K}_{2} \mathrm{PtCl}(5$ $\mathrm{mM})+\mathrm{CD}_{3} \mathrm{COOD}(30 \%)+\mathrm{DCl}\left(9 \mathrm{M}\right.$ with $\left.\left.\mathrm{D}_{2} \mathrm{O}\right)+\mathrm{CH}_{4}\right]$ at $200{ }^{\circ} \mathrm{C}$ (a) exchange ratio v.s. time and (b) relative isotopomer distribution. 
Besides the thermodynamic study through molecular modeling computations, we have also conducted empirical kinetic study on methane H/D exchange in our HT-Shilov system. The quantum mechanical computation, the emprical kinetic fitting and the experimental observation can crosscheck each other as well as give integrated understanding of the underneath mechanisms. Such fundamental mechanistic understandings will be greatly helpful in optimizing the catalytic system and the experimental conditions.

As defined in

Table 6.5, there are totally 13 possible reactions during the H/D exchange experiments in Shilov system among which Reactions 1, 6 and 10 depict the generation of the precursors for the final deuterated methane isotopomer products. For each reaction, the rate constant $\mathrm{k}$ is determined by three factors (temperature $\mathrm{T}$, frequency $\mathrm{A}_{\mathrm{f}}$, and activation energy $\mathrm{E}_{\mathrm{a}}$ ) as in $k=A_{f} e^{-E_{a} / R T}$. Because $100 \%$ mass balance is guaranteed for experiments conducted in our mini gold tube reactors, distribution of the 5 different methane isotopomers is only decided by the rate constant of each reaction and the reaction time. Employing the data listed in

Table 6.4, kinetic fitting has been preceded with a program named PMOD. Several simplifications are made for the fitting in order to achieve some preliminary results based on the limited experimental data. Because the frequency factor and the activation energy interact with each other and all experiments were conducted at the same temperature, we set the frequency factor for each reaction as a constant of $10^{9}$. In addition, the reactions producing those precursors are expected to be similar with each other but relatively fast compared to the following reactions producing the methane isotopomers, so that the activation energies for Reactions 1, 6 and 10 are all set as 20 $\mathrm{kCal} / \mathrm{mol}$.

Table 6.5 also lists one set of the fitting results of the activation energies and the coefficients. As presented in Figure 6.3, the calculated methane isotopomer distribution agrees pretty well with the experimental data. Though, this empirical kinetics study is still very inconclusive, it suggests that, for each exchange event single or double H/D exchange is the majority, while exchange with three or four H/D pairs is unlikely to happen under our experimental conditions.

Rudakov et al. proposed the formation of platinum-carbene $(\mathrm{Pt}=\mathrm{C})$ to explain the methane isotopomer distribution of the H/D exchange experiments in Shilov system. However, our molecular modeling computations show that the formation of platinumcarbene presents unrealistically high energy barriers. With more experimental data, we 
will be able to conduct more precise fitting to give more conclusive description of the $\mathrm{H} / \mathrm{D}$ exchange kinetics in Shilov system and thus providing information for the reaction mechanism.

Table 6.5: Definition of reactions occurred in methane H/D exchange experiments for kinetics fitting and the preliminary fitting results

\begin{tabular}{|c|c|c|}
\hline I.D. & Reaction & Ea, kCal $/ \mathrm{mol}$ \\
\hline 1 & 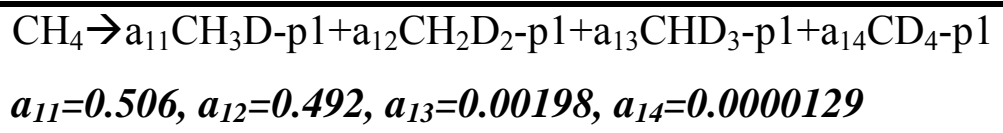 & 20 \\
\hline 2 & $\mathrm{CH}_{3} \mathrm{D}-\mathrm{p} 1 \rightarrow \mathrm{CH}_{3} \mathrm{D}$ & 29.9 \\
\hline 3 & $\mathrm{CH}_{2} \mathrm{D}_{2}-\mathrm{p} 1 \rightarrow \mathrm{CH}_{2} \mathrm{D}_{2}$ & 30.0 \\
\hline 4 & $\mathrm{CHD}_{3}-\mathrm{p} 1 \rightarrow \mathrm{CHD}_{3}$ & 30.1 \\
\hline 5 & $\mathrm{CD}_{4}-\mathrm{p} 1 \rightarrow \mathrm{CD}_{4}$ & 37.2 \\
\hline 6 & $\begin{array}{l}\mathrm{CH}_{3} \mathrm{D} \rightarrow \mathrm{a}_{21} \mathrm{CH}_{2} \mathrm{D}_{2}-\mathrm{p} 2+\mathrm{a}_{22} \mathrm{CHD}_{3}-\mathrm{p} 2+\mathrm{a}_{23} \mathrm{CD}_{4}-\mathrm{p} 2 \\
\boldsymbol{a}_{21}=\mathbf{0 . 4 1 4}, \boldsymbol{a}_{22}=\mathbf{0 . 5 6 7}, \boldsymbol{a}_{23}=\mathbf{0 . 0 1 9}\end{array}$ & 20 \\
\hline 7 & $\mathrm{CH}_{2} \mathrm{D}_{2}-\mathrm{p} 2 \rightarrow \mathrm{CH}_{2} \mathrm{D}_{2}$ & 31.9 \\
\hline 8 & $\mathrm{CHD}_{3}-\mathrm{p} 2 \rightarrow \mathrm{CHD}_{3}$ & 28.2 \\
\hline 9 & $\mathrm{CD}_{4}-\mathrm{p} 2 \rightarrow \mathrm{CD}_{4}$ & 30.3 \\
\hline 10 & $\begin{array}{l}\mathrm{CH}_{2} \mathrm{D}_{2} \rightarrow \mathrm{a}_{31} \mathrm{CHD}_{3}-\mathrm{p} 3+\mathrm{a}_{32} \mathrm{CD}_{4}-\mathrm{p} 3 \\
\boldsymbol{a}_{31}=\mathbf{0 . 7 3 5}, \boldsymbol{a}_{32}=\mathbf{0 . 2 6 5}\end{array}$ & 20 \\
\hline 11 & $\mathrm{CHD}_{3}-\mathrm{p} 3 \rightarrow \mathrm{CHD}_{3}$ & 26.5 \\
\hline 12 & $\mathrm{CD}_{4}-\mathrm{p} 3 \rightarrow \mathrm{CD}_{4}$ & 30.4 \\
\hline 13 & $\mathrm{CHD}_{3} \rightarrow \mathrm{CD}_{4}$ & 25.7 \\
\hline
\end{tabular}

Notation:

1) $a_{11}$ : coefficient of the corresponding product with a sum of 1 for all the products of each reaction.

2) $\mathrm{CH}_{3} \mathrm{D}$-p: the precursor of $\mathrm{CH}_{3} \mathrm{D}$ product

3) number in bold: set value; number in bold and italic: fitted value 


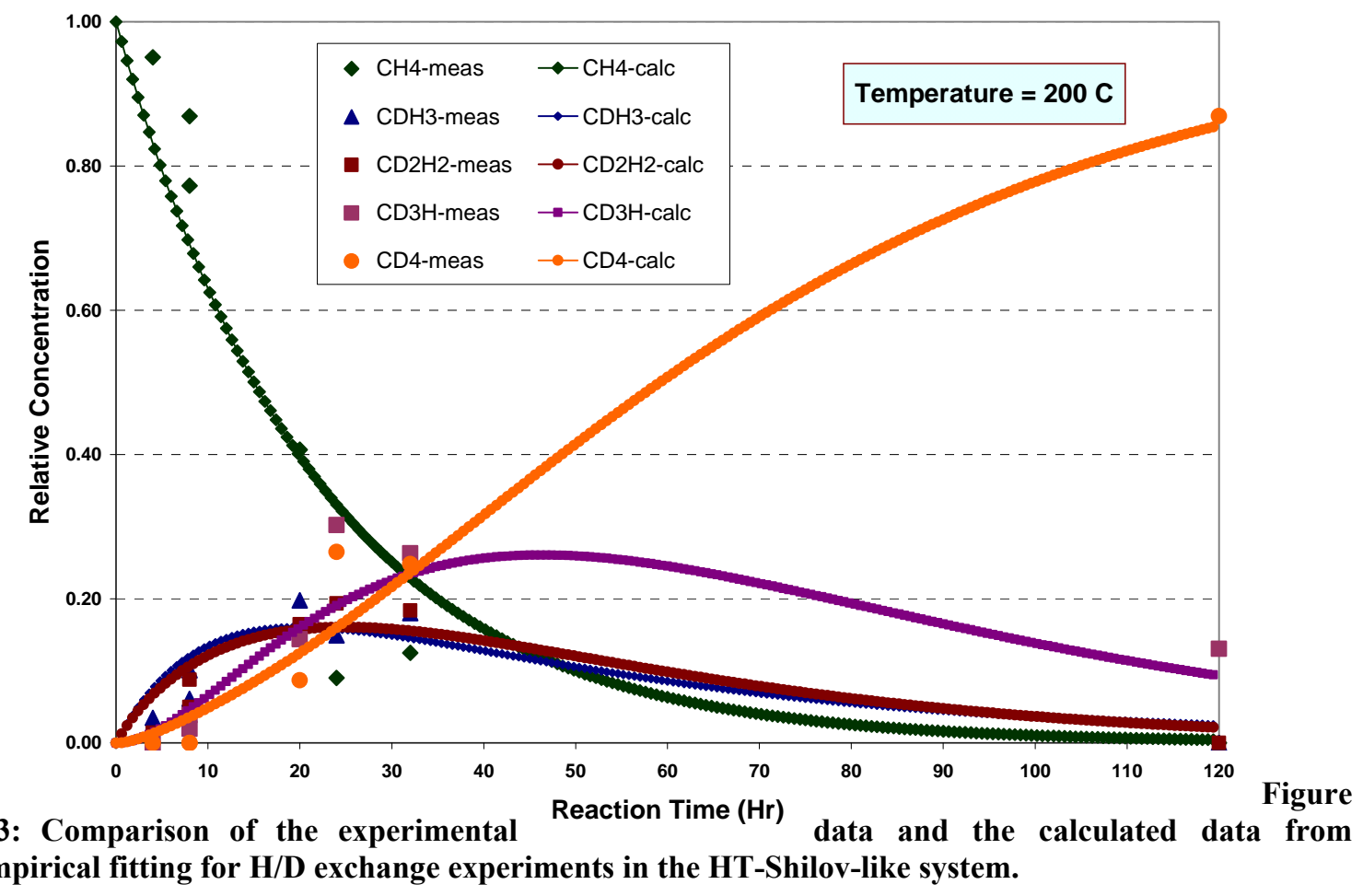

\subsection{STABILITIES OF VARIOUS PARTIAL OXIDATION PRODUCTS OF METHANE}

As described in our previous quarterly reports, the $\mathrm{C}-\mathrm{H}$ activation step of the methane partial oxidation processes we are currently developing is relatively successful. Mechanistic calculations indicate that the activation step is the most energetically difficult step during the activation-oxidation-functionalization three-step homogeneously catalyzed methane oxidation process. However, the current experimental results show that the oxidation step is indeed the rate limiting step. While putting efforts on the theoretical investigation of the possible oxidation approaches during our Pt-catalyzed methane oxidation process, we are also trying to accelerate the oxidation step by using 
stronger oxidants or increasing the reaction temperature. However, such approaches will raise the concerns of over-oxidation, i.e. poor selectivity of the catalytic system.

The strength of $\mathrm{C}-\mathrm{H}$ bond in $\mathrm{CH}_{4}$ is stronger than any of those in its partially oxidized derivatives, such as $\mathrm{CH}_{3} \mathrm{OH}, \mathrm{HCHO}, \mathrm{HCOOH}$ and $\mathrm{CH}_{3} \mathrm{Cl}$. Therefore, the selectivity issue is a common obstacle for most methane conversion processes. If a system is strong enough to break the $\mathrm{C}-\mathrm{H}$ bond in $\mathrm{CH}_{4}$, it is most likely very efficient in breaking the $\mathrm{C}-\mathrm{H}$ bond or other functional group in the partial oxidized products of $\mathrm{CH}_{4}$ resulting in production of the undesirable over-oxidized $\mathrm{CO}_{2}$. The poor selectivity is the main reason why radical reactions for $\mathrm{CH}_{4}$ conversion processes are not favorable. With the application of appropriate catalyst, reaction media and experimental conditions, it is possible to achieve good selectivity in methane conversion processes. Because a heterogeneously catalyzed process usually requires higher reaction temperature than a homogeneously catalyzed process, the latter is usually intrinsically superior to the former on achieving better selectivity. Two classic homogeneously catalyzed methane-methanol processes, the Shilov system and the Periana system both demonstrate excellent selectivity. In the Shilov system, the methane oxidation products were characterized as almost $50 \% \mathrm{CH}_{3} \mathrm{OH}$ and $50 \% \mathrm{CH}_{3} \mathrm{Cl}$. The lack of over-oxidized product, $\mathrm{CO}_{2}$, might be attributed to the low reaction temperature $\left(\sim 120^{\circ} \mathrm{C}\right)$. In the Periana system, overoxidation is avoided by the formation of methlybisulfate $\left(\mathrm{CH}_{3} \mathrm{OSO}_{3} \mathrm{H}\right)$, which is more stable than methane in highly concentrated sulfuric acid under the Pt-based catalysts at temperatures lower than $220^{\circ} \mathrm{C}$.

As a very important part of optimizing our developed catalytic systems, systematic experiments have been conducted on the studies of stability of various methane partial oxidation products to provide insightful guidance on improving process selectivity.

First, experiments were designed to investigate the protecting effect of forming methylbisulfate over methanol under different reaction conditions. At room temperature, the hydrolysis reaction $\mathrm{CH}_{3} \mathrm{OSO}_{3} \mathrm{H}+\mathrm{H}_{2} \mathrm{O} \rightarrow \mathrm{CH}_{3} \mathrm{OH}+\mathrm{H}_{2} \mathrm{SO}_{4}$ occurs when the reaction media contains significant amount of water, i.e. the concentration of sulfuric acid is not high enough. However, preliminary quantum mechanical calculations indicate that the equilibrium should move to the left as temperature increases. Though, without accurate data from the theoretical calculations, experiments were conducted to discover whether stable methlybisulfate can be formed in relatively dilute sulfuric acid. Table 6.6 lists several typical experiments testing the stability of methanol under various reaction conditions.

Table 6.6: Gold-tube experiments on methanol stability tests under various reaction conditions.

\begin{tabular}{|c|c|c|c|c|}
\hline Entry & Reaction Media & $\begin{array}{c}\text { Temperature } \\
\left({ }^{\circ} \mathrm{C}\right)\end{array}$ & $\begin{array}{c}\text { Time } \\
(\mathrm{h})\end{array}$ & $\begin{array}{c}\mathrm{CO}_{2} \\
(\mu \mathrm{mol})\end{array}$ \\
\hline 1 & $\mathrm{H}_{2} \mathrm{SO}_{4}(64$ w.t. $\%)$ & 280 & 3 & 14 \\
\hline
\end{tabular}




\begin{tabular}{|c|c|c|c|c|}
\hline 2 & $\mathrm{H}_{2} \mathrm{SO}_{4}(85$ w.t. \%) & 250 & 3 & 18 \\
\hline 3 & $\mathrm{H}_{2} \mathrm{SO}_{4}(96$ w.t.\%) & 250 & 3 & 19 \\
\hline 4 & $\mathrm{CuCl}_{2}(300 \mathrm{mM})+\mathrm{HCl}(8.4 \mathrm{M})$ & 250 & 3 & 2 \\
\hline 5 & $\mathrm{CuCl}_{2}(300 \mathrm{mM})+\mathrm{HCl}(8.4 \mathrm{M})$ & 300 & 3 & 14 \\
\hline 6 & $\begin{array}{c}\mathrm{CuCl}_{2}(300 \mathrm{mM})+\mathrm{K}_{2} \mathrm{PtCl}_{4}(5 \\
\mathrm{mM})+\mathrm{HCl}(8.4 \mathrm{M})\end{array}$ & 300 & 2 & 16 \\
\hline
\end{tabular}

All these experiments were conducted in our custom-made mini-gold-tube reactors. $10 \mu \mathrm{L}$ of methanol was added into $1 \mathrm{~mL}$ of reaction liquid with designed compositions and about $0.3 \mathrm{~mL}$ of the final reaction liquid was loaded into the gold tube reactor. The addition of methanol into the sulfuric acid solution was operated with the vial dipped in ice-water mixture to avoid methanol vaporization due to heat releasing. After loading the reaction liquid, the gold tube reactor was flushed and filled with $\mathrm{N}_{2}$ gas and sealed with a welder gun. An external hydraulic pressure about 3400 PSi was applied through a steel autoclave during the reaction. After heating, the autoclave was taken out of the air-circulating oven and quenched in cold water. Gas analysis was conducted through a HP5890 GC equipped with an FID detector as well as two TCD detectors. The $\mathrm{CO}_{2}$ quantification was realized through a calibration curve of the TCD signal peak area v.s partial pressure of the injected $\mathrm{CO}_{2}$ amount.

Entries 1 to 3 suggest that protecting methanol through formation of methylbisulfate does not work at temperatures higher than $250{ }^{\circ} \mathrm{C}$ even at concentration as high as $96 \%$. Methanol is so active that dilute sulfuric acid is strong enough to oxidize it to carbon dioxide. However, in our newly developed high temperature Shilov-like system the chemistry could be different with the presence of highly concentrated $\mathrm{HCl}$ acid. Entries 5 and 6 show that methanol has been oxidized by $\mathrm{CuCl}_{2}$ to carbon dioxide with/without $\mathrm{Pt}(\mathrm{II})$ catalyst at $300{ }^{\circ} \mathrm{C}$. While, at lower temperature $\left(250{ }^{\circ} \mathrm{C}\right)$, no significant amount of carbon dioxide was observed without Pt(II) catalyst (Entry 4). However, for entries 4 to 6 , significant amount of $\mathrm{CH}_{3} \mathrm{Cl}$ was observed. In summary, these experiments suggest the instability of methanol at high temperatures (above $250{ }^{\circ} \mathrm{C}$ ) under our typical catalytic methane conversion conditions. On the other hand, the coexistence of $\mathrm{CH}_{3} \mathrm{OH}$ and $\mathrm{HCl}$ might result in the formation of $\mathrm{CH}_{3} \mathrm{Cl}$ which can possibly survive under certain experimental conditions. Therefore, new chemistry or experimental protocols need to be developed for the methane conversion processes to avoid complete over-oxidation, i.e formation of $\mathrm{CO}_{2}$.

In our high temperature Shilov-like system, we have detected the formation of three major oxidation products of methane: methlychloride $\left(\mathrm{CH}_{3} \mathrm{Cl}\right)$, formic acid $(\mathrm{HCOOH})$ and $\mathrm{CO}_{2}$ as previously reported. Such product distribution is quite different from that claimed by the conventional Shilov system (about $50 \% \mathrm{CH}_{3} \mathrm{OH}$ and $50 \%$ 
$\mathrm{CH}_{3} \mathrm{Cl}$ ). In fact the proposed mechanism of the conventional Shilov system can be described as below

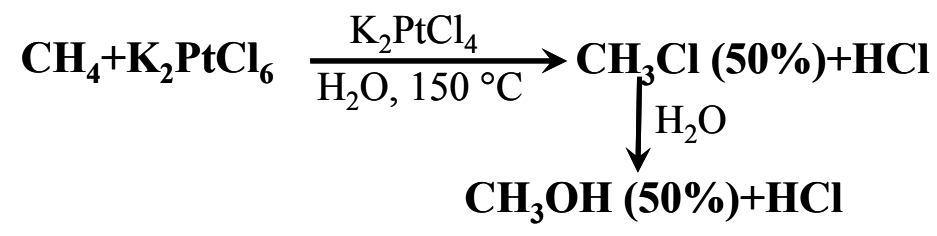

in which the formation of $\mathrm{CH}_{3} \mathrm{OH}$ through hydrolysis of $\mathrm{CH}_{3} \mathrm{Cl}$ mostly likely occurs due to the low reaction temperate and the long reaction time. In fact, the equilibrium of hydrolysis reaction of $\mathrm{CH}_{3} \mathrm{Cl}$ under high concentration of $\mathrm{HCl}$ is highly favorable to the $\mathrm{CH}_{3} \mathrm{Cl}$ side. Obviously, $\mathrm{CH}_{3} \mathrm{Cl}$ is more stable than $\mathrm{CH}_{3} \mathrm{OH}$ and stands more chances surviving under the catalytic methane oxidation conditions since the catalyst may selectively activate the $\mathrm{C}-\mathrm{H}$ bond in methane but stay relatively inert to $\mathrm{CH}_{3} \mathrm{Cl}$. Therefore, our next set of experiments was conducted to test the stability of $\mathrm{CH}_{3} \mathrm{Cl}$ under various conditions. Because we don't have pure $\mathrm{CH}_{3} \mathrm{Cl}$ gas in stock, the reactant gas is a mixture of $90 \% \mathrm{CH}_{4}$ and $10 \% \mathrm{CH}_{3} \mathrm{Cl}$. The preliminary results are listed in Table 6.7

Table 6.7: Gold-tube experiments on methlychloride stability tests under various reaction conditions.

\begin{tabular}{|c|c|c|c|c|c|c|}
\hline Entry & Reaction Media & $\begin{array}{c}\text { Temp. } \\
\left({ }^{\circ} \mathrm{C}\right)\end{array}$ & $\begin{array}{c}\mathrm{Time} \\
(\mathrm{h})\end{array}$ & $\begin{array}{c}\mathrm{CH}_{4} \\
(\%)\end{array}$ & $\begin{array}{c}\mathrm{CH}_{3} \mathrm{Cl} \\
(\%)\end{array}$ & $\begin{array}{c}\mathrm{CO}_{2} \\
(\%)\end{array}$ \\
\hline 1 & $\mathrm{CuCl}_{2}(300 \mathrm{mM})+\mathrm{HCl}(8.4 \mathrm{M})$ & 250 & 3 & 84 & 16 & 0 \\
\hline 2 & $\mathrm{CuCl}_{2}(300 \mathrm{mM})+\mathrm{HCl}(8.4 \mathrm{M})$ & 300 & 3 & 56 & 31 & 13 \\
\hline 3 & $\begin{array}{c}\mathrm{CuCl}(300 \mathrm{mM})+\mathrm{K}_{2} \mathrm{PtCl}_{4}(5 \\
\mathrm{mM})+\mathrm{HCl}(8.4 \mathrm{M})\end{array}$ & 250 & 3 & 57 & 30 & 13 \\
\hline 4 & $\begin{array}{c}\mathrm{CuCl}_{2}(300 \mathrm{mM})+\mathrm{K}_{2} \mathrm{PtCl}_{4}(5 \\
\mathrm{mM})+\mathrm{HCl}(8.4 \mathrm{M})\end{array}$ & 250 & 6 & 59 & 22 & 19 \\
\hline 5 & $\begin{array}{c}\mathrm{CuCl}_{2}(300 \mathrm{mM})+\mathrm{K}_{2} \mathrm{PtCl}_{4}(5 \\
\mathrm{mM})+\mathrm{HCl}(8.4 \mathrm{M})\end{array}$ & 230 & 12 & 57 & 28 & 15 \\
\hline
\end{tabular}

In these experiments, $0.3 \mathrm{~mL}$ of reaction liquid was loaded into each gold tube followed by the loading of about $60 \mu \mathrm{mol}\left[\mathrm{CH}_{4}(90 \%)+\mathrm{CH}_{3} \mathrm{Cl}(10 \%)\right]$ gas mixture. After sealing, the gold tube reactor was place into a high pressure autoclave with application of about 3400 PSi external hydraulic pressure and heated in an air-circulating oven at the desired temperatures for certain time periods. It needs to be pointed out that the gas loading procedure can not be precisely controlled so that the total amount of gas loaded may vary as much as $10 \mu \mathrm{mol}$ for each experiment. In addition, the currently employed gas transfer protocol uses a cold trap of about $\sim-80{ }^{\circ} \mathrm{C}$ mixture of liquid nitrogen and ethanol. Recently, it was discovered that the variation of the cold trap temperature can also affect the amount of $\mathrm{CH}_{3} \mathrm{Cl}$ transferred into the gas analysis system due to the 
relatively high boiling point of $\mathrm{CH}_{3} \mathrm{Cl}\left(-24.2^{\circ} \mathrm{C}\right)$. In addition, the percentage of each gas component was calculated assuming a $100 \%$ of all gas-phase products $\left(\mathrm{CH}_{4}, \mathrm{CH}_{3} \mathrm{Cl}\right.$ and $\mathrm{CO}_{2}$ ). Therefore, the current gas analysis results presented by percentage of each gas product are only qualitative data.

Entries 1 to 3 indicate that the Pt-catalyst promotes the oxidations both of $\mathrm{CH}_{4}$ and $\mathrm{CH}_{3} \mathrm{Cl}$. Without the Pt-catalyst, no significant amount of $\mathrm{CO}_{2}$ was observed at 250 ${ }^{\circ} \mathrm{C}$. When the temperature was increased to $300{ }^{\circ} \mathrm{C}$, some of the $\mathrm{CH}_{3} \mathrm{Cl}$ was oxidized to $\mathrm{CO}_{2}$ even without the Pt-catalyst. Entries 3 to 5 show that a longer reaction time did not proportionally/significantly increase the $\mathrm{CH}_{4}$ conversion, but resulted in a worse selectivity (increased $\mathrm{CO}_{2}$ percentage). Lowering the reaction temperature as increasing the reaction time did not improve the selectivity either. The preliminary conclusions from these experiments are: (1) the high-temperature Shilov-like system can have significant methane conversion at $\sim 250{ }^{\circ} \mathrm{C}$; (2) significant amount of $\mathrm{CO}_{2}$ will also be produced as the further oxidation product of $\mathrm{CH}_{3} \mathrm{Cl}$; (3) longer reaction time can result in worse selectivity.

In fact, most industrial production of $\mathrm{CH}_{3} \mathrm{Cl}$ is prepared through the reaction of $\mathrm{CH}_{3} \mathrm{OH}+\mathrm{HCl} \rightarrow \mathrm{CH}_{3} \mathrm{Cl}+\mathrm{H}_{2} \mathrm{O}$, either by bubbling $\mathrm{HCl}$ gas through boiling methanol with or without a $\mathrm{ZnCl}_{2}$ catalyst, or by passing combined $\mathrm{CH}_{3} \mathrm{OH}$ and $\mathrm{HCl}$ vapors over an $\mathrm{Al}_{2} \mathrm{O}_{3}$ catalyst at $350{ }^{\circ} \mathrm{C}$. It is suggested that $\mathrm{CH}_{3} \mathrm{Cl}$ is stable at temperature as high as over $350{ }^{\circ} \mathrm{C}$ and the reaction moves quickly (in seconds) towards the $\mathrm{CH}_{3} \mathrm{Cl}$ side, while the reverse reaction is much slower. Therefore, it might be possible to achieve good selectivity in our high temperature Shilov-like system through quick contact (short reaction time), high temperature reactions as long as the Pt-catalyst can survive at that temperature and acceptable methane conversion can be achieved during the quick contact. In order to realize the desirable short contact high temperature reactions, a fast heating system has been developed as described in the following section.

\subsection{OPTIMIZATION OF THE HT-SHILOV-LIKE SYSTEM}

According to literatures and our preliminary quantum mechanistic calculations, the rate limiting step in the Shilov system should be the $\mathrm{C}-\mathrm{H}$ activation step. i.e. the oxidation and functionalization steps should proceed much faster than the $\mathrm{C}-\mathrm{H}$ activation due to relatively lower energy barriers. However, our experimental observations indicate the presence of some high energy-barrier step since the final oxidized methane is much less than the activated one. Entry 26 in Table 6.2 shows a case of over oxidation, where lot of $\mathrm{SO}_{2}$ and $\mathrm{CO}_{2}$ were observed, but the remaining methane did not contain much exchanged isotopomers as the result of slower $\mathrm{C}-\mathrm{H}$ activation than oxidation. In many of our high temperature (above $200{ }^{\circ} \mathrm{C}$ ) experiments (exchange experiments and oxidation experiments), we detected a large percentage of methane which has been activated but not oxidized. Thus, the next critical step to achieve optimized catalytic performance should be the optimization of the oxidation and functionalization steps.

With $\mathrm{FeCl}_{3}$ and $\mathrm{CuCl}_{2}$ as oxidants to replace the expensive Pt(IV)-oxidant, we have developed systematic protocols to identify and quantify the oxidation products as 
the foundation of further optimization of the catalytic system and mechanistic understanding.

An HP 6890 GC system equipped with a Gas Pro column, an FID detector as well as a TCD detector and coupled with a Wasson ECE TCD detector is utilized to quantify the gas phase products. The customized gas transfer system attached to the GC system is able to provide the total amount of gas in the reaction gas mixtures. Standard $\mathrm{CH}_{4}$ with $15 \% \mathrm{He}$ as internal standard is used to quantify the methane conversion. In order to obtain a significant change on $\mathrm{CH}_{4} / \mathrm{He}$ ratio to reduce the influence of the scatter of the $\mathrm{GC}$ results, we decided to decrease the amount of $\mathrm{CH}_{4}$ loaded from $\sim 100 \mu$ mole to $\sim 25$ $\mu$ mole. Both the over-oxidized product, $\mathrm{CO}_{2}$ and the partial-oxidized product $\mathrm{CH}_{3} \mathrm{Cl}$ were detected by this GC system.

The liquid products have been characterized by GC-MS revealing that the major liquid oxidation product is formic acid $(\mathrm{HCOOH})$. However, the quantification of formic acid formation is difficult with GC-MS. The reaction liquid is strongly acidic ( $\mathrm{PH}-1)$, which is not tolerable for the GC-MS system. Thus, the reaction liquid has to be neutralized to about $\mathrm{PH} 3$ before measurements. However, due to the small amounts of reaction liquid and gas, the neutralization means at least 5-10 times dilution and thus a very low concentration of formic acid. In addition, the formic acid contained sample always has some remaining at the injection port of the GC-MS. Therefore, GC-MS is not effective for formic acid quantification for our current experiments.

To precisely quantify the formic acid, we have developed a protocol based on HPLC-UV technique. Good repeatability has been achieved with selection of appropriate sample treatment, column and other parameters. The major uncertainty comes from the pretreatment of the sample. More calibrations need to be done to estimate to formic acid concentration change after the sample passes two cartridges for $\mathrm{Cl}^{-}$and $\mathrm{Fe}^{3+} / \mathrm{Cu}^{2+}$ ions removal. The quantification can be greatly improved if applying the modified Parr reactor with larger volume of reaction liquid and possible higher formic acid concentration in the reaction liquids.

Figure 6.4 shows the GC-MS chromatograph (a) and spectrum (b) of an experiment conducted in $8.4 \mathrm{M} \mathrm{DCl}$ and $\mathrm{D}_{2} \mathrm{O}$ solution with $\mathrm{K}_{2} \mathrm{PtCl}_{4}(5 \mathrm{mM})$ and $\mathrm{FeCl}_{3}$ $(300 \mathrm{mM})$. As compared with the standard spectrum of $\mathrm{HCOOH}(\mathrm{c})$, the oxidation product was identified as HCOOD. This is strong evidence for that the formic acid is formed during the experiment instead of from contamination. GC-MS analysis was also conducted on the gas phase products with exploration of almost $100 \%$ exchanged $\mathrm{CD}_{\mathrm{x}} \mathrm{H}_{4}$ ${ }_{x}$ and $\mathrm{CD}_{\mathrm{x}} \mathrm{H}_{3-\mathrm{x}} \mathrm{Cl}$ for this experiment.

Though, only semi-quantified results have been achieved, we have found that significant oxidation occurred at temperature of $280{ }^{\circ} \mathrm{C}$ or even lower. Further increasing the temperature can increase the conversion but at the same time will probably result in high ratio of over oxidation and short catalyst lifetime. Therefore, one of the major targets of optimization is to improve the product selectivity while keeping, if not enhancing the methane conversion. 

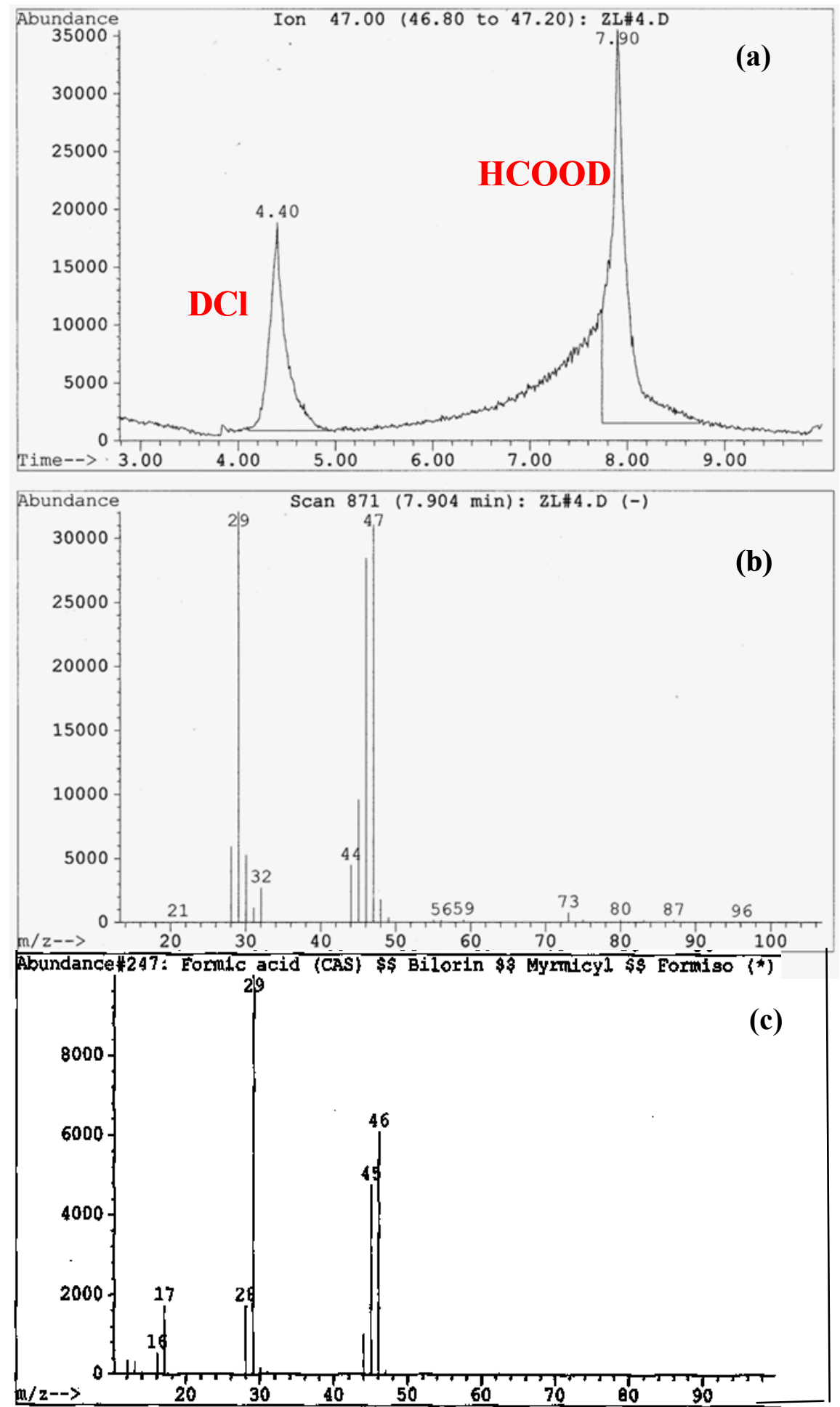

Figure 6.4: GC-MS chromatogram and spectrum for liquid products of reaction $\left[0.3 \mathrm{~mL} \mathrm{D}_{2} \mathrm{O}\right.$ (with 8.4 M DCl, $5 \mathrm{mM} \mathrm{K} \mathrm{PtCl}_{4}$ and $\left.300 \mathrm{mM} \mathrm{FeCl}_{3}\right)+100 \mu$ mole $\mathrm{CH}_{4}$ ] in gold tube reactor with $\sim 3700$ PSi hydraulic external pressure at $\sim 320{ }^{\circ} \mathrm{C}$ for $4 \mathrm{~h}$. (a) Chromatogram, (b) Spectrum of the HCOOD peak, and (c) standard spectrum of $\mathrm{HCOOH.}$ 
Stability tests have shown that $\mathrm{CH}_{3} \mathrm{OH}$ will be converted to $\mathrm{CO}_{2}$ in sulfuric acid (concentrated or diluted) and partially converted to $\mathrm{CH}_{3} \mathrm{Cl}$ in about 26 w.t.\% hydrochloric acid. The over oxidation to $\mathrm{CO}_{2}$ seems like inevitable considering the $\mathrm{C}-\mathrm{H}$ bond strength of $\mathrm{CH}_{4}$ is stronger than any of its partially oxidized products if without any catalytic mechanism or protecting intermediates. In nature, the $\mathrm{C}-\mathrm{H}$ bond in $\mathrm{CH}_{3} \mathrm{Cl}$ is relatively strong among these partially oxidized products of methane. Experiments have found that $\mathrm{CH}_{3} \mathrm{Cl}$ can survive at certain percentage if the temperature is not as high as $300{ }^{\circ} \mathrm{C}$ and the oxidant (like $\mathrm{Cu}$ (II) is not too strong. Such information suggests that if we can remove the $\mathrm{CH}_{3} \mathrm{Cl}$ product in time, we might be able to greatly reduce the production of $\mathrm{CO}_{2}$. As stated before, experiments conducted on our experimental apparatus are mostly at equilibrium state not allowing the instant removal of the product. However, quick reactions might give us some hints how the product equilibrium changes upon reaction temperature and time. Table 6.8 shows the results of several experiments conducted at set-temperatures of 280 and $310{ }^{\circ} \mathrm{C}$ with different reaction time. All experiments were conducted on the new fast heating system. Gas products were measured by an HP GC6890 with one FID and two TCD detectors. Methane conversion was calculated through the internal standard He mixed in the original methane gas at $15 \mathrm{vol}$. \%. Though, a significant $\mathrm{CH}_{3} \mathrm{Cl}$ peak was identified on the FID chromatogram, accurate quantification has not been achieved yet, possibly due to the poor repeatability of the cold-trapping gas transfer process. Therefore, the amount of $\mathrm{CH}_{3} \mathrm{Cl}$ was the calculated value assuming all reacted $\mathrm{CH}_{4}$ was oxidized to $\mathrm{CH}_{3} \mathrm{Cl}$ and $\mathrm{CO}_{2}$. The selectivity is defined as the amount of $\mathrm{CH}_{3} \mathrm{Cl}$ produced over the $\mathrm{CH}_{4}$ reacted. As shown by Entries 1-3 and 4-6, the product selectivity decreases when the reaction time increases as well as when the reaction temperature increases. This is encouraging information indicating potential high product selectivity realized by instant removal of the $\mathrm{CH}_{3} \mathrm{Cl}$ produced during the reaction when utilizing some appropriately designed flow reactor in the future larger scale demonstration or even industrial applications.

Table 6.8: Fast heating gold-tube experiments investigating the effect of reaction temperature and time on product selectivity of high-temperature Shilov-like system. (Experimental conditions: $\mathrm{K}_{2} \mathrm{PtCl}_{4}(5 \mathrm{mM})+\mathrm{CuCl}_{2}(300 \mathrm{mM})+\mathrm{HCl}(8.4 \mathrm{M})+\mathrm{CH}_{4}(\sim 50 \mathrm{PSi})+$ Hydraulic Pressure ( $\left.\left.3400 \mathrm{PSi}\right)\right)$

\begin{tabular}{|l|l|l|l|l|l|l|}
\hline Entry & $\begin{array}{l}\text { Temp. } \\
\left({ }^{\circ} \mathbf{C}\right)\end{array}$ & $\begin{array}{l}\text { Time } \\
(\mathbf{m i n})\end{array}$ & $\begin{array}{l}\mathbf{C H}_{\mathbf{4}} \\
(\mathbf{\%})\end{array}$ & $\begin{array}{l}\mathbf{C O}_{2} \\
(\mathbf{\%})\end{array}$ & $\begin{array}{l}\mathbf{C H}_{3} \mathbf{C l}^{*} \\
(\mathbf{\%})\end{array}$ & $\begin{array}{l}\text { Selectivity* } \\
(\%)\end{array}$ \\
\hline $\mathbf{1}$ & 310 & 5 & 10 & 2 & 8 & 80 \\
\hline $\mathbf{2}$ & 310 & 10 & 20 & 15 & 5 & 25 \\
\hline $\mathbf{3}$ & 310 & 20 & 37 & 29 & 8 & 22 \\
\hline $\mathbf{4}$ & 280 & 20 & 11 & 4 & 7 & 64 \\
\hline $\mathbf{5}$ & 280 & 30 & 17 & 6 & 11 & 65 \\
\hline $\mathbf{6}$ & 280 & 65 & 38 & 20 & 18 & 47 \\
\hline
\end{tabular}




\section{CHAPTER SEVEN: REAXFF METHOD AND VRP METHOD}

\subsection{A BRIEF SUMMARY ON CALIBRATING THE REAXFF METHOD WITH DFT CALCULATIONS}

Favorable properties of ionic liquids (IL), such as a wide liquid temperature range, high density, high heat capacity, low volatility, and nonflammability, make these compounds an excellent replacement for volatile organic solvents, especially in the case of the Periana catalyst system where concentrated $\mathrm{H}_{2} \mathrm{SO}_{4}$ is used. To gain insight into the physics and chemistry of imidazole-based ionic liquids in the presence of sulfur-based acids we developed a ReaxFF potential for fluorinated and non-fluorinated neutral imidazoles, imidazole cations and sulfoxide-based acids. The ReaxFF reactive force field methodology combines a bond-order/bond distance approach with a geometry-dependent polarizable charge calculation, making it highly suitable for this application. In order to develop ReaxFF potentials for imidazolium/anion ionic liquids and their interaction for Pt-complexes we have performed quantummechanical (QM) calculations on a range of small compounds. By distorting bonds and valence angles in these compounds we obtained a QM-derived training set against which we could test and optimize the ReaxFF parameters. All QM-calculations were performed using the Jaguar-package. For the ILrelated compounds (imidazolium $/ \mathrm{PF}_{6} / \mathrm{BF}_{4}$ ) we performed calculations using the hybrid DFT/B3LYP functional with a $6-311 \mathrm{G}^{* *^{++}}$-basis set. For the Pt-complexes the QMsimulations were performed using the DFT/B3LYP functional, describing the metal atom with an LACVP**-basis set and all other elements with a 6-31G** basis set. The QMdata obtained from these simulations were used by the ReaxFF-program to optimize ReaxFF-parameters for the imidazolium cation, the $\mathrm{BF}_{4}$ and $\mathrm{PF}_{6}$ anions and for $\mathrm{PtCl}_{2-}$ complexes.

This ReaxFF potential was tested against a wide range of QM-data, including hydrogen transfer reactions between imidazoles and imidazole cations, pKa-data for imidazoles and sulfoxide cations and imidazole dimer energies. We have performed molecular dynamics simulations with this ReaxFF potential and analyzed the proton diffusion behaviour as a function of imidazole cation/imidazole ratio.

Our ReaxFF method has been proved being able to reproduce quantum calculation results, which are accurate but expensive, in terms of charges distributions and energetics quite well (see Figure 7.1and Figure 7.2). Furthermore, using ReaxFF MD-simulations, we have studied hydrogen transfer reactions between imidazole and imidazole cations at atomistic level, and calculated vehicular diffusion, that is measurable chemical/physical property. Figure 7.3 is a snapshot from a ReaxFF MD/NVT simulation on a trifluorimidazole cation/HTFS anion/trifluorimidazole mixture, showing a concerted hydrogen transfer event. Figure 7.4 shows the total and vehicular diffusion obtained from ReaxFF MD/NVT simulations at $400 \mathrm{~K}$ on $8 \%$ and $30 \%$ triflurorimidazole cation/ triflurorimidazole/ HTFS anion mixtures. The excellent qualitative agreement with experimental results indicates that ReaxFF can successfully describe imidazole-based liquids. 

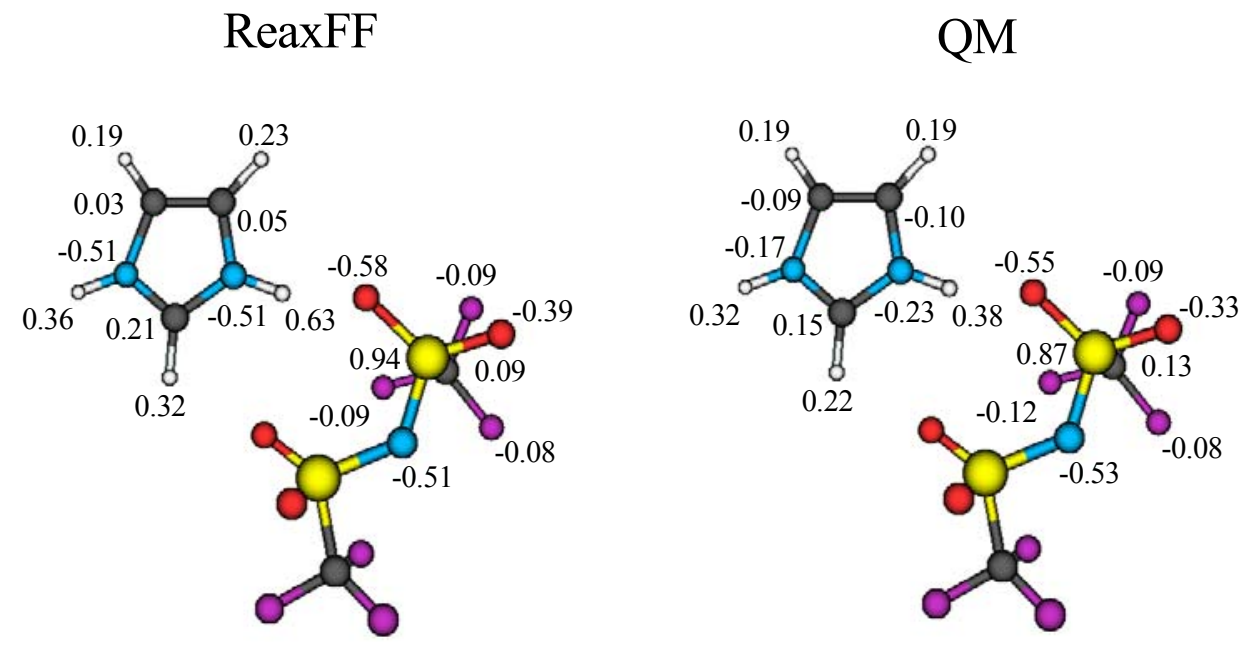

Figure 7.1: ReaxFF and QM (Mulliken) charge distributions for an imidazole cation/HTFS anion dimer.

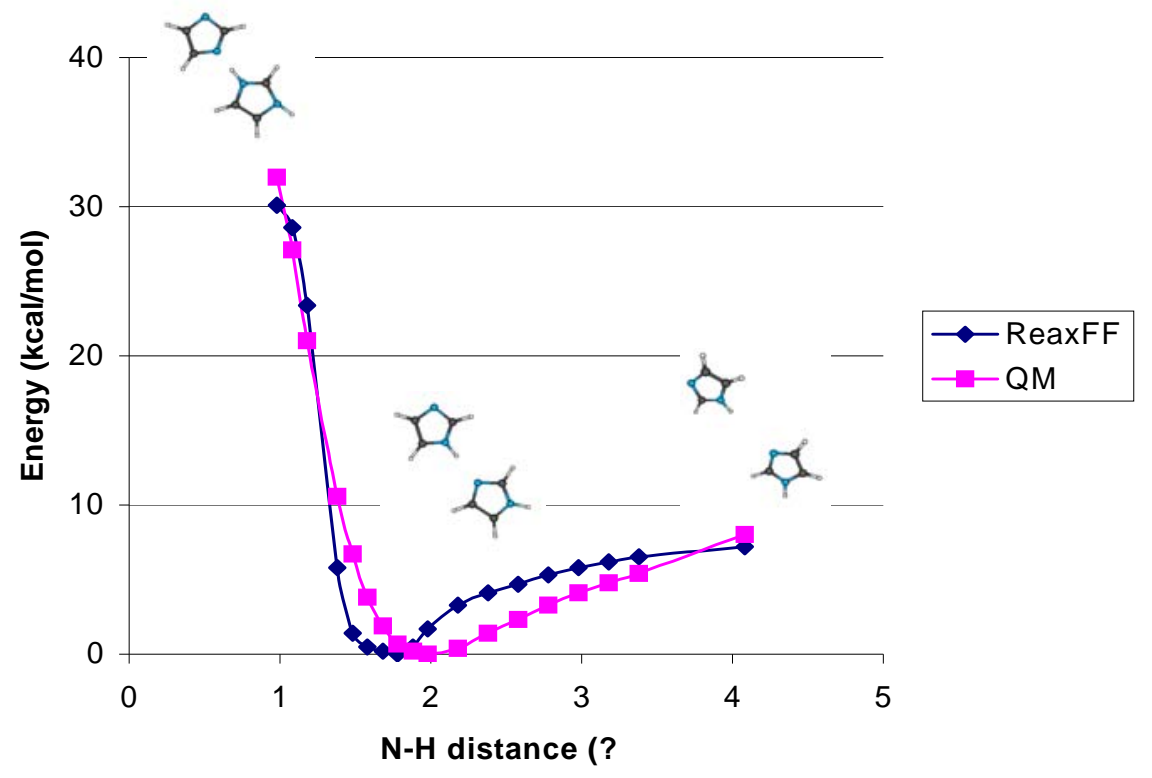

Figure 7.2: ReaxFF and QM-energies for an imidazole dimer as a function of intermolecular N-H distance. 


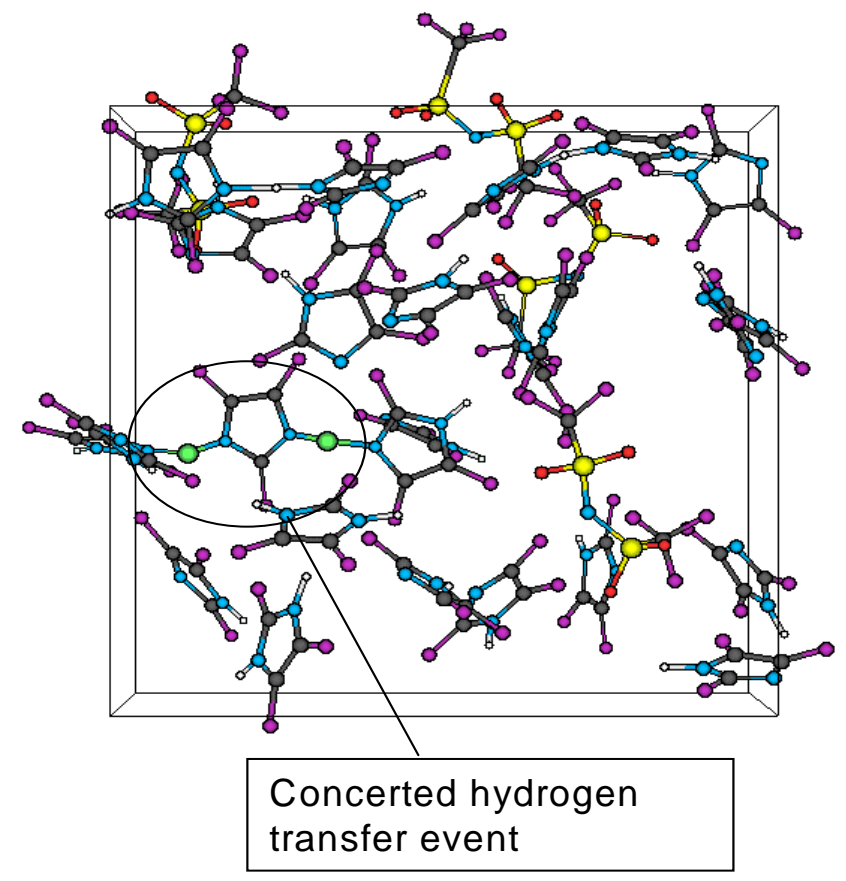

Figure 7.3: Snapshot from a ReaxFF MD/NVT simulation on a trifluorimidazole cation/HTFS anion/trifluorimidazole mixture, showing a concerted hydrogen transfer event. Hydrogens involved in the transfer event are bright green (for clarity), other hydrogens are white. Note that in the simulations ReaxFF uses the same atom type for all hydrogens.

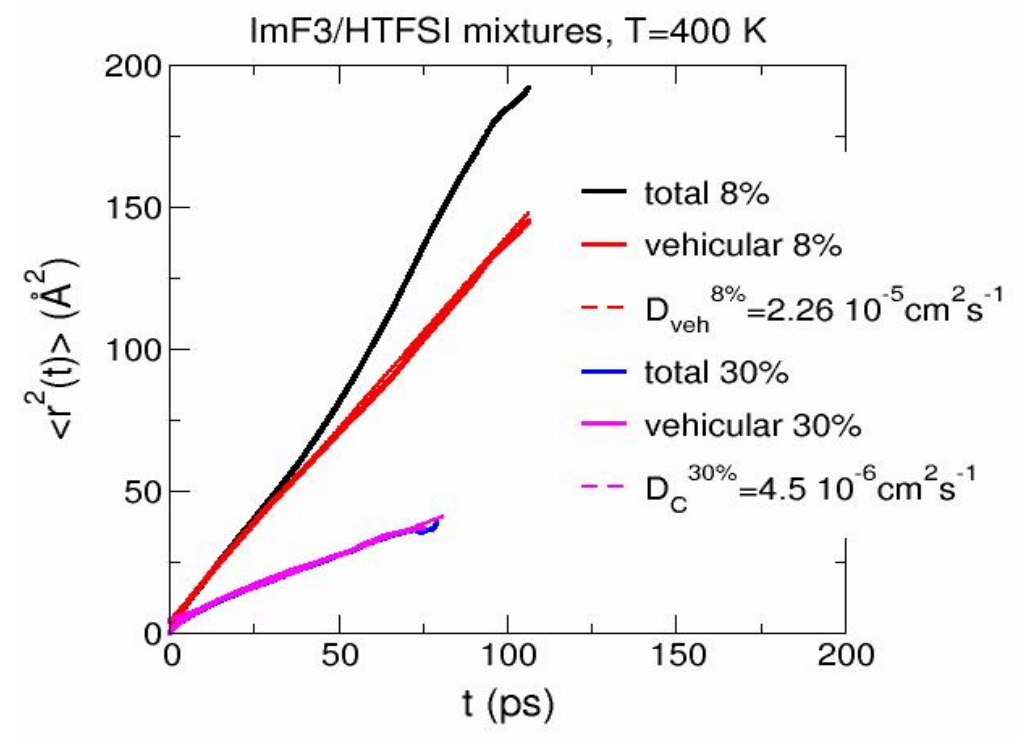

Figure 7.4Total and vehicular diffusion obtained from ReaxFF MD/NVT (400K) simulations on $8 \%$ and $30 \%$ trifluorimidazole cation/trifuorimidazole/HTFS anion mixtures. 
In summary, after achieving the ReaxFF potential parameters which can describe the intrinsic physical and chemical properties of ionic liquids, we are able to pursue the much more comprehensive mechanisms involved in the methane-methanol conversion catalyzed by our novel ternary catalyst/IL/acid systems and thus to provide efficient theoretical guidance in pursuing an optimized system.

\subsection{THE REAXFF POTENTIAL FOR IONIC LIQUIDS AND QM STUDIES OF CATALYST STABILITY}

\subsubsection{Development of a ReaxFF potential for imidazolium/anion ionic liquids}

To develop ReaxFF parameters for $\mathrm{BF}_{4}$ and $\mathrm{PF}_{6}$ anions we performed bond dissociation and angle distortion calculations using the QM-methodology described in the previous section. These data were used to derive ReaxFF parameters. To ensure that ReaxFF is capable of describing the solvent properties of imidazolium-based ionic liquids we compared the ReaxFF-derived atomic charges with Mulliken charges derived from the QM-calculations. Furthermore, we also compared the ReaxFF and QM dimerization energies for various imidazolium/anion pairs. To test the ReaxFF description for these liquid phases we performed a series of molecular dynamics (MD) simulations on a butylmethyl-imidazolium(BMIM) $/ \mathrm{BF}_{4}{ }^{-}$ionic liquid a simulated temperature of $300 \mathrm{~K}$. In this way we obtained a relation between energy and system density. ReaxFF finds an optimal density between 1.1 and $1.3 \mathrm{~kg} / \mathrm{dm}^{3}$, which is in good agreement with the experimentally observed density for this IL $\left(1.16 \mathrm{~g} / \mathrm{cm}^{3}\right)$

\subsubsection{Development of a ReaxFF potential for Pt-complexes}

To development of a ReaxFF description for Pt-complexes was initiated by fitting ReaxFF parameters to QM-data for $\mathrm{Pt}-\mathrm{X}$ bond dissociation in a $\mathrm{PtCl}\left(\mathrm{NH}_{3}\right)_{2}$ complex, where $\mathrm{X}=\mathrm{H}, \mathrm{OH}, \mathrm{NH}_{2}, \mathrm{NH}_{3}, \mathrm{CH}_{3}$ or $\mathrm{Cl}$. Figure 7.5 demonstrates that ReaxFF can be parameterized to reproduce the QM-dissociation profiles for these bonds. Importantly, ReaxFF can capture the difference in $\mathrm{NH}_{2}$ and $\mathrm{NH}_{3}$-binding to the Pt-complex; the QMdata shows that the $\mathrm{Pt}-\mathrm{NH}_{2}$ bond is significantly stronger than the $\mathrm{Pt}_{-} \mathrm{NH}_{3}$ bond and ReaxFF successfully reproduces this. As such, ReaxFF can describe the binding of both radical $\left(\mathrm{NH}_{2}, \mathrm{OH}, \mathrm{CH}_{3}, \mathrm{H}\right)$ and non-radical $\left(\mathrm{NH}_{3}\right)$ to Pt-complexes, indicating that ReaxFF might be capable of reproducing QM-data for the catalytic conversion of methane by Pt-complexes. 


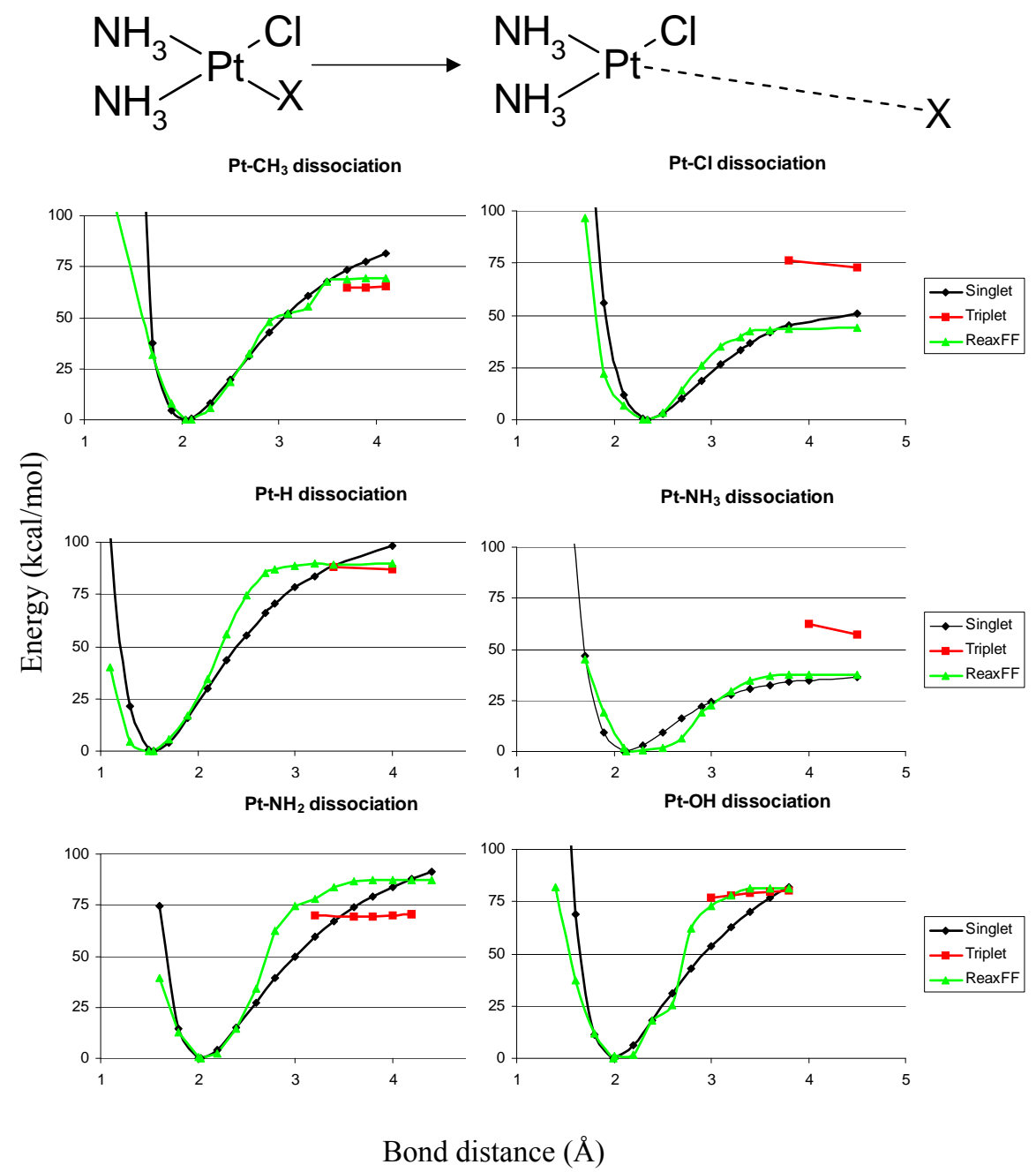

Figure 7.5: DFT singlet (black) /triplet (red) and ReaxFF (green) energies for Pt-X bond dissociation in $\operatorname{PtClX}\left(\mathrm{NH}_{3}\right)_{2}$-clusters.

Thus, by fitting parameters against QM-data describing bond dissociation, angle bending, charge distributions and cation/anion dimer energies we developed a ReaxFF description for imidazolium/anion ionic liquids. We also initiated the development of a ReaxFF description of Pt-catalyzed methane conversion by determining ReaxFF parameters for Pt-X bond dissociation, where $\mathrm{X}=\mathrm{H}, \mathrm{Cl}, \mathrm{OH}, \mathrm{NH}_{2}, \mathrm{CH}_{3}$ and $\mathrm{NH}_{3}$. For all cases considered we have found good agreement between ReaxFF and QM, indicating that ReaxFF can provide a reliable, computationally inexpensive tool for studying the solubility and catalytic activity of Pt-complexes in ionic liquids.

\subsubsection{Molecular modeling and calibration of the ReaxFF method on methane activation in ionic liquids}

To understand why $\mathrm{PtCl}_{2}$ dissolves in ionic liquids and what the possible structures of $\mathrm{PtCl}_{2}$-ionic liquid complex are, we examined $\mathrm{PtCl}_{2}$ in (substituted) imidazolium-chloride using QM-methods. 
1) QM-studies on the structure of $\mathrm{Pt}$ complexes in ionic liquids $\mathrm{PtCl}_{2}+[\mathrm{mmIm}][\mathrm{Cl}], \mathrm{PtCl}_{2}+[\mathrm{mIm}][\mathrm{Cl}], \mathrm{PtCl}_{2}+[\mathrm{Im}][\mathrm{Cl}]$

We have studied the possible structures of complex resulting from $\mathrm{PtCl}_{2}$ and several imidazolium-based ionic liquid salts. Geometry optimizations of $\mathrm{PtCl}_{2}+[\mathrm{mmIm}][\mathrm{Cl}], \mathrm{PtCl}_{2}+[\mathrm{mIm}][\mathrm{Cl}]$, and $\mathrm{PtCl}_{2}+[\mathrm{Im}][\mathrm{Cl}]$ were carried out in vacuum and solvent. Here we report minima and other stationary states for all three types of complexes located on the singlet surface. In case of $[\mathrm{mmIm}][\mathrm{Cl}]$ one minimum was found, for $[\mathrm{mIm}][\mathrm{Cl}]$ three minima, and for $[\mathrm{Im}][\mathrm{Cl}]$ two minima were found in gas phase. All these structures have similar symmetry and $\mathrm{Cl}-\mathrm{H}$ distances. We found that solvation leads to longer $\mathrm{Cl}-\mathrm{H}$ distances

2) Development of $\mathrm{ReaxFF}_{\mathrm{Pt} / \mathrm{IL}}$ potential for ionic liquid/Pt systems

We continued the development of a ReaxFF reactive force field for the simulation of Pt-complexes in an ionic liquid environment. The motivation for the development of a ReaxFF $_{\mathrm{Pt} / \mathrm{IL}}$ potential stemmed from the desire to facilitate the fast and economical screening of solubilty and catalytic activity of Pt-complexes in ionic liquids. To calibrate the ReaxFF potentials for imidazole(pyrazinium)/anion ionic liquids and their interactions for Pt-complexes, we performed quantum mechanical (QM) calculations on a range of anions, imidazolium cations, pyrazinium cations, and Pt-complexes (Figure 7.6).

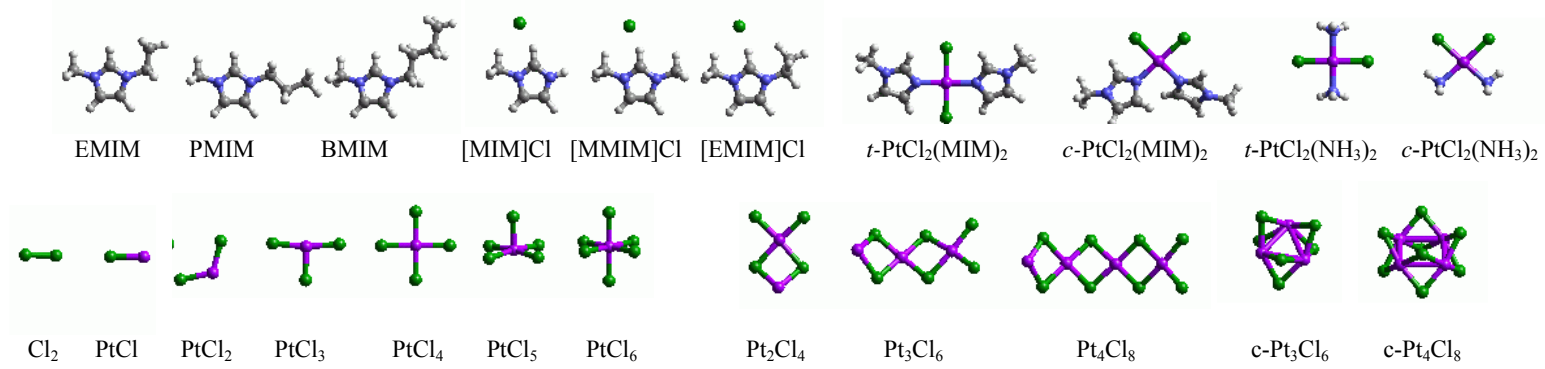

Figure 7.6: Imidazole/pyrazine cations, anions, and Pt-complexes obtained from DFT simulations and included in the ReaxFF training set. (White, gray, blue, green and purple balls represent $\mathrm{H}, \mathrm{C}, \mathrm{N}, \mathrm{Cl}$, and Pt atoms respectively.)

Extension of a ReaxFF ${ }_{I L}$ potential for ionic liquids to chlorine and pyrazines

ReaxFF parameters for anions were fitted to data obtained by performing bond dissociation and valence angle distortion calculation using QM-methods. We extended the $\mathrm{ReaxFF}_{\mathrm{IL}}$ potential to include $\mathrm{Cl}-\mathrm{Cl}$, and $\mathrm{Cl}-\mathrm{H}$ interactions and pyrazine ILs.

Proper description of solvent properties (charge polarization, dimerization energy, liquid density) for various IL prototypes are key to the development of a reactive force field that is suitable for screening/identifying the best ionic liquid for the optimal Ptcatalyst/IL system. ReaxFF atomic charges for IL systems were calibrated from 
Mulliken charges derived from QM-calculations and ReaxFF charges are in good agreement with QM charges.

\section{Extension of the ReaxFF description for Pt-complexes}

Precipitation of $\mathrm{PtCl}_{2}$ and $\mathrm{Pt}$-phases, as observed during the application of the Periana amine catalyst $\left(\mathrm{PtCl}_{2}\left(\mathrm{NH}_{3}\right)_{2}\right)$ in hot concentrated sulfuric acid, is an important obstacle in the development of a successful methane conversion catalyst. To enable simulations on the precipitation chemistry of Pt-complexes in the presence of ionic liquid, we combined both the ReaxFF ionic liquid and platinum descriptions into one potential and added the QM-data for platinum chloride compounds to the training set.

\section{Application of the ReaxFF potential to platinum precipitation from an IL-medium}

To test the reactive force field description for $\mathrm{Pt} / \mathrm{PtCl}_{2}$ precipitation, we performed NVT-simulations at $300 \mathrm{~K}$ on the precipitation of $\left(\mathrm{PtCl}_{2}\right)_{\mathrm{n}}$-particles inside a $20 \AA x 20 \AA x 20 \AA$ simulation box in the presence and absence of [MMIM]Cl. Cell compression-expansion runs were performed to obtain the optimal volume to particle density in the simulation box. ReaxFF found an optimal density of $1.19 \mathrm{~g} / \mathrm{cm}^{3}$ for the $1: 1$ ratio $[\mathrm{MMIM}] \mathrm{Cl}-\mathrm{PtCl}_{2}$ system. The simulation box was then subjected to NVT simulation at $300-600 \mathrm{~K}$ for 10,000 iterations. We observed that $\left(\mathrm{PtCL}_{2}\right)_{\mathrm{n}}$ precipitation was significantly repressed in the $\mathrm{PtCl}_{2}$-[MMIM] Cl case. In the absence of [MMIM]Cl, precipitation of $\mathrm{PtCl}_{2}$ occurred at higher frequency and at lower temperature $(300 \mathrm{~K})$.

To gain insight into the solubility and activity of Pt-complexes in IL-solvents, and the possible $\mathrm{PtCl}_{2}$-IL complexes that will be formed, we used DFT methods to examine a range of structures and relative energies of Pt-chloride complexes with substituted imidazolium. One possible concern was the precipitation of the catalyst out of solution; to address this issue we included condensed state phases of $\mathrm{PtCl}_{2}$ and $\mathrm{PtCl}_{4}$ and the relative energy of dimerization for various $\mathrm{Pt}_{n} \mathrm{Cl}_{\mathrm{m}}$ clusters. We used these $\mathrm{QM}$-data to develop a ReaxFF force field capable of efficient and fast screening of a Pt-catalyst/IL sytem. In our study, we used imidazolium-based salts as our model ionic liquid system. However, our methods are easily applicable and transferable to other ionic liquid systems

1) $\mathrm{QM}$ study of the $\mathrm{PtCl}_{2}\left(\mathrm{NH}_{3}\right) \mathrm{X}$ complex: $\mathrm{X}=$ imidazole

To understand what species are being formed as $\mathrm{PtCl}_{2}$ dissolves in imidazolium chloride, we analyzed the energetics of $\mathrm{PtCl}_{2}\left(\mathrm{NH}_{3}\right)$ imidazole for the various bondings of the Pt atom to the imidazole ring (Figure 7.7) using DFT methods. We found that structure $e$ was the only complex where the imidazole ring was oriented planar to the rest of the $\mathrm{PtCl}_{2}\left(\mathrm{NH}_{3}\right)$ complex, probably due to steric forces. 

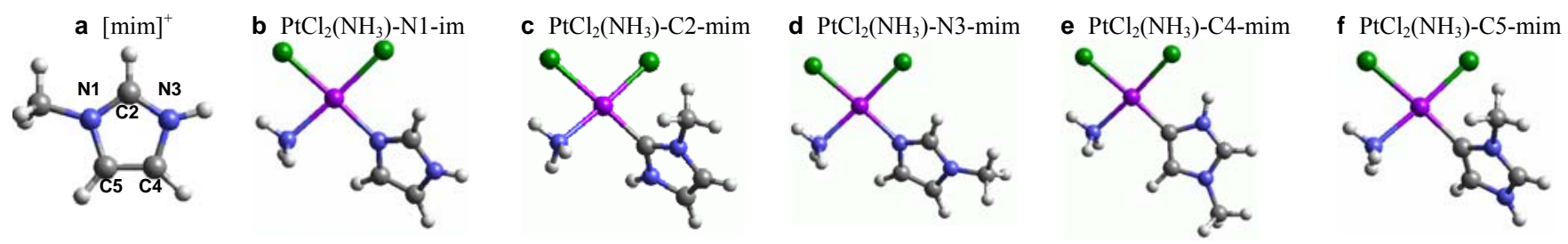

Figure 7.7: Various bonding configurations of a $\mathrm{PtCl}_{2}\left(\mathrm{NH}_{3}\right)$ complex to a) 1-methylimidazole cation [mim] ${ }^{+}$through the b) $\mathrm{N} 1$ atom, c) $\mathrm{C} 2$ atom, d) $\mathrm{N3}$ atom, e) $\mathrm{C} 4$ atom, and the f) $\mathrm{C} 5$ atom. Blue, gray and white balls represent $\mathrm{N}$, $\mathrm{C}$ and $H$ atoms, respectively.

We compared the energies for the various $\mathrm{PtCl}_{2}\left(\mathrm{NH}_{3}\right)$-imidazole complexes (Table 7.1). We found that the most favorable coordination site on the imidazole ring was at the $\mathrm{C} 2$ atom. This is not surprising since the $\mathrm{C} 2$ atom is the most electrophilic position on the ring. Charges obtained from Mulliken analysis for the N1, C2, N3, C4, and $\mathrm{C} 5$ atoms are $-0.30,0.30,-0.31,0.07$, and 0.04 respectively. Gas phase energies

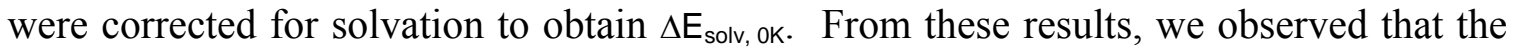
energy differences for the various coordination sites to the imidazoles are small except for the empty site. $\mathrm{Pt}(\mathrm{II})$ prefers to be four coordinated, square planar complex, thus the unsaturated $\mathrm{PtCl}_{2}\left(\mathrm{NH}_{3}\right)$ will coordinate to the 1-methyl imidazole.

We have also conducted preliminary investigations of competition between water and imidazole. The Periana (bpim) $\mathrm{PtCl}_{2}$ system is severely inhibited by water, which is one of the main obstacles to commercial development. Experimental investigations indicated that the initial activity of the $\mathrm{PtCl}_{2} /$ imidazole is not inhibited by water. Our calculations support this observation, as we find that replacing chloride with water is largely thermoneutral.

Table 7.1: Coordination energies for imidazole- $\mathrm{PtCl}_{2}\left(\mathrm{NH}_{3}\right)$ complexes at various position on the imidazole ring. All complexes with $P t$ were calculated using B3LYP/LACV3P**++ otherwise B3LYP/6311G**++. Diffuse functions were excluded in solvation-phase calculation.

\begin{tabular}{lcc}
\hline $\mathrm{PtCl}_{2}\left(\mathrm{NH}_{3}\right)($ site-imidazole $)$ & $\begin{array}{c}\Delta \mathrm{E}_{\text {gas, oK }} \\
(\mathrm{kcal} / \mathrm{mol})\end{array}$ & $\begin{array}{c}\Delta \mathrm{E}_{\text {solv }, 0 \mathrm{~K}} \\
(\mathrm{kcal} / \mathrm{mol})\end{array}$ \\
\hline $\mathrm{PtCl}_{2} \mathrm{NH}_{3}+[\mathrm{mimCl}]$ & 43.49 & 17.62 \\
$\mathrm{PtCl}_{2} \mathrm{NH}_{3}(\mathrm{~N} 1-\mathrm{im})+\mathrm{HCl}$ & 1.01 & 2.77 \\
$\mathrm{PtCl}_{2} \mathrm{NH}_{3}(\mathrm{C} 2-\mathrm{mim})+\mathrm{HCl}$ & 0.00 & 0.00 \\
$\mathrm{PtCl}_{2} \mathrm{NH}_{3}(\mathrm{~N} 3-\mathrm{mim})+\mathrm{CH}_{3} \mathrm{Cl}$ & 2.96 & 1.47 \\
$\mathrm{PtCl}_{2} \mathrm{NH}_{3}(\mathrm{C} 4-\mathrm{mim})+\mathrm{HCl}$ & 7.60 & 2.87 \\
$\mathrm{PtCl}_{2} \mathrm{NH}_{3}(\mathrm{C} 5-\mathrm{mim})+\mathrm{HCl}$ & 12.15 & 3.87
\end{tabular}

However, replacing one of the $\mathrm{Cl}$ ligands with imidazole is very exothermic, with a calculated $\Delta \mathrm{H}$ of $-18 \mathrm{kcal} / \mathrm{mol}$. Consequently, it is likely that the resting state of the catalyst is the cationic $\mathrm{PtCl}(\mathrm{mim})_{3}{ }^{+}$species. This is also most likely the cause of the initially lower activation, as this can be considered an inhibited ground state. Nevertheless, as the experimental activity is not so much lower as to account for 18 
$\mathrm{kcal} / \mathrm{mol}$, it is also likely that the spectator imidazole ligands play an electronic role in facilitating the activation of $\mathrm{CH}_{4}$.

Table 7.2: Relative energies of amidazole (mim), $\mathrm{Cl}^{-}$and $\mathrm{H}_{2} \mathrm{O}$ for $\mathrm{PtCl}_{2}$ in imidazole. All complexes with Pt were calculated using B3LYP/LACV3P**++ otherwise B3LYP/6311G**++. Diffuse functions were excluded in solvation-phase calculation.

\begin{tabular}{lcc} 
Complex & $\begin{array}{c}\Delta \mathrm{E}_{\text {gas, ok }} \\
(\mathrm{kcal} / \mathrm{mol})\end{array}$ & $\begin{array}{c}\Delta \mathrm{E}_{\text {solv }, 0 \mathrm{~K}} \\
(\mathrm{kcal} / \mathrm{mol})\end{array}$ \\
\hline $\mathrm{PtCl}_{2}(\mathrm{mim})_{2}+\mathrm{H}_{2} \mathrm{O}+\mathrm{mim}$ & -68.3 & 18.57 \\
{$\left[\mathrm{PtCl}(\mathrm{mim})_{3}\right]^{+}+\mathrm{Cl}^{-}+\mathrm{H}_{2} \mathrm{O}$} & 0 & 0 \\
{$\left[\mathrm{PtCl}(\operatorname{mim})_{2}\left(\mathrm{H}_{2} \mathrm{O}\right)\right]^{+}+\mathrm{Cl}^{-}+\operatorname{mim}$} & 25.4 & 18.28
\end{tabular}

\section{$\underline{\mathrm{PtCl}_{2}} \underline{\text { condensed states }}$}

An obstacle to the development of commercial methane conversion catalysis has been precipitation of $\mathrm{PtCl}_{2}$ and Pt-phases, as observed during the application of the Periana amine catalyst $\left(\mathrm{PtCl}_{2}\left(\mathrm{NH}_{3}\right)_{2}\right)$ in hot concentrated sulfuric acid. DFT unilateral cell compression/expansion runs for $\alpha-\mathrm{PtCl}_{2}$ were performed and incorporated into the ReaxFF training sets.

We extended the ReaxFF IL potential to include $\mathrm{PtCl}_{2}\left(\mathrm{NH}_{3}\right) \mathrm{OH}, \mathrm{PtCl}_{2}\left(\mathrm{NH}_{3}\right) \mathrm{H}$, $\mathrm{PtCl}_{2}\left(\mathrm{NH}_{3}\right) \mathrm{CH}_{3}$, and $\mathrm{PtCl}_{2}\left(\mathrm{NH}_{3}\right) \mathrm{OSO}_{3} \mathrm{H}$ complexes along with their associated bond distortion (Pt-O) and angle bending (N-Pt-H, Cl-Pt-H, N-Pt-O, Cl-Pt-O, N-Pt-C, Cl-Pt-C) profiles. ReaxFF provides good agreements to DFT derived values for each angle bending energy profile.

To establish potential catalyst structures, we specifically studied the binding imidazole binding modes to $\mathrm{PtCl}_{2}$. Table 7.3 shows the results when comparing the most favorable $\mathrm{Pt}(\mathrm{NH} 3) \mathrm{Cl}_{2}\left(\eta^{2}-\mathrm{IM}\right)$ (abbreviated $\mathrm{C} 4=\mathrm{C} 5$ ) plus free $\mathrm{Cl}^{-}$with the Pt-carbenoid at the N1, C2 and $\mathrm{C} 4$ positions. These simulations indicate that the carbon-sites are preferred over the nitrogen-sites for Pt/IM-binding. Furthermore, we find that for nonmethylated IM $(\mathrm{R}=\mathrm{H})$ the carbene-form of the Pt-complex is quite stable, approximately thermoneutral with the $\eta^{2}$ ligand. These carbene-Pt complexes are in many ways similar to the nitrogen-linked bipyridine-complexes associated with the Periana-catalyst, but are anticipated to have significantly different catalytic properties due to their vastly increased electron donating properties.

Table 7.3: Coordination energies for imidazole- $\mathrm{PtCl}_{2}\left(\mathrm{NH}_{3}\right)$ complexes at various position on the imidazole ring. All complexes with $\mathrm{Pt}$ were calculated using B3LYP/LACV3P ${ }^{* *++}$ otherwise $B 3 L Y P / 6311 G^{* *++}$. Diffuse functions were excluded in solvation-phase calculations.

\begin{tabular}{|c|c|c|c|}
\hline \multirow{5}{*}{$\mathrm{NH}_{3}$} & Coordination site & $\begin{array}{l}\mathrm{R}=\mathrm{H} \\
\Delta \mathrm{E}_{\text {solv }, 0 \mathrm{~K}}(\mathrm{kcal} / \mathrm{mol})\end{array}$ & $\begin{array}{l}\mathrm{R}=\mathrm{CH}_{3} \\
\Delta \mathrm{E}_{\mathrm{solv}, 0 \mathrm{~K}}(\mathrm{kcal} / \mathrm{mol})\end{array}$ \\
\hline & $\mathrm{N} 1+\mathrm{RCl}$ & 4.96 & 6.72 \\
\hline & $\mathrm{C} 2+\mathrm{HCl}$ & 0.56 & 5.69 \\
\hline & $\mathrm{C} 4+\mathrm{HCl}$ & 5.37 & 9.29 \\
\hline & $\mathrm{C} 4=\mathrm{C} 5+\mathrm{Cl}^{-}$ & 0.00 & 0.00 \\
\hline
\end{tabular}


Having established that the carbene complex is feasible with respect to the Ptimidazole complex, we also investigated the stability with respect to water, $\mathrm{HSO}_{4}{ }^{-}$and $\mathrm{Cl}^{-}$ . The results of our preliminary calculations are summarized in Table 7.4. These results indicate that it is favorable to replace the carbene-bound IM with either water, $\mathrm{HSO}_{4}{ }^{-}$or $\mathrm{Cl}^{-}$, with the $\mathrm{PtCl}_{3}$-complex being the most stable of these four options, although more possible conformations must be sampled before a definite conclusion can be made. Nevertheless, it seems that the carbene complex should be thermodynamically unstable under the high acid concentrations of the reaction conditions. This does not necessarily preclude the possibility of an active carbene complex, as it might be kinetically stable. Indeed, this is the case for the Periana (bpym) $\mathrm{PtCl}_{2}$ complex, as the reaction (bpym) $\mathrm{PtCl}_{2}$ $+2 \mathrm{HCl} \rightarrow \mathrm{PtCl}_{4}{ }^{2-}$ is exothermic, but the chelating nature of bpym prevents easy ligand dissociation and consequent protonation.

Table 7.4: Relative energies of L-PtCl(IM) complexes and ligands. All complexes with Pt were calculated using B3LYP/LACV3P ${ }^{* *++}$ otherwise B3LYP/6311G ${ }^{* *++}$. Diffuse functions were excluded in solvation-phase calculations.

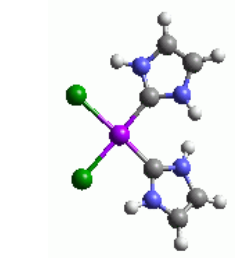

$\left[\right.$ cis- $\left.-\mathrm{PtCl}_{2}(\mathrm{IM})_{2}\right]$

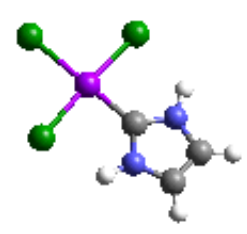

$\left[\mathrm{PtCl}_{3} \mathrm{IM}\right]^{-}$

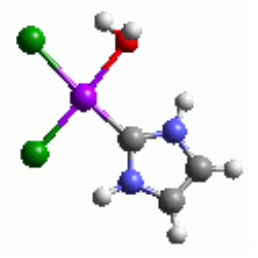

$\left[\mathrm{PtCl}_{2}\left(\mathrm{H}_{2} \mathrm{O}\right) \mathrm{IM}\right]$

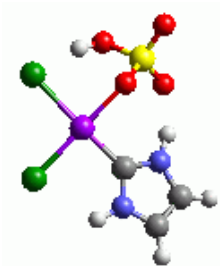

$\left[\mathrm{PtCl}_{2}\left(\mathrm{OSO}_{3} \mathrm{H}\right)(\mathrm{IM})\right]^{-}$

\begin{tabular}{|c|c|}
\hline Reaction & $\begin{array}{l}\mathrm{X}=\mathrm{IM} \\
\Delta \mathrm{E}_{\mathrm{solv}, 0 \mathrm{~K}}(\mathrm{kcal} / \mathrm{mol})\end{array}$ \\
\hline $\begin{array}{l}\text { cis- } \mathrm{PtCl}_{2}(\mathrm{IM})_{2}+\mathrm{H}_{2} \mathrm{SO}_{4}+\mathrm{HCl}+\mathrm{H}_{2} \mathrm{O} \\
{\left[\mathrm{PtCl}_{3}(\mathrm{IM})\right]^{-}+\mathrm{H}_{2} \mathrm{O}+\mathrm{H}_{2} \mathrm{SO}_{4}+[\mathrm{IM}]^{+}} \\
{\left[\mathrm{PtCl}_{2}\left(\mathrm{H}_{2} \mathrm{O}\right) \mathrm{IM}\right]+\left[\mathrm{HSO}_{4}\right]^{-}+[\mathrm{IM}]^{+}+\mathrm{HCl}} \\
{\left[\mathrm{PtCl}_{2}\left(\mathrm{OSO}{ }_{3} \mathrm{H}\right)(\mathrm{IM})\right]^{-}+[\mathrm{IM}]^{+}+\mathrm{H}_{2} \mathrm{O}+\mathrm{HCl}}\end{array}$ & $\begin{array}{l}13.87 \\
0.00 \\
9.19 \\
10.50\end{array}$ \\
\hline
\end{tabular}

By optimizing ReaxFF parameters against a QM-based training set, containing a wide range of molecular and multimolecular data including charge distributions, bond dissociation energies, angle distortion energies, hydrogen transfer barriers and intermolecular potential energy curves, we have managed to obtain a ReaxFF description for imidazoles, fluorinated imidazoles, imidazole cations and sulfoxide anions. This ReaxFF potential was tested against a wide range of QM-data, including hydrogen transfer reactions between imidazoles and imidazole cations, $\mathrm{pKa}$-data for imidazoles and sulfoxide cations and imidazole dimer energies. We performed a range of MDsimulations on fluorinated imidazole/imidazole cation/HTFS anion mixtures at different cation/neutral imidazole concentrations. We found the imidazole and sulfoxide anions to be stable throughout the entire simulation and observed frequent hydrogen transfer events. Furthermore, we found that at increased cation concentration the influence of hydrogen transfer reactions on the overall diffusion disappears. This is in good qualitative agreement with experimental results, indicating that ReaxFF can successfully describe imidazole-based liquids. 


\subsubsection{ReaxFF simulation for the Pt complexes in $\mathrm{H}_{2} \mathrm{SO}_{4}$ with ionic liquids}

As very little is known about the behavior of Pt complexes in the sulfuric acid solution with ionic liquids, identifying the stable and active species in the solutions is a daunting but also a 'must' task.

We first tested ReaxFF for proton binding energies in $\mathrm{H}_{2} \mathrm{SO}_{4}$ and imidazole and performed ReaxFF simulations at elevated temperatures to check the behavior of this method under realistic conditions.

As experiments have shown that $\mathrm{PtCl}_{2}$ is soluble in the imidazolium-based ionic liquid with concentrated sulfuric acid, we investigated the possible Pt complexes in the solutions by looking at a series of chemical reactions and calculating the relative reaction energies. The relative energies of each reaction are compared to the reaction energy (29.4 $\mathrm{kcal} / \mathrm{mol}$ in $\mathrm{H}_{2} \mathrm{SO}_{4}$ solution) of the model reaction $\left(\mathrm{PtCl}_{2}\right)_{6} \rightarrow 6 \mathrm{PtCl}_{2}$. The purpose of this part was to screen possible Pt complexes and identify the species which may serve as the starting reagent in the catalytic cycle of the methane oxidation.

Since the imidazolium has been found to be the favored state in the acidic solution, we considered this cationic species as a possible ligand for the $\mathrm{Pt}(\mathrm{II})$ complex. Other possible ligands include $\mathrm{Cl}^{-}, \mathrm{HSO}_{4}{ }^{-}, \mathrm{H}_{2} \mathrm{O}$, un-protonated imidazole (IM) and imidazole in carbene coordination mode.

Table 7.5: Relative stabilities of selected $\mathrm{Pt}(\mathrm{II})$ complexes in $\mathrm{H}_{2} \mathrm{SO}_{4}$ solutions.

\begin{tabular}{|c|c|c|c|}
\hline & $\begin{array}{l}\text { Structure of } \\
\text { Complex }\end{array}$ & Related Chemical Reaction & $\begin{array}{c}\text { Energy } \\
(\mathrm{kcal} / \mathrm{mol})\end{array}$ \\
\hline 1 & & $\mathrm{PtCl}_{2}+[\mathrm{HIM}]^{+}+2 \mathrm{Cl}^{-} \rightarrow \mathrm{HCl}+\left[\mathrm{PtCl}_{3}\left(\mathrm{~N}^{1}-\mathrm{IM}\right)\right]^{-}$ & -23.5 \\
\hline 2 & & $\mathrm{PtCl}_{2}+[\mathrm{HIM}]^{+}+\mathrm{Cl}^{-} \rightarrow \mathrm{PtCl}_{3}\left(\eta^{2}-\mathrm{HIM}\right)$ & -30.8 \\
\hline 3 & & $\mathrm{PtCl}_{2}+[\mathrm{HIM}]^{+}+2 \mathrm{Cl}^{-} \rightarrow \mathrm{HCl}+\left[\mathrm{PtCl}_{3}\left(\mathrm{C}^{2}-\mathrm{IM}\right)\right]^{-}$ & -32.2 \\
\hline 4 & & $\begin{array}{c}\mathrm{PtCl}_{2}+[\mathrm{HIM}]^{+}+2 \mathrm{HSO}_{4}^{-} \rightarrow[\text { trans-PtCl} \\
2 \\
\mathrm{IM})\left(\mathrm{C}^{2}-\right.\end{array}$ & -34.5 \\
\hline 5 & ] & $\begin{array}{c}\mathrm{PtCl}_{2}+[\mathrm{HIM}]^{+}+2 \mathrm{HSO}_{4}^{-} \rightarrow\left[\text { cis- }{ }^{-} \mathrm{PtCl}_{2}\left(\mathrm{C}^{2}-\right.\right. \\
\left.\mathrm{IM})\left(\mathrm{HSO}_{4}\right)\right]^{-}+\mathrm{H}_{2} \mathrm{SO}_{4}\end{array}$ & -32.1 \\
\hline
\end{tabular}




\begin{tabular}{|c|c|c|c|}
\hline 6 & $a+q=80$ & $\begin{array}{c}\mathrm{PtCl}_{2}+[\mathrm{HIM}]^{+}+\mathrm{HSO}_{4}^{-} \rightarrow \text { trnas- }-\mathrm{PtCl}_{2}\left(\eta^{2}-\right. \\
\mathrm{HIM})\left(\mathrm{HSO}_{4}\right)\end{array}$ & -23.0 \\
\hline 7 & & $\begin{array}{c}\mathrm{PtCl}_{2}+[\mathrm{HIM}]^{+}+\mathrm{HSO}_{4}^{-} \rightarrow \text { cis- } \mathrm{PtCl}_{2}\left(\eta^{2}-\right. \\
\mathrm{HIM})\left(\mathrm{HSO}_{4}\right)\end{array}$ & -22.7 \\
\hline 8 & & $\mathrm{PtCl}_{2}+2[\mathrm{HIM}]^{+}+2 \mathrm{Cl}^{-} \rightarrow\left[\mathrm{PtCl}_{4}\right][\mathrm{HIM}]_{2}$ & -26.4 \\
\hline 9 & & $\begin{array}{c}\mathrm{PtCl}_{2}+2[\mathrm{HIM}]^{+}+2\left[\mathrm{HSO}_{4}\right]^{-} \rightarrow \\
{\left[\mathrm{PtCl}_{2}\left(\mathrm{HSO}_{4}\right)_{2}\right][\mathrm{HIM}]_{2}}\end{array}$ & -20.0 \\
\hline 10 & & $\mathrm{PtCl}_{2}+2 \mathrm{H}_{2} \mathrm{SO}_{4} \rightarrow \mathrm{PtCl}_{2}\left(\mathrm{H}_{2} \mathrm{SO}_{4}\right)_{2}$ & -14.0 \\
\hline
\end{tabular}

Table 7.5 shows the selected $\mathrm{Pt}(\mathrm{II})$ complexes and their relative stabilities in terms of the reaction energies of the related chemical reactions in the ionic liquid solutions of $\mathrm{H}_{2} \mathrm{SO}_{4}$. We can see that, Structures 2-5 could be the stable species in the ionic liquid solutions because the related reactions are exothermic and can release more energy than that required by the endothermic model reaction of $\left(\mathrm{PtCl}_{2}\right)_{6} \rightarrow 6 \mathrm{PtCl}_{2}$. On the other hand, the formation energy of complex $10(-14.0 \mathrm{kcal} / \mathrm{mol})$ from $\mathrm{PtCl}_{2}$ and $\mathrm{H}_{2} \mathrm{SO}_{4}$ is much less than the decomposition energy for the model reaction, in agreement with the experimental observation that $\mathrm{PtCl}_{2}$ does not dissolve in neat $\mathrm{H}_{2} \mathrm{SO}_{4}$.

Table 7.6: QM results for selected Pt(II) complexes react with methane.

\begin{tabular}{|c|c|c|c|}
\hline & $\begin{array}{c}\text { Structure of } \\
\text { Product }\end{array}$ & Reaction & Energy \\
\hline 11 & & & \\
\hline & & &
\end{tabular}




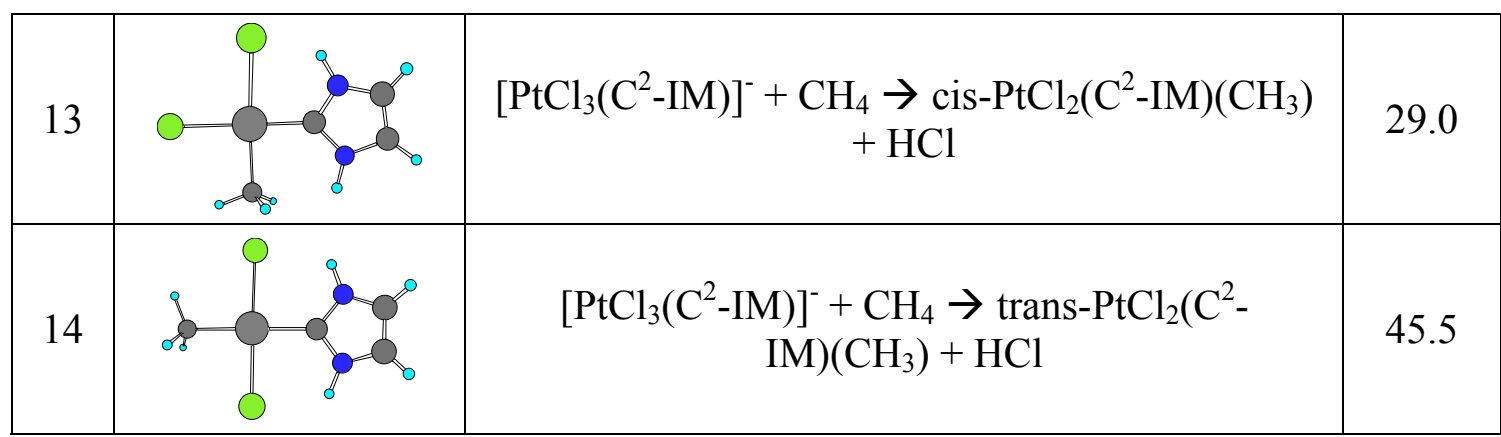

We further considered Complexes 2-5 as candidates for methane oxidation reagents and calculated the reaction energies for $\mathrm{CH}_{4}$ reacts with these $\mathrm{Pt}(\mathrm{II})$ complexes. Interestingly, our primary QM results (shown in Table 7.6) suggest that the $\mathrm{PtCl}_{3}\left(\eta^{2}\right.$ HIM) complex can cleavage the H-C bond of methane with a modest energy cost of 6.9 $\mathrm{kcal} / \mathrm{mol}$ and therefore may serve as the starting reagent for the catalytic reaction. Reactions of methane with complexes $\mathbf{2}$ and $\mathbf{3}$ producing $\mathrm{Pt}_{-} \mathrm{CH}_{3}$ complexes and $\mathrm{HCl}$ are much more endothermic and therefore are not believed to be involved in the catalytic cycles.

Experimental results indicate that the initial activity of the $\mathrm{PtCl}_{2} /$ imidazole is not inhibited by water although the Periana (bpym) $\mathrm{PtCl}_{2}$ system is severely inhibited by water, which is one of the main obstacles to commercial development. Our calculations (see Table 7.7) seem to support this observation, as we found that replacing a chloride with a water molecule in complexes $\mathbf{2}$ and $\mathbf{3}$ are indeed endothermic or less exothermic ($1.8 \mathrm{kcal} / \mathrm{mol})$ when compared to the similar reaction of the Periana system $(-6.8$ $\mathrm{kcal} / \mathrm{mol})$.

Table 7.7: QM results for replacing a chloride ligand in complexes 2 and 3 with a water molecule.

\begin{tabular}{|c|c|c|c|}
\hline & Structure & Reaction & Energy \\
\hline 15 & & $\begin{aligned} \mathrm{PtCl}_{3}\left(\eta^{2}-\mathrm{HIM}\right)+\mathrm{H}_{2} \mathrm{O} \rightarrow & \rightarrow\left[\text { cis- } \mathrm{PtCl}_{2}\left(\eta^{2}-\mathrm{HIM}\right)\left(\mathrm{H}_{2} \mathrm{O}\right)\right]^{+} \\
& +\mathrm{Cl}^{-}\end{aligned}$ & 2.2 \\
\hline 16 & & $\begin{array}{c}\mathrm{PtCl}_{3}\left(\eta^{2}-\mathrm{HIM}\right)+\mathrm{H}_{2} \mathrm{O} \rightarrow\left[\text { trans- } \mathrm{PtCl}_{2}\left(\eta^{2}-\right.\right. \\
\left.\mathrm{HIM})\left(\mathrm{H}_{2} \mathrm{O}\right)\right]^{+}+\mathrm{Cl}^{-}\end{array}$ & 1.4 \\
\hline 17 & & 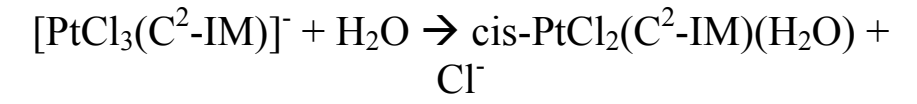 & -1.8 \\
\hline
\end{tabular}


In a short summary, it is proposed for the first time that $[\mathrm{im}]_{2}\left[\mathrm{PtCl}_{4}\right]$ is likely the starting effective complex for methane activation in our ternary $\mathrm{Pt} / \mathrm{IL} / \mathrm{H}_{2} \mathrm{SO}_{4}$ systems. Furthermore, we found the energy barrier to activate $\mathrm{C}-\mathrm{H}$ bond of methane is ternary systems are much lower than the Catalytica reaction, which is in general agreement with our experimental finding of higher deuterium exchange rate for $\mathrm{CH}_{4}$ catalyzed by $\mathrm{PtCl}_{2}$ in sulfuric acid solution with ionic liquids.

\subsection{A VIRTUAL RAPID PROTOTYPING (VRP) METHOD FOR FAST- SCREENINGS OF APPROPRIATE IONIC LIQUIDS}

To select the right ionic liquids for the methane to methanol conversion process, on one hand we have done extensive experimental work to test their solubility and stability in reaction media; and on the other hand, theoretical tools such as quantum chemistry calculation can also provide useful insights about their stability. The thermal stability of the ionic liquid is one of the most critical properties for a commercial system. Based on the extensive experimental and theoretical work, we successfully developed a Virtual Rapid Prototyping (VRP) methodology for fast screenings of stable ionic liquids. VRP is a Quantum Mechanics-based theoretical protocol developed by our group to screen a large number of potential synthetic targets and quickly weed out targets that do not pass established criteria. If the number of calculations required can be reduced to two or three for each species, we can achieve a substantial advantage in speed compared to experimental testing.

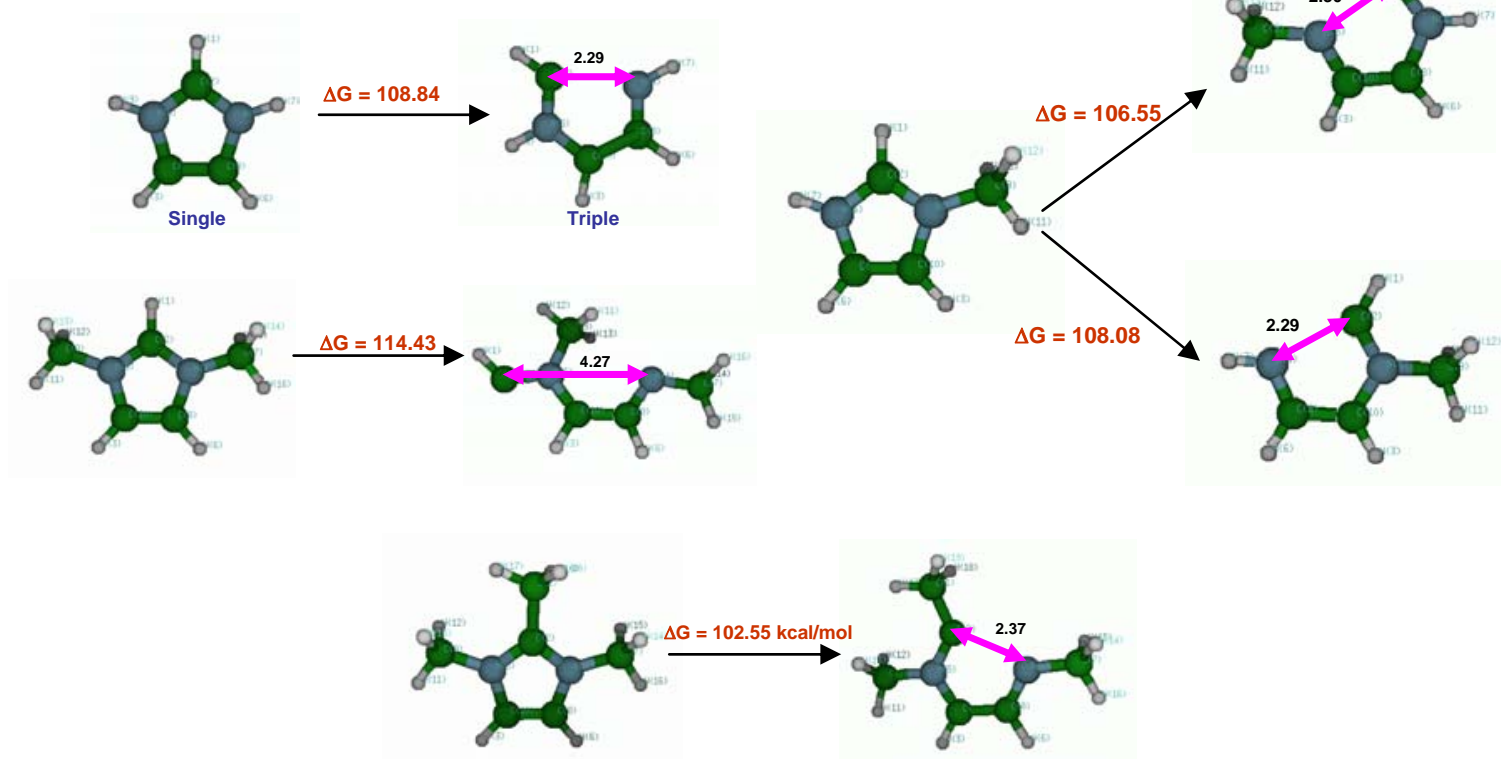

Figure 7.8: Optimized molecular geometry of the stable and ring-opened imidazole and their derivatives for different $\mathrm{C}-\mathrm{N}$ bond ruptures. 
Table 7.8: Calculated C-N Bond Rupture Energies of Imidazolium and their Derivatives.

\begin{tabular}{|c||c|c|c|c|c|c|}
\hline \hline \multirow{2}{*}{ Anion } & \multirow{3}{*}{ Bond } & \multicolumn{2}{|c|}{$\begin{array}{c}\text { Gibbs' Free Energy } \\
\text { (Hartree) }\end{array}$} & \multicolumn{2}{c|}{$\begin{array}{r}\text { Solvation Energy } \\
\text { (kcal/mol }\end{array}$} & \multirow{2}{*}{$\Delta \mathbf{G}$} \\
\cline { 3 - 6 } & & Stable & di-Radical & Stable & di-Radical & \\
\cline { 2 - 6 } & & Singlet & Triplet & Singlet & Triplet & (kcal/mol) \\
\hline \hline IM & C-N & -226.500256 & -226.328255 & -67.0550 & -66.1516 & 108.84 \\
\hline MIM & C-NH & -265.789322 & -265.620979 & -60.5199 & -59.6038 & 106.55 \\
\hline MIM & C-NCH3 & -265.789322 & -265.616799 & -60.5199 & -60.6966 & 108.08 \\
\hline MMIM & C-N & -305.077693 & -304.894162 & -55.4641 & -56.2017 & 114.43 \\
\hline \hline Me-MMIM & C-N & -344.377054 & -344.214318 & -52.5452 & -52.1153 & 102.55 \\
\hline
\end{tabular}

Notes: All calculations are at the DFT/B3LYP/6-31G** Level.

$\Delta \mathrm{G}$ is the Gibbs' Free energy difference at $\mathrm{T}=200{ }^{\circ} \mathrm{C}$.

Sulfuric Acid $\left(\mathrm{H}_{2} \mathrm{SO}_{4}\right)$ as Solvent $(\varepsilon=100, \mathrm{r} 0=4.33)$.

1 Hartree $=627.5095 \mathrm{kcal} / \mathrm{mol}$
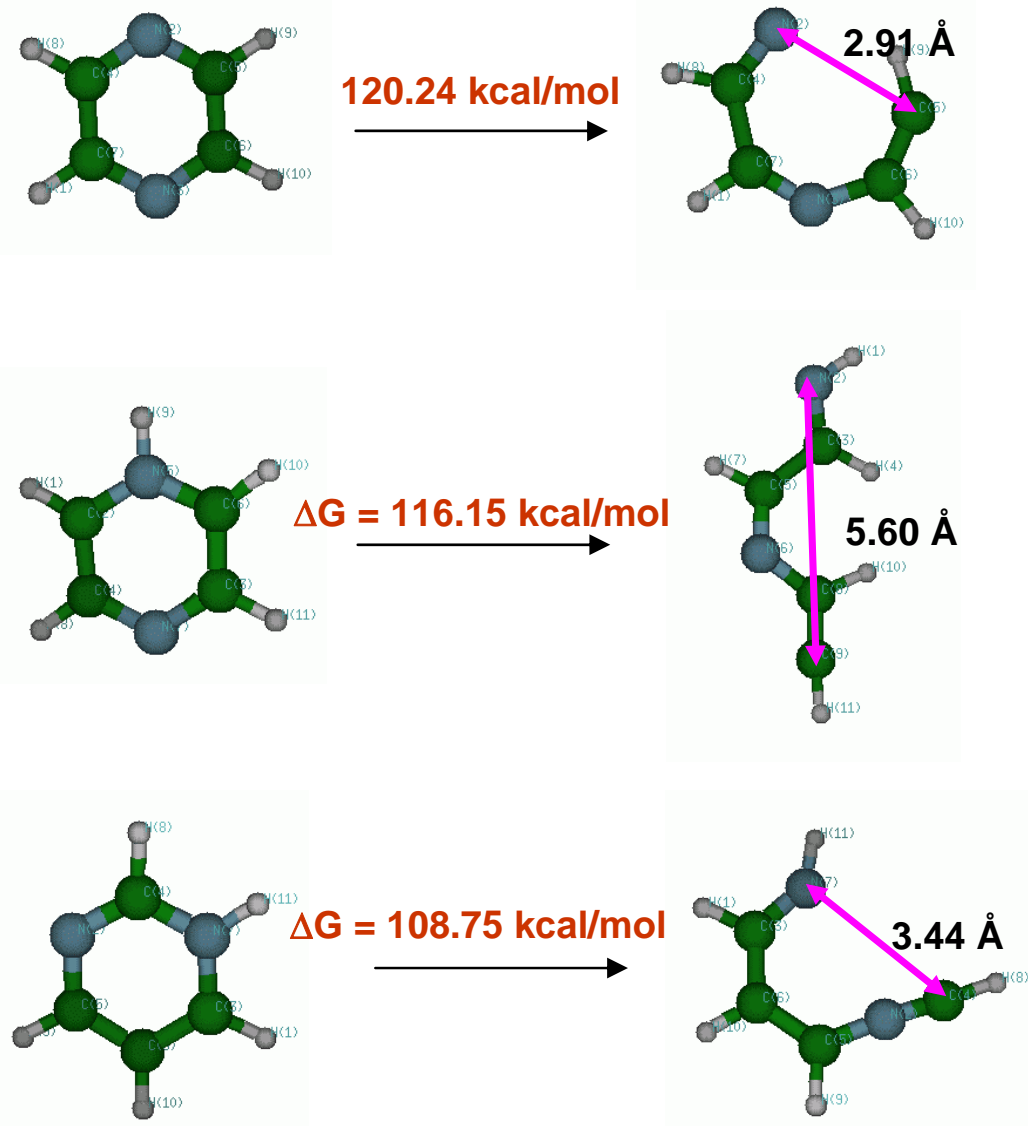

Figure 7.9: Optimized molecular geometry of the stable and ring-opened diazine and their derivatives for different $\mathrm{C}-\mathrm{N}$ bond ruptures. 
Table 7.9: Calculated C-N Bond Rupture Energies of Diazine and their Derivatives.

\begin{tabular}{|c|c|c|c|c|c|c|c|}
\hline \multirow{2}{*}{ Molecule } & \multirow{2}{*}{$\begin{array}{l}\text { Spin } \\
\text { State }\end{array}$} & $\mathrm{E}_{0}$ & $\mathrm{ZPE}$ & $\delta \mathrm{G}$ & $\mathrm{E}_{\mathrm{sol}}$ & $\Delta \mathrm{G}$ & $\Delta \Delta \mathrm{G}$ \\
\hline & & (Hartree) & $(\mathrm{kcal} / \mathrm{mol})$ & $(\mathrm{kcal} / \mathrm{mol})$ & $(\mathrm{kcal} / \mathrm{mol})$ & $(\mathrm{kcal} / \mathrm{mol})$ & $(\mathrm{kcal} / \mathrm{mol})$ \\
\hline \multirow{2}{*}{$\begin{array}{l}\text { 1,4-N2- } \\
\text { Diazine }\end{array}$} & singlet & -264.323102 & 51.813 & -28.456 & -5.7231 & -165819.17 & \multirow{2}{*}{120.24} \\
\hline & triplet & -264.122825 & 46.298 & -33.539 & -5.6471 & -165698.93 & \\
\hline \multirow{2}{*}{$\begin{array}{c}\text { 1,4-N2H- } \\
\text { Diazine }\end{array}$} & singlet & -264.676489 & 61.561 & -29.180 & -68.9261 & -166094.38 & \multirow{2}{*}{116.15} \\
\hline & triplet & -264.485752 & 56.382 & -33.913 & -67.2829 & -165978.22 & \\
\hline \multirow{2}{*}{$\begin{array}{l}\text { 1,3-N2- } \\
\text { Diazine }\end{array}$} & singlet & -264.329594 & 51.898 & -29.103 & -8.3677 & -165825.80 & \multirow{2}{*}{105.57} \\
\hline & triplet & -264.171421 & 53.660 & -31.512 & -3.8188 & -165720.24 & \\
\hline \multirow{2}{*}{$\begin{array}{c}\text { 1,3-N2H- } \\
\text { Diazine }\end{array}$} & singlet & -264.687104 & 61.720 & -29.795 & -68.4498 & -166100.40 & \multirow{2}{*}{108.73} \\
\hline & triplet & -264.505843 & 56.682 & -33.264 & -68.4289 & -165991.68 & \\
\hline
\end{tabular}

We report on molecular stabilities, represented with the calculated $\mathrm{C}-\mathrm{N}$ bond rupture energies at different ring positions. The molecular structures of both the stable configuration (singlet) and the bond-opening configuration (triplet) have been fully optimized and their Gibbs' free energy differences are calculated. From Figure 7.8, we can be seen that all configurations are relatively stable with the $\mathrm{C}-\mathrm{N}$ bond energy $\sim 100$ $\mathrm{kcal} / \mathrm{mol}$. This indicates that most of imidazoles and their derivatives are thermally stable without the presence of the special catalysts such as Pt. Similar results are also found for the diazine and their derivatives (Figure 7.9).

in

Calculated C-N bond rupture energies of imidazole family and diazine family are compiled

Table 7.8 and

Table 7.9, respectively. In the case of imidazole and its derivatives, 1,3dimethylimidazole has the strongest $\mathrm{C}-\mathrm{N}$ bond; and in the case of diazine and their derivatives, pyrazine has the strongest $\mathrm{C}-\mathrm{N}$ bond. All these results are in excellent agreement with our experimental work, e.g., 1,3-dimethylimidazolium ionic liquids experienced the least decomposition in the presence of $\mathrm{Pt}$ and $\mathrm{H}_{2} \mathrm{SO}_{4}$, and pyrazinium ionic liquids are stable up to $200^{\circ} \mathrm{C}$.

We calculated the molecular stabilities and the Mulliken charge distributions of various diazine family members (pyrazine, pyrimidine, pyridazine) with two nitrogen atoms at different substituted positions and their protonated and methyl-substituted derivatives. In addition, we calculated the $\mathrm{pKa}$ values (acidity) of selected molecules.

For the stability of the ionic liquids, we have established that destruction of the cation occurs through oxidation of the $\mathrm{C}-\mathrm{H}$ bond, most likely via a mechanism similar to the one leading to methyl bisulfate. Once the cationic ring is oxidized, complete oxidation to $\mathrm{CO}_{2}$ and $\mathrm{NH}_{3}$ is believed to be rapid, and if we assume that the rate of oxidation of the Pt-R intermediate is proportional only to the relative concentration of the Pt-R intermediate, we can predict the thermal stability of any individual ionic liquid 
based on the feasibility of the first $\mathrm{C}-\mathrm{H}$ activation event. Furthermore, if we assume that the rate of $\mathrm{C}-\mathrm{H}$ activation is proportional to the relative exothermicity of the $\mathrm{C}-\mathrm{H}$ activation step according to the Hammond postulate, we can reduce the number of data points required for the prediction of any ionic liquid to exactly one, i.e. the relative energy of the Pt-R intermediate.

The energy of this intermediate can easily be calculated through the reaction sequence $\left[\mathrm{PtCl}_{4}\right][\mathrm{HR}]_{2} \rightarrow\left[\mathrm{PtCl}_{3}-\mathrm{R}\right][\mathrm{HR}]+\mathrm{HCl}$, where $\left[\mathrm{PtCl}_{4}\right][\mathrm{HR}]_{2}$ is the anionic $\mathrm{PtCl}_{4}{ }^{2-}$ species stabilized by two ionic liquid cations $\left(\mathrm{HR}^{+}\right)$and $\left[\mathrm{PtCl}_{3}-\mathrm{R}\right][\mathrm{HR}]$ is the $\mathrm{CH}$ activated intermediate. Thus, calculations on the ionic liquid [H-Imidazole][Cl] $([\mathrm{Him}][\mathrm{Cl}])$ show that the reaction $\left[\mathrm{PtCl}_{4}\right][\mathrm{HIm}]_{2} \rightarrow\left[\mathrm{PtCl}_{3}-\mathrm{Im}\right][\mathrm{HIm}]+\mathrm{HCl}$ is exothermic by $-0.1 \mathrm{kcal} / \mathrm{mol}$, while calculations on the ionic liquid [H-Pyrazolium] $[\mathrm{Cl}]$ $([\mathrm{HPz}][\mathrm{Cl}])$ show that the reaction $\left[\mathrm{PtCl}_{4}\right][\mathrm{HPz}]_{2} \rightarrow\left[\mathrm{PtCl}_{3}-\mathrm{Pz}\right][\mathrm{HPz}]+\mathrm{HCl}$ is endothermic by 8.9 or $12.1 \mathrm{kcal} / \mathrm{mol}$, depending on what carbon coordinates to the Pt. Consequently, our calculations predict that $[\mathrm{Him}][\mathrm{Cl}]$ should be thermally unstable during the reaction conditions, while $[\mathrm{HPz}][\mathrm{Cl}]$ should be thermally stable, which is consistent with experimental observations.
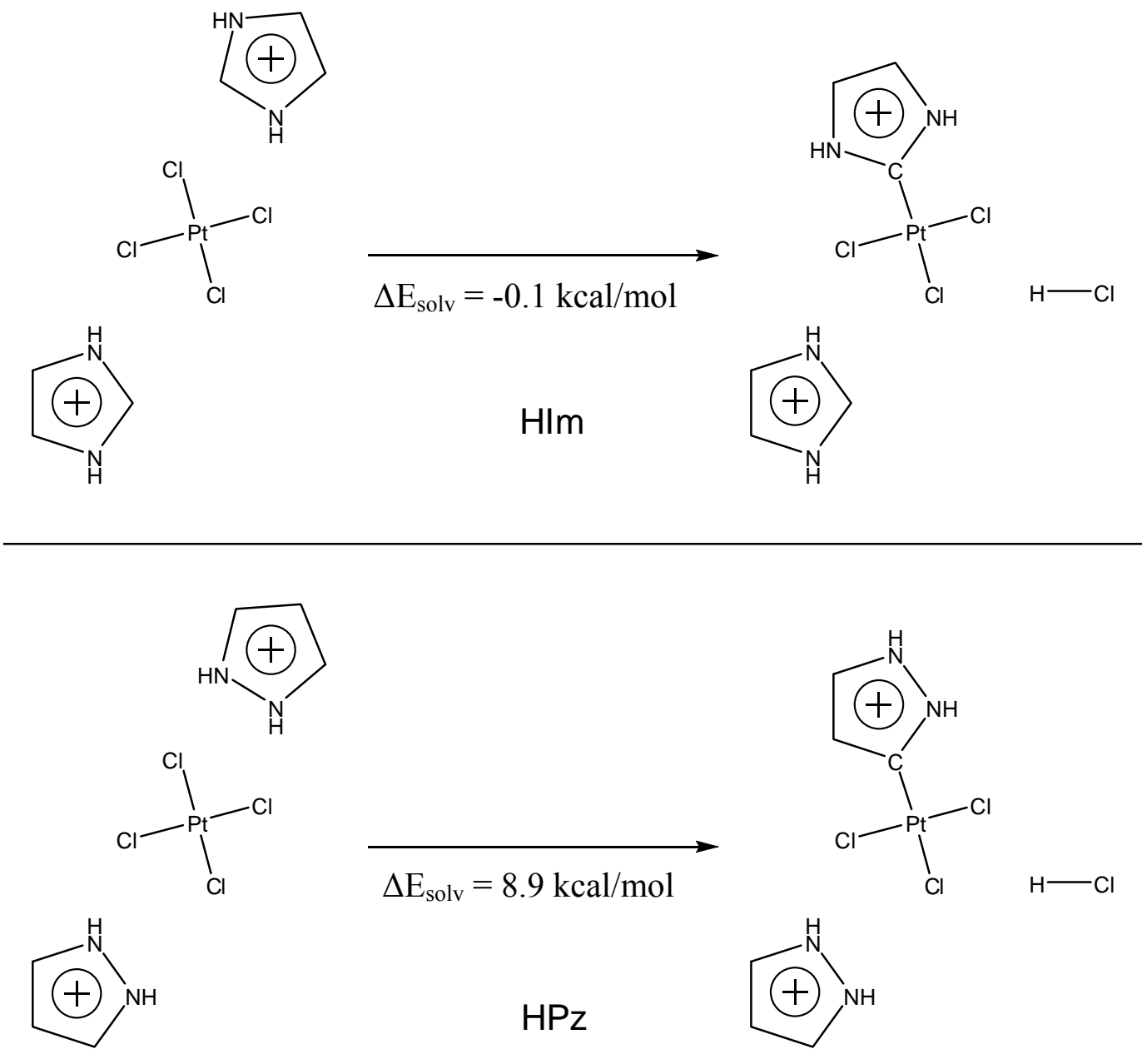

Figure 7.10: Development and applications of the Virtual Rapid Prototyping (VRP) to identify stable ionic liquids in the presence of the Pt catalyst. that the reaction $\left[\mathrm{PtCl}_{4}\right][\mathrm{HIm}]_{2} \rightarrow\left[\mathrm{PtCl}_{3}-\mathrm{Im}\right][\mathrm{HIm}]+$ 
$\mathrm{HCl}$ is exothermic by $-0.1 \mathrm{kcal} / \mathrm{mol}$, while calculations on the ionic liquid [H-Pyrazolium][Cl] $([\mathrm{HPz}][\mathrm{Cl}])$ show that the reaction $\left[\mathrm{PtCl}_{4}\right][\mathrm{HPz}]_{2} \rightarrow \quad\left[\mathrm{PtCl}_{3}-\mathrm{Pz}\right][\mathrm{HPz}]+\mathrm{HCl}$ is endothermic by 8.9 or $12.1 \mathrm{kcal} / \mathrm{mol}$. 


\section{CHAPTER EIGHT: MECHANISTIC INVESTIGATION}

\subsection{TYPICAL QUANTUM MECHANICAL METHODS UTILIZED}

Quantum mechanical computations on methane oxidation mechanisms have been performed using the B3LYP density functional. Detail information related to the computation method can be found in the literatures. This functional is a combination of the hybrid three-parameter Becke exchange functional ${ }^{6}$ (B3) and the Lee-Yang-Parr correlation functional $^{7}$ (LYP). Past basis sets used with B3LYP were constructed as follows. For platinum we used the core-valence effective core potential of Hay and Wadt $^{8}$ with a triple-zeta contraction of valence orbitals, while the Pople-style 6$311 \mathrm{G}^{* *++{ }^{9}}$ basis set was utilized for hydrogen, carbon and oxygen atoms. Recently the newer $\mathrm{M} 6^{10}$ functional has been increasingly employed for a more accurate description of non covalent interactions.

All calculations correct for the effect of solvent interactions by using the polarizable continuum model (PCM) of solvation ${ }^{11}$. We solvate with water, with a dielectric constant of 80.37 and a probe radius of $1.4 \AA$. Geometries are optimized withing the solvent model. Calculations were made with the Jaguar $6^{12}$ or 7.0207 computational package.

The reported total free energies are computed at each stationary point and used for relative free energy calculations (at $298.15 \mathrm{~K}$ ). The final free energy expression for species A is:

$$
G_{\mathrm{A}}=E_{\mathrm{SCF}}^{\mathrm{SP}}+E_{\mathrm{ZPVE}}+H_{\mathrm{Tot}}-T S_{\mathrm{vib}}+\Delta G^{0 \rightarrow *}
$$

in which $G_{\mathrm{A}}$ is the net free energy of species $A, E_{\mathrm{SCF}}^{\mathrm{SP}}$ is the solution-phase (continuum) electronic energy, $E_{Z P V E}$ is the zero-point vibrational energy, $\mathrm{H}_{\mathrm{Tot}}$ is the thermal contribution to the free energy (the vibrational thermal energy along with a PV term), and $-\mathrm{TS}_{\mathrm{vib}}$ is the vibrational contribution to the entropic free energy. For the absolute free energy of the proton a $\mathrm{pH}=0$, we use the value of $-270.29 \mathrm{kcal}$ mol-1, which is obtained using the experimental solvation energy of a proton of $-264.0 \mathrm{kcal} \mathrm{mol}-1$ (obtained from Tissandier et $\mathrm{al}^{13}$ ), and the relation $\mathrm{G}_{\mathrm{SP}}\left(\mathrm{H}^{+}\right)=\Delta \mathrm{G}_{\mathrm{solv}}\left(\mathrm{H}^{+}\right)+\mathrm{G}_{\mathrm{GP}}\left(\mathrm{H}^{+}\right)$, and ideal gas approximations were made to evaluate $\mathrm{G}_{\mathrm{GP}}\left(\mathrm{H}^{+}\right)$.

\subsection{REACTION MECHANISM OF C-H ACTIVATION CATALYZED BY PTCL $_{4}{ }^{2-}$ IN IONIC LIQUID SOLUTIONS}

We first compared the influences between hydronium $\left(\mathrm{H}_{3} \mathrm{O}^{+}\right)$and pyrazolium. Figure 8.1 shows the energy profile based on quantum chemical calculations for the $\mathrm{C}-\mathrm{H}$ activation of $\mathrm{CH}_{4}$ catalyzed by $\mathrm{PtCl}_{4}{ }^{2-}$ in acidic condition (a system neutralized by $\mathrm{H}_{3} \mathrm{O}^{+}$). We can see that the $\mathrm{CH}_{4}$ uptake step has a lower barrier (H-TS1 of $19.5 \mathrm{kcal} / \mathrm{mol}$ ) than that of the $\mathrm{C}-\mathrm{H}$ activation step $(\mathrm{H}-\mathrm{TS} 2$ of $21.2 \mathrm{kcal} / \mathrm{mol})$, indicating that the $\mathrm{C}-\mathrm{H}$ activation step is the control step for the $\mathrm{C}-\mathrm{H}$ activation process. The immediate product (H-MD2) of the $\mathrm{C}-\mathrm{H}$ activation step is a 'hydride-like' complex with a short $\mathrm{Pt}-\mathrm{H}$ distance of $1.58 \AA$. Interestingly, the interaction between the leaving $\mathrm{Cl}^{-}$and the 'hydide- 
like' ligand $(\mathrm{H})$ remains rather strong, indicating by the short $\mathrm{Cl}-\mathrm{H}$ distance $(1.99 \AA)$ which is similar to that of a strong hydrogen bond. Also, the two hydroniums $\left(\mathrm{H}_{3} \mathrm{O}^{+}\right)$ interact with the leaving $\mathrm{Cl}^{-}$and the other three $\mathrm{Cl}$ ligands with strong hydrogen bonds (indicated by the short $\mathrm{Cl}-\mathrm{H}$ distances of about $2.0 \AA$ ). All these interactions make HMD2 a quite accessible complex during the action procedure, with a relative stability of only $7.2 \mathrm{kcal} / \mathrm{mol}$ higher than the reactant H-RT.

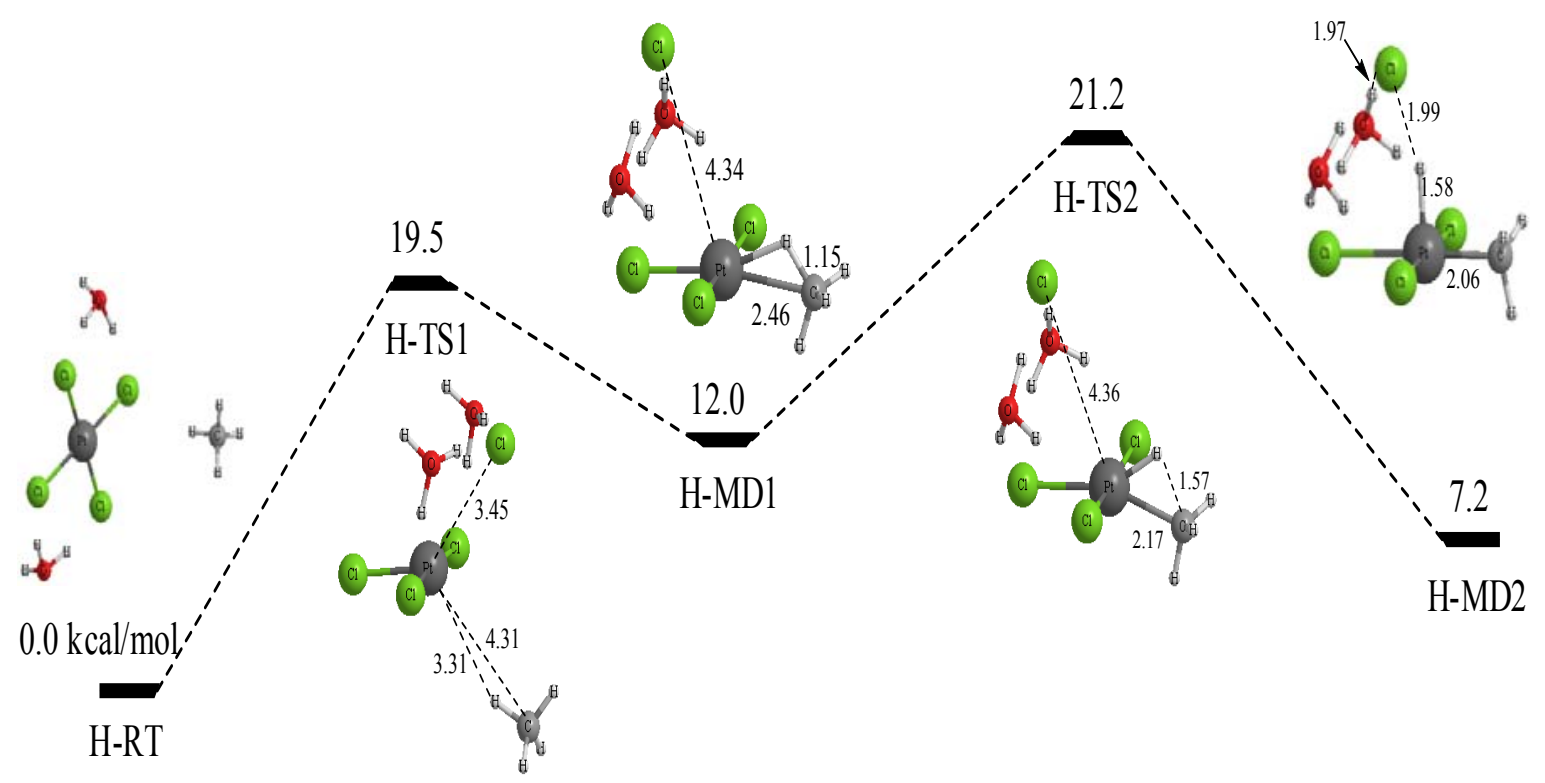

Figure 8.1: Reaction energy profile of $\mathrm{C}-\mathrm{H}$ activation catalyzed by $\mathrm{PtCl}_{4}{ }^{2-}$ in acidic condition (relative energies are in $\mathrm{kcal} / \mathrm{mol}$ )

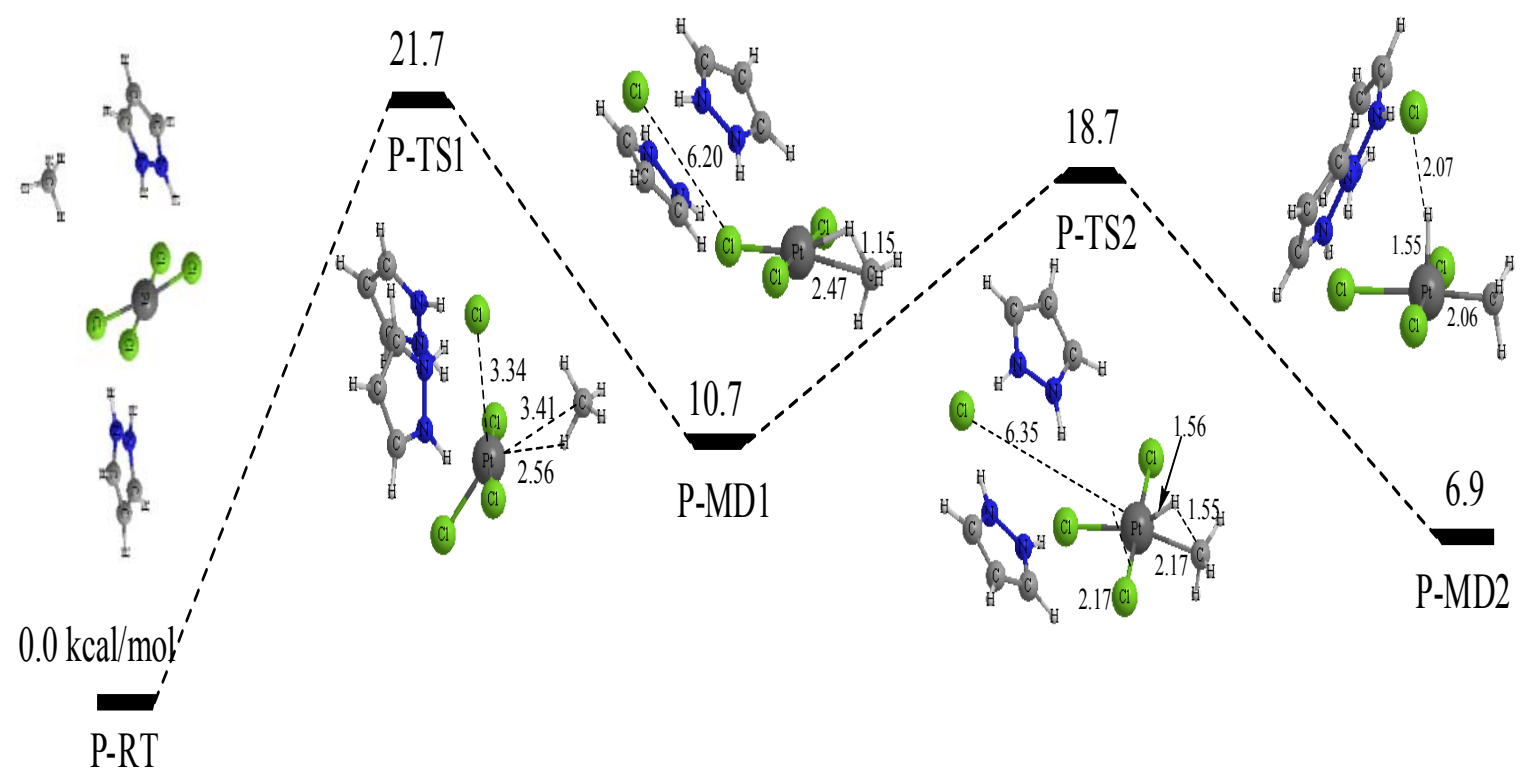

Figure 8.2: Reaction energy profile of $\mathrm{C}-\mathrm{H}$ activation catalyzed by $\mathrm{PtCl}_{4}{ }^{2-}$ in pyrazolium based ionic liquid solution (relative energies are in $\mathrm{kcal} / \mathrm{mol}$ ) 
Our quantum calculation results for a pyrazolium based ionic liquid system (depicted in Figure 8.2) shows that the $\mathrm{CH}_{4}$ uptake is the control step for $\mathrm{C}-\mathrm{H}$ activation process, with a barrier of $21.7 \mathrm{kcal} / \mathrm{mol}$ and the $\mathrm{C}-\mathrm{H}$ activation step has lower reaction barrier $(18.7 \mathrm{kcal} / \mathrm{mol})$. The immediate product (P-MD2) has similar structure features as its counter-part of the hydronium system (H-MD2) and is slightly more stable $(6.9 \mathrm{kcal} / \mathrm{mol})$ than $\mathbf{H}-\mathbf{M D 2}$.

By comparing Figure 8.1and Figure 8.2, we can see that, although the overall reaction barriers for both hydronium $(21.2 \mathrm{kcal} / \mathrm{mol})$ and pyrazolium $(21.7 \mathrm{kcal} / \mathrm{mol})$ systems are quite similar, both P-MD1 and P-MD2 of the pyrazolium system are more accessible than H-MD1 and H-MD2 of the hydronium system, indicating the pyrazolium system could be more efficient than pure $\mathrm{PtCl}_{4}{ }^{2-}$ system at high temperature.

We have also investigated the H/D exchange process by simulating a model reaction procedure as depicted in Figure 8.3 using quantum calculation methods. We found that, for $\mathrm{atCl}_{4}{ }^{2-}$ system in acidic condition (hydronium), the $\mathrm{H} / \mathrm{D}$ exchange step is expected to be faster than the $\mathrm{C}-\mathrm{H}$ activation step, suggesting multi-exchange $\mathrm{CH}_{4}$ (forming $\mathrm{CD}_{\mathrm{n}} \mathrm{H}_{4-\mathrm{n}}, \mathrm{n}>1$ ) can be observed at mild reaction condition. This result is consistent with experimental findings.

7.2
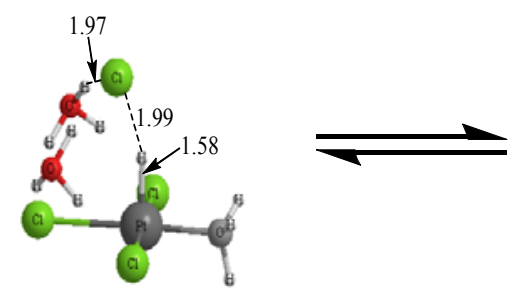

H-MD2
10.5

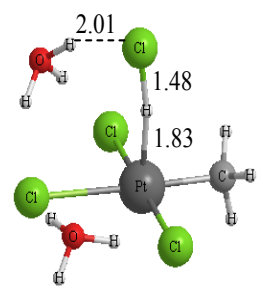

H-MD2'
17.8

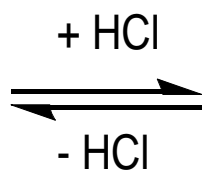

H-MD2' + $\mathrm{HCl}$

Figure 8.3: Key structures and relative stabilities (kcal/mol) along a possible hydrogen exchange pathway

\subsection{MECHANISTIC UNDERSTANDING ON SHILOV CHEMISTRY}

Extensive work has been conducted on the C-H activation step of the PerianaCatalytica system, the PEER system and the Shilov system successfully exploring that ionic liquids function much like the highly charge-stabilizing water solvent in the traditional Shilov system. The results have been published on Organometallics. Consequently, it is suggested that the function of the ionic liquids is to migrate the Shilov $\mathrm{C}-\mathrm{H}$ activation process from water into the oxidizing media characteristic of the PerianaCatalytica system. The activation energies associated with the proposed transition states of the $\mathrm{C}-\mathrm{H}$ activation are calculated. The energy barrier was predicated to be 26.5 
$\mathrm{kcal} / \mathrm{mol}$, which is higher than that of the Shilov system but significantly lower than that of the Periana system. Such findings stimulated our enhanced efforts (both theoretical and experimental) on the Shilov chemistry.

We present results on several different portions of Shilov Chemistry, focusing first on the equilibria the reference catalyst, $\mathrm{PtCl}_{4}{ }^{2-}$ has with water, then the conventional Shilov uptake and oxidative addition pathways, and finally the various mechanisms possible when acetic acid is present.

\section{A. Equilibria in water}

The $\mathrm{PtCl}_{4}{ }^{2-}$ catalyst can undergo substitution reactions with water to form the mono-, di-, tri- and tetra-aquo species. The relative free energies of these species are shown in Table 8.1.

Table 8.1: Free energies, relative to $\mathrm{PtCl}_{4}{ }^{2-}$ in kcal mol ${ }^{-1}$, for substituted $\mathrm{Pt}^{\mathrm{II}}$ species.

\begin{tabular}{lcc}
\hline \hline & $\begin{array}{c}\Delta \mathrm{G}^{0} \\
\text { Comp }\end{array}$ & $\begin{array}{c}\Delta \mathrm{G}^{0} \\
\text { Expt. }\end{array}$ \\
\hline $\mathrm{PtCl}_{4}{ }^{2-}$ & 0.0 & \\
$\mathrm{PtCl}_{3} \mathrm{OH}_{2}{ }^{-}$ & 3.7 & 2.1 \\
$\mathrm{PtCl}_{2}\left(\mathrm{OH}_{2}\right)_{2}$ & 5.9 & 6.1 \\
$\mathrm{PtCl}\left(\mathrm{OH}_{2}\right)_{3}{ }^{+}$ & 6.4 & \\
$\mathrm{Pt}\left(\mathrm{OH}_{2}\right)_{4}{ }^{2+}$ & 8.2 & \\
\hline \hline
\end{tabular}

Taking into account a high water concentration would lower each of these $\Delta$ Gs by $1-2 \mathrm{kcal} \mathrm{mol}^{-1}$. We should emphasize the large error bars on the computed values for the two cationic species. Formation of these species results in the formation of a very high number of charged species, consider $\mathrm{PtCl}_{4}{ }^{2-}+4 \mathrm{H}_{2} \mathrm{O} \leftrightarrows \mathrm{Pt}\left(\mathrm{OH}_{2}\right)_{4}{ }^{2+}+4 \mathrm{Cl}^{-}$, in which the products have 5 charged moieties. Current continuum methods have difficulty dealing with this type of situation. What we can say with confidence is that the mono- and diaquo species are the dominant forms and are all that we will consider.

\section{B. Conventional Shilov Chemistry: Methane uptake}

The first step of the Shilov mechanism is methane uptake, namely the substitution of a chloride or water with a methane, for example $\mathrm{PtCl}_{4}{ }^{2-}+\mathrm{CH}_{4} \leftrightarrows \mathrm{PtCl}_{3} \mathrm{CH}_{4}{ }^{+}+\mathrm{Cl}^{-}$. This can happen via a stepwise dissociative path, or a concerted associative way. We consider the dissociative pathway first.

The dissociative pathway would entail the formation of trivalent $\mathrm{T}$-shaped species like $\mathrm{PtCl}_{3}{ }^{-}$, and the free energies of these species are shown in Table 8.2. Note that the lowest energy species is $\mathrm{PtCl}_{3}^{-}$at $25.6 \mathrm{kcal} \mathrm{mol}^{-1}$. 
Table 8.2: Free energies, relative to $\mathrm{PtCl}_{4}{ }^{2-}$ in $\mathrm{kcal} \mathrm{mol}^{-1}$, for dissociative methane uptake intermediates.

\begin{tabular}{ll}
\hline \hline & $\Delta \mathrm{G}^{0}$ \\
\hline $\mathrm{PtCl}_{3}^{-}$ & 25.6 \\
$\mathrm{PtCl}_{2} \mathrm{OH}_{2}$ cis & 31.2 \\
$\mathrm{PtCl}_{2} \mathrm{OH}_{2}$ trans & 33.5 \\
$\mathrm{PtCl}\left(\mathrm{OH}_{2}\right)_{2}^{+}$cis & 32.5 \\
$\mathrm{PtCl}\left(\mathrm{OH}_{2}\right)_{2}{ }^{+}$trans & 29.0 \\
\hline
\end{tabular}

Before we consider the associative methane uptake transition states, we first consider the water uptake transition state, shown in Figure 8.4. The barrier for water uptake is $13.0 \mathrm{kcal} \mathrm{mol}^{-1}$. Figure 8.4 also includes three other possible associative methane uptake transition states. The lowest energy methane uptake is $\mathbf{1 c}^{\ddagger}$ in which methane displaces a water molecule from the platinum catalyst with a barrier of $14.6 \mathrm{kcal}$ $\mathrm{mol}^{-1}$. The two other methane uptake transition states are significantly higher in energy, consistent with the prior work of Ziegler et al. Several other uptake transition states are possible, but we were unable to find them on our potential energy surface, however they are almost positively higher in energy than the 14.6 barrier of $1 \mathbf{c}^{\ddagger}$ (as seen in the very high barrier for $\mathbf{1 d}^{\ddagger}$ ).
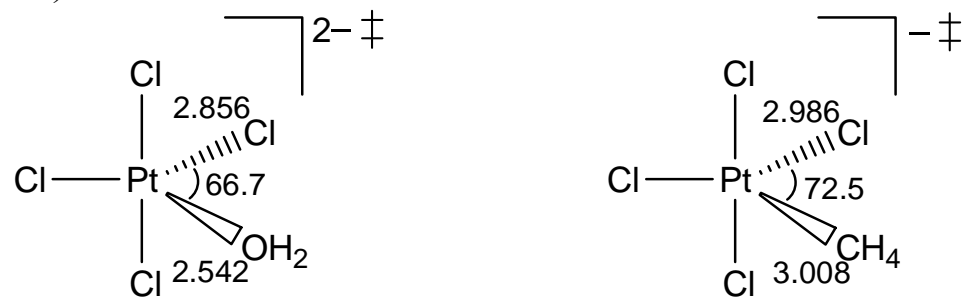

$$
\Delta \mathrm{G}^{\circ}=13.0
$$$$
\Delta \mathrm{G}^{\circ:}=22.1
$$

$1 \mathbf{a}^{+}$

$1 \mathbf{b}^{+}$
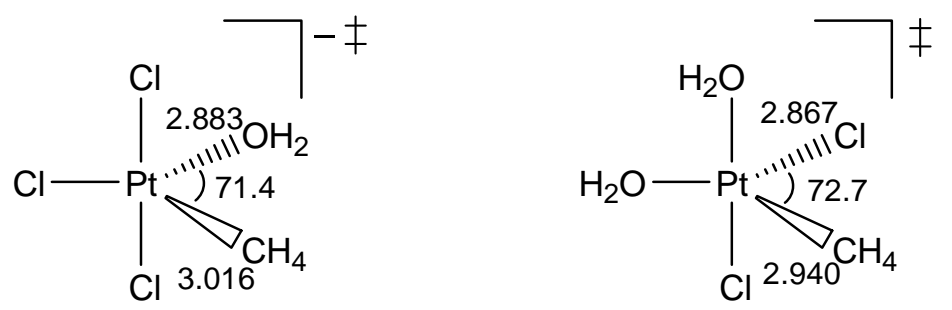

$$
\begin{gathered}
\Delta \mathrm{G}^{\circ}=14.6 \\
\mathbf{1 c}^{\star}
\end{gathered}
$$

$$
\begin{gathered}
\Delta \mathrm{G}^{\circ}=47.6 \\
\mathbf{1 d}^{\ddagger}
\end{gathered}
$$

Figure 8.4: Schematics and free energies, relative to $\mathrm{PtCl}_{4}{ }^{2-}$ in $\mathrm{kcal} \mathrm{mol}^{-1}$, for four methane uptake transition states. 
The methane uptake products are the complexes methane make with the T-Shaped dissociative intermediates. 5 different orientations of chlorides, water and methane are possible and the relative free energies are listed in Table 8.3. Any substitution of water leads to higher energy methane complexes

Table 8.3: Free energies, relative to $\mathrm{PtCl}_{4}{ }^{2-}$ in $\mathrm{kcal} \mathrm{mol}^{-1}$, for the methane uptake products.

\begin{tabular}{ll}
\hline \hline$\left[\mathrm{PtCl}_{3} \cdot \mathrm{CH}_{4}\right]^{-}$ & $\Delta \mathrm{G}^{0}$ \\
{$\left[\mathrm{PtCl}_{2} \mathrm{OH}_{2} \cdot \mathrm{CH}_{4}\right]$ cis $^{\mathrm{a}}$} & 18.0 \\
{$\left[\mathrm{PtCl}_{2} \mathrm{OH}_{2} \cdot \mathrm{CH}_{4}\right]$ trans } & 22.7 \\
{$\left[\mathrm{PtCl}\left(\mathrm{OH}_{2}\right)_{2} \cdot \mathrm{CH}_{4}\right]^{+}$cis } & 23.3 \\
{$\left[\mathrm{PtCl}\left(\mathrm{OH}_{2}\right)_{2} \cdot \mathrm{CH}_{4}\right]^{+}$trans } & 24.7 \\
\hline \hline
\end{tabular}

${ }^{a}$. cis/trans refers to the orientation of the two identical ligands on the metal. e.g. in cis $\left[\mathrm{PtCl}_{2} \mathrm{OH}_{2} \cdot \mathrm{CH}_{4}\right]$ the $\mathrm{Cl}$ atoms are cis.

\section{Conventional Shilov Chemistry: Oxidative Addition}

The second step in the activation process is the oxidiative addition of the methane to the platinum center. Figure 8.5 highlights the 5 distinct oxidative addition transition states and concomitant products in which the $\mathrm{Pt}$ center is formally a $\mathrm{Pt}(\mathrm{IV})$. The activation barrier is directly proportional to the stretch in the $\mathrm{C}-\mathrm{H}$ bond of methane. The lowest energy barriers are $\mathbf{2} \mathbf{a}^{\ddagger}$ and $\mathbf{2} \mathbf{d}^{\ddagger}$ which both have the smallest stretch of the $\mathrm{C}$-H bond. Species $\mathbf{2} \mathbf{d}^{\ddagger}$ actually has the lowest absolute activation barrier for oxidative addition, that is when we compare the transition state to the methane complex (consistent with $\mathbf{2 \mathbf { d } ^ { \ddagger }}$ having the shortest $\mathrm{C}$-H distance), however the relatively high energy of the trans $\left[\mathrm{PtCl}_{2} \mathrm{OH}_{2} \cdot \mathrm{CH}_{4}\right]$ complex leads to $\mathbf{2 d}^{\ddagger}$ having a higher net barrier than $\mathbf{2} \mathbf{d}^{\ddagger}$. However when the high concentration of water is taken into account, $\mathbf{2} \mathbf{d}^{\mathbf{*}}$ has a very similar net barrier to $\mathbf{2} \mathbf{a}^{\ddagger}$. In addition to oxidative addition we looked for a metathesis barrier in which a proton would get transferred to a chloride (from the $\left[\mathrm{PtCl}_{3} \cdot \mathrm{CH}_{4}\right]^{-}$ complex). This process has a barrier of $28.6 \mathrm{kcal} \mathrm{mol}^{-1}$. We were unable to find an electrophilic substitution in which a methane would donate a proton to a chloride in $\mathrm{PtCl}_{4}{ }^{2-}$ in a concerted fashion. 

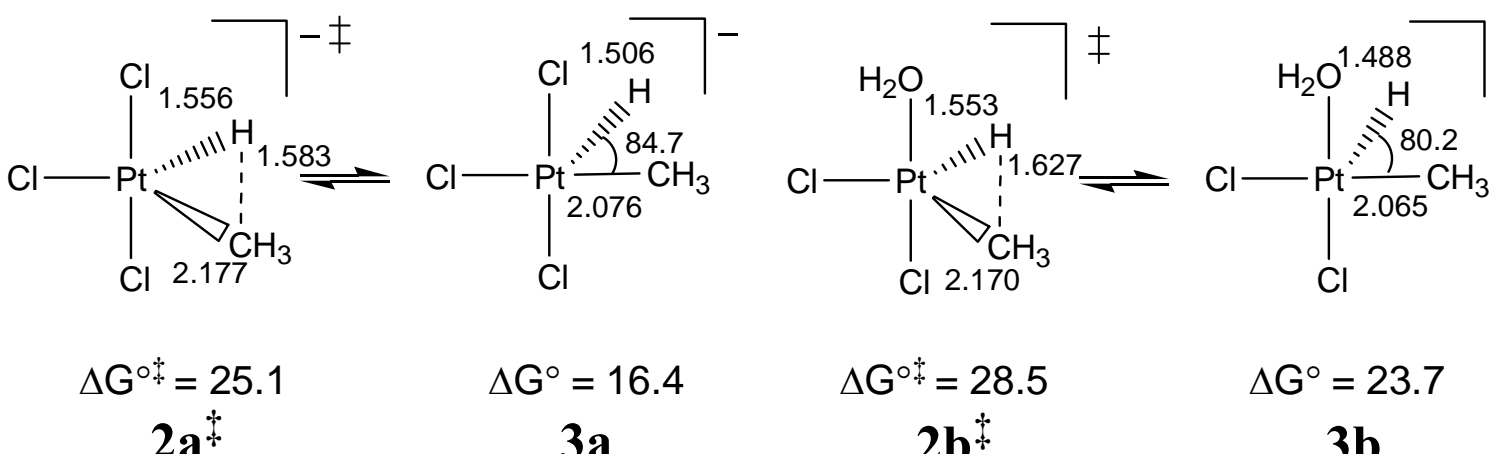

$\Delta \mathrm{G}^{\circ}=16.4$

$\Delta G^{\circ}:=28.5$

$\Delta \mathrm{G}^{\circ}=23.7$

$2 \mathbf{a}^{4}$

$3 \mathbf{a}$

$2 \mathbf{b}^{\ddagger}$

3b
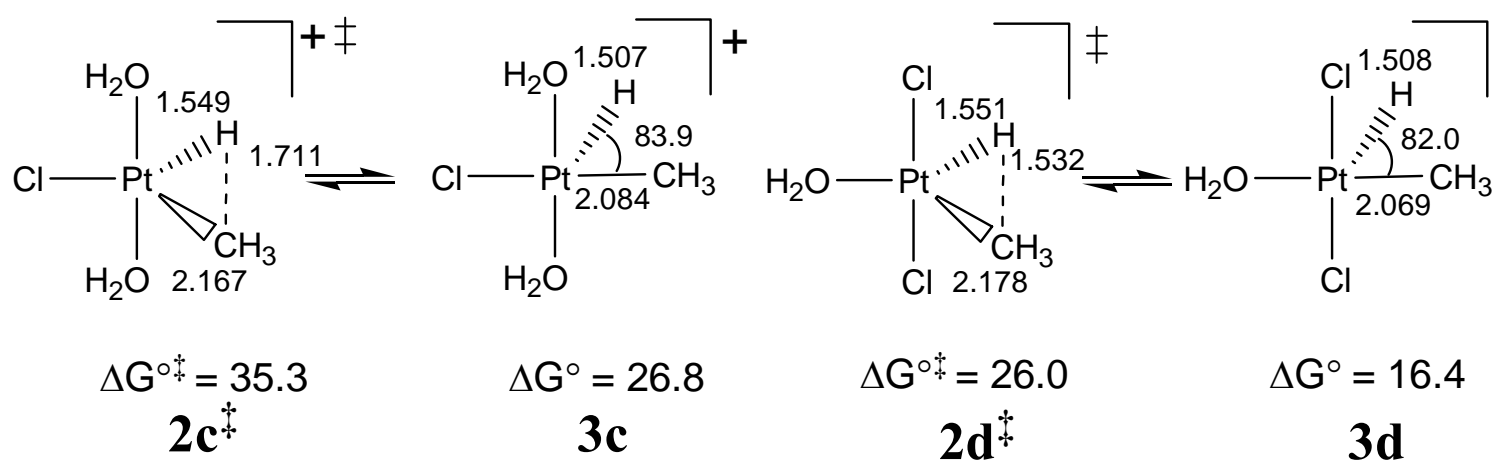

$$
\Delta G^{\circ}=26.8
$$

3c<smiles>C=C[I+][TeH](Cl)Cl</smiles>

$$
\begin{gathered}
\Delta G^{\circ}=40.9 \\
2 e^{\ddagger}
\end{gathered}
$$

$$
\begin{gathered}
\Delta \mathrm{G}^{\circ \ddagger}=26.0 \\
\mathbf{2 d}^{\ddagger}
\end{gathered}
$$$$
\Delta \mathrm{G}^{\circ}=16.4
$$

3d

Figure 8.5: Reaction schematic for oxidative addition transition state and pyramidal product for the 5 possible cases. Free energies are in $\mathrm{kcal} \mathrm{mol}^{-1}$, bond distances in Angstroms and angles in degrees.

The final step in the activation process would be for a solvent water molecule to abstract the proton, converting the Pt center back to $\mathrm{Pt}(\mathrm{II})$. The free energies for these deprotonated species are shown in Table 8.4. 
Table 8.4: Free energies, relative to $\mathrm{PtCl}_{4}{ }^{2-}$ in $\mathrm{kcal} \mathrm{mol}^{-1}$, for the deprotonated oxidative addition products.

\begin{tabular}{lc}
\hline \hline & $\Delta \mathrm{G}^{0}$ \\
\hline $\mathrm{PtCl}_{3} \mathrm{CH}_{3}{ }^{2-}$ & 0.8 \\
$\mathrm{PtCl}_{2} \mathrm{OH}_{2} \mathrm{CH}_{3}{ }^{-}$cis $^{a}$ & 6.7 \\
$\mathrm{PtCl}_{2} \mathrm{OH}_{2} \mathrm{CH}_{3}{ }^{-}$trans & 1.3 \\
$\mathrm{PtCl}_{\left(\mathrm{OH}_{2}\right)_{2} \mathrm{CH}_{3} \text { trans }}$ & 8.3 \\
$\mathrm{PtClOH}_{2} \mathrm{CH}_{3}{ }^{b}$ & 11.5 \\
\hline \hline
\end{tabular}

a. cis/trans refers to the orientation of the two identical ligands on the metal. e.g. in cis $\left[\mathrm{PtCl}_{2} \mathrm{OH}_{2} \cdot \mathrm{CH}_{4}\right]$ the $\mathrm{Cl}$ atoms are cis. ${ }^{b}$ This molecule has an empty site trans to the methyl, following from product $2 \mathrm{e}$ in Figure 8.5 .

After considering all of the data presented thus far we highlight the lowest energy pathway to methane activation and formation of the final $\mathrm{Pt}^{\mathrm{II}}-\mathrm{CH}_{3}$ species in Figure 8.6. The final net barrier for activation is $25.1 \mathrm{kcal} \mathrm{mol}^{-1}$.

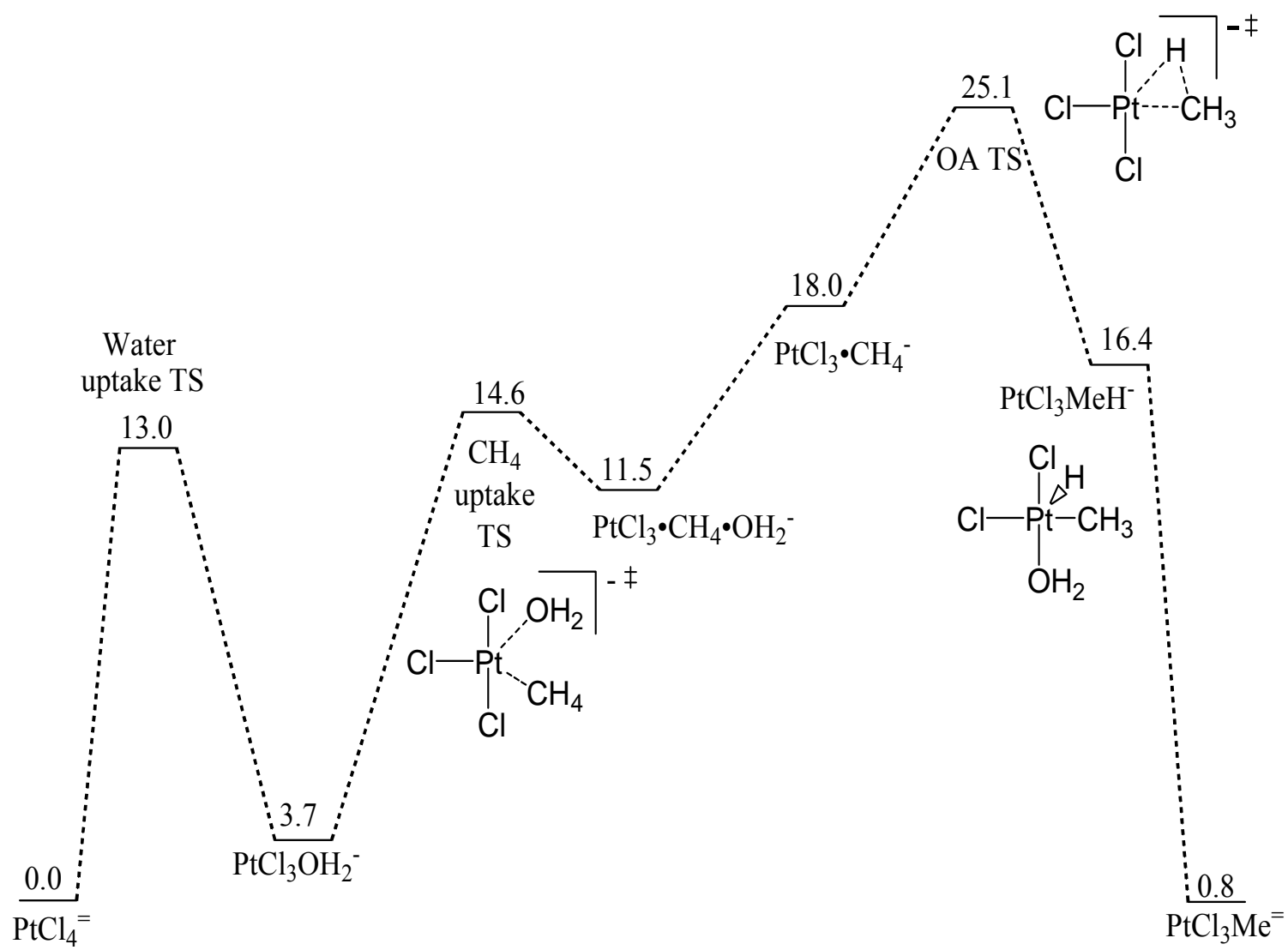

Figure 8.6: Free energy schematic for lowest energy mechanism to form activated $\mathrm{Pt}^{\mathrm{II}}-\mathrm{CH}_{3}$. All free energies are in $\mathrm{kcal} \mathrm{mol}^{-1}$. 


\section{Catalyst Equilibria when Acetic Acid is Present}

Experimental observations indicate that rate of $\mathrm{H}-\mathrm{D}$ exchange between methane and the solvent is increased upon the presence of a high concentration of acetic acid. This is indicative of a lowering of the overall net barrier for methane activation. As such we will explore the same series of reactions as shown in sections B and C, but with acetic acid. We first consider the equilibria between various substituted reference $\mathrm{Pt}^{\mathrm{II}}$ species, as shown in Table 8.5. When only a single acetate is bound to the platinum center, water in all cases destabilizes the catalyst. Placement of two acetate moieties also destabilizes the the platinum species relative to the ground state $\mathrm{PtCl}_{3} \mathrm{OAc}^{2-}$.

Table 8.5; Free energies, relative to $\mathrm{PtCl}_{4}{ }^{2-}$ in $\mathrm{kcal} \mathrm{mol}^{-1}$, for the deprotonated oxidative addition products.

\begin{tabular}{lc}
\hline \hline & $\Delta \mathrm{G}^{0}$ \\
\hline Single Acetate & -7.9 \\
$\mathrm{PtCl}_{3} \mathrm{OAc}^{2-}$ & 0.5 \\
$\mathrm{PtCl}_{2}\left(\mathrm{OH}_{2}\right) \mathrm{OAc}^{-}$cis $^{a}$ & -0.9 \\
$\mathrm{PtCl}_{2}\left(\mathrm{OH}_{2}\right) \mathrm{OAc}^{-}$trans & \\
$\mathrm{Two}^{\mathrm{Acetates}}$ & -1.6 \\
$\mathrm{PtCl}_{2}(\mathrm{OAc})_{2}^{2-}$ cis & -1.7 \\
$\mathrm{PtCl}_{2}(\mathrm{OAc})_{2}^{2-}$ trans & \\
\hline \hline
\end{tabular}

\section{E. Shilov Activation Chemistry with a Single Acetate Attached to Platinum}

We explored the activation of methane with respect to the ground state single acetate molecule, $\mathrm{PtCl}_{3} \mathrm{OAc}^{2-}$, and show this schematic in Figure 8.7. We have not explored the uptake mechanisms as they will be lower in energy. Both the cis and trans methane complexes lead to oxidative addition barriers larger than the conventional Shilov mechanism. We also explored a number of additional mechanisms, including metathesis mechanism in which the hydrogen was passed to the alpha oxygen (barrier of $36.6 \mathrm{kcal}$ $\mathrm{mol}^{-1}$, not shown in Figure 8.7) and one in which the proton was transferred to the gamma oxygen (barrier of $30.7 \mathrm{kcal} \mathrm{mol}^{-1}$, shown in Figure 8.7). Based on our work it does not seem likely that any of the shown mechanisms involving the platinum catalyst with a single acetate are responsible for the increased rate of methane activation. 


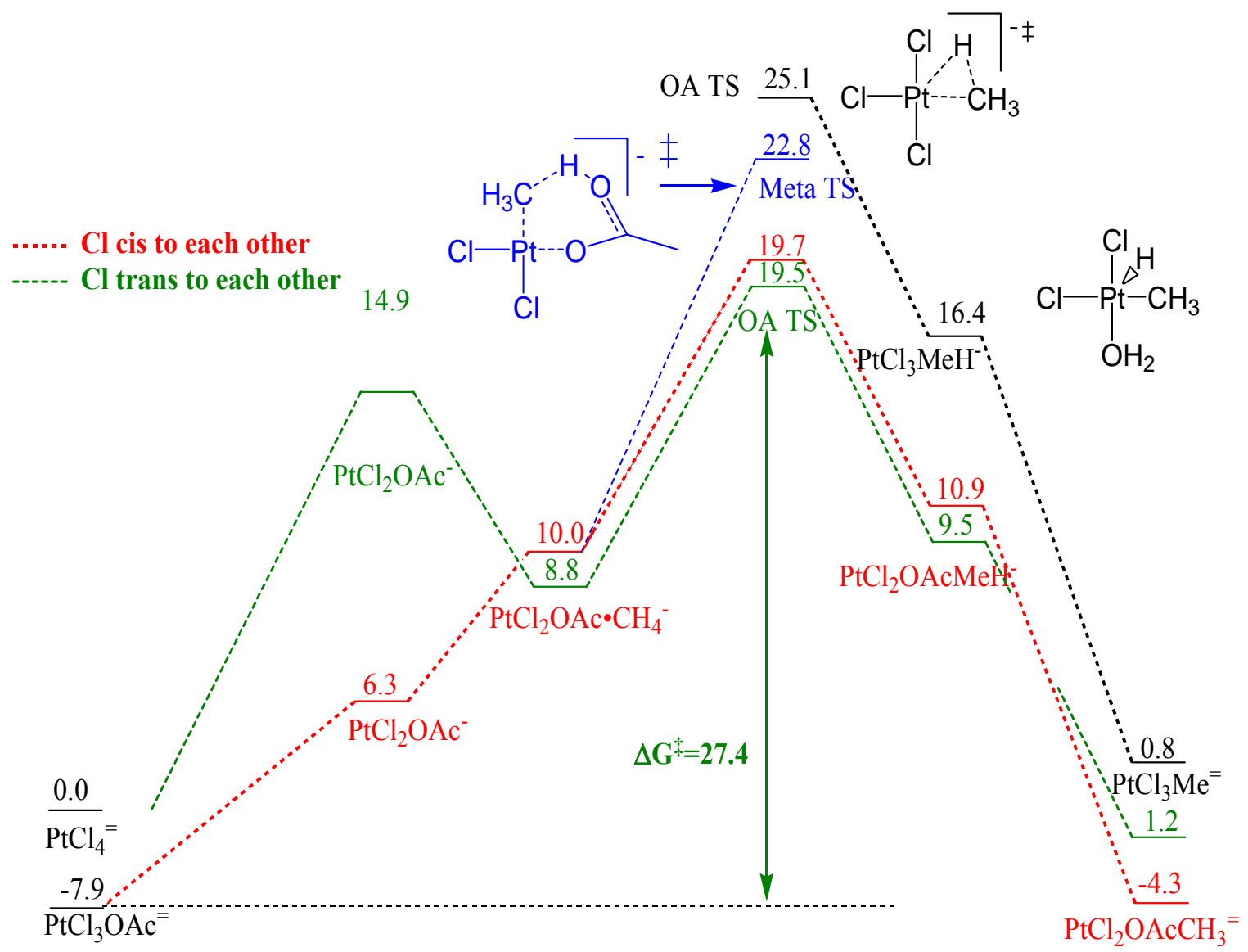

Figure 8.7: Free energy diagram, relative to $\mathrm{PtCl}_{4}{ }^{2-}$ in $\mathrm{kcal} \mathrm{mol}^{-1}$, for methane activation using the lowest energy single acetate species, $\mathrm{PtCl}_{3} \mathrm{OAc}^{2-}$.

\section{F. Shilov Activation Chemistry with Two Acetate Moieties Attached to Platinum}

As per our previous discussion of the equilibrium with acetic acid, $\mathrm{PtCl}_{3} \mathrm{OAc}^{2-}$ is the ground state from which all barriers must be referenced. In

Figure 8.8, we highlight the relative oxidative addition barriers when two acetate moieties are bonded to the central platinum. We again have not listed uptake barriers which should be lower than the oxidative addition. The most salient point is the net barrier of $24.7 \mathrm{kcal}$ $\mathrm{mol}^{-1}$ for oxidative addition starting from the trans $\mathrm{PtCl}_{2} \mathrm{OAc}_{2}{ }^{2-}$ species. This is $0.4 \mathrm{kcal}$ $\mathrm{mol}^{-1}$ smaller than the conventional Shilov system. The cis pathway has a larger barrier of $30.7 \mathrm{kcal} \mathrm{mol}^{-1}$. 


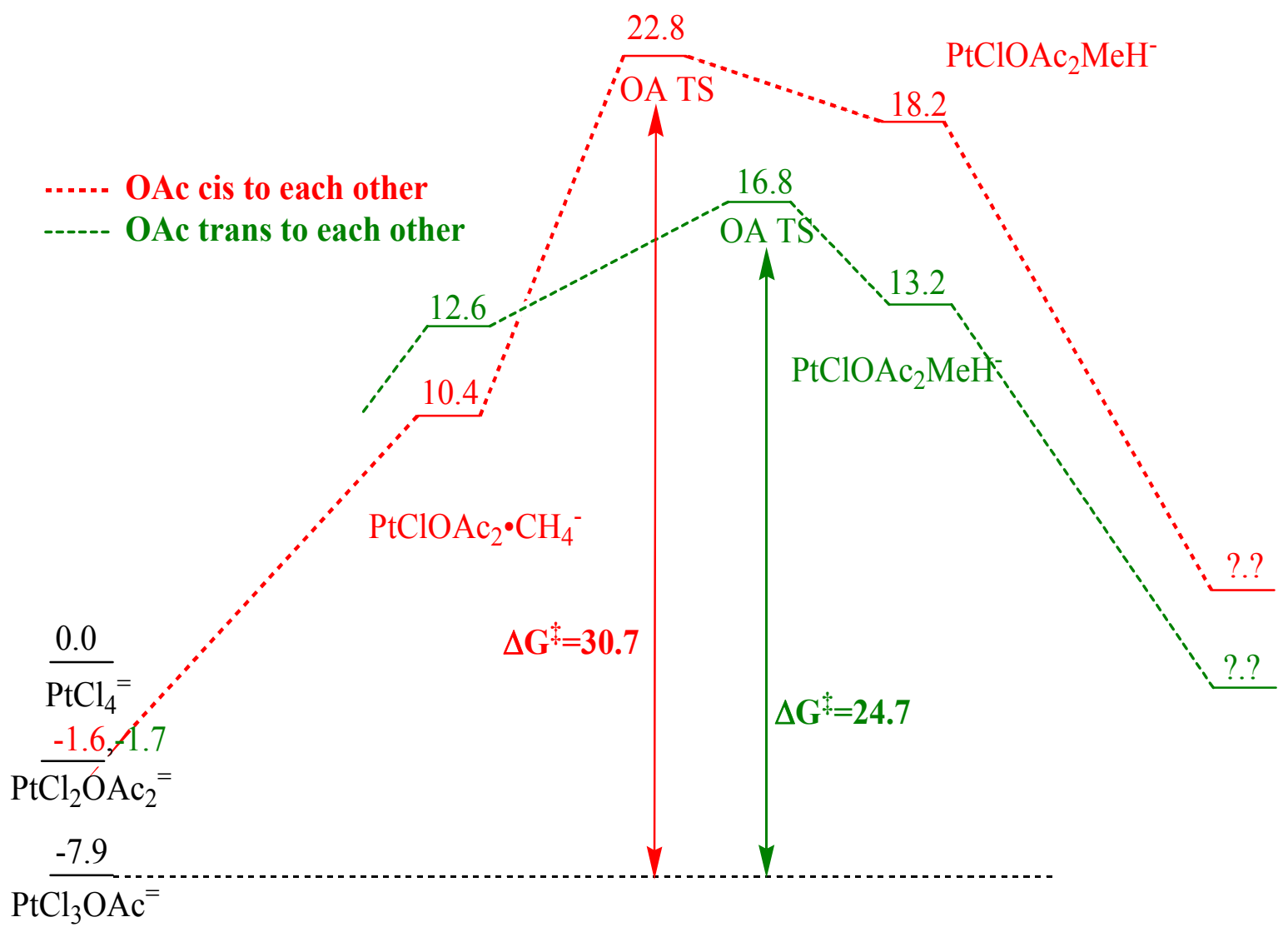

Figure 8.8: Free energy diagram, relative to $\mathrm{PtCl}_{4}{ }^{2-}$ in $\mathrm{kcal} \mathrm{mol}^{-1}$, for methane activation using the cis and trans bis-acetate species, $\mathrm{PtCl}_{2} \mathrm{OAc}_{2}{ }^{2-}$.

This result is pretty encouraging. However, the experimental data indicate that the addition of acetic acid increases the rate 10-100 times, consistent with a decreased barrier of 2-3 $\mathrm{kcal} \mathrm{mol}^{-1}$. During our earlier analysis we made the observation that explicit waters are very important in the description of the equilibrium between $\mathrm{PtCl}_{4}{ }^{2-}$ and $\mathrm{Pt}\left(\mathrm{OH}_{2}\right)_{2}(\mathrm{OAc})_{2}$, but they can also play an important role in the description of the $\mathrm{PtCl}_{3} \mathrm{OAc}^{2-}$. $\mathrm{PtCl}_{3} \mathrm{OAc}^{2-}$ is not as nucleophilic as $\mathrm{PtCl}_{4}{ }^{2-}$ and should be stabilized less with explicit waters. Preliminary work with 2 explicit waters on the platinum species show some interesting results. The conventional Shilov barriers changes little, from 25.1 $\mathrm{kcal} \mathrm{mol}^{-1}$ to $25.5 \mathrm{kcal} \mathrm{mol}^{-1}$. The mono-acetate barriers actually get larger from 27.4 to $30.3 \mathrm{kcal} \mathrm{mol}^{-1}$ (for the cis case), this is despite the fact that the $\mathrm{PtCl}_{3} \mathrm{OAc}^{2-}$ complex is destabilized to a relative energy of $-5.8 \mathrm{kcal} \mathrm{mol}^{-1}$ (from -7.9) when 2 explicit waters are included. However the trans bis-acetate net barrier is reduced to $22.5 \mathrm{kcal} \mathrm{mol}^{-1}$. This is $3.0 \mathrm{kcal} \mathrm{mol}^{-1}$ less than the conventional Shilov system, in line with experimental results. 


\section{G. Methodological Improvements for Describing Shilov Chemistry}

We are concerned with the accurate calculation of redox potentials for platinum and other metals which may be useful as oxidants. Tabulated reference data for three chemical oxidations was used to determine the basis functions which are required by our metals for accurate thermochemistry. Table 8.6 compares the performance of the "offthe-shelf" pseudopotential and basis set of Hay and Wadt with the performance of a valence basis we have created by adding additional $p$ - and f-angular momentum functions. The $p$-functions allow expansion or contraction of the $6 p$ electrons of platinum as charge is donated or withdrawn from the atom. F-functions allow angular optimization of the bonding orbitals in environments far from spherical. These additional functions are very effective in correcting deficiencies in the standared bases.

Table 8.6: Comparison of the performance of the standard Los Alamos pseudopotentials and valence basis functions with a valence basis augmented with additional p- and f-functions.

\begin{tabular}{|l|l|l|l|l|}
\hline & \multicolumn{3}{|l|}{$\Delta \mathrm{G}_{\mathrm{rxn}}(\mathrm{kcal} / \mathrm{mol})$} \\
& & $\begin{array}{l}\text { B3LYP } \\
\text { Los Alamos } \\
\text { standard } \\
\text { valence }\end{array}$ & $\begin{array}{l}\text { Los Alamos } \\
\text { augmented } \\
\text { valence }\end{array}$ & $\begin{array}{l}\text { Explicit } \\
\text { solvent }\end{array}$ \\
\hline Reaction & Experiment & -20.1 & -30.9 & -32.2 \\
\hline $\mathrm{Pt}^{\mathrm{II}} \mathrm{Cl}_{4}{ }^{2-}(1 \mathrm{M})+\mathrm{Cl}_{2}(1 \mathrm{~atm}) \rightarrow \mathrm{Pt}^{\mathrm{IV}} \mathrm{Cl}_{6}{ }^{2-}(1 \mathrm{M})$ & -29.0 & -18.9 & -29.9 & - \\
\hline $\mathrm{Pt}^{\mathrm{II}}\left(\mathrm{NH}_{3}\right) \mathrm{Cl}_{3}{ }^{1-}+\mathrm{Cl}_{2} \rightarrow \mathrm{Pt}^{\mathrm{IV}}\left(\mathrm{NH}_{3}\right) \mathrm{Cl}_{5}{ }^{1-}$ & -30.9 & 2.8 & -3.1 & - \\
\hline $\mathrm{Pd}^{\mathrm{II}} \mathrm{Cl}_{4}{ }^{2-}+\mathrm{Cl}_{2} \rightarrow \mathrm{Pd}^{\mathrm{IV}} \mathrm{Cl}_{6}{ }^{2-}$ & -3.1 & 2.8 & \\
\hline
\end{tabular}

We repeated the platinum tetrachloride oxidation, including six explicit water molecules around the platinum chloride complexes which could accept fractional charge from the anions. The continuum dielectric is still used outside of the entire metal-water cluster. Table 8.7 also shows that this role of explicit solvent is unnecessary and has little effect on the calculated free energy change.

Table 8.7: Comparision of two pseudopotentials (by Los Alamos and Ermler, et al.)

\begin{tabular}{|c|c|c|c|}
\hline \multirow[b]{2}{*}{ Reaction } & \multicolumn{3}{|c|}{$\begin{array}{c}\Delta \mathrm{G}_{\mathrm{rxn}}(\mathrm{kcal} / \mathrm{mol}) \\
\mid \text { B3LYP }\end{array}$} \\
\hline & Exp. & $\begin{array}{l}\text { Los Alamos } \\
\text { augmented }\end{array}$ & Ermler(2f) \\
\hline $\mathrm{Pt}^{\mathrm{II}} \mathrm{Cl}_{4}^{2-}+\mathrm{Cl}_{2} \rightarrow \mathrm{Pt}^{\mathrm{IV}} \mathrm{Cl}_{6}^{2-}$ & -29.0 & -30.9 & -30.5 \\
\hline $\mathrm{Pt}^{\mathrm{II}}\left(\mathrm{NH}_{3}\right) \mathrm{Cl}_{3}{ }^{1-}+\mathrm{Cl}_{2} \rightarrow \mathrm{Pt}^{\mathrm{IV}}\left(\mathrm{NH}_{3}\right) \mathrm{Cl}_{5}{ }^{1-}$ & -30.9 & -29.9 & -28.7 \\
\hline $\mathrm{Pd}^{\mathrm{II}} \mathrm{Cl}_{4}^{2-}+\mathrm{Cl}_{2} \rightarrow \mathrm{Pd}^{\mathrm{IV}} \mathrm{Cl}_{6}^{2-}$ & -3.1 & -3.1 & - \\
\hline
\end{tabular}

For the same three testing reactions we compared two pseudopotentials and two density functionals (Table 8.7). The more recent pseudopotential of Ermler, et al ${ }^{14}$., (again with f-functions added) offered similar performance to the Los Alamos pseudopotential. 
Table 8.8: Evaluation chlorine thermodynamics with and without $d$ - and f-angular momentum polarization functions

\begin{tabular}{|l|l|l|l|}
\hline \multirow{2}{*}{ Reaction } & \multicolumn{3}{|l|}{$\Delta \mathrm{H}_{\mathrm{rxn}}(\mathrm{kcal} / \mathrm{mol})$} \\
\cline { 3 - 4 } & \multirow{2}{*}{ Exp. } & $6-311 \mathrm{G}^{* *++}$ & $6-311 \mathrm{G}++-3 \mathrm{df}$ \\
\hline $1 / 2 \mathrm{Cl}_{2}+\mathrm{e}^{-} \rightarrow \mathrm{Cl}^{-}$ & -57.2 & -63.6 & -58.8 \\
\hline $1 / 2 \mathrm{Cl}_{2} \rightarrow \mathrm{Cl} \cdot$ & 29.1 & 24.7 & 29.4 \\
\hline $1 / 2 \mathrm{Cl}_{2} \rightarrow \mathrm{e}^{-}+\mathrm{Cl}^{+}$ & 331.1 & 327.8 & 332.5 \\
\hline
\end{tabular}

Capturing the thermochemistry of chlorine is equally important in our investigations. Table 8.8 compares the performance of the moderately sized $6-311 \mathrm{G}^{* *++}$ basis to the same basis augmented with $\mathrm{d}$ - and f-angular momentum polarization functions. Without the polarization functions, chlorine in a nonspherical environment (e.g. $\mathrm{Cl}_{2}$ or $\mathrm{M}-\mathrm{Cl}$ ) is consistently destabilized relative to chlorine in a spherical potential (e.g., free $\mathrm{Cl}^{-}$). The addition of polarization functions corrects this behavior.

These expanded basis sets, along with the density functional and solvation model validated here and in other calculations, give us great confidence in predicting the thermochemistry of new and interesting oxidation reactions.

\subsection{EFFECTIVE OXIDATION STATE OF PT-CATALYST IN HOT CONCENTRATED SULFURIC ACID FOR CATALYTIC METHANE CONVERSION}

This multi-year project started from the Catalytica system reported by Periana et.al in 1998 in which (bpym) $\mathrm{Pt}^{\mathrm{II}} \mathrm{Cl}_{2}$ efficiently catalyzes the partial oxidation of $\mathrm{CH}_{4}$ to $\mathrm{CH}_{3} \mathrm{OSO}_{3} \mathrm{H}$ in hot concentrated $\mathrm{H}_{2} \mathrm{SO}_{4}$. The high selectivity, relatively high reaction rate and system stability make this low temperature methane conversion approach highly attractive for economically utilization of abundant yet untapped natural gas resources. However, critical hurdles need to be overcome for this approach including the system deactivation upon water/methanol production, high product separation cost and utilization of highly corrosive concentrated sulfuric acid. Indepth understanding on the reaction mechanisms has critical significance on improving the Catalytica system. Our latest work has revealed that the concentrated sulfuric acid not only serves as the oxidant but also functions as a co-catalyst. In addition, we have explored the possible pathway for the stabilization of the effective oxidation state of the Pt-catalyst.

Experimental observations on the Catalytica system showed that 1) $\mathrm{Pt}(\mathrm{IV})$ is the inactive species for $\mathrm{C}-\mathrm{H}$ activation in $\mathrm{CH} 4$; 2) $\mathrm{Pt}(\mathrm{IV})$ is the highest thermodynamically accessible (i.e. the stable oxidation state in stead of $\mathrm{Pt}(\mathrm{II})$ ) under the reaction conditions for the Catalytica methane to methanol conversion system; 3 ) the over-oxidation of $\mathrm{Pt}(\mathrm{II})$ to $\mathrm{Pt}(\mathrm{IV})$ through hot concentrated $\mathrm{H}_{2} \mathrm{SO}_{4}$ with generation of $\mathrm{SO}_{2}$ gas is irresversible 
Firstly, we investigated how the oxidation of the non-methylated (bpym) $\mathrm{Pt}^{\mathrm{II}}$ complex could occur. The previously proposed mechanism by Ziegler et al. ${ }^{15}$ was found, in our hands, to have an inaccessible barrier of $44 \mathrm{kcal} \mathrm{mol}^{-1}$ (for oxidant $=\mathrm{H}_{2} \mathrm{SO}_{4}, 39$ when oxidant $=\mathrm{H}_{2} \mathrm{~S}_{2} \mathrm{O}_{7}$ ). Another path was located which starts with replacement of one of the chlorides on $\mathbf{1}$ to yield the bisulphate complex $\mathbf{2}$ and $\mathrm{HCl}$. $\mathrm{HCl}$ and $\mathrm{H}_{2} \mathrm{SO}_{4}$ is known to react to give chlorosulfonic acid. We calculate that reaction to be endergonic by 14.1 $\mathrm{kcal} \mathrm{mol}^{-1}\left(9.4 \mathrm{kcal} \mathrm{mol}^{-1}\right.$ for reaction between $\mathrm{HCl}$ and $\left.\mathrm{H}_{2} \mathrm{~S}_{2} \mathrm{O}_{7}\right)$. The chlorosulfonic acid can then react with the non-methylated $\mathrm{Pt}^{\mathrm{II}}$ complex 2 via an inner-sphere electron transfer (3ts) similar to that proposed for $\mathrm{Pt}^{\mathrm{II}}$ and $\mathrm{Pt}^{\mathrm{IV}}$ interchange to give the $\mathrm{Pt}^{\mathrm{IV}}$ complex 4 and water and $\mathrm{SO}_{2}$. The overall barrier for the electron transfer relative to 1 and $\mathrm{H}_{2} \mathrm{SO}_{4}$ was found to be $35.9 \mathrm{kcal} \mathrm{mol}^{-1}\left(31.2 \mathrm{kcal} \mathrm{mol}^{-1}\right.$ for $\left.\mathrm{H}_{2} \mathrm{~S}_{2} \mathrm{O}_{7}\right)$ and the overall reaction was found to be exergonic by $1.0 \mathrm{kcal} \mathrm{mol}^{-1}$ (6.x kcal mol${ }^{-1}$ for $\mathrm{H}_{2} \mathrm{~S}_{2} \mathrm{O}_{7}$ ). The value we calculate for the barrier is very close to the value reported for the overall catalytic conversion of methane to methanol. This shows that the complete oxidation of the non-methylated form of the (bpym) $\mathrm{Pt}^{\mathrm{II}}$ catalyst under the optimal reaction conditions $\left(102 \% \mathrm{H}_{2} \mathrm{SO}_{4}\right)$ will be complete within a few turnovers. As can be seen from the transition state for the inner-sphere reaction, the reaction is facilitated by the high proton availability that leads to protonation of the $\mathrm{OH}$ group of the chlorosulfuric acid. This protonation facilitates both the kinetics and thermodynamics of the inner-sphere transfer. Thus, protonation activates the cholorosulfonic acid by reducing the energy of the Cl-S anti-bonding orbital, the LUMO, to attach of the $\mathrm{Pt}(\mathrm{II}) \mathrm{d}_{\mathrm{z}}{ }^{2} \mathrm{HOMO}$ at the Cl-group with water instead of $\mathrm{OH}^{-}$as the leaving group. This contrasts to the classic self-exchange studies by Basolo where the $\left[\mathrm{PtCl}_{4}\right]^{2-} \mathrm{d}_{\mathrm{z}}{ }^{2} \mathrm{HOMO}$ energy is increased by coordination of $\mathrm{Cl}^{-}$generate a five coordinate $\left[\mathrm{PtCl}_{5}\right]^{3-}$ intermediate that attacks the Cl-Pt anti-bonding orbital, the LUMO, of $\left[\mathrm{PtCl}_{6}\right]^{2-}$. 
1)
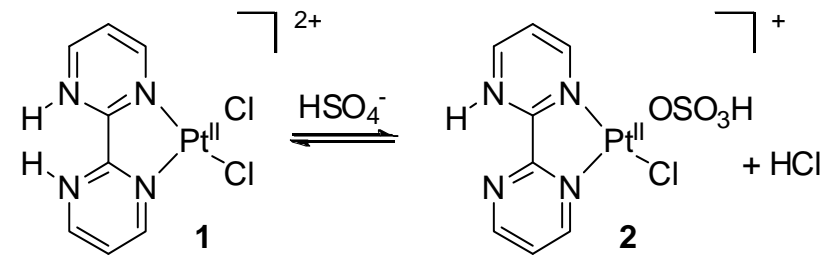

$\Delta \mathrm{G}(500 \mathrm{~K})=1.6 \mathrm{kcal} \mathrm{mol}^{-1}$

2) $\mathrm{HCl}+\mathrm{H}_{2} \mathrm{SO}_{4}+\mathrm{H}^{+} \longrightarrow \mathrm{HSO}_{3} \mathrm{Cl}+\mathrm{H}_{3} \mathrm{O}^{+}$

$\Delta \mathrm{G}(500 \mathrm{~K})=14.1 \mathrm{kcal} \mathrm{mol}^{-1}$

or $\mathrm{HCl}+\mathrm{H}_{2} \mathrm{~S}_{2} \mathrm{O}_{7} \longrightarrow \mathrm{HSO}_{3} \mathrm{Cl}+\mathrm{H}_{2} \mathrm{SO}_{4}$ in oleum $\Delta \mathrm{G}(500 \mathrm{~K})=9.4 \mathrm{kcal} \mathrm{mol}^{-1}$

3)
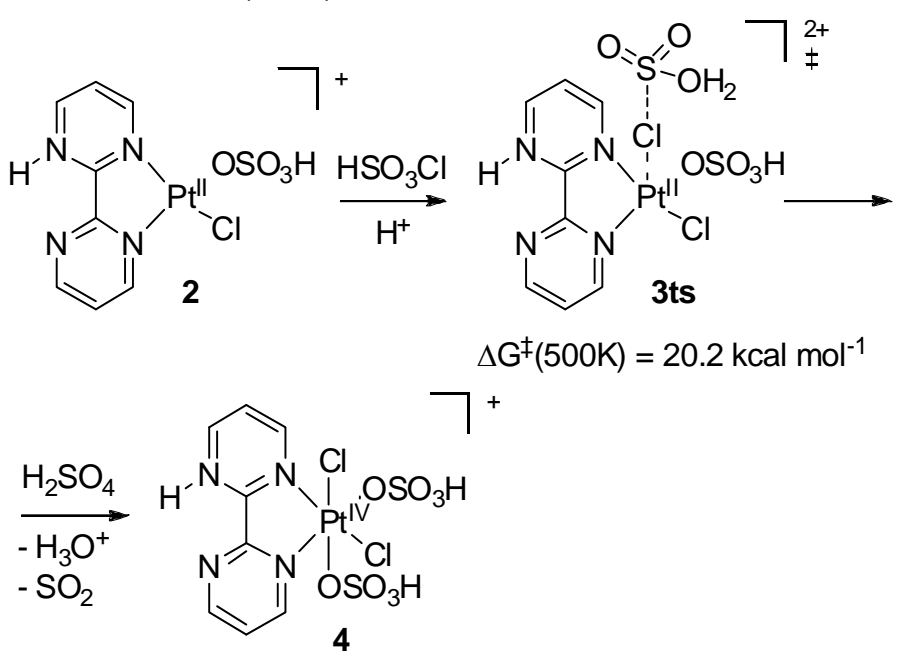

Overall barrier from 1 to $3 \mathrm{ts}=35.9 \mathrm{kcal} \mathrm{mol}^{-1}$ (31.2 kcal mol${ }^{-1}$ in oleum)

Figure 8.9:. Oxidation of the $\mathrm{Pt}^{\mathrm{II}}$ complex 1 to the $\mathrm{Pt}^{\mathrm{IV}}$ complex 

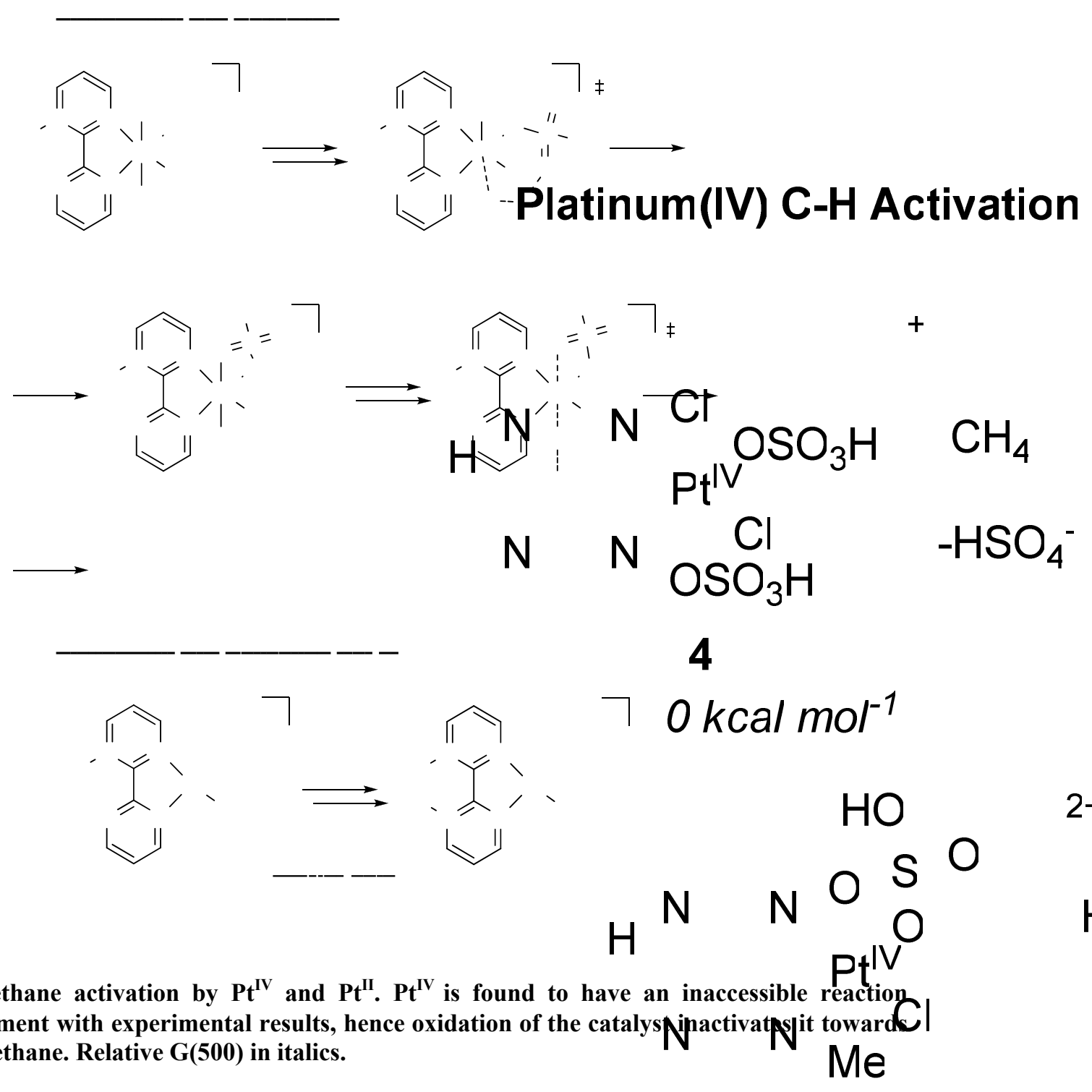

Theoretical calculations also support the view that it is (bpym)Pt(II) $\mathbf{6}^{\text {not }}$ (bpym) $\mathrm{Pt}(\mathrm{IV}$ ) acting as the active catalyst for the C-H activation. The lowest energy calculated barriers corresponding to the (bpym) $\mathrm{Pt}(\mathrm{IV})$ catalyst are substantially higher than the observed barriers for catalyzed oxidation reaction of methane to methañ 4 : The highest point on the path for reaction between (bpym) $\mathbf{P t}^{\mathbf{I V}}$ and methane is the $\mathrm{C}-\mathrm{H}$ cleavage which is calculated to have a barrier of $41.2 \mathrm{kcal} \mathrm{mol}^{-1}$
to the barrier of 2 which we recently published, of $27.7 \mathrm{kcal} \mathrm{mol}^{-1}$. Moreove can functionalization of the $\mathrm{Pt}^{\mathrm{IV}}$ methyl has a barrier of $23.3 \mathrm{kcal} \mathrm{mol}^{-1}$, while the protonation of the same $\mathrm{Pt}^{\mathrm{IV}}$ methyl bond, which is the microscopic reverse of the reaction of $\mathbf{4}$ and methane, has a barrier of $43.9 \mathrm{kcal} \mathrm{mol}^{-1}$. These results are not compatible with the
experimental observation that the methyl group of the deuterated when the reaction is performed in $\mathrm{D}_{2} \mathrm{SO}_{4}$. $\mathrm{Pt}^{\mathrm{II}}$ however has been shown to incorporate multiple deuterium atoms in the reversible $\mathrm{C}-\mathrm{H}$ activation of methane in $\mathrm{D}_{2} \mathrm{SO}_{4}$, and we believe that this further proves that $\mathrm{Pt}^{\mathrm{II}}$ is the active state of the catalyst. 
If $\mathrm{CH}$ Activation by $\mathrm{Pt}^{\mathrm{IV}}$ is eliminated, then the basis for the stability of the Catalytica system remains to be elucidated. Another possibility is the known reaction between $\mathrm{Pt}^{\mathrm{IV}}$ and $\mathrm{Pt}^{\mathrm{II}}-\mathrm{CH}_{3}$ as has been shown for the Shilov system. However, to be the basis for the high stability of the system, this reaction would have to be competitive with the over-oxidation of resulting from the reactions of $\mathrm{Pt}^{\mathrm{II}}$ with solvent $\mathrm{H}_{2} \mathrm{SO}_{4}$. Since the steady state concentrations of $\mathrm{Pt}^{\mathrm{II}}$ and $\mathrm{Pt}^{\mathrm{IV}}$ would be in the ppt and ppm respectively, this reaction would certainly have to operate at diffusion controlled rates to be competitive. The known self exchange rates between $\left.\mathrm{PtCl}_{4}\right]^{2-}$ and $\left.\mathrm{PtCl}_{6}\right]^{2-}$ are much too slow for this to be the reaction mechanism although Bercaw showed that with $\mathrm{Pt}^{\mathrm{II}}-\mathrm{CH}_{3}$ species that the reactions can be faster.

In the Shilov system, ${ }^{16} \mathrm{Pt}^{\mathrm{IV}}$ is used as the stoichiometric oxidant. The proposed mechanism for this system is that $\mathrm{Pt}^{\mathrm{II}}$ activates methane to yield a $\mathrm{Pt}^{\mathrm{II}}$ methyl complex. This complex then reacts with the $\mathrm{Pt}^{\mathrm{II}}$ via an inner-sphere electron transfer to give a $\mathrm{Pt}^{\mathrm{IV}}$ methyl and non-methylated $\mathrm{Pt}^{\mathrm{II}}$. We recently reported the mechanism for the acid catalyzes methane uptake. In that study we showed that the platinum methyl complex 8 formed in the $\mathrm{C}-\mathrm{H}$ activation is $17.7 \mathrm{kcal} \mathrm{mol}^{-1}$ higher in energy than 2 . If there is a similar electron transfer between $\mathbf{4}$ and $\mathbf{8}$ it therefore needs to be very facile since the barrier will be added to the energy of $\mathbf{8}$.

We have indeed found a facile an inner-sphere electron transfer transition state 9ts from the reaction between $\mathbf{4}$ and $\mathbf{8}$ in which a sulphuric acid molecule had been dissociated. The free energy of 9ts is calculated to be only $5.5 \mathrm{kcal} \mathrm{mol}^{-1}$ relative to the methyl complex 8 and the $\mathrm{Pt}^{\mathrm{IV}}$ complex 4. Such low barrier indicates that the reaction is essentially diffusion controlled. The resulting complexes of the reaction is the organometallic $\mathrm{Pt}^{\mathrm{IV}}$ methyl complex $\mathbf{1 0}$ and the non-methlated $\mathrm{Pt}^{\mathrm{II}}$ complex 2 . The reaction is exergonic by $25.4 \mathrm{kcal} \mathrm{mol}^{-1}$. The fact that the electron transfer is calculated to have such low barrier means that it is likely responsible for the reduction of the oxidized catalyst and regeneration of the $\mathrm{C}-\mathrm{H}$ activation capable $\mathrm{Pt}^{\mathrm{II}}$, and at the same time it oxidizes the $\mathrm{Pt}^{\mathrm{II}}$ methyl to $\mathrm{Pt}^{\mathrm{IV}}$ methyl which can readily form the methyl bisulphate reductively.

It is interesting to note that this inner-sphere electron transfer is facilitated by the acid by protonation of the bisulphate leaving group, rather than chloride catalyzed as in the classical [Cl----Pt $\left.{ }^{\mathrm{II}}---\mathrm{Cl}---\mathrm{Pt}^{\mathrm{IV}}-\mathrm{Cl}\right]^{-}$system. ${ }^{17}$ In the classical system, one could postulate that the pre-equilibrium reaction between $\left[\mathrm{PtCl}_{4}\right]^{2-}$ and $\mathrm{Cl}^{-}$to generate $\left[\mathrm{PtCl}_{5}\right]^{3-}$ served to increases the nucleophilicity of the $\mathrm{Pt}^{\mathrm{II}}$ center and that this facilitates the attack on the $\mathrm{Cl}$ center and the displacement of $\mathrm{Pt}^{\mathrm{II}}$ and $\mathrm{Cl}^{-}$from the $\mathrm{Cl}-\mathrm{Pt}^{\mathrm{IV}}-\mathrm{Cl}$ complex. Since the energetic cost of generating $\mathrm{Cl}^{-}$in concentrated sulphuric acid is prohibitively high, the activation and inner-sphere electron-transfer proceeds via a complementary pathway involving activation by protonation as opposed to $\mathrm{Cl}^{-}$activation. Thus, in this case, rather than the $\mathrm{Pt}^{\mathrm{II}}$ complex being activated to be a stronger nulecophile, the lowest energy pathway involves protonolysis of the $\mathrm{X}$ group of the $\mathrm{Cl}-\mathrm{Pt}^{\mathrm{IV}}-\mathrm{X}$ ground state. This serves to increases the electrophilicty the $\mathrm{Cl}$ atom of the $\mathrm{Cl}-\mathrm{Pt}^{\mathrm{IV}}-\mathrm{XH}$ complex and also generates a more labile, HX leaving group in 6ts. This illustrates the importance of the acid solvent 
not only in the $\mathrm{C}-\mathrm{H}$ activation even, but also in the oxidation and as will shown later, in the functionalization reactions.

Significantly, we find that trans to the chloride of $\mathbf{1 0}$ it is favourable to coordinate bisulphate while trans to the methyl group of $\mathbf{1 2}$ it is more favourable to solvate the bisulphate. The unfavourable coordination trans to the methyl group is likely due to a combination of the strong trans influence of the methyl group and the weakly coordinating properties of the bisulphate. Since the methyl group on $\mathbf{1 2}$ is electrophilic and leads to a more stable 4-corodinate $\mathrm{Pt}^{\mathrm{II}}$ product on nucleophilic attack of $\mathrm{HSO}_{4}{ }^{-}$on the methyl group, the functionalization reaction proceeds from the 5-coordinate complex 12 versus the 6-coordinate 10. The reorganization between $\mathbf{1 0}$ and $\mathbf{1 2}$ is calculated to have a barrier (11ts) of $14.0 \mathrm{kcal} \mathrm{mol}^{-1}$ and is exergonic by $15.1 \mathrm{kcal} \mathrm{mol}^{-1}$. Nucleophilic functionalization by a bisulphate on the methyl group occurs via 13ts. The barrier was calculated to be $27.6 \mathrm{kcal} \mathrm{mol}^{-1}$. Now the product have been generated and a $\mathrm{Pt}^{\mathrm{II}}$ species 14 have been regenerated which can activate methane.

To conclude, our calculations have proposed to use a lower than the highest accessible oxidation state of the metal catalyst for reaction with methane in the case of the (bpym) $\mathrm{PtCl}_{2} / \mathrm{H}_{2} \mathrm{SO}_{4}$ system where methane $\mathrm{CH}$ activation is proposed to react with a $\mathrm{Pt}^{\mathrm{II}}$ species rather than the thermodynamically more stable, higher oxidation state, $\mathrm{Pt}(\mathrm{IV})$. The C-H activation generates a $\mathrm{Pt}^{\mathrm{II}}-\mathrm{Me}$ species, which is oxidized to a $\mathrm{Pt}^{\mathrm{IV}}-\mathrm{Me}$ species. This complex is then readily undergoes reductive functionalization by nucleophilic substitution on the methyl group, to generate the product and regenerates the active, lower oxidation state catalytic species, $\mathrm{Pt}(\mathrm{II})$. For the mechanism where the catalyst is in the highest available oxidization state, it is likely to be more susceptible to poisoning by water or other coordinating molecules, since higher oxidation states are typically kinetically less labile due to the stronger ligand metal bond strengths. On the other hand, since the highest available oxidation state of the catalyst is the thermodynamically stable state, the catalyst will not be sensitive to deactivation through oxidation of the active species. For the mechanism where the active state is a lower oxidation state than is thermodynamically accessible. Since this lower oxidation state is less electron withdrawing than the higher oxidized states and forms weaker bonds to its ligands, it will likely be less sensitive to water poisoning and more kinetically labile. However, there is a risk that the active, reduced oxidation state catalyst will be deactivated by over oxidation reactions. 

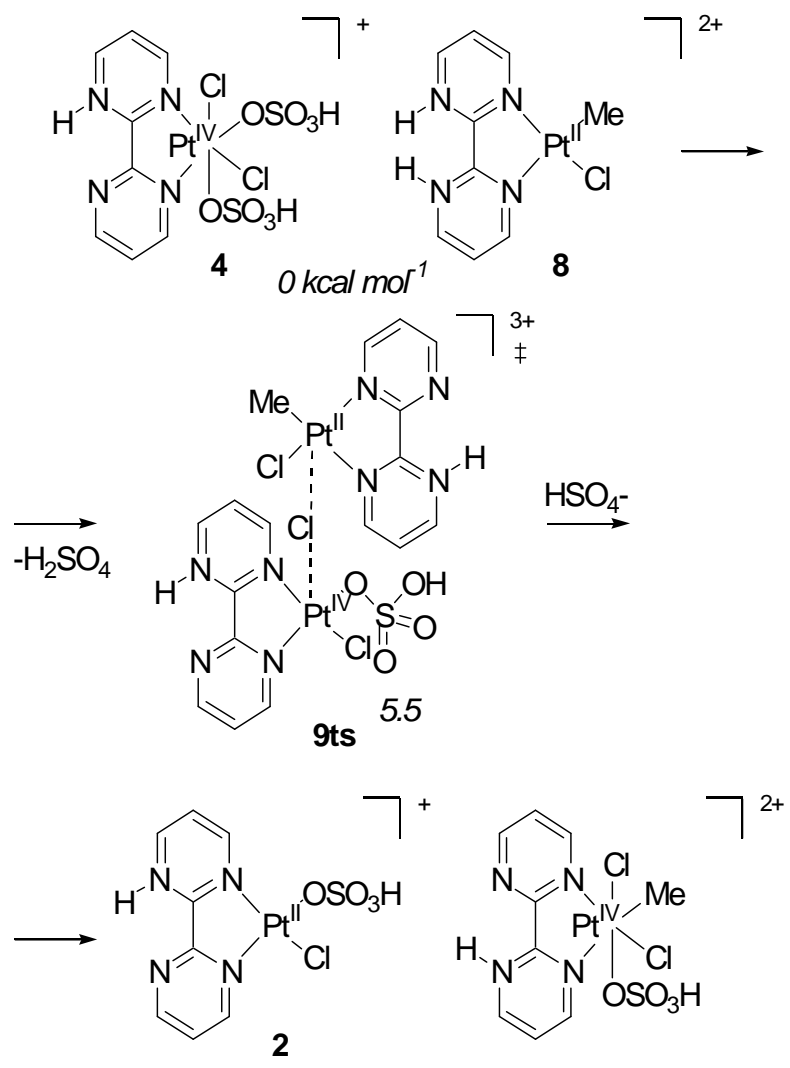

$-25.4$

10

Figure 8.11: Inner-sphere electron transfer between non-methylated $\mathbf{P t}^{\mathrm{IV}}$ and methylated $\mathbf{P t}^{\mathrm{II}}$. Relative G(500) in italics.
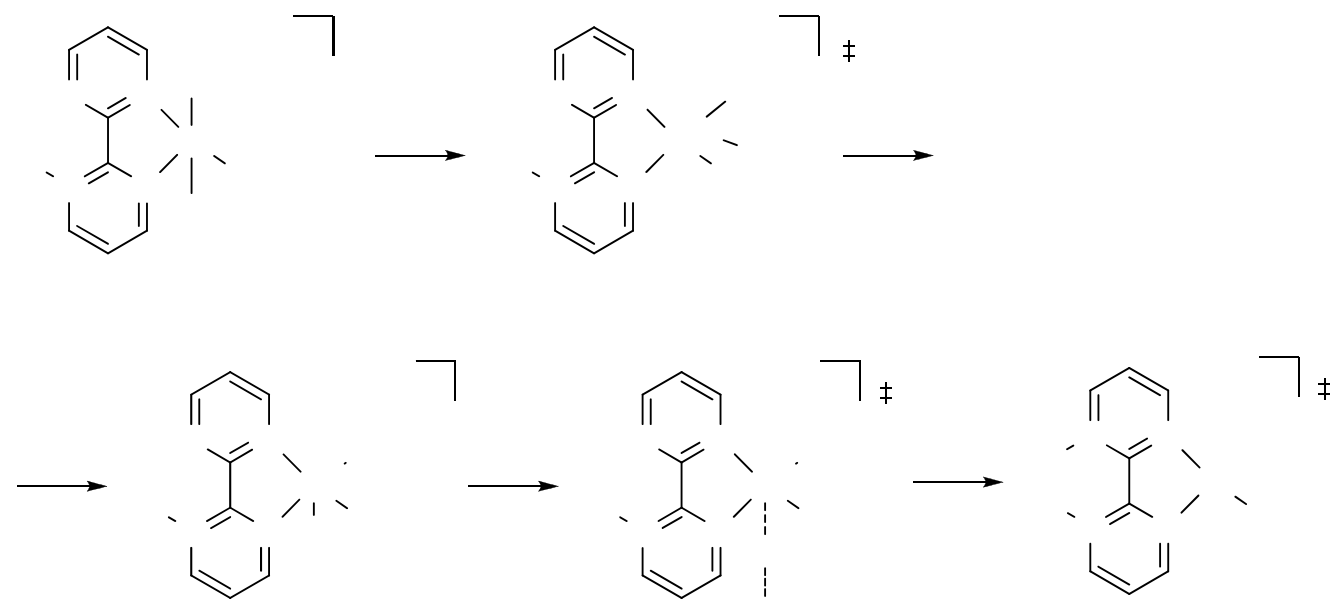

Figure 8.12: Nucleophilic functionalization of the methylated $\mathrm{Pt}^{\mathrm{IV}}$ generates the methyl bisulphate product and regenerates the active $\mathrm{Pt}^{\mathrm{II}}$ catalyst. Relative $\mathrm{G}(500)$ in italics. 


\subsection{THE OXIDATION STEP OF SHILOV CHEMISTRY WITH HIGHLY- CONCENTRATED [CL']}

We used quantum chemical models to determine the rate-limiting factors in the class of reactions in which an $\mathrm{M}^{\mathrm{n}}-\mathrm{CH}_{3}$ intermediate is oxidized to $\mathrm{M}^{\mathrm{n}+2}-\mathrm{CH}_{3}$ by a metal halide. The oxidation step of the Shilov cycle, $\mathrm{Pt}^{\mathrm{IV}} \mathrm{Cl}_{6}{ }^{2-}+\mathrm{Pt}^{\mathrm{II}}-\mathrm{CH}_{3} \rightarrow \mathrm{Pt}^{\mathrm{IV}}-\mathrm{CH}_{3}+\mathrm{Pt}^{\mathrm{II}} \mathrm{Cl}_{4}{ }^{2-}$ , serves as the reaction of interest. In light of the literature available treating this reaction and its role in our experimental work, we spent our primary effort developing detailed and validated models for this reaction. Such work aims at providing theoretical guidance for further search of alternative cheap oxidants. We mapped the free energy surface of the oxidation of $\mathrm{Pt}^{\mathrm{II}}\left(\mathrm{CH}_{3}\right)(\mathrm{Cl})_{2}\left(\mathrm{H}_{2} \mathrm{O}\right)^{1-}$ by $\mathrm{Pt}^{\mathrm{IV}} \mathrm{Cl}_{5}\left(\mathrm{H}_{2} \mathrm{O}\right)^{1-}$ to determine the relative contributions of electrostatic repulsion, redox potentials and entropy to the overall activation barrier. The number of chloride anions contained in the encounter complex was varied in order to understand the oxidation rate's dependence on $\left[\mathrm{Cl}^{-}\right]$.

The oxidation reactions in aqueous solution were broken into stages. First we consider ligand substitution reactions (between water and chloride) by which higherenergy intermediates of the form $\mathrm{Pt}^{\mathrm{II}}\left(\mathrm{CH}_{3}\right)(\mathrm{Cl})_{\mathrm{x}}\left(\mathrm{H}_{2} \mathrm{O}\right)_{3-\mathrm{x}}$ and $\mathrm{Pt}^{\mathrm{IV}}(\mathrm{Cl})_{y}\left(\mathrm{H}_{2} \mathrm{O}\right)_{6-y}$ may be generated from the most stable stoichiometries. A distribution of these species determined by reaction conditions is expected to exist. Second we consider the loose association of a $\mathrm{Pt}^{\mathrm{II}}-\mathrm{CH}_{3}$ monomer with a $\mathrm{Pt}^{\mathrm{IV}}-\mathrm{Cl}$ monomer. To represent these encounter complexes (an assumed prerequisite of the oxidation reaction) we constrained the key platinum-chloride $\left(\mathrm{Pt}^{\mathrm{II}} \cdots \mathrm{Cl}-\mathrm{Pt}^{\mathrm{IV}}\right)$ distance to $3.0 \AA$ and relaxed all other coordinates. The choice of $3.0 \AA$ is arbitrary but allows a qualitative decomposition of the reaction profile into stages. An additional water molecule is included in the encounter complexes to allow the $\mathrm{Pt}^{\mathrm{IV}}-\mathrm{CH}_{3}$ product to assume an octahedral coordination environment. We included in each calculation an entropic penalty $-\mathrm{T} \Delta \mathrm{S}=-(473 \mathrm{~K})(-$ 15 e.u. $)=7.1 \mathrm{kcal} / \mathrm{mol}$, where 15 entropy units is typical for a reduction in molecularity by one. Finally, the transfer of $\mathrm{Cl}^{+}$from the $\mathrm{Pt}^{\mathrm{IV}}$ to the $\mathrm{Pt}^{\mathrm{II}}-\mathrm{CH}_{3}$ center is examined. The topography of the energy surface for this step varies qualitatively with changes in stoichiometry, and since it is sensitive to four internal coordinates (the bond lengths along the $\mathrm{H}_{2} \mathrm{O} \cdots \mathrm{Pt}^{\mathrm{II}} \cdots \mathrm{Cl} \cdots \mathrm{Pt}^{\mathrm{IV}} \cdots \mathrm{L}$ axis) locating well-defined minima and saddle points along the reaction coordinate was difficult. Employing a nudged-elastic band approach will aid locating transition states in this multidimensional space.

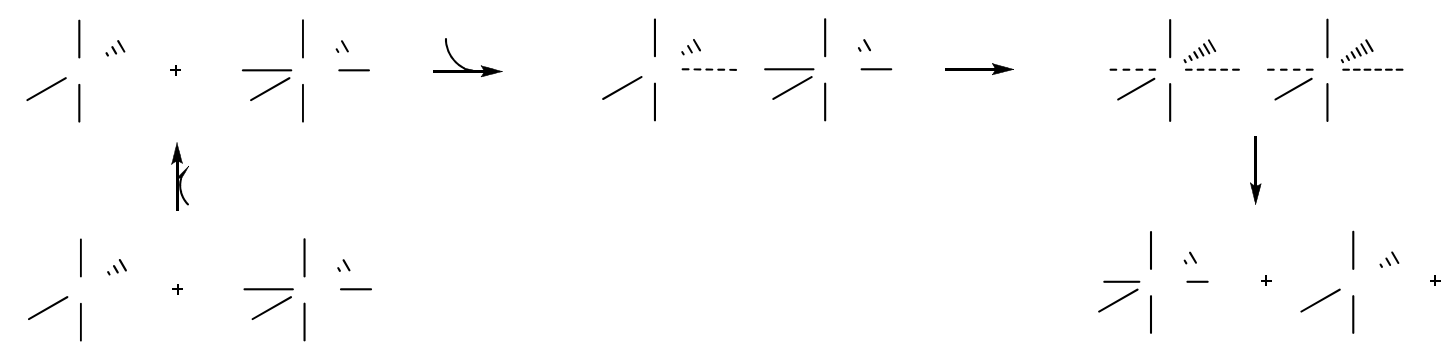

Scheme 1: Variable stoichiometries for oxidation of $\mathrm{Pt}^{\mathrm{II}}-\mathrm{CH}_{3}$ by $\mathrm{Pt}^{\mathrm{IV}}$ 


\section{Reactants}

We find the most stable stoichiometry for the $\mathrm{Pt}^{\mathrm{II}}-\mathrm{CH}_{3}$ and inorganic $\mathrm{Pt}^{\mathrm{IV}}$ states at $1 \mathrm{M}\left[\mathrm{Cl}^{-}\right]$to be $\mathrm{Pt}^{\mathrm{II}}\left(\mathrm{CH}_{3}\right)(\mathrm{Cl})_{2}\left(\mathrm{H}_{2} \mathrm{O}\right)^{-1}$ and $\mathrm{Pt}^{\mathrm{IV}}(\mathrm{Cl})_{6}{ }^{-2}$, respectively. The stoichiometry of these species in the oxidation transition states may differ, since a more negative $\mathrm{Pt}^{\mathrm{II}}-\mathrm{CH}_{3}$ may be more easily oxidized and a more positive $\mathrm{Pt}^{\mathrm{IV}}$ may be a stronger oxidant. Replacing the water bound trans to the methyl group in 1 costs $4 \mathrm{kcal} / \mathrm{mol}$ at $1 \mathrm{M}\left[\mathrm{Cl}^{-}\right]$. To incorporate the concentration of free chloride, we adjust its free energy according the statistical mechanics correction $\mathrm{kT} \ln \left(\left[\mathrm{Cl}^{-}\right] /[1 \mathrm{M}]\right)$, using $\mathrm{T}=473 \mathrm{~K}$. Thus substitution of chloride into the coordination sphere is encouraged by higher chloride concentrations.

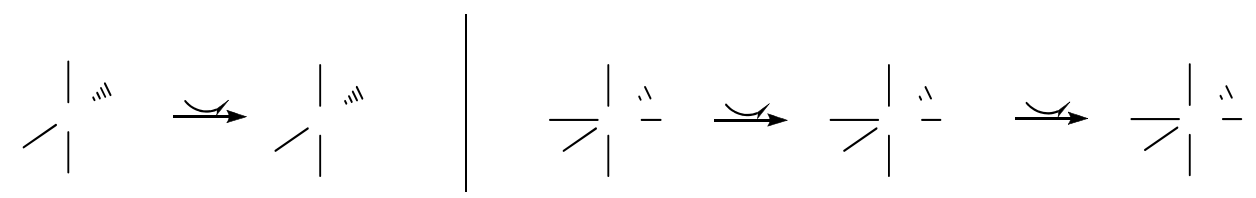

Figure 8.13: Free Energies of variously substituted reactant complexes in Shilov system

Encounter complexes:

1-C: $\mathrm{Pt}^{\mathrm{II}}\left(\mathrm{CH}_{3}\right)(\mathrm{Cl})_{2}\left(\mathrm{H}_{2} \mathrm{O}\right) \cdot \mathrm{Pt}^{\mathrm{IV}}(\mathrm{Cl})_{4}\left(\mathrm{H}_{2} \mathrm{O}\right)_{2}{ }^{1-}$

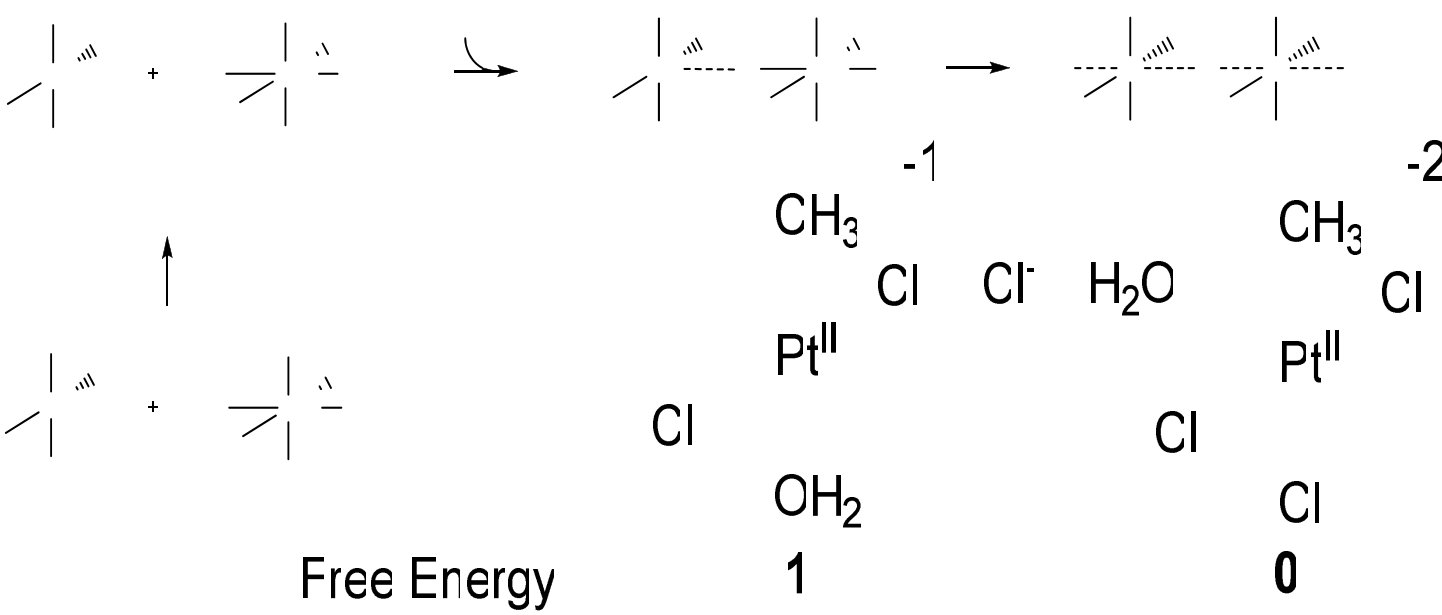

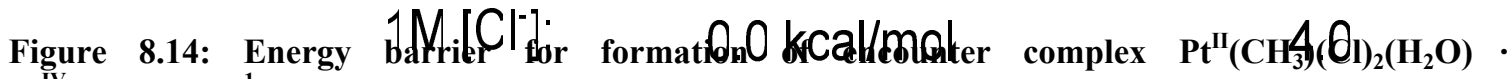
$\mathrm{Pt}^{\mathrm{IV}}(\mathrm{Cl})_{4}\left(\mathrm{H}_{2} \mathrm{O}\right)_{2}{ }^{1-}$

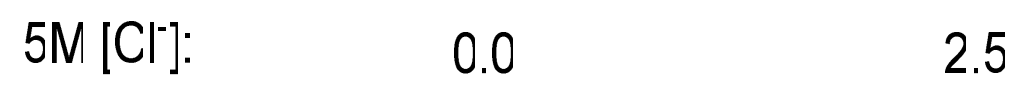

Substituting two chloride ligands of $\mathrm{Pt}^{\mathrm{IV}} \mathrm{Cl}_{6}{ }^{2-}$ with waters costs $13.5 \mathrm{kcal} / \mathrm{mol}$, but results in a neutral $\mathrm{Pt}^{\mathrm{IV}}$ and sets up a more exothermic oxidation. Complexation of $\mathbf{1}$ and $\mathbf{C}$, as judged by the constrained complex, is then exothermic but disfavored due to 
entropy. The oxidation reaction apparently proceeds from there without a barrier. Increased chloride concentration will disfavor the preequilibrium between $\mathbf{A}$ and $\mathbf{C}$, inhibiting the reaction rate.

\section{1-B: $\mathrm{Pt}^{\mathrm{II}}\left(\mathrm{CH}_{3}\right)(\mathrm{Cl})_{2}\left(\mathrm{H}_{2} \mathrm{O}\right) \cdot \mathrm{Pt}^{\mathrm{IV}}(\mathrm{Cl})_{5}\left(\mathrm{H}_{2} \mathrm{O}\right)^{2-}$}
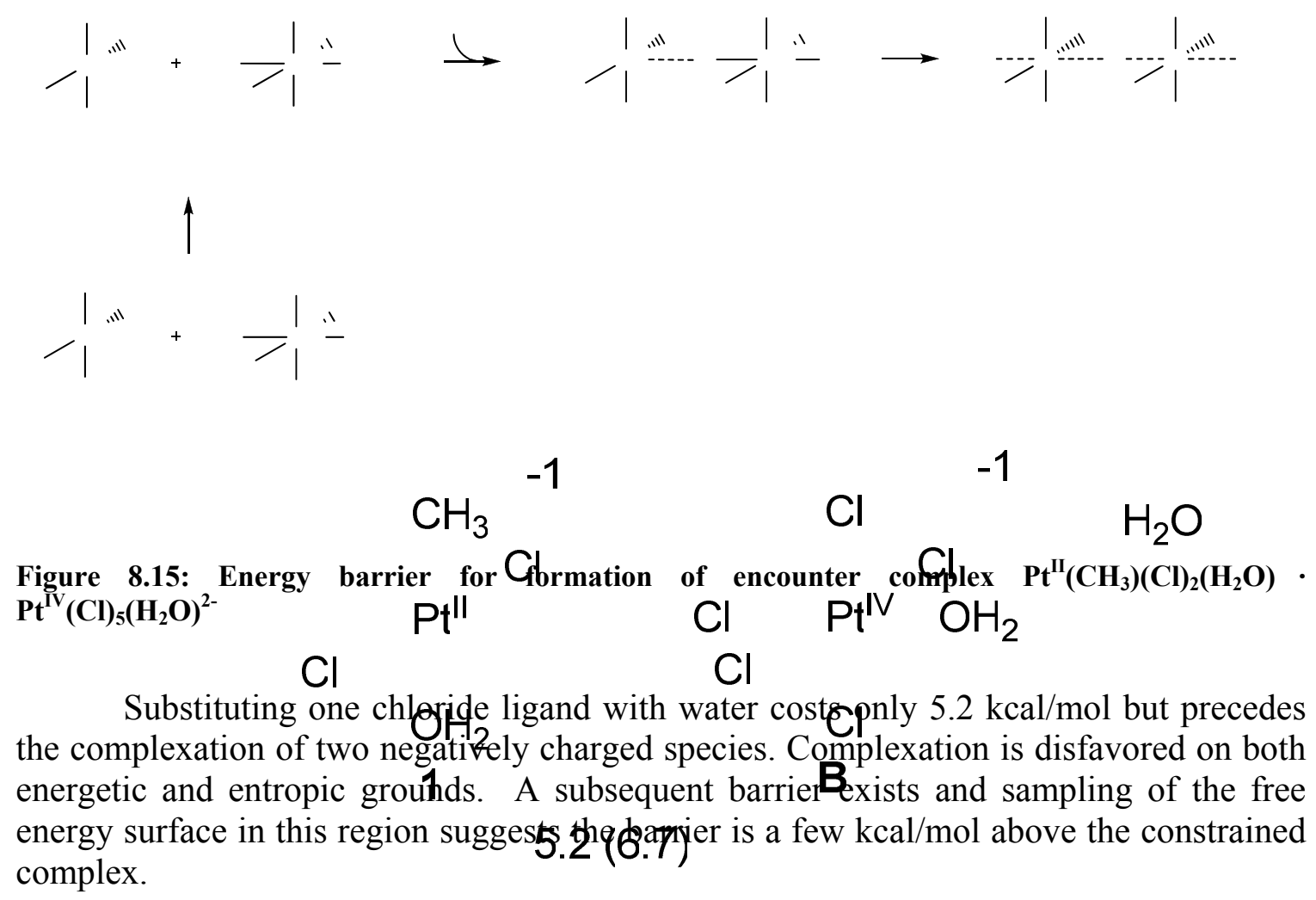

\section{1-A: $\mathrm{Pt}^{\mathrm{II}}\left(\mathrm{CH}_{3}\right)(\mathrm{Cl})_{2}\left(\mathrm{H}_{2} \mathrm{O}\right) \cdot \mathrm{Pt}^{\mathrm{IV}}(\mathrm{Cl})_{6}{ }^{3-}$}

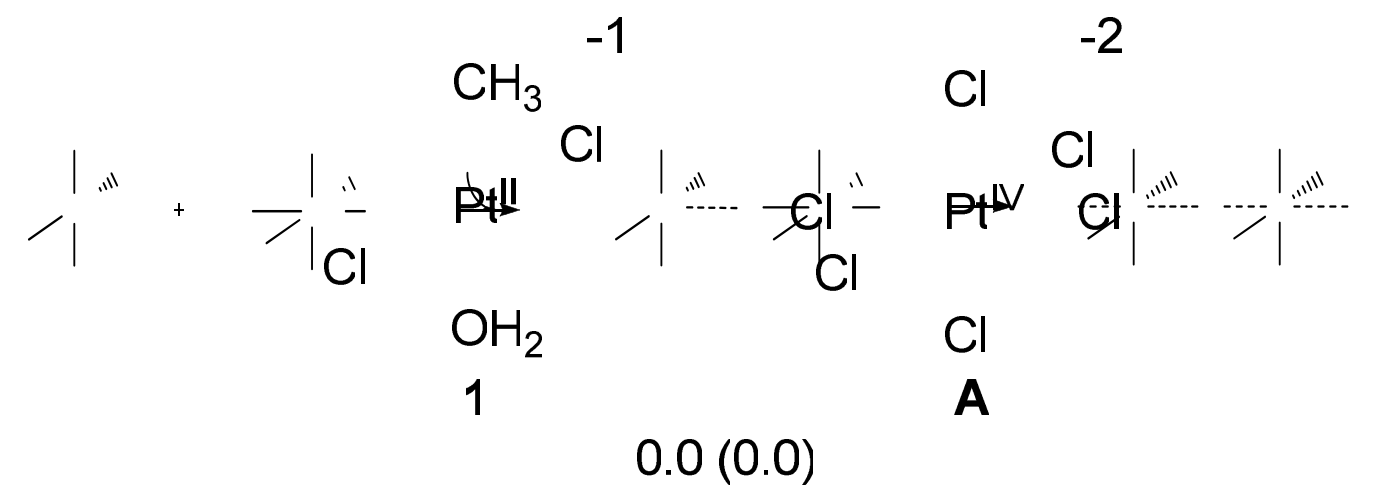

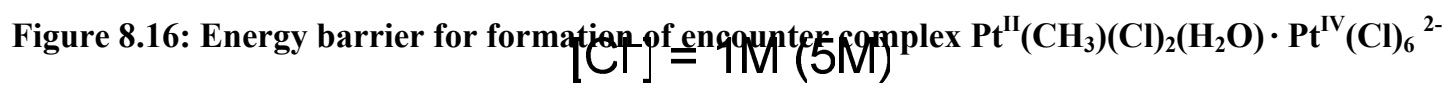

In the oxidation of $\mathbf{1}$ by $\mathbf{A}$, the complexation is the most endergonic in the series, forming a highly charged complex. 
The energies of the constrained encounter complexes are remarkably similar, despite differences in composition and charge. Based on the given data it is reasonable that complex 1-B provides the lowest energy pathway to products at $\left.1 \mathrm{M}^{-} \mathrm{Cl}^{-}\right]$. However, this pathway will suffer as the chloride concentration is increased, favoring both $\mathbf{0}$ to $\mathbf{1}$ and $\mathbf{A}$ to $\mathbf{B}$. The increased negative charge on both reactants is expected to raise the energy of the encounter complexes, retarding oxidation rates.

Faster oxidation of $\mathrm{Pt}^{\mathrm{II}}-\mathrm{CH}_{3}$ intermediates may be achieved if the oxidant is more positively charged at high chloride concentrations. This suggests the exploration of neutral chelating ligands on metals intended as oxidants. Such ligands are expected to inhibit $\mathrm{CH}$ activation, but they could possibly be chosen to preferentially bind to $\mathrm{Cu}$ or Fe. 


\section{CHAPTER NINE: PROPOSED FUTURE WORK}

Upon the successful completion of this five-year project and corresponding to the current economy and energy crisis faced by the U.S., we have proposed a future research plan to further advance the development of the ionic liquid affiliated homogenous methane catalytic system towards final industrial commercialization. Described below is a three-year research plan given sufficient financial supports from the government and industrial partners. Successful completion of the tasks proposed below will lead this current technology to the Technology Readiness Level $\mathbf{5}$ serving as a critical step for transferring the proposed research technology to practical industrial applications which can be of great benefits to the nation's economic strategy, energy crisis as well as environment protection.

Milestone 1 (Year 1): Design, screen and develop new catalytic systems for methane conversion with high yield (>90\%) and high selectivity $(>90 \%)$.

Subtask 1.1 Using molecular design technology to design and screen potential ionic liquid affiliated catalytic methane conversion systems

Our previous work has already provided some molecular level understanding of the chemistry involved in some Pt-based catalytic systems the PEER system, Catalytica system and the Shilov system. Powerful computational approaches based on QM, ReaxFF and MD have been developed to simulate certain chemistries involved in ionic liquids affiliated methane conversion systems. Therefore, in this stage, we will further extend our theoretical efforts on various possibility of combination of ionic liquids, catalysts, oxidants and reaction media to point out the possible systems for efficient methane conversion.

Subtask 1.2 Experimental test and evaluation of various catalytic systems guided by the theoretical predications

Experimental efforts will be taken on synthesizing necessary ionic liquids or catalysts, testing compatibility of designed system and evaluating the catalytic performance of some systems. For example, we are the first to observe the catalytic ability of Os(III) and Os(IV)-compounds on $\mathrm{C}-\mathrm{H}$ activation of methane. Further search for compatible oxidants and reaction media might lead to an Os-based catalytic system for efficient methane conversion.

Subtask 1.3 Screen and identify the most promising systems with best conversion and selectivity

Integrating the computational and experimental findings, we will be able to screen and identify the most promising systems with best conversion and selectivity. The Virtual Rapid Prototyping (VRP) Method for fast screening of promising catalytic methane conversion systems will be further developed and enhanced. With such a VRP approach, 
the cost and time required for developing a methane conversion system with desired performance will be significantly decreased.

\section{Milestone 2 (Year 2): Optimize and improve selected catalyst systems for methane conversion}

Subtask 2.1 Perform detailed chemistry analysis on reaction rate, selectivity and deactivation of selected catalytic system.

Upon reaching the first milestone, we will narrow down our theoretical and experimental efforts to the most promising systems. Further optimization will be based on indepth mechanistic understanding of the detailed chemistry influencing the performance (reaction rate, selectivity, deactivation, etc.) of the selected catalytic system.

Subtask 2.2 Optimize the catalytic system in terms of composition, reactor design, experimental protocols and conditions

As instructed by the indepth mechanistic understanding on the system performance, experimental work will be conducted systematically to achieve optimized composition, reactor design, experimental protocols and other experimental conditions (temperature, pressure, reactants mixing etc.).

Realization of both Milestones 1 and 2 sets its strong basis on our previously established theoretical (QM, MD, ReaxFF modeling; data base for molecular and other properties of ionic liquids, possible reaction pathway investigation of methane activation, oxidation and functionalization) and experimental (specially designed reactor and reaction protocol for testing various factors of catalytic methane conversion, characterization and analytic tools for quantitative and quantitative evaluations) approaches. Successful completion of the first two milestones will present us one or several optimized methane catalytic systems with high potentials for commercially viable applications.

\section{Milestone 3 (Year 3): Scaling-up test and preliminary economic analysis}

Subtask 3.1 Bench-scale reactor design and build-up

Subtask 3.2 Bench-scale testing

Subtask 3.3 Preliminary Economic Analysis

After discovering/identifying the best system and chemistry at the laboratory level, the next step will be bench-scale test to provide necessary data for justification of further pilot-scale test and economic feasibility analysis. This part serves as the critical transitional step between successful lab-chemistry to revolutionary technology which can be applied at an industrial scale and bring huge beneficial impacts to the nation's energy and economic security as well as the environment protection. This part of work will be conducted through closely collaboration with the industrial partners. In addition, our previous work have already identified some key factors for the bench-scale reactor design 
including corrosion resistance, temperature and pressure control, system mixing, and insitu reaction characterization and analysis.

We have established efficient laboratory-scale experimental apparatus and the accompanied analytical protocol for developing optimized methane partial oxidation systems. We have been able to conduct small scale experiments with $100 \%$ mass balance and excellent temperature. However, demonstration and further optimization of the selected systems requires a larger-scale reactor, which can load a relatively large amount of sample, optimize the performance of the selected systems and allow in situ experimental analysis.

Several key features needed for the bench scale reactor will include:

(1) Relatively large sample capacity

(2) Excellent corrosion resistance to conduct experiments under concentrate sulfuric acid, hydrochloric acid, or other strongly corrosive media

(3) High pressure tolerance with in situ pressure monitor

(4) Fast heating rate and precise temperature control

(5) High speed reaction solution stirring to achieve good contact between the catalytic system and the methane gas

(6) Capability of reaction equilibrium control for better product selectivity

(7) In situ experimental analysis for better process control, system optimization and mechanistic investigation

Since it is known that $\mathrm{Pt}(\mathrm{II})$ is related to the $\mathrm{C}-\mathrm{H}$ activation step and $\mathrm{Pt}(\mathrm{IV})$ is related to methane oxidation step, using in-situ UV-Vis could monitor oxidation states distribution the $\mathrm{Pt}(\mathrm{II}) / \mathrm{Pt}(\mathrm{IV})$ at deferent reaction stage which will provide very important message on catalyst and media system designing and controlling of reaction conditions. Also equally important is knowing of distribution of oxidation products and intermediates at all reaction stages $\left(\mathrm{CH}_{3} \mathrm{Cl}, \mathrm{CH}_{3} \mathrm{OH}, \mathrm{HCOH}, \mathrm{HCOOH}, \mathrm{CO}_{2}\right.$, etc.).

We propose to develop in-situ UV-vis spectroscopic method that could monitor the oxidation state changes of $\mathrm{Pt}\left(\mathrm{Pt}^{\mathrm{II}} \Leftrightarrow \mathrm{Pt}^{\mathrm{IV}}\right)$. The $\mathrm{Pt}^{\mathrm{IV}}$ in ionic liquid should have absorption features at $360 \mathrm{~nm}$ and $420 \mathrm{~nm}^{11}$, and we will use UV multimode fiber with special high temperature jacket to deliver Xe-lamp light sources to the reactor and collect the transmission also through multimode fiber. The reactor will be constructed with two Sapphire windows built in for the transmission measurement. The spectrometer detector and light source are located outside the oven. The schematic is given in Figure 9.1.

With the Sapphire windows built-in reactor, we will also be able to conduct Raman spectroscopy on certain product small molecules, e.g. $\mathrm{CH}_{3} \mathrm{OH},\left(\mathrm{CH}_{3}\right)_{2} \mathrm{O}, \mathrm{HCOOH}$ and $\mathrm{HCOH}$. We propose to use the 3rd harmonic of a pulsed Nd:YAG laser, i.e. $355 \mathrm{~nm}$, for the Raman excitation and also measuring the Pt concentration through its UV transmission measurement. 


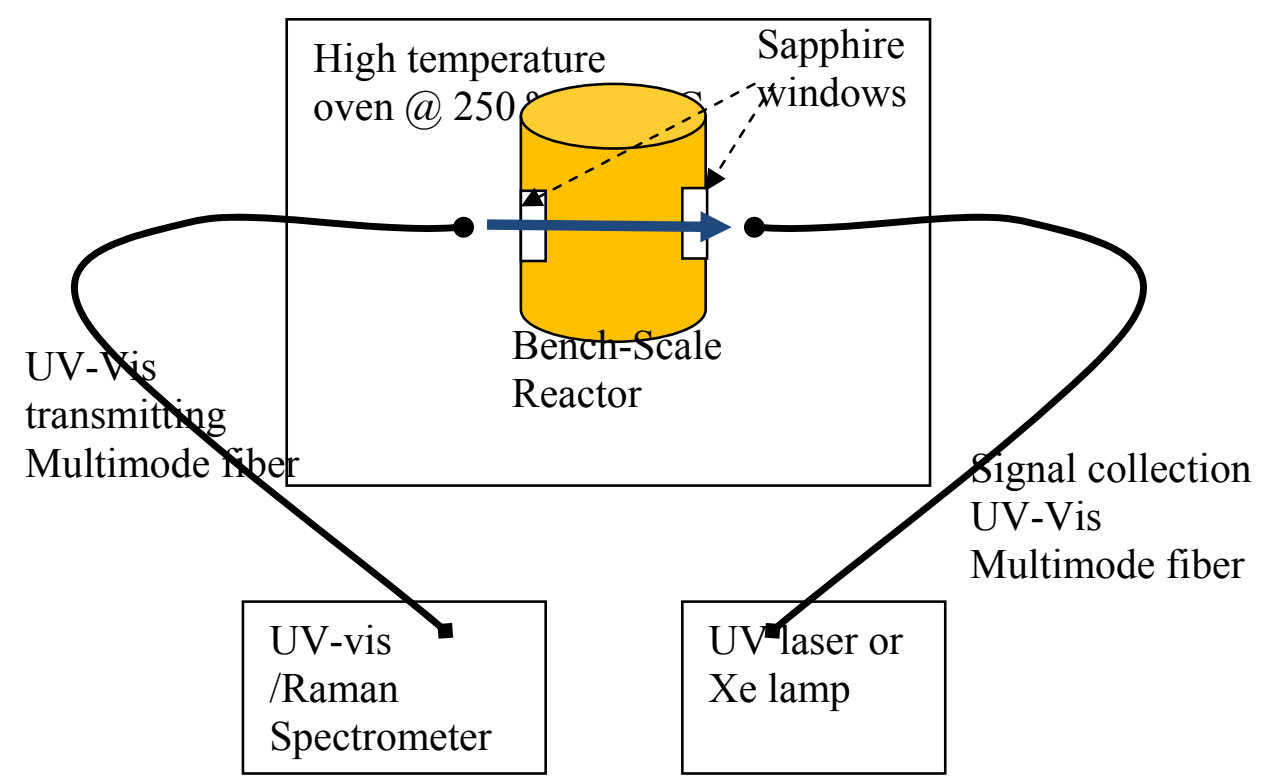

Figure 9.1: Schematic Diagram of in situ UV-vis spectroscopy to monitor the oxidation state change of $\mathrm{Pt}^{\mathrm{II}}$ and $\mathrm{Pt}^{\mathrm{IV}}$ 


\section{REFERENCES:}

${ }^{1}$ R. A. Periana, D. J. Taube, S. Gamble, H. Taube, T. Satoh, and H. Fujii, "Platinum catalysts for the high-yield oxidation of methane to a methanol derivative," Science, 280, 560-564, 1998

2 (a) A. E. Shilov, and G. B. Shul'pin, Activation and catalytic reactions of saturated hydrocarbons in the presence of metal complexes (Kluwer Academic Publishers, Dordrecht, 2000); (b) R. J. Hodeges, D. E. Webster, and P. B. Wells, "The activation of Saturated hydrocarbons by transition-metal complexes in solution. Part I. Hydrogendeuterium exchange in alkanes catalysed by potassium tetrachloroplatinate (II) in acetic acid," J. Chem. Soc. (A), 3230-3238, 1971; (c) M. Muehlhofer, T. Strassner, and W. A. Herrmann, "New catalyst systems for the catalytic conversion of methane into methanol," Angew. Chem. int. Ed., 41, 1745-1747, 2002; (d) V. R. Ziatdinov, J. Oxgaard, O. A. Mironov, K. J. H. Young, W. A. Goddard III, and R. A. Periana, "Carboxylic solvents and O-donor effects on CH activation by Pt(II)," J. Am. Chem. Soc., 128, 7404-7405, 2006.

${ }^{3}$ T. Gregory, P. Harper, R. S. Shinomoto, M. A. Deming and T. C. Flood, "Activation of Methane by the Reactive Intermediate Tris (trimethylphosphine) Osmium(0)", J. Am. Chem. Soc. 110, pp 7915-16 (1988)

${ }^{4}$ Gol'dshleger, N.F., Tyabin, M.B., Shilov, A.E. and Shteinman, A.A, Russion J. Phys Chem. 1969, 43, 1222

${ }^{5}$ Rudkov, E.S. and Shteinman, A.A., Kinet. Katal. 1973, 13, 1346 (in Russian)

${ }^{6}$ Becke, A. D., J. Chem. Phys. 1993, 98, 5648.

${ }^{7}$ Lee, C.; Yang, W.; Parr, R. G., Phys. Rev. B. 1988, 37, 785.

${ }^{8}$ Hay, P. J.; Wadt, W. R., J. Chem. Phys. 1985, 82, 299.

${ }^{9}$ (a)Krishnan, R.; Binkley, J. S.; Seeger, R.; Pople, J. A., J. Chem. Phys. 1980, 72, 650. (b)Clark, T.; Chandrasekhar, J.; Schleyer, P. v. R., J. Comput. Chem. 1983, 4, 294.

${ }^{10}$ Zhao, Y.; Truhlar, D. G. Acc. Chem. Res. 2008, 41, 157.

11 (a) Marten, B.; Kim, K.; Cortis, C.; Friesner, R. A.; Murphy, R.; Ringnalda, M.; Sitkoff, D.; Honig, B., J. Phys. Chem. 1996, 100, 9098. (b) Tannor, D. J.; Marten, B.; Murphy, R.; Friesner, R. A.; Sitkoff, D.; Nicholls, A.; Ringnalda, M.; Goddard, W. A.; Honig, B., J. Am. Chem. Soc. 1994, 116, 11775.

12 6.0, J. Schrodinger, LLC: Portland, Oregon, 2005.

${ }^{13}$ Tissandier, M. D.; Cowen, K. A.; Feng, W. Y.; Gundlach, E.; Cohen, M. H.; Earheart, A. D.; Coe, J. V.; Tuttle, T. R., J. Phys. Chem. A 1998, 102, 7787. 
${ }^{14}$ Ross, R. B.; Powers, J. M.; Atashroo, T.; Ermler, W. C.; LaJohn, L. A.; Christiansen, P. A. J. Chem. Phys. 1990, 93(9) 6654.

${ }^{15}$ I. H. Hristov, T. Ziegler, Organometallics 2001, 22, 1668-1674. We believe that the major part of the discrepancy is due to the fact that we include the energy of generating $\mathrm{SO}_{3}$ from $\mathrm{H}_{2} \mathrm{SO}_{4}$ or $\mathrm{H}_{2} \mathrm{~S}_{2} \mathrm{O}_{7}$, which are the more stable forms of $\mathrm{SO}_{3}$ in sulphuric acid.

${ }^{16}$ a) N. F. Gol'dshleger, V. V. Es'kova, A. E. Shilov, A. A. Shteinman Russ. J. Phys. Chem. 1972, 46, 785-786. b) L. A. Kushch, V. V. Lavrushko, Y. S. Misharin, A. P. Moravsky, A. E. Shilov, Nouveau Journal de Chimie 1983, 7, 729-733.

${ }^{17}$ R. G. Pearson, M. L. Morris, F Basolo Disc. Faraday, Soc. 1960, 29, 80-91. 